\title{
Aging and Large-Scale Consolidation in Centrifuge Cake Oil Sands Tailings
}

By

David Igbinedion B.Eng., Carleton University, 2020

A thesis submitted to the Faculty of Graduate and Postdoctoral Affairs in partial fulfillment of the requirements for the degree of

\author{
Master of Applied Science \\ In \\ Environmental Engineering
}

Department of Civil and Environmental Engineering Carleton University

Ottawa-Carleton Institute of Civil and Environmental Ottawa, Ontario

C2020, Igbinedion David 


\begin{abstract}
Consolidation in centrifuge cake tailings generated from bitumen extraction was studied in two phases. In phase I, $0.1 \mathrm{~m}$ thick layers of centrifuged tailings were deposited in polypropylene columns and processed at different time steps for oedometer testing, water content profiles, and fall cone measurement. In phase II, a large-scale consolidation apparatus consisting of a $0.49 \mathrm{~m}$ by $0.35 \mathrm{~m}$ steel box was used with tailings deposited to a height of $0.62 \mathrm{~m}$. Volume change, porewater pressure, and water contents behaviour were monitored over time. The cake self weight consolidated and was loaded incrementally up to an effective stress of $16 \mathrm{kPa}$. Finally, the largestrain consolidation model UNSATCON was used to analyze consolidation in the large cell.

Results from both tests indicate that creep and aging were important factors in the behaviour of the centrifuge cake. The preconsolidation pressure increased with time, and very high creep was observed as this preconsolidation pressure was exceeded.
\end{abstract}




\section{Dedication}

To my loving parents,

Thanks for the opportunity and sacrifices you both have made for this to be possible.

To my siblings,

Thanks for the support every step of the way.

"Whatever your hands find to do, do it with all thy might"

Ecclesiastes 9:10 


\section{Acknowledgements}

First, I would like to express my deepest appreciation to my supervisor Paul $\mathrm{H}$. Simms for the opportunity to learn and be mentored under his leadership.

I would also like to thank the staff of the Department of Civil and Environmental Engineering at Carleton University for their support and help through this journey.

I am forever grateful to my fellow researchers, Dr. Shunchao Qi, Dr. Abdulghader Abdulrahman, Dr. Muhammad Salam, Dr. Amin Esmaeilzadeh, Yagmur Babaoglu, Narges Gheisari, Arazoo Patel, Oswaldo Hurtado, Chris Hey, Hissan Khattak, Etienne Parent, Hirlatu Peruga, Nadine Sallam, Alex Xia, Aisha Al-Zouaghi, Lynnette Gonzara and Kenneth Omenogor for their advice and help during this process.

Also, special thanks to Michael Gutland, Angele Genereux, and Nadine De Bruyn for their assistance during this study.

Lastly, I would like to thank my friends Uche, Adetola, Adeola, Adanne and Taylor for the encouragement through this journey.

Special appreciation to the sponsors, Natural Science and Engineering Research Council of Canada (NSERC) and the Canada's Oil Sands Innovation Alliance (COSIA) for providing the necessary equipment for the project. 
Table of Content

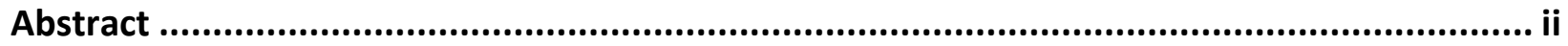

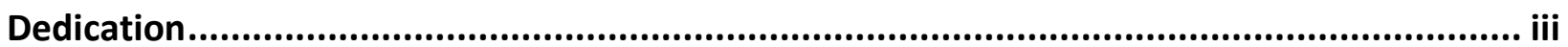

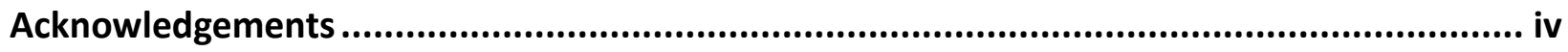

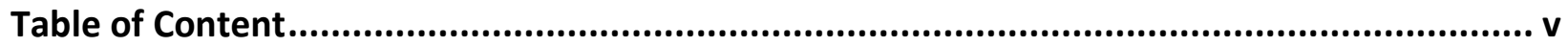

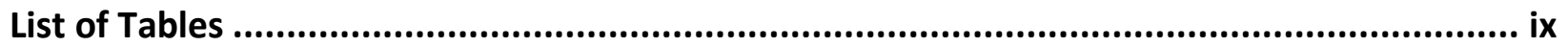

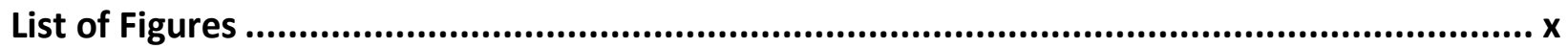

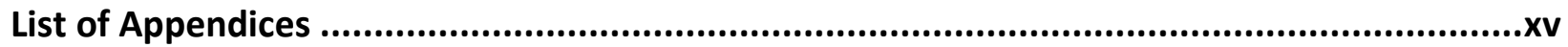

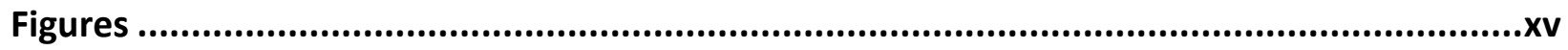

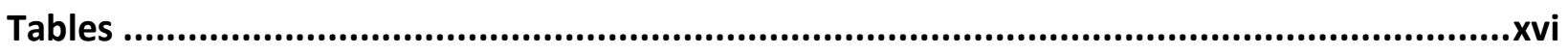

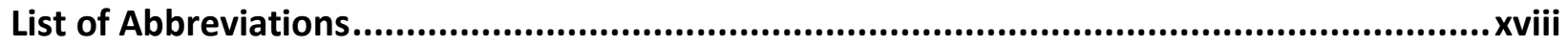

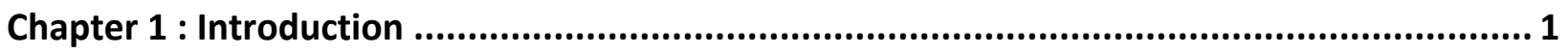

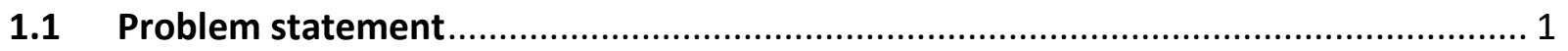

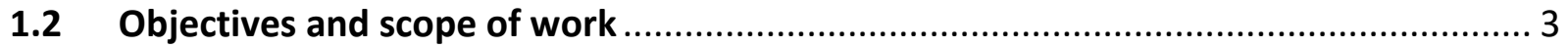

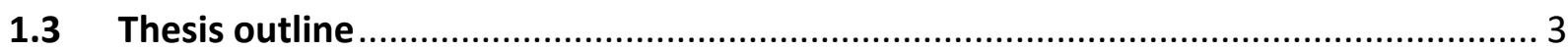

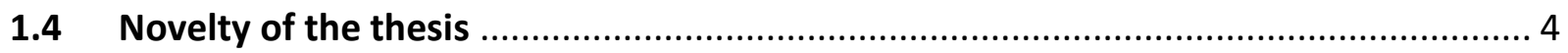

Chapter 2 : Literature Review ....................................................................................... 5

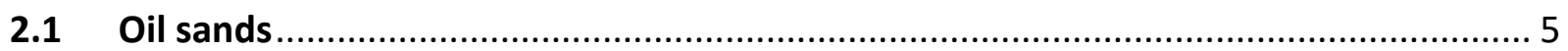

2.1.1 Oil Sands Characteristics and deposits ......................................................... 5

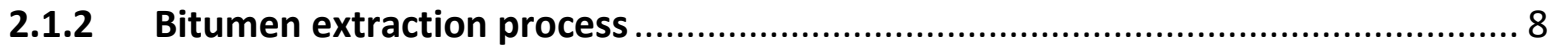

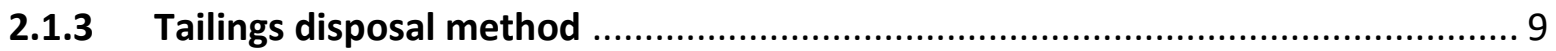

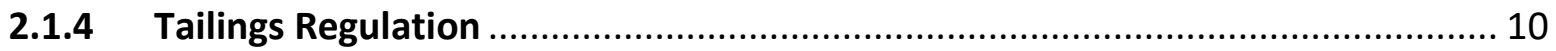

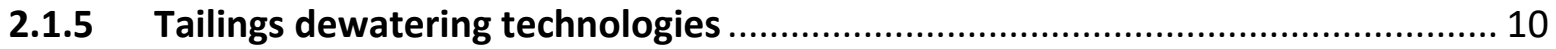

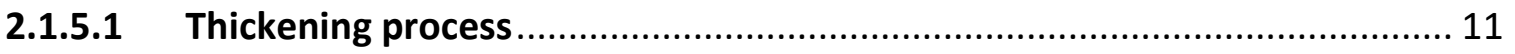

2.1.5.2 In-line flocculation (ILF) and Thin-Lift drying ........................................ 11

2.1.5.3 Non-segregating Tailings (NST) and Composite Tailings (CT) ................... 11

2.1.5.4 Water-Capped Tailings and Permanent Aquatic Storage Structure ............. 12

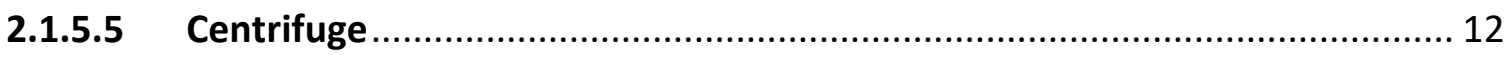

2.2 Consolidation and time-dependent behaviour in oil sands tailings ........................ 13

2.2.1 Flocculation, sedimentation, and consolidation ........................................ 13 


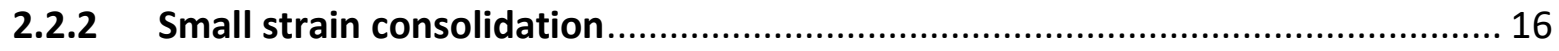

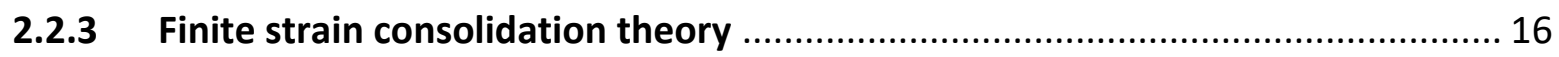

2.2.4 Piecewise-linear model and UNSATCON ...................................................... 17

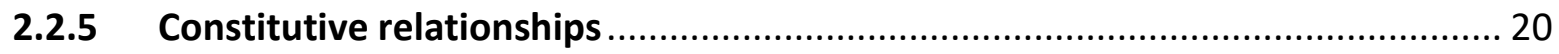

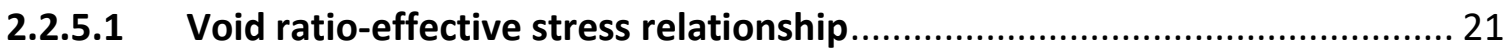

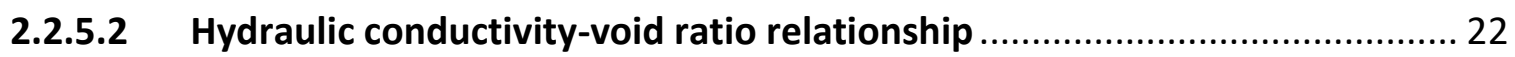

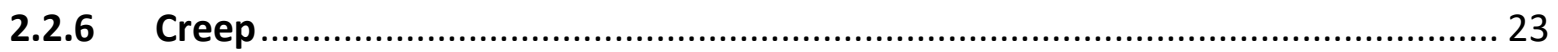

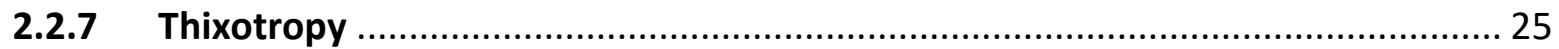

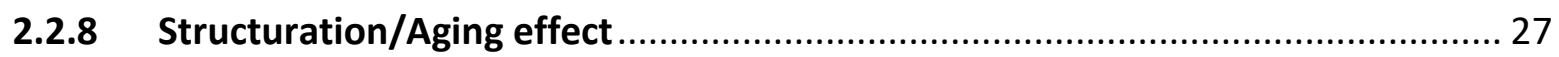

2.3 Temperature effect on consolidation, creep, and aging behaviour ........................ 29

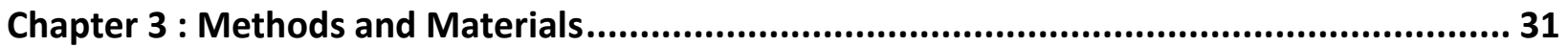

3.1 Centrifuge cake oil sands tailings characteristics and properties.......................... 31

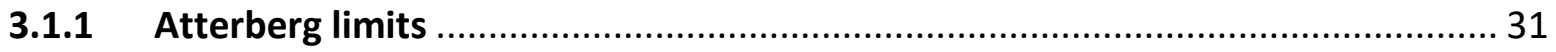

3.1.2 Clay Content (Methylene blue index test) ................................................ 32

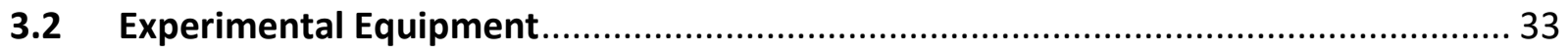

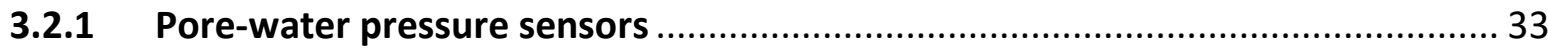

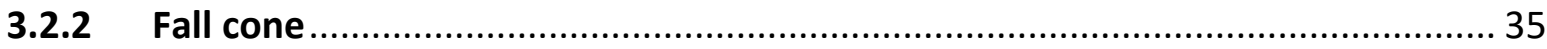

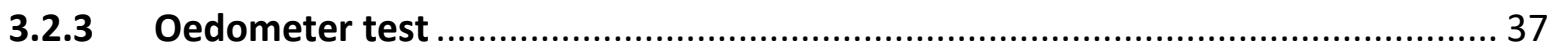

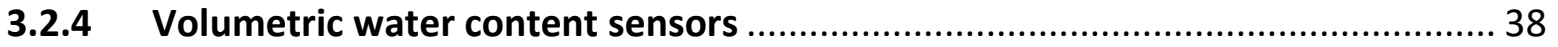

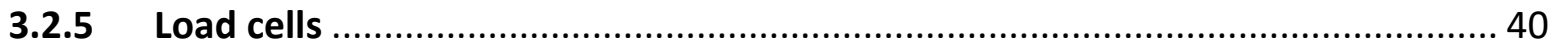

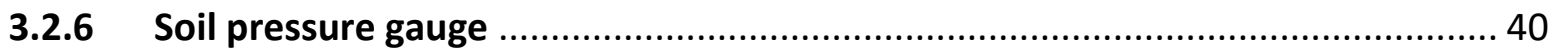

3.2.7 Linear Variable Differential Transformer (LDVT) ......................................... 41

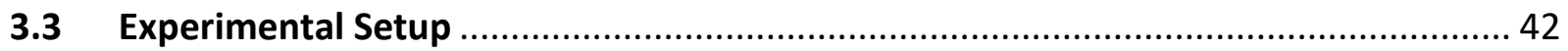

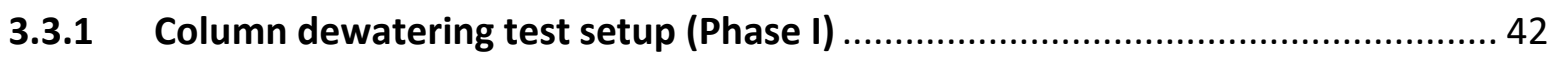

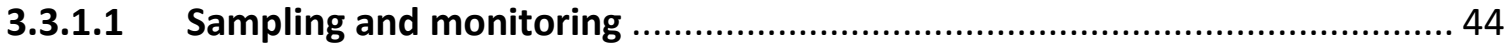

3.3.2 Large-scale consolidation setup (Phase II) .................................................... 47

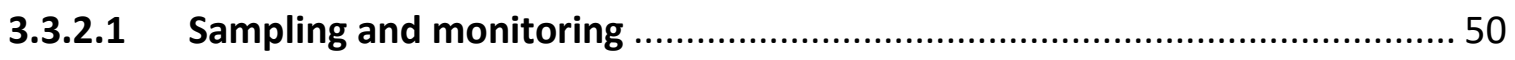

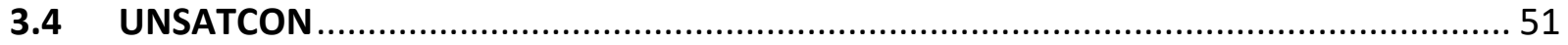

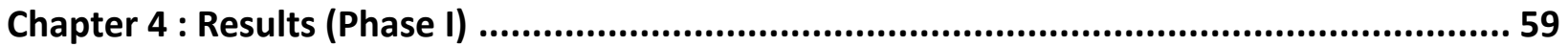

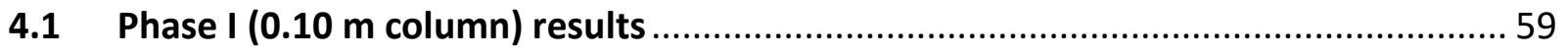

4.1.1 Pore-water pressure and water content ................................................... 59 


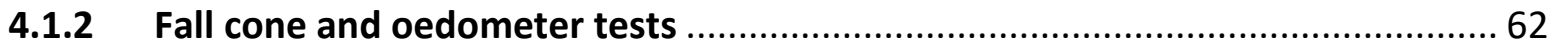

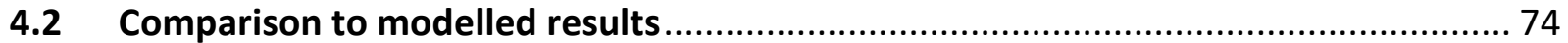

4.2.1 Average gravimetric water content with time ......................................... 82

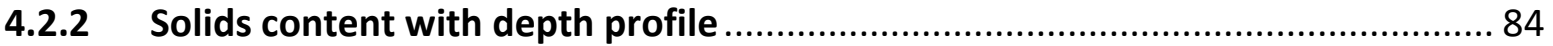

4.2.3 Pore-water pressure with time

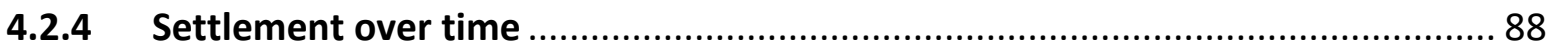

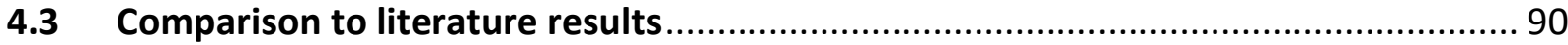

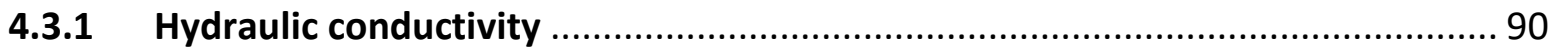

4.3.2 Ratio of creep coefficient to compression index vs effective stress .................. 91

4.3.3 Undrained shear strength with time ..................................................... 92

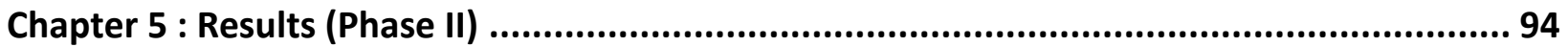

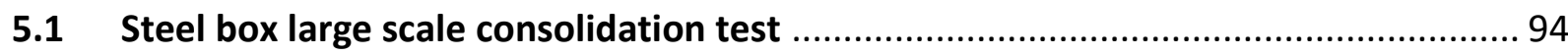

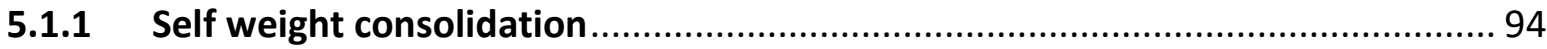

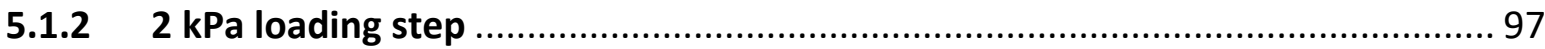

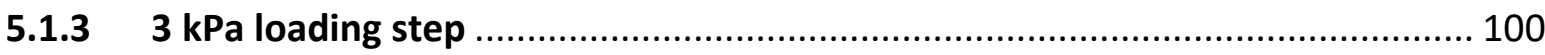

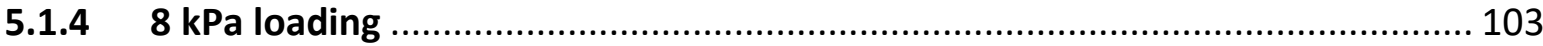

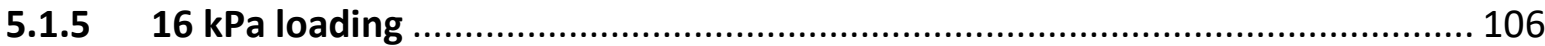

5.1.6 Combined results (self weight consolidation and $2 \mathrm{kPa}, 3 \mathrm{kPa}, 8 \mathrm{kPa}$, and $16 \mathrm{kPa}$

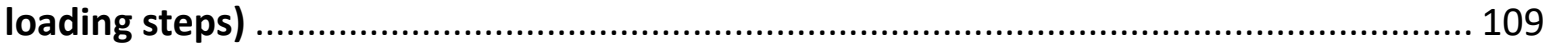

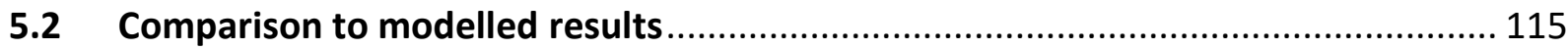

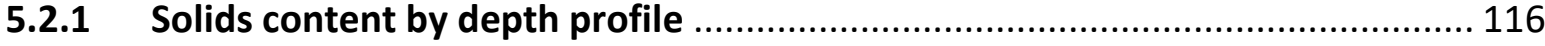

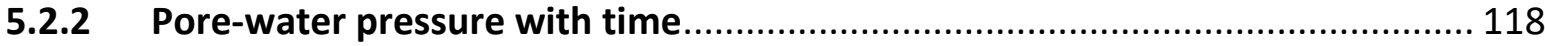

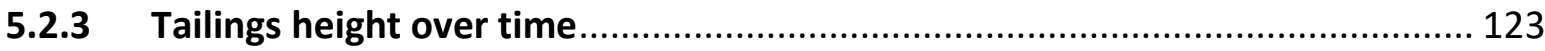

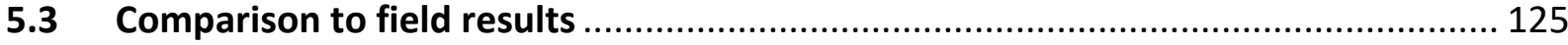

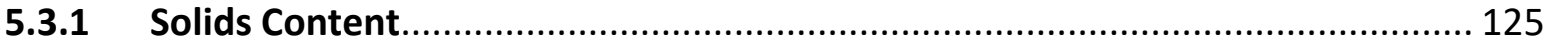

5.3.2 Pore-water pressure

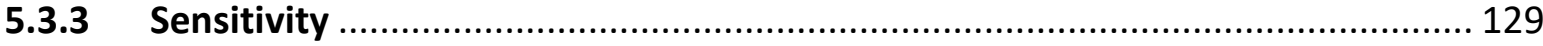

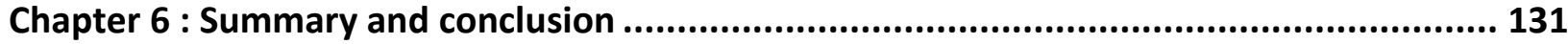

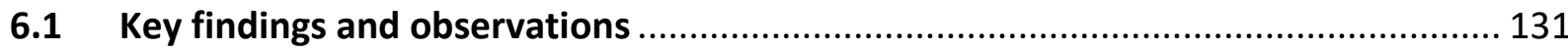

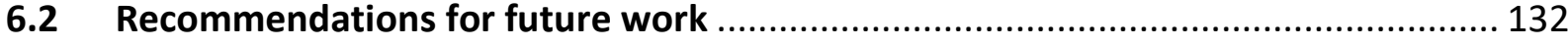

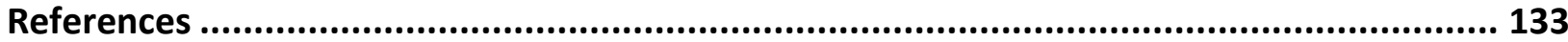




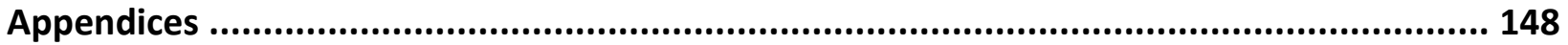




\section{List of Tables}

Table 3-1: Breakdown of columns used in phase I. ................................................................. 43

Table 3-2: Scheduled measurements on columns at specific days. ........................................ 45

Table 3-3: Applied loads with corresponding day. .............................................................. 50

Table 3-4: Sensors measurement and position in box (Phase II). ............................................ 51

Table 4-1: Height of tailings in the two replicates columns with tensiometers at the beginning of deposition, 65 days after deposition and 126 days after deposition..................................... 59

Table 4-2: Replicate column thixotropy strength gain ........................................................ 64

Table 4-3: Initial void ratios for remolded and undisturbed samples at different days. .............65

Table 4-4: Constitutive relationship used in original $0.10 \mathrm{~m}$ column model prediction............. 77

Table 4-5: Constitutive relationship used in $0.10 \mathrm{~m}$ column calibrated model prediction.......... 78

Table 5-1: Constitutive relationship used in original steel box model prediction..................... 115

Table 5-2: Constitutive relationship used in steel box calibrated model prediction. ................ 116 


\section{List of Figures}

Figure 2.1. J.H Cottrell (1963) proposed model of oil sands (from Carrigy, 1963)......

Figure 2.2. Map showing the location of the three main Alberta oil sands deposit (Modified by Baniak et al., 2018, from Hubbard et al., 2011).

Figure 2.3. Schematic diagram of Clark Hot Water Extraction Process (Modified by

Jeeravipoolvarn, 2010, from Chalaturnyk et al., 2004). 9

Figure 2.4. Schematic diagram of the three settling stages involved in clay-water interaction

(Modified by Krizek, 2004, from Imai, 1981). 14

Figure 2.5. (a) compressibility curve for flocculated and untreated FFT; and (b) Hydraulic conductivity for treated and untreated FFT (Adapted from Wilson et al., 2018). ..................... 15

Figure 2.6. Process diagram for CS2 (Modified from Fox et al., 1997)..................................... 19

Figure 2.7. Compressibility curves of FFT (modified by Jeeravipoolvarn, 2010, from Suthaker, 1995).

Figure 2.8. Variation of flow velocity with time (modified by Jeeravipoolvarn, 2010, from Suthaker, 1995).

Figure 2.9. The void ratio - log (time) curve showing creep coefficient determination using hypothesis A (Adapted from Yin et al., 2016). 24

Figure 2.10. Effect of creep, thixotropy and structuration on (a) compressibility curve for clay soil; and (b) shear strength (undrained) for clay soil (Adapted from Leroueil et al., 1990). 27 Figure 2.11. Comparison of structured and destructed soil samples compressibility (Adapted from Leroueil et al., 1990). 29 Figure 2.12. Preconsolidation pressure variation with temperature (adapted from Moritz, 1995).

Figure 3.1. Linear log plot of penetration depth vs water content used in calculating plastic limit (Adapted from Feng 2001). 32

Figure 3.2. Labelled pore-water pressure sensor (UMS T5 tensiometer) (from Meter

Environment, 2018). 34

Figure 3.3. (a) Sutron 9210 xLite data logger (https://www.sutron.com/product/xlite-9210b/); and, (b) DI2e datalogger (https://www.delta-t.co.uk/product/dl2e/)................................... 35

Figure 3.4. A M\&L fall cone testing equipment. .................................................................... 36

Figure 3.5. Conventional oedometer test frame (Adapted from Salam, 2020). ....................... 37

Figure 3.6. Modified oedometer with T5x tensiometers installed in the base and connected to

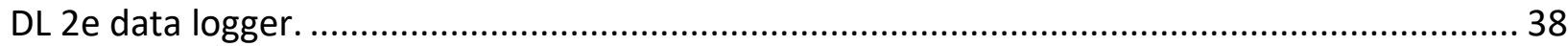

Figure 3.7. Volumetric water content sensor (Decagon, 2016). ............................................... 39

Figure 3.8. Decagon 5TE calibration (from Abdulrahman, 2019).............................................. 39

Figure 3.9. Four Artech 70210-5k load cells (from Hurtado, 2018)......................................... 40

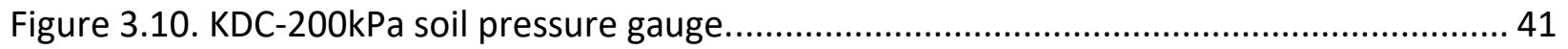

Figure 3.11. LDVT sensor on the load transfer component of the lever arm.......................... 42

Figure 3.12. Schematic diagram showing replicate columns with $0.10 \mathrm{~m}$ thick tailings............ 43 
Figure 3.13. Schematic diagram showing replicate column with pore-water pressure (PWP) sensor.

Figure 3.14. Visible marks on tailings from previous measurements.

Figure 3.15. Schematic diagram of the large-scale consolidation test apparatus: A: Steel beam;

B: Loading arm; C: Load transfer; D: Weights; E: Steel box; F: Load cells. 47

Figure 3.16. Schematic diagram showing large scale setup and sketched design. ................... 48

Figure 3.17. Steel box balanced on load cells................................................................... 49

Figure 3.18. Schematic diagram showing pore-water pressure (tensiometer), soil gauge pressure

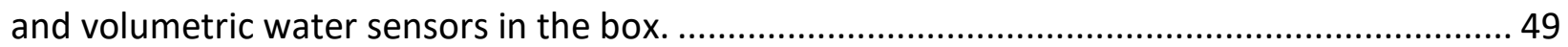

Figure 3.19. Screenshot of the deposition scheme window in UNSATCON............................ 52

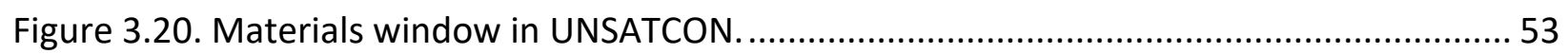

Figure 3.21. Hydraulic - boundary condition window in UNSATCON. .................................... 54

Figure 3.22. Mechanical - boundary condition window in UNSATCON.................................... 55

Figure 3.23. Numerical parameter window in UNSATCON. ............................................... 56

Figure 3.24. Overall settlement versus time plot generated by UNSATCON for steel box using oedometer calculated hydraulic conductivity.

Figure 3.25. Overall results from UNSATCON with plotted geotechnical properties for steel box using oedometer calculated hydraulic conductivity. 58

Figure 4.1. Pore-water pressure (hPa) at $0.064 \mathrm{~m}(\mathrm{T5})$ depth from the top of the tailings at room temperature. 60

Figure 4.2. Pore-water pressure (hPa) at $0.056 \mathrm{~m}(\mathrm{~T} 5)$ depth from the top of the tailings at room temperature.

Figure 4.3. Depth profile of water content in the replicate columns.

Figure 4.4. Undrained shear strength of the three-fall cone and the water content replicate columns over recorded over different days.

Figure 4.5. Water content over time in columns plotted with undrained shear strength

development 64

Figure 4.6. The compressibility curves for undisturbed column samples at 79 and 126 days..... 65

Figure 4.7. Plot of creep rate $\left(C_{\alpha e}\right)$ /compression index $\left(C_{c}\right)$ ratio for day $79 . \ldots \ldots \ldots \ldots \ldots \ldots \ldots \ldots . . . . . . . . . . . . . .66$

Figure 4.8. Plot of creep rate (Cae)/compression index (Cc) ratio for day 126. 67

Figure 4.9 Change in compressibility curve in centrifuge cake tailings from replicate $0.10 \mathrm{~m}$ tall columns at day 79. 68

Figure 4.10. Comparing compressibility of remolded days 79 and 126 samples. 69

Figure 4.11. Plot of creep coefficient $\left(C_{\alpha}\right)$ / compression index ratio $\left(C_{c}\right)$ for remolded day $79 . .70$ Figure 4.12. Plot of creep coefficient $\left(C_{\alpha}\right)$ / compression index $\left(C_{c}\right)$ ratio for remolded day $79 . .70$ Figure 4.13. Compressibility curve from oedometer tests started at 0 day and 28 days. 71 Figure 4.14. Settlement vs time plot showing pore-water pressure dissipation for the $220 \mathrm{kPa}$ loading step for the 28 days sample. 72

Figure 4.15. Settlement vs time plot showing pore-water pressure dissipation for the $220 \mathrm{kPa}$ loading step for the 79 days sample. 
Figure 4.16. Settlement vs time plot showing pore-water pressure dissipation for the $220 \mathrm{kPa}$

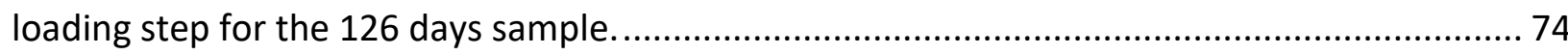

Figure 4.17. UNSATCON deposition scheme parameter window. ....................................... 75

Figure 4.18. Fitted 79-day remolded plot used in developing volume compressibility relationship

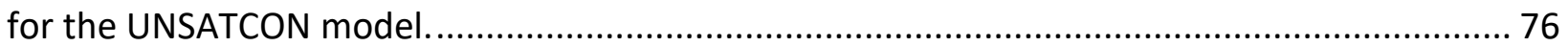

Figure 4.19. Oedometer calculated day-0 hydraulic conductivity-void ratio data used in developing constitutive relationship for the UNSATCON model. ............................................. 77

Figure 4.20. Calibrated oedometer day-0 hydraulic conductivity-void ratio data used in developing constitutive relationship for the UNSATCON model. ........................................ 78

Figure 4.21. UNSATCON materials parameter window showing the oedometer calculated

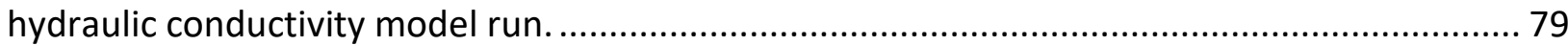

Figure 4.22. UNSATCON boundary conditions - hydraulic parameter window. ....................... 80

Figure 4.23. UNSATCON boundary conditions - mechanical parameter window...................... 81

Figure 4.24. UNSATCON numerical parameter window................................................ 82

Figure 4.25. Average gravimetric water content with time modelled using oedometer calculated hydraulic conductivity.

Figure 4.26. Average gravimetric water content with time modelled using calibrated hydraulic conductivity.....

Figure 4.27. Measured and predicted solids content profile model using oedometer calculated hydraulic conductivity for $0.10 \mathrm{~m}$ columns.

Figure 4.28. Measured and predicted solids content profile model using calibrated hydraulic conductivity for $0.10 \mathrm{~m}$ columns.

Figure 4.29. Measured and predicted PWP using oedometer calculated hydraulic conductivity for 0.10 m columns.

Figure 4.30. Measured and predicted PWP using calibrated hydraulic conductivity for $0.10 \mathrm{~m}$ columns.

Figure 4.31. Measured and predicted tailings height over time using oedometer calculated hydraulic conductivity for $0.10 \mathrm{~m}$ columns.

Figure 4.32. Measured and predicted tailings height over time using calibrated hydraulic conductivity for $0.10 \mathrm{~m}$ columns. 90

Figure 4.33. Hydraulic conductivity of different oil sand tailings within the void ratio range of 1 to 4 (Adapted from Liu, 2017).

Figure 4.34. Comparison of $C_{\alpha e} / C_{c}$ ratio vs effective stress for clays and centrifuge cake (Adapted from Graham et al., 1983).

Figure 4.35. Dewatering and fall-cone strength in replicate $0.10 \mathrm{~m}$ tall columns of in-line flocculated FFT (Adapted from Salam, 2018).

Figure 5.1. Displacement measurement from steel box test during first 23 days of self-weight consolidation 94

Figure 5.2. Water content by depth at day 1 and day 23 during self-weight consolidation....... 95

Figure 5.3. PWP readings at different depths........................................................................ 96

Figure 5.4. Volumetric water content profile at the top, middle and bottom layer.................. 97 
Figure 5.5. PWP readings at different depths for $2 \mathrm{kPa}$ loading step..... 98

Figure 5.6. Settlement vs time plotted with excess pore-water pressure vs time for $2 \mathrm{kPa}$ loading step using the $0.11 \mathrm{~m}$ PWP sensor. 99

Figure 5.7. Volumetric water content at different depth for 2 kPa loading step...................... 100

Figure 5.8. PWP readings at different depths for 3 kPa loading step...................................... 101

Figure 5.9. Settlement vs time plotted with excess pore-water pressure vs time for $3 \mathrm{kPa}$ loading step using the $0.11 \mathrm{~m}$ PWP sensor..... 102

Figure 5.10. Volumetric water content at different depths for $3 \mathrm{kPa}$ loading step................. 103

Figure 5.11. PWP readings at different depths for 8 kPa loading step................................... 104

Figure 5.12. Settlement vs time plotted with excess pore-water pressure vs time for $8 \mathrm{kPa}$

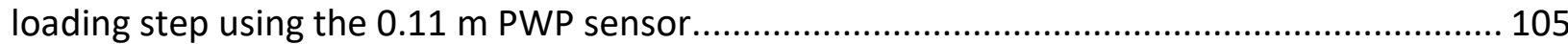

Figure 5.13. Volumetric water content at different depth during the $8 \mathrm{kPa}$ loading step........ 106

Figure 5.14. PWP readings at different depths for $16 \mathrm{kPa}$ loading step.................................. 107

Figure 5.15. Settlement vs time plotted with excess pore-water pressure vs time for $16 \mathrm{kPa}$

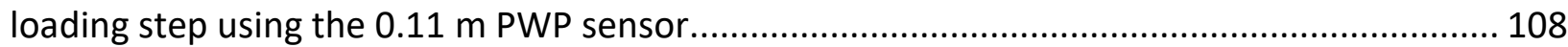

Figure 5.16. Volumetric water content at different depth during the $16 \mathrm{kPa}$ loading step. ..... 109

Figure 5.17. Tensiometer located at $0.11 \mathrm{~m}$ depth PWP reading over the period of test........ 110

Figure 5.18. Tensiometer located at $0.10 \mathrm{~m}$ depth PWP reading over the period of test........ 110

Figure 5.19. Tensiometer located at $0.25 \mathrm{~m}$ depth PWP reading over the period of test......... 111

Figure 5.20. Tensiometer located at $0.30 \mathrm{~m}$ depth PWP reading over the period of test......... 112

Figure 5.21. Tensiometer located at $0.54 \mathrm{~m}$ depth PWP reading over the period of test......... 113

Figure 5.22. Volumetric water content over the test period. ........................................... 114

Figure 5.23. Comparison between the oedometer and steel box compressibility curves......... 115

Figure 5.24. Measured and predicted solids content by depth profile using oedometer calculated hydraulic conductivity.

Figure 5.25. Measured and predicted solids content by depth profile using calibrated hydraulic conductivity. 118

Figure 5.26. Measured and predicted PWP profile at $0.11 \mathrm{~m}$ depth using oedometer calculated hydraulic conductivity. 119

Figure 5.27. Measured and predicted PWP profile at $0.25 \mathrm{~m}$ depth using oedometer calculated hydraulic conductivity..... 120

Figure 5.28. Measured and predicted PWP profile at $0.54 \mathrm{~m}$ depth using oedometer calculated hydraulic conductivity.

Figure 5.29. Measured and predicted PWP profile at $0.10 \mathrm{~m}$ depth using calibrated hydraulic conductivity......

Figure 5.30. Measured and predicted PWP profile at $0.25 \mathrm{~m}$ depth using calibrated hydraulic conductivity....

Figure 5.31. Measured and predicted PWP profile at $0.54 \mathrm{~m}$ depth using calibrated hydraulic conductivity. 123

Figure 5.32. Measured and predicted tailings height over time using oedometer calculated hydraulic conductivity. 124 
Figure 5.33. Measured and predicted tailings height over time using calibrated hydraulic conductivity.

Figure 5.34. Solids content versus depth profile in a $10 \mathrm{~m}$ deep pilot study of consolidation of centrifuge cake FFT.

Figure 5.35. Solids content versus depth profile in $0.10 \mathrm{~m}$ columns experimental investigation

(phase I).

Figure 5.36. Pore-water pressure measurement in a $10 \mathrm{~m}$ deep pilot study of consolidation of centrifuge cake FFT. 128

Figure 5.37. PWP pressure measurements for 8 and $16 \mathrm{kPa}$ loading steps at different elevations in the steel box (phase II).

Figure 5.38. Sensitivity profile in a $10 \mathrm{~m}$ deep pilot study of consolidation of centrifuge cake FFT. 


\section{List of Appendices}

\section{Figures}

Appendix A. AGAT laboratory tailings characterization test results: ............................... 148

Figure A-1. Methylene blue index analysis for centrifuge cake FFT. ................................... 148

Figure A-2. XRD analysis for centrifuge cake FFT ............................................................. 148

Figure A-3. Inorganic chemistry water for centrifuge cake FFT........................................ 149

Figure A-4. Total water hardness for centrifuge cake FFT................................................ 149

Figure A-5. Dean stark analysis for centrifuge cake FFT.................................................. 150

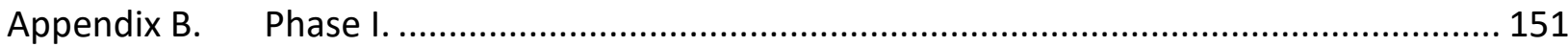

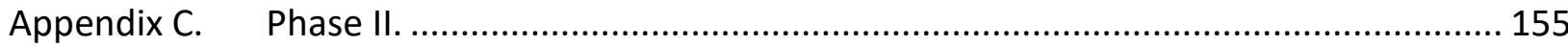

Figure C-1. Load cell underneath steel box tracking mass changes in the box during self-weight

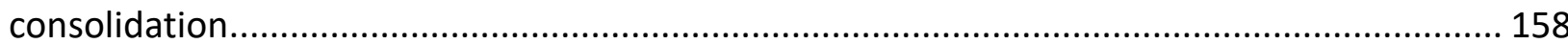

Figure C-2. Three pressure gauges positioned at the bottom of the box in different orientations track stress at the bottom of the box during self-weight consolidation.

159

Figure C-3. Load cell underneath steel box tracking mass changes in the box during $2 \mathrm{kPa}$ loading step 160

Figure C-4. Three pressure gauges positioned at the bottom of the box in different orientations track stress at the bottom of the box for $2 \mathrm{kPa}$ loading step. 161

Figure C-5. Load cell underneath steel box tracking mass changes in the box during $3 \mathrm{kPa}$ loading step. 162

Figure C-6. Three pressure gauge positioned at the bottom of the box in different orientations track stress at the bottom of the box for $3 \mathrm{kPa}$ loading step. 163

Figure C-7. Load cell underneath steel box tracking mass changes in the box during $8 \mathrm{kPa}$ loading step..... 164

Figure C-8. Three pressure gauge positioned at the bottom of the box in different orientations track stress at the bottom of the box for $8 \mathrm{kPa}$ loading step. 165

Figure C-9. Load cell underneath steel box tracking mass changes in the box during $16 \mathrm{kPa}$ loading step 166

Figure $\mathrm{C}-10$. Three pressure gauge positioned at the bottom of the box in different orientations

track stress at the bottom of the box for $16 \mathrm{kPa}$ loading step. 167

Figure C-11. Load cell measurement over the duration of the experiment............................ 168

Figure $\mathrm{C}-12$. Pressure gauge readings over the duration of the experiment. 169

Figure C-13. Core samples at different horizonal locations solids content depth profile taken at the end of the test. 170

Appendix D. Phase II box and apparatus design........................................................... 171

Figure D-1. Schematic diagram of entire steel box......................................................... 171

Figure D-2. Schematic diagram of box bottom plate.......................................................... 172

Figure D-3. Schematic diagram of first side plate without opening..................................... 173 
Figure D-4. Schematic diagram of first side plate with holes.

Figure D-5. Schematic diagram of second side plate without holes. ................................... 175

Figure D-6. Schematic diagram of second side plate with holes.......................................... 176

Figure D-7. Schematic diagram showing beam component with two connecting side plates. . 177 Figure D-8. Schematic diagram showing the beam component of the lever arm loading system.

Figure D-9. Schematic diagram showing the connecting bracket for the loading arm apparatus.

Figure D-10. Schematic diagram showing the entire apparatus - loading arm, beam, load platform and load application. 180

Figure D-11. Schematic diagram showing load transfer component of the lever arm loading system.

Figure D-12. Schematic diagram showing load application component of the lever arm loading system. 182

Figure D-13. Schematic diagram showing loading arm component of the lever arm loading system. 183

Figure D-14. Schematic diagram showing the loading arm, load transfer and load application components. 184

Figure D-15. Schematic diagram showing the pivot bolt apparatus for the loading arm. 185 Figure D-16. Schematic diagram showing the connecting pivot bolt and side steel plates connected to the beam. 186

Figure D-17. Schematic diagram showing the steel plates attached to beam. 187 Appendix E. UNSATCON. 188

Figure E-1. Overall settlement plot generated by UNSATCON for $0.10 \mathrm{~m}$ column using oedometer calculated hydraulic conductivity. 188 Figure E-2. Overall result from UNSATCON with plotted geotechnical properties for $0.10 \mathrm{~m}$ column using oedometer calculated hydraulic conductivity..... 189 Figure E-3. Overall settlement plot generated by UNSATCON for $0.10 \mathrm{~m}$ column using calibrated hydraulic conductivity. 190 Figure E-4. Overall result from UNSATCON with plotted geotechnical properties for $0.10 \mathrm{~m}$ column using calibrated hydraulic conductivity. 191

Figure E-5. Overall settlement versus time plot generated by UNSATCON for steel box using calibrated hydraulic conductivity...... 192 Figure E-6. Overall results from UNSATCON with plotted geotechnical properties for steel box using calibrated hydraulic conductivity. 193

Figure E-7. Overall settlement versus time plot for $0.10 \mathrm{~m}$ columns using a spatial node of 20 and time increment of $50 \mathrm{~s}$.

Figure E-8. Solids content by depth profile for steel box (phase II) using a spatial node of 20. 195 Tables

Appendix A. AGAT laboratory tailings characterization test results: 148 


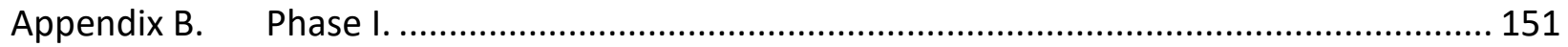

Table B-1: Pre-mixing and after mixing solids content for phase I...................................... 151

Table B-2: Fall cone 1 solids content by depth broken after 518 days................................... 152

Appendix Table B-3: Fall cone 2 solids content by depth broken after 518 days. ................... 153

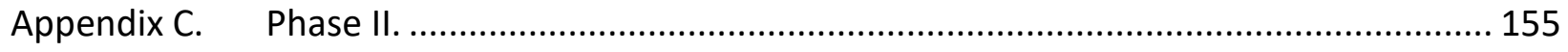

Table C-1: Initial solids content of tailings by depth in the box at the beginning of the test. ... 155

Table C-2: Initial solids content of tailings by depth in the box at the end of self-weight

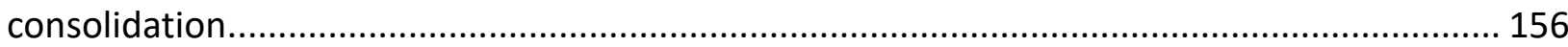

Table C-3. Estimated saturation of the core sample taken at the beginning and end of self-

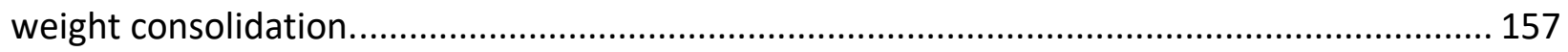

Appendix D. Phase II box and apparatus design.......................................................... 171

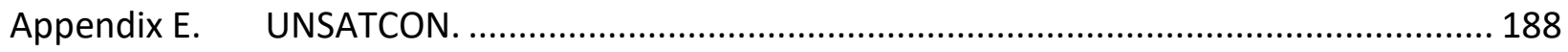




\section{List of Abbreviations}

AER

AFD

ASTM

CHWE

$\operatorname{COSIA}$

CS2

CT

FFT

GWC

ILF

LDVT

LHS

LL

MBI

$\mathrm{MC}$

MFT

NST

PL

PP

PWP

RHS

SC

TRO

TT

UTM
Alberta Energy Regulator

Atmospheric fines drying

American Society for Testing and Materials

Clark Hot Water Extraction

Canada's Oil Sands Innovation Alliance

Consolidation Settlement 2

Composite Tailings

Fluid Fine Tailings

Gravimetric water content

In-line Flocculation

Linear Variable Differential Transformer

Left-hand side

Liquid Limit

Methylene Blue Index

Moisture Content

Matured Fine Tailings

Non-segregating Tailings

Plastic Index

Polypropylene

Pore-water pressure

Right-hand side

Solids content

Tailings reduction operation

Thickened tailings

Universal testing machine 
Volumetric water content

XRD

X-ray diffraction 
Chapter 1 : Introduction

\subsection{Problem statement}

Mining of Alberta oil sands deposits and the subsequent bitumen extraction process generates a low solids content slurry called oil sands tailings; they consist of sand, water, fine clay particles, residual oil, and organic matter from the bitumen. The tailings are transported to large manmade impoundments. The sand sized particles settle out to form beaches rapidly (weeks to several months only), however, about half of the finer particles remain suspended in the water (Scott et al., 1985). This suspension equilibrates at about $30 \%-35 \%$ solids (by weight) or $200 \%$ water content (gravimetric - mass of water by mass of solids) within a few years after deposition, and it is termed fluid fine tailings (FFT) at this point. The water content of the FFT (>200\%) is higher than the liquid limit $(50-70 \%)$ at this state and they exhibit low strength and load bearing capacity (< $1 \mathrm{kPa}$ undrained shear strength) (Beier et al., 2013; BGC Engineering Inc. 2010; Wilson et al., 2018). More problematic is that further densification of the FFT is much slower (about 100 times slower) than at the beginning when freshly discharged into the dam, which is attributed to negligible dewatering of the tailings due to poor consolidation properties and development of preconsolidation pressure due to thixotropic re-alignment of particles (Scott et al., 2013). As of 2017, over 1 billion $\mathrm{m}^{3}$ of FFT are accumulated in these ponds, and the projection for 2034 is approximately 2 billion m3 (McNeill et al., 2017; BGC Engineering Inc., 2010).

To tackle the environmental impacts of the oil sands industry production, the Alberta Energy Regulator (AER) has proposed the current regulation for oil sands tailings management 'Directive 085 Fluid Tailings Management for Oil Sands Mining Projects'. This requires impoundments to reach "ready to reclaim" status within 10 years of the end-of-mine life (Alberta Energy Regulator, 2017). Some operators have interpreted "ready to reclaim" to imply that tailings deposits must be sufficiently strong to enable their placement in gently sloped landforms, similar in topography to the surrounding boreal forest uplands. From simple slope stability calculations, this implies that an undrained shear strength greater than $20 \mathrm{kPa}$ is needed to avoid deep seated slope stability failures (Mckenna et al., 2016). This in turn implies, for fines dominated deposits, a solids concentration greater than $70 \%$ (by weight), or a gravimetric water content $(w)$ at about the plastic limit of the tailings ( $40 \%$ ). Directive 085 entails no mandatory pathway in meeting the target outlined in the guidelines hence varying tailings dewatering processes have been tested at pilot and commercial demonstration scales with in-line flocculation, tank thickening and centrifuge technologies recording successes at the pilot scale and being implemented on a larger scale by the oil sands operators in tailings management. 
Centrifuge technology involves the application of a force several times that of gravity resulting in denser tailings effluent with solids content as high as 60\% solids (by weight) (Devenny, 2010). Syncrude began pilot study for this technology in 2005 and after successful studies they opted for implementation on a larger scale in 2015 with a \$1.9 billion full scale centrifuge plant containing 16 centrifuges (Chandler, 2017). Although this centrifuge technology has been shown to reliably produces tailings with solids content greater than $50 \%$, there is need for further dewatering to achieve the targeted solids concentration of $70 \%$ (by weight). Understanding mechanisms contributing to post-deposition such as consolidation and aging effects plays a vital role in achieving regulatory requirements.

The product of the centrifugation process is called 'Centrifuge Cake Oil Sands Tailings', a material with increased solids content and strength properties, formed from the addition of a coagulant (gypsum) or flocculant (polyacrylamide) to FFT. This centrifuge cake is continuously deposited in dedicated disposal areas (DDA) at high disposal rates where further dewatering and volume changes are influenced by consolidation at a very slow rate which could take up to decades to achieve target final settlement (Beier et al.,2013). Currently, the industry operators and researchers have attempted modelling pilot studies, to predict full scale dewatering behaviour, but non-consolidation behaviours are apparent (Suthaker 1995; Jeeravipoolvarn, 2005; Jeeravipoolvarn et al., 2008, 2009). This may be due to the aging effects i.e. thixotropy, structuration and creep also playing a role in the rate of settlement in natural clay and polymer amended FFT (Locat et al., 1986; Burland, 1990; Athanasopoulos, 1993).

Research conducted at the University of Alberta on a lab scale with two $10 \mathrm{~m}$ high, $0.9 \mathrm{~m}$ diameter standpipes in 1982 filled with oil sands fine tailings in one standpipe and a mix of fine tailings and tailings sand in the other pipe to investigate the long term consolidation behavior of the fine tailings showed that creep and not consolidation was responsible for the settlement which occurred after 20.6 years (Jeeravipoolvarn, 2005). Similarly, the tailings research group at Carleton University performed $0.10 \mathrm{~m}$ sample thick column dewatering tests on polymer amended tailings with results demonstrating aging effect (aging preconsolidation) influenced tailings compressibility (Salam, 2018a). Final settlement prediction of a $50 \mathrm{~m}$ tailings deposit using compressibility curves from the test showed the samples with stiffer curves (developed preconsolidation pressure) had a higher final elevation (less settlement) predicted when compared to less stiff curves (no preconsolidation pressure) (Salam, 2020). Furthermore, column dewatering tests on centrifuge cake tailings showed that the consolidation rate was influenced by development of apparent preconsolidation pressure (structuration) (Igbinedion et al., 2019). These oil sands tailings investigations showed dewatering behavior is controlled by both consolidation and non-consolidation behavior i.e. creep and aging effects. This means using a single compressibility relationship measured in fresh tailings with large-strain consolidation modelling may not be sufficient to predict tailings settlement in the field. Using a set of similar curves that incorporates consolidation, creep, and aging effects in predicting the long-term tailings settlement behavior in the deposits would be a better approach (Jeeravipoolvarn, 2005). 
The goal of this investigation is understanding the consolidation and non-consolidation volume change behaviours such as, creep, thixotropy, and structuration in centrifuge cake tailings to accurately predict the long-term dewatering behaviour and final settlement in tailings pond. This experimental program studies consolidation and non-consolidation behaviors affecting volume change in long term deposits of centrifuge cakes tailings by using $0.16 \mathrm{~m}$ dewatering columns and $0.49 \mathrm{~m}$ by $0.35 \mathrm{~m}$ by $0.72 \mathrm{~m}$ steel box. These experiments are analyzed using the large-strain consolidation numerical model UNSATCON (Qi et al., 2019, Qi et al., 2017).

\subsection{Objectives and scope of work}

1. The main objectives of this research are: Investigate the influence of creep and aging effects in centrifuge cake oil sands tailings dewatering, if any.

2. To obtain sufficient data that could be used to model dewatering of tailings by incorporating consolidate, creep and aging effects.

To achieve these objectives, the following experimental work were performed:

1. Centrifuge cake tailings characterization tests to determine water retention curve, water chemistry, particle size distribution, bitumen, solids, and water content, MBI and XRD analysis, among others.

2. A suite of $0.15 \mathrm{~m}$ high $0.075 \mathrm{~m}$ diameter columns of centrifuge cake were studied over 126 days to understand the dewatering behaviour in tailings and the influence of time dependent behaviour. These were monitored for pore-pressure, and volume change, and destructively tested for water content, shear strength, and pore chemistry changes. Some samples were used to conducted oedometer tests at different aging times.

3. A large experiment simulating cake consolidation. A $0.6 \mathrm{~m}$ thick deposit in a specially fabricated steel consolidation cell, using lever arm system under saturated conditions, fitted with multiple sensors and $0.62 \mathrm{~m}$ thick deposition to track large-scale consolidation, secondary compression, and aging effects.

4. Simulation of experimental data with numerical model UNSATCON to have better understanding of dewatering behaviour.

\subsection{Thesis outline}

The outline of this thesis is presented below: 
Chapter 2: Literature Review - A review of the history of oil sands tailings industry, large-strain consolidation, creep, and aging effects. In addition, a summary on UNSATCON relevant to this topic.

Chapter 3: Methods and Materials - This section describes the material used for both the longterm dewatering column and steel box. Also, the procedures employed over the course of the study are further explained.

Chapter 4: Results (Phase I) - Result of the $0.10 \mathrm{~m}$ dewatering columns.

Chapter 5: Results (Phase II) - Result of the large-scale consolidation steel box test.

Chapter 6: Summary and conclusions drawn from results followed by recommendations.

\subsection{Novelty of the thesis}

Most of the existing studies conducted on aging effect and creep have been in clays, recent research has been towards understanding this behaviour in oil sand tailings. Little information is available in literature on creep and aging effect and there is no existing consolidation model that incorporates these phenomena when predicting the dewatering behaviour in tailings ponds. This research presented column dewatering tests in tracking consolidation and non-consolidation behaviours such as creep and aging effects.

This research also presented using a steel box in monitoring large-scale consolidation, secondary compression, and aging effect. This large-scale novel consolidation test enabled larger and multiple sampling of centrifuge cake material at different points. Data from this large-scale consolidation test would be used in future and ongoing work on incorporating time -dependent effect in the large-scale consolidation analysis. This is the first publicly published study on aging effects and creep in centrifuge cake oil sands tailings. During this study, to the best of the author's knowledge, no other work on creep and aging effect in centrifuge cake tailings have been published in the journals or reported in conference papers. 


\section{Chapter 2 : Literature Review}

The chapter provides some background information on the oil sands industry. It also presents the varying technologies and approaches used in the oil sands extraction in Alberta. Later sections briefly review the relevant technical background (consolidation, creep, aging).

\subsection{Oil sands}

In northern Alberta, large mineral deposits of unrefined oil (oil sands) are contained in rocks formation (oil sands deposits) that cannot be explored by conventional oil well production methods due to the viscosity of the bitumen contained in them (Meyer, 1977; Hurtado, 2018). The origin of oil sands can be linked to dead marine animals at the bottom of the sea millions of years ago and they metamorphosed through pressure and heat over time to be oil sands (Oil Sands Discovery Centre, 2016). Though the $20^{\text {th }}$ century was the age of technological development for the oil sands, members of Canada's First Nations communities had distinct knowledge of the oil sands for centuries prior to that time period and made use of them for various purposes (Roberts, 2018).

\subsubsection{Oil sands characteristics and deposits}

Oil sands sediments are typically composed mainly of uncemented quartzose sands and connected finer grained rocks that are water wet or hydrophilic; Each grain of sand is covered by a film of water ( $10 \mathrm{~nm}$ ), which is then surrounded by bitumen (Figure 2.1) (Jeeravipoolvarn, 2010; Zhu, 2013; Oil Sands Discovery Centre, 2016). This bitumen has a physical property of being viscous i.e. difficult to flow thereby making mining from deposits involve more form of processing since it cannot be pumped directly from the deposits. The percentage of bitumen in a deposit (usually 1 - 18\%) determines the viability of a deposit with (>12\%) considered rich and $(<6 \%)$ poor; the Fort McMurray deposit is composed of bitumen (12\%), water (3-6\%) sands, silts (6\%) and clays minerals (84-86\%) (Chalaturnyk et al., 2002; Oil Sands Discovery Centre, 2016). Canada has the second largest oil sands deposit in the world with an estimated recoverable oil of 173.2 billion barrels (Giesy, 2010). The availability of large oil sands deposits in Canada makes exploration on a large scale an economic viable option with oil sands mining the major crude oil production source in Canada (McWhinney, 2014; Canadian Association of Petroleum Producers, 2016). 


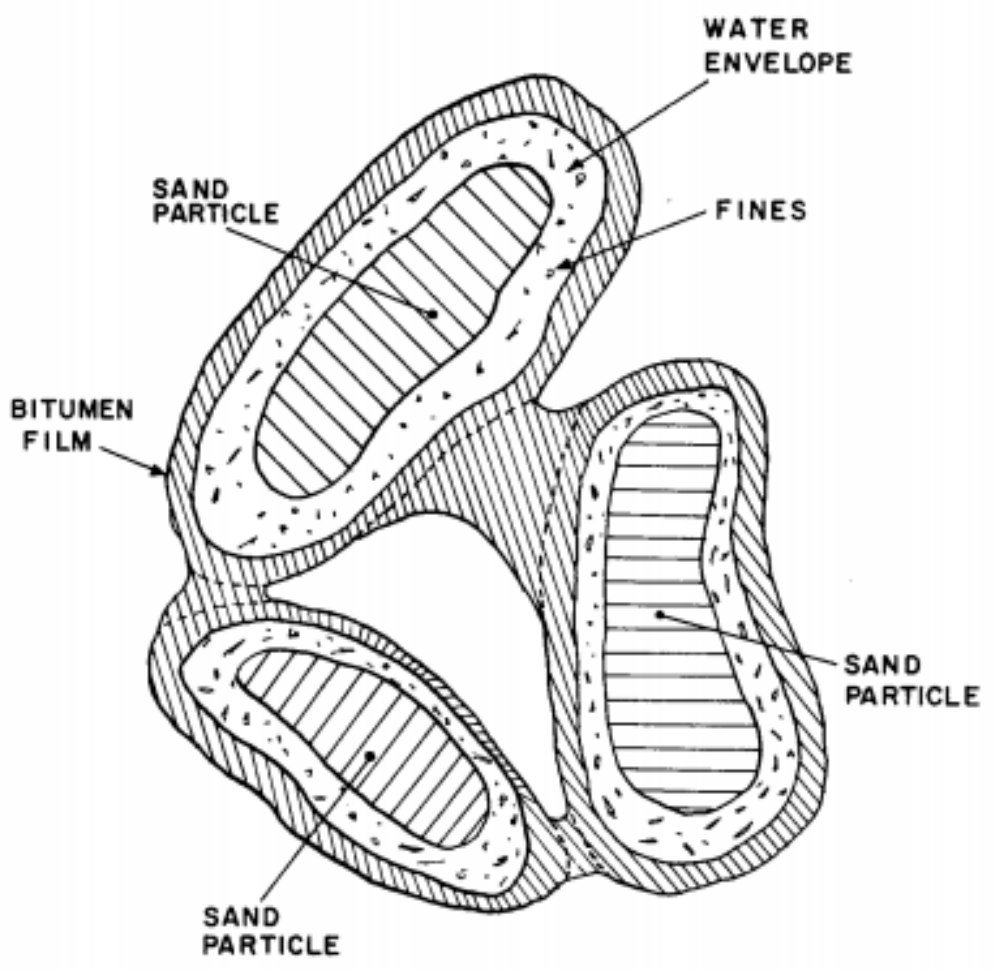

Figure 2.1. J.H Cottrell (1963) proposed model of oil sands (from Carrigy, 1963).

There are three major deposits in Alberta namely: Athabasca, Peace River, and Cold Lake (Figure 2.2). These three deposits cover a combined surface area of $142,000 \mathrm{~km}^{2}$ and possibly contain as large as 1.8 trillion barrels of bitumen (Alberta Energy Regulator, 2015, Baniak et al., 2018). 


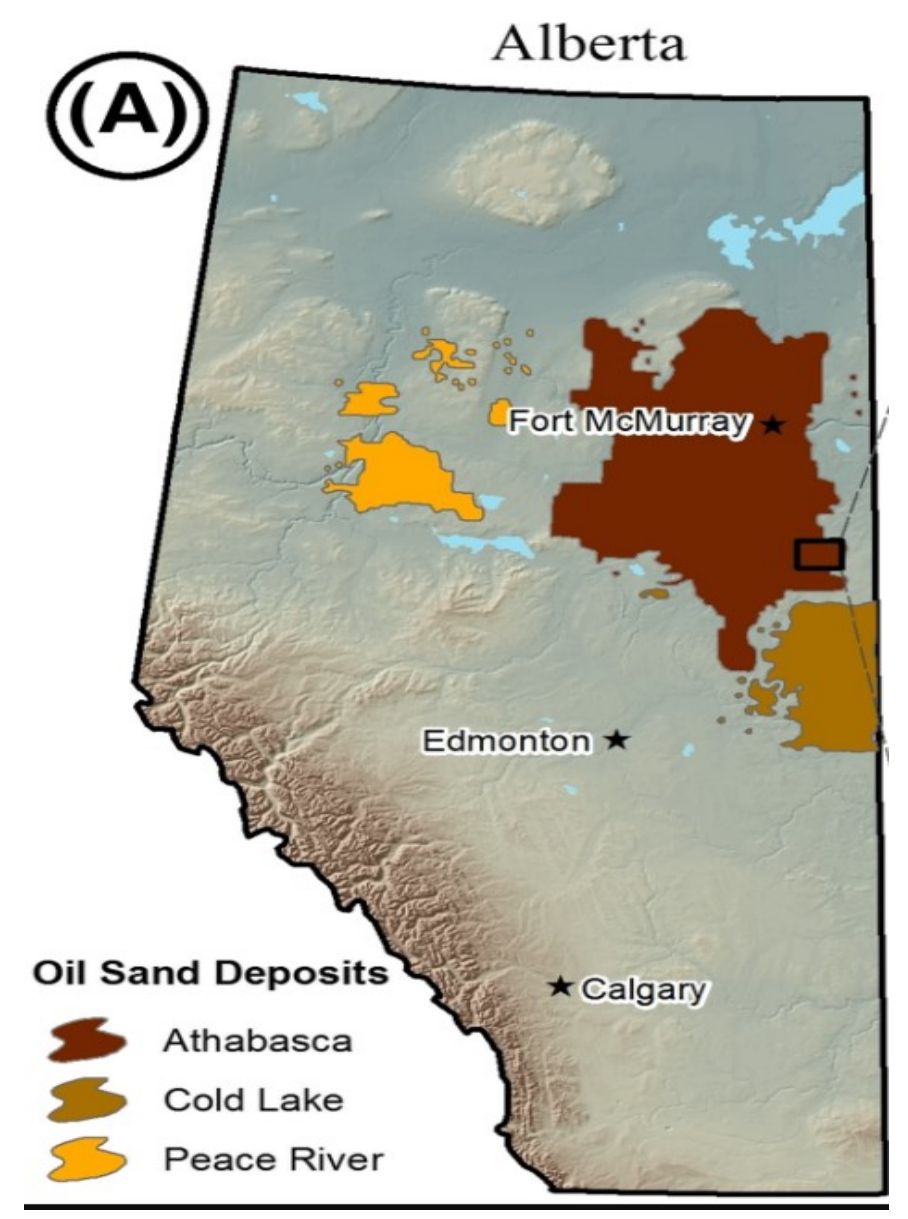

Figure 2.2. Map showing the location of the three main Alberta oil sands deposit (Modified by Baniak et al., 2018, from Hubbard et al., 2011).

Athabasca deposit covers the largest surface area (Figure 2.2) and is estimated to contain over 1.5 trillion barrels of bitumen (Alberta Energy Regulator, 2015). The Aptian McMurray Formation ( 125 - $113 \mathrm{Ma})$ and Wabiskaw Member of the Albian Clearwater Formation ( 113 - $100 \mathrm{Ma})$ contain most of the bitumen formation within the Athabasca deposit (Baniak et al., 2018). The largest surface minable area (less than $65 \mathrm{~m}$ deep) is located in this deposit although about $82 \%$ of the bitumen resource lay deeper than $65 \mathrm{~m}$ and have to be extracted by in situ technology (Alberta Energy Regulator, 2015). In 2014, the oil production for Athabasca deposit was 813 bbl./d making it the highest rate among the 3 deposits (Alberta Energy Regulator, 2015).

Covering a surface area of approximately $22,000 \mathrm{~km}^{2}$, the Cold Lake deposit is estimated to hold an estimated 182.9 billion barrels of bitumen and oil production rate of $398 \mathrm{bbl} . / \mathrm{d}$ (Alberta Energy Regulator, 2015). Most of the bitumen formation occurs within the grand rapids and clearwater formation with mineable areas 300 to $600 \mathrm{~m}$ deep, making the in-situ technology the main source of bitumen extraction in this deposit (Gingras et al., 2004; Oil Sands Discovery Centre, 2016). 
Peace River deposit covers the smallest area $\left(\sim 8000 \mathrm{~km}^{2}\right)$ with an approximate in-place bitumen volume of 135 billion barrels and lowest production rate of approximately $54 \mathrm{bbl}$./d and (Alberta Energy Regulator, 2015). The bitumen formation is found in the Bluesky and Gething formations (similar to McMurray formation in Athabasca) with mineable areas 300 to $770 \mathrm{~m}$ deeps thus making in-situ technologies the main extraction source (Gingras et al., 2004, Oil Sands Discovery Centre, 2016).

\subsubsection{Bitumen extraction process}

Though discovery of oil sands precedes the $20^{\text {th }}$ century, efficient and economical extraction technology were not available until 1920s when Dr. Karl Clark developed the Clark Hot Water Extraction process (CHWE) to extract the bitumen from the oil sands (Chastko, 2004). CHWE process of extraction involves three stages: conditioning, separation, and scavenging (Figure 2.3) (Speight, 2013). During conditioning, oil sands chunks are reduced in size after which caustic soda $(\mathrm{NaOH})$ and hot water are added to create a slurry and facilitate the separation of the bitumen from mineral solids. Hot water lowers the viscosity of the bitumen and $\mathrm{NaOH}$ increases the $\mathrm{pH}$ of the solution $(8-8.5)$ while reducing the surface and interfacial tension which results in clay and silt particles becoming well dispersed and bitumen hydrophobic. Poor dewatering in tailings have been linked to the dispersion of clay particles in this stage (Boratynec et al., 1998; Chalaturnyk et al., 2002). In the separation stage, the fully conditioned solution goes through froth flotation technique and develops a segregated profile with majority of bitumen floating on top, a suspension consisting mostly of fine particles and some bitumen in the middle (middlings stream), and coarse soil grains settled at the bottom. The floating bitumen are scrapped off the surface and taken for further treatment and the accumulated sands at the bottom are removed as part of the tailings stream with the middlings going for further process in the scavenging stage. In this stage, further bitumen removal is achieved by discharging middlings stream slurry into scavenger cells where additional air is injected. The waste stream from the separation and scavenging stages are combined, and the addition of water creates a pumpable tailings stream (Boratynec, 2003). 


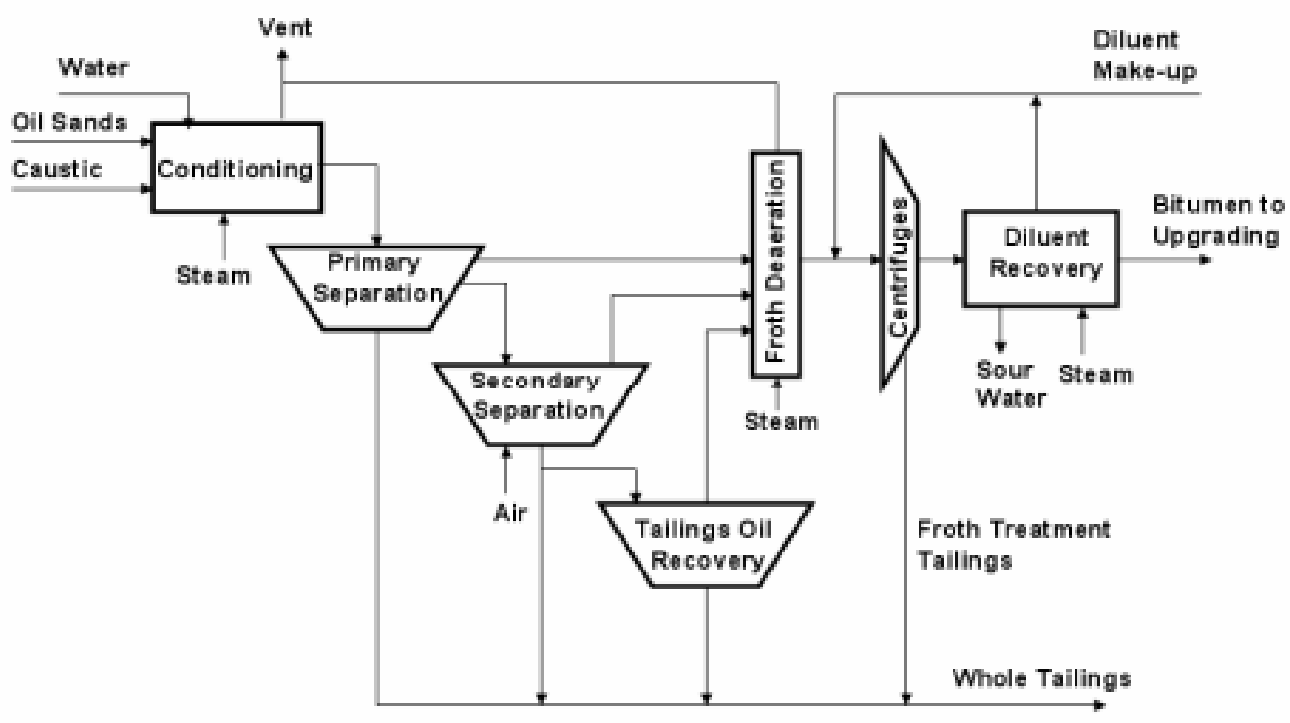

Figure 2.3. Schematic diagram of Clark Hot Water Extraction Process (Modified by Jeeravipoolvarn, 2010, from Chalaturnyk et al., 2004).

Despite some differences in details, CHWE process has been adopted in commercial operations by different oil sands operators due to its success in bitumen extraction from the oil sands (Masliyah et al., 2008).

\subsubsection{Tailings disposal method}

Operators in the oil sands industry operate under the 'zero discharge policy' ensure no fines or processed affected water can be discharged or allowed to migrate to an offsite location (Boratynec, 2003). The tailings leave the bitumen extraction process as the waste stream and are transported to dam impoundment structures or disposal areas with substantial footprint called tailings ponds. Sands in the tailings settle down to form beaches relatively quickly, leaving a more problematic suspension of fine particles. This suspension has solid content between $5 \%$ to $8 \%$ (by weight) initially, and equilibrates at about $30 \%$ - 35\% solids (by weight) or about $200 \%$ water content (gravimetric) within a few years after deposition, at which point it is termed fluid fine tailings (FFT). As of 2017, FFT in tailing ponds cover more than 250 square kilometers and hold over 1 billion $\mathrm{m}^{3}$ of material with the projection for 2034 at approximately 2 billion $\mathrm{m}^{3}$ (BGC Engineering Inc., 2010; McNeill et al., 2017; Orland, 2018). 
Further densification of the FFT is slower (about 100 time slower) than at the beginning when freshly discharged into the dam. The addition of caustic soda $(\mathrm{NaOH})$ during bitumen extraction has been linked to the poor consolidation property of the FFT through negative surface charges and promoting dispersion among clay particles (Beier et al., 2008; BGC Engineering Inc., 2010). This slower settling rate means a larger volume of dam impoundment and land area are needed to accommodate large amount of water and tailings accumulating over time, thus creating a challenge for the industry. In addition, the water budget (twelves barrels of water are used to extract one barrel of oil from oil sands) and tailings generated (1.5 $\mathrm{m}^{3}$ of FFT are generated for every $1 \mathrm{~m}^{3}$ of bitumen produced) from this process could potentially influence the ecosystem (Kasperski, 2011). To tackle these environmental impacts of the oil sands industry production, the Alberta Energy Regulator has proposed the current regulation for oil sands tailings management 'Directive 085 Fluid Tailings Management for Oil Sands Mining Projects'.

\subsubsection{Tailings regulation}

The current regulation for oil sands tailings management 'Directive 085 Fluid Tailings Management for Oil Sands Mining Projects' requires that oil sands operators develop reclamation plans to reclaim all tailings impoundments within 10 years of the end-of-mine life (Alberta Energy Regulator, 2017). The target state of the tailings is "ready to reclaim". Some operators have interpreted these regulations to imply that tailings deposits must be sufficiently strong to enable their placement in gently sloped landforms, similar in topography to the surrounding boreal forest uplands From simple slope stability calculations, this implies than an undrained shear strength greater than $20 \mathrm{kPa}$ is needed to avoid deep seated slope stability failures (Mckenna, 2017). This in turn implies, for fines dominated deposits, a solids concentration greater than $70 \%$, or a geotechnical water content $(w)$ at about the plastic limit of the tailings ( $40 \%)$.

A variety of tailings dewatering technologies have been developed to aid the operators in realizing the current regulation requirements. More information about these technologies is discussed in the next sub section.

\subsubsection{Tailings dewatering technologies}

Significant research of natural, physical, chemical, and physiochemical dewatering processes has been investigated with varying degrees of success at the conceptual, research, pilot scale and commercial scale levels. Some limitations of these technologies ranges from high operational cost, skilled labor shortage, long time commitment, low energy efficiency, low bitumen extraction, inconsistency due to tailings variability, difficulty to remove supernatant liquid, detrimental effects on water quality, and low pumping efficiency (Mikula et al., 2006; BGC 
Engineering Inc, 2010). Some of the technologies available are:

\subsubsection{Thickening process}

This technology is also known as paste technology, it involves the rapid settling and sedimentation of suspended fines (from bitumen extraction process) within a vessel called the thickener through the addition of flocculants with the underflow producing Thickened Tailings (TT) (BGC Engineering Inc, 2010; Alberta Energy Regulator, 2018). TT can have a solids content of about $50 \%$ (by weight) in the thickener underflow with the addition of coagulants and hydrophobicity modifying agents, and the most common flocculent used in this process is the polyacrylamide flocculent (OSTC Companies, 2012; Sobkowicz, 2012; Moussavi, 2013). Canadian Natural Upgrading Limited (CNUL) and Imperial Oil Resources Limited (Imperial) operators currently apply this technology with the goal of terrestrial closure with wetlands for their final reclamation plan (Alberta Energy Regulator, 2018). The T-207 thickeners are currently industry favored with plans to upgrading to T-208 thickeners to achieve a TT solids content of $60 \%$ (wt) (Sobkowicz, 2012; Moussavi, 2013).

\subsubsection{In-line flocculation (ILF) and Thin-Lift drying}

In-line flocculation (ILF) involves using a moving mixing element to blend a polymer flocculant added to the tailings stream while they are still in the transfer pipeline, ensuring contact between the clays and flocculants, leading to larger flocs which settle more rapidly after deposition (Beier et al., 2013; Webster et al, 2016). After flocculation, thin lift drying also known as atmospheric fines drying (AFD) or tailings reduction operation (TRO) is used as a secondary treatment process where the resulting tailings mixture are thinly spread over a large area taking advantage of evaporation and capillary suction to achieve dewatering (COSIA, 2017; Alberta Energy Regulator, 2018). Initially after deposition at solid contents of $30-35 \%$ (by weight), flocculation is the driving dewatering agent after which consolidation, evaporation, settlement, seepage and freeze-thaw cycle are the main mechanism behind the dewatering process (BGC Engineering Inc, 2010; Kolstad et al., 2012). Optimal polymer dosage and mixing speed are the most important factors in this process (COSIA, 2017). Suncor implemented this technology as part of its tailings' reduction operations (TRO) (Mamer, 2010; Wells et al, 2011) at a commercial scale. Atmospheric Fines Drying (AFD) has also been implemented at the CNUL Muskeg River Mine location (Alberta Energy Regulator, 2017).

\subsubsection{Non-segregating Tailings (NST) and Composite Tailings (CT)}


Nonsegregating tailings (NST) and composite tailings (CT) technologies require mixing tailings with sand from extraction process and coagulant, before placing the mixture in a tailings pond. The key difference with both technologies is that NST uses TT from thickeners while CT uses FFT from already deposited ponds (Alberta Energy Regulator, 2018). Canadian Natural Resources Limited (CNRL) Horizon use NST treatment process while Syncrude, Suncor and CNUL apply the CT technology with all four operators targeting terrestrial closure with wetlands (Mamer, 2010; Alberta Energy Regulator, 2018).

\subsubsection{Water-Capped Tailings and Permanent Aquatic Storage Structure}

Water-capped tailings technology involves putting a layer of water above tailings such that the overlying pond can develop a self-sustaining ecology and can therefore be considered reclaimed. In this scenario, the tailings are largely contained in the mined out pit, potentially sealed with a dam, and do not require the same level of strength, though they must not substantially flow in the event of a dam breach. (BGC Engineering Inc, 2010; Alberta Energy Regulator, 2018). Permanent aquatic storage structure (PASS) is FFT treated with addition of a coagulant and flocculant and depositing the tailings in a pond and they have only been approved for the first phase to enable the operator monitor their performance (Alberta Energy Regulator, 2018). Water-capped tailings technology is not currently approved by the regulator with the technology subject to further evaluation, but Syncrude and Suncor had applied this remediation technique at the field trial stage (BGC Engineering Inc, 2010; Alberta Energy Regulator, 2018).

\subsubsection{Centrifuge}

Centrifuge technology involves the application of a force several times that of gravity resulting in denser tailings effluent with solids content as high as 60\% solids (by weight) (Devenny, 2010). The influent is mixed with a polyacrylamide flocculant and the effluent (cake) is treated as a solid, allowing it to be transported to the disposal site. Syncrude began pilot studies for this technology in 2005 and after successful studies they opted for implementation on a larger scale in 2015 with a $\$ 1.9$ billion full scale centrifuge plant and about 16 centrifuges (Chandler, 2017). Although this centrifuge technology has been shown to reliably produces tailings with solids content greater than $50 \%$, there is need for further dewatering to achieve the targeted solids concentration of $70 \%$ (by weight).

Current results have shown no single method can achieve the target state required by "Directive 085' rather a combination of these methods is increasingly considered. For more detailed information about this subject, an in-depth review on existing oil sands fine tailings treatment 
technologies and future works are published by BGC Engineering Inc (2010) and Sobkowicz (2012).

\subsection{Consolidation and time-dependent behaviour in oil sands tailings}

Understanding long term dewatering processes such as consolidation and how potential effects of creep and structuration affect the settling of tailings after technological aided dewatering and deposition could be vital in achieving regulatory requirements.

\subsubsection{Flocculation, sedimentation, and consolidation}

Imai, (1981) suggested three stages of clay-water interaction using a slurry, namely: flocculation, sedimentation (Figure 2.4). 


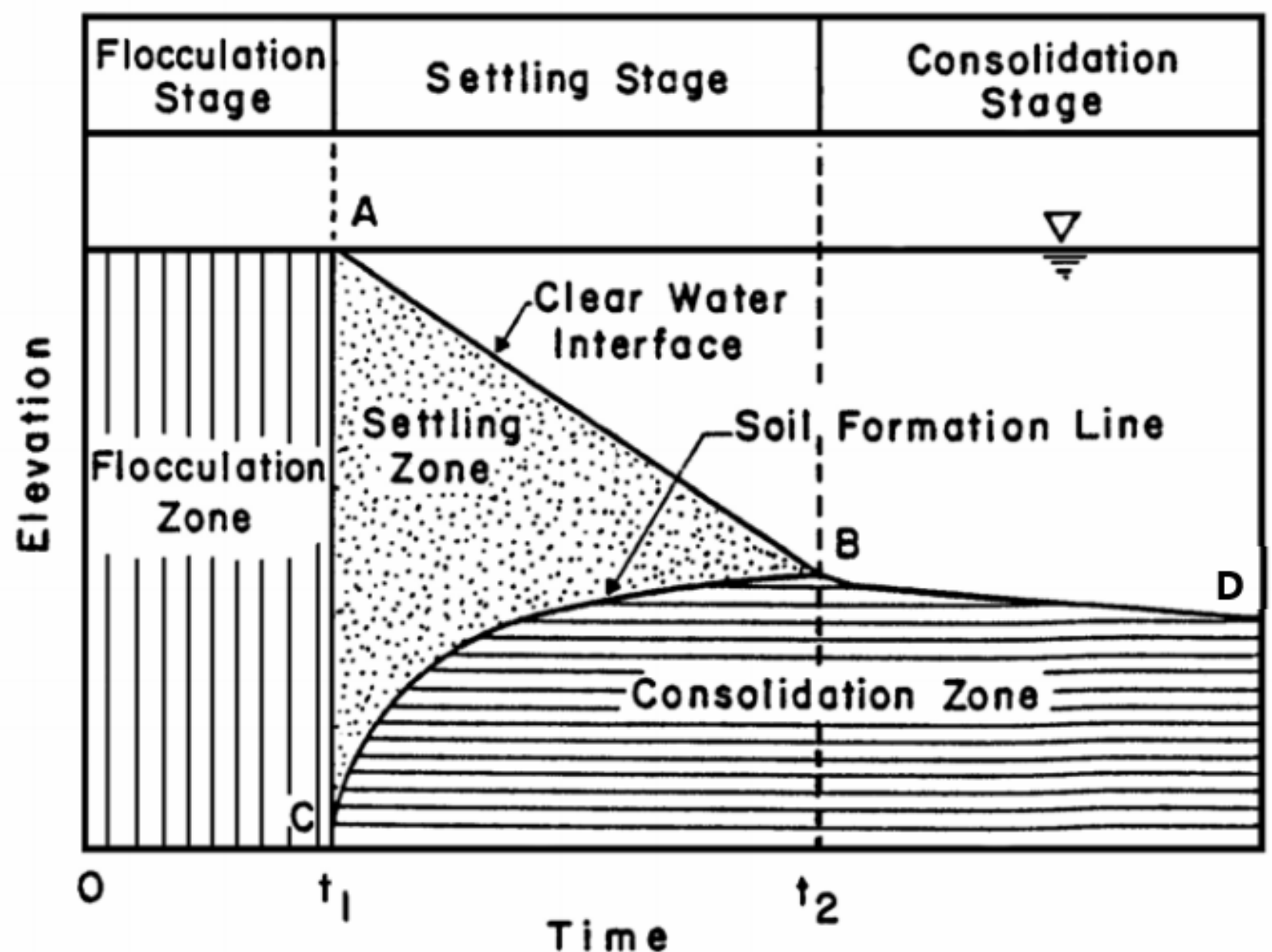

Figure 2.4. Schematic diagram of the three settling stages involved in clay-water interaction (Modified by Krizek, 2004, from Imai, 1981).

After deposition, the release of entrapped water from the suspended fine particles pores by settlement due to gravity is limited due to the dispersed state of the clay particles at high $\mathrm{PH}$ leading to repulsion between particles. To achieve substantial dewatering in the tailing ponds, the repulsion caused by negative charges is reversed by the addition of flocculants in a process termed flocculation to promote particle aggregation which would lead to faster and undisturbed settling. Flocculation is the process of using long polymer chains (flocculants) in aiding aggregation of non-settling fine particles (Vajihinejad et al., 2018; Vajihinejad et al., 2019). In flocculation stage, no settlement takes place instead flocs (particle aggregation) build up (Figure 2.4). Wilson et al. (2018) compared untreated tailings (FFT) to flocculated tailings (TT3) and flocculated freeze-thaw tailings (TT4) (Figure 2.5a), and the results showed that flocculated tailings consolidated faster than untreated FFT due to a higher hydraulic conductivity in the flocculated tailings (Figure $2.5 \mathrm{a}, \mathrm{b}$ ). 

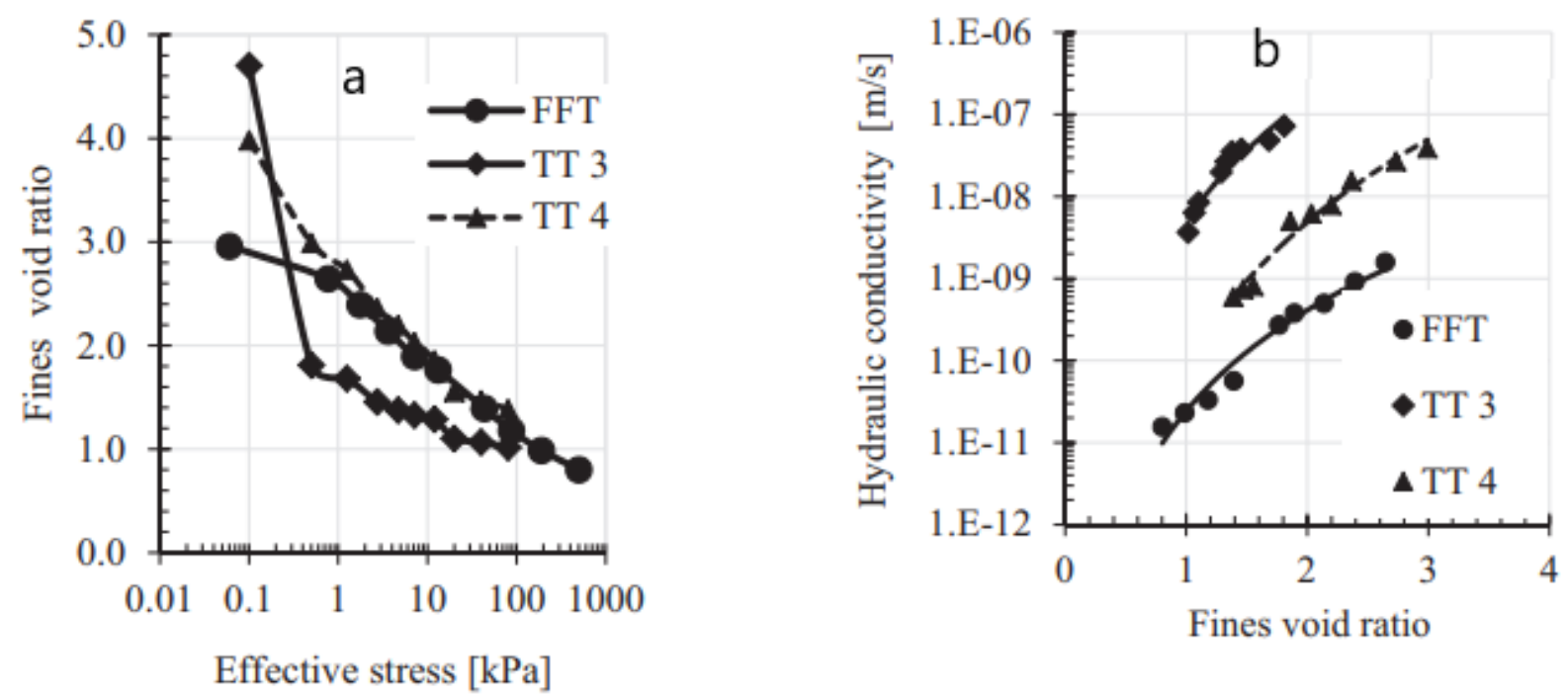

Figure 2.5. (a) compressibility curve for flocculated and untreated FFT; and (b) Hydraulic conductivity for treated and untreated FFT (Adapted from Wilson et al., 2018).

In the second stage (settling stage), the flocs rapidly settle from point A through B and the same time sediments start to form at point $C$. These sediments pile up with time until the tailingswater interface line is at the accumulated sediment height (when effective stress develops due to the soil particles in contact). This decrease in height from point A through B can be referred to as sedimentation (Figure 2.4). McRoberts et al. (1976) and Kaminsky et al. (2015) defined sedimentation as a prior stage of settlement when effective stress does not exist. Subsequently, self weight consolidation stage occurs between point $B$ and $D$, with the settlement (change in interface height) taking place until equilibrium is reached (complete dissipation of excess pore water pressure) (Figure 4). Pore-water pressure is the pressure of water held within the soil voids and due to applied load the increase in pore-water pressure is known as excess pore-water pressure which is linked with consolidation (Mitchell, 1962; Mesri et al., 1974). Consolidation is a time-dependent process by which soil decreases in volume while gaining effective stress through the dissipation of excess pore water pressure. The exact point at which the sedimentation process becomes a consolidation process is not completely agreed upon leading Jeeravipoolvarn (2010) to conclude the end and start of consolidation are arbitrarily chosen because the void ratio at which effective stress starts is not uniquely defined.

Permeability and compressibility control consolidation and it is induced by the weight of the particles; Both controlling factors are described by void ratio-effective stress relationship and hydraulic conductivity-void ratio relationship, making both relationships the most important properties for consolidation in oil sands tailings (Jeeravipoolvarn et al., 2008; Babaoglu et al. 2018). Various consolidation theories have been proposed to help predict settlement occurring 
in soil, with the small strain consolidation theory one of the most effective under certain assumptions.

\subsubsection{Small strain consolidation}

In 1923, Karl Terzaghi proposed the conventional one-dimension small-strain consolidation theory for the estimation of settlement in saturated soils. In deriving this theory, the influence of self-weight of soils, movement of solid particles, boundary movement during consolidation, secondary consolidation, and time dependent effects such as aging were ignored and the following assumptions were made (Qiu, 2000; Bharat et al., 2011; Priestley, 2011):

- Fully saturated soil with water

- Incompressible porewater and soil particles

- Fluid flow within pores are governed by Darcy's law

- Void ratio and effective stress control the strains of the soil skeleton through linear time-dependent relationship

- Strains, stress increments and velocities are small with the theory quasi-static

- Homogenous soil

- Changes in the compressibility and permeability of the soil are constant under a specific load increment during consolidation

This theory can be expressed mathematically as:

$$
c_{v} \frac{\partial^{2} u}{\partial z^{2}}=\frac{\partial u}{\partial t}
$$

In this equation, $\mathrm{u}$ is the excess pore water pressure, $\mathrm{t}$ is the time, $\mathrm{z}$ is the vertical dimension and $c_{v}$ is the coefficient of consolidation (rate of settlement in a soil layer).

This theory has its limitation when considering soft soils that experience large settlement and non-linear compressibility and permeability, such as tailings. The need for more accurate calculations for soft soils and slurries led to the development of the finite strain consolidation theory.

\subsubsection{Finite strain consolidation theory}


Finite (large) strain consolidation theory differs from small strain theory by taking into account large deformation under stress increments, moving boundary conditions, changing soil thickness, changes in hydraulic conductivity and compressibility during a specific load increment, and non-linear relationships between void ratio and effective stress, and the void ratio and hydraulic conductivity. This theory was developed to resolve limitations of the small strain theory with regards linearity and small strain deformation and allow for much more complex problems to be evaluated. Mikasa (1965) and Gibson et al. (1967) proposed the one-dimensional large strain consolidation theory for modelling large settlement consolidation behaviour of saturated soft soils. Gibson et al. (1967) introduced a one-dimensional non-linear finite strain theory of consolidation in terms of void ratio and hydraulic conductivity:

$$
\pm\left(\frac{\rho_{s}}{\rho_{f}}-1\right) \frac{d}{d e}\left[\frac{k(e)}{1+e}\right] \frac{\partial e}{\partial z}+\frac{\partial}{\partial z}\left[\frac{k(e)}{\rho_{f}(1+e)} \frac{d \sigma \prime}{d e} \frac{\partial e}{\partial z}\right]+\frac{\partial e}{\partial t}=0
$$

where $\rho_{s}$ is solids density, $\rho_{\mathrm{f}}$ is fluid density, $\mathrm{e}$ is void ratio, $\mathrm{t}$ is time, $\mathrm{z}$ is a reduced or material coordinate, $\mathrm{k}$ is hydraulic conductivity and $\sigma^{\prime}$ is effective stress.

This equation considered $z$ (soil layer) to be in a fixed space i.e. $z$ contains the same amount of solids particle at any given with the flow of water from the voids controlled by $k$ (which is a function of e) and rate of change in effective stress versus rate of change in void ratio. Similarly, Lee (1979) and Somogyi (1980) proposed other formulations of the finite strain consolidation theory using different initial boundary conditions with the former expressing the theory in terms of porosity and the latter excess pore-water pressure. Bromwell (1984) gives further information on two-dimension and three-dimensional finite strain consolidation models. UNSATCON large strain consolidation tool utilizes a variation of finite strain consolidation theory called piecewiselinear model in solving large strain problems.

\subsubsection{Piecewise-linear model and UNSATCON}

The dimensionless piecewise-linear model known as Consolidation Settlement 2 (CS2) was proposed by Fox et al. (1997) in one-dimensional large-strain consolidation modelling; this entails considering the soil layer $(z)$ in a fixed space and dividing the problem into small enough elements where mass of solids and fluxes are calculated individually using discrete data points from constitutive relationships. The user is required to define the number of vertical elements $(\mathrm{Rj}), 2$ constitutive relationship data points $\left(\mathrm{e}-\sigma^{\prime}\right.$ and $\left.\mathrm{k}-\mathrm{e}\right)$, groundwater elevation $\left(H_{w}^{*}\right)$, overburden stress $\left(q_{o}^{*}\right)$, stress increment $\left(\Delta q^{*}\right)$, specific gravity, boundary conditions and termination criteria for iteration to stop (Figure 5) (Fox et al., 1997; Bonin et al., 2014). 
Figure 2.6 summarizes the workflow process of the CS2 model with initial values of void ratio and settlement calculated using the inputted information, thereafter total stress, effective stress, hydraulic conductivity, total head, pore-water pressure, degrees of consolidation and vertical compression of each element are calculated and a time increment is applied. If the termination criterion is met the program terminates otherwise an iterative process follows where all variables are updated at the end of each time increment. CS2 provided comparable results to other models and lab experiments when used in solving small strain, large strain, self-consolidation, and nonlinear constitutive relationship related problems (Fox et al., 1997; Bonin et al., 2014). Similarly, Daliri et al., (2016) concluded that the CS2 produced accurate results in comparison to conventionally formulated large strain consolidation models when solving large strain consolidation problems under saturated conditions. 


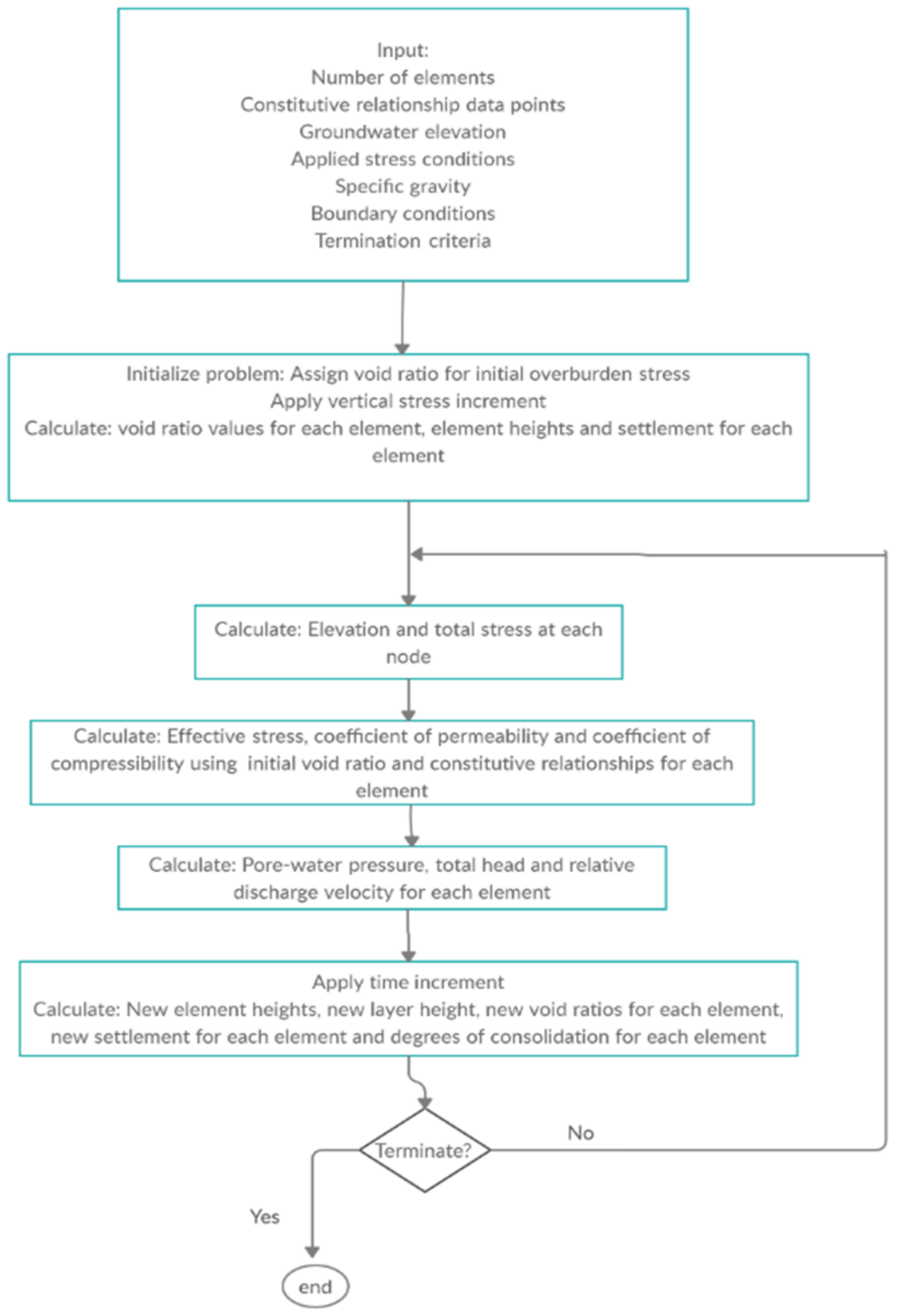

Figure 2.6. Process diagram for CS2 (Modified from Fox et al., 1997). 
Qi et al., (2017) developed a large-strain consolidation model for unsaturated and saturated conditions, based on the CS2 approach of associating calculation with finite fixed masses of solids, but extending the model to elasto-plastic unsaturated soil behaviour. This model is called UNSATCON and it is used later in this thesis to compare with experimental results under saturated conditions. Qi et al.(2017) and (2020) verified the software using a column test (Soleimani et al., 2014) and a field test (Dunmola et al., 2013a, b) on oil sands tailings as well as dry box test on gold tailings (Daliri et al., 2016). Void ratio, pore water pressure, and water content results from the stimulations were comparable to the experimental findings (Qi et al., 2017, 2020). Creep, thixotropy and structuration effects are not considered currently during UNSATCON large-strain analysis but three creep models (Leoni et al. 2008; Yin et al., 1994, Rowe et al., 1998) have been incorporated into UNSATCON software to include creep effect in the large strain consolidation solution (Qi et al. 2018; Salam 2020). However, in this thesis, only large-scale consolidation analysis was used by UNSATCON. The most important relationships used by UNSATCON tool in converging at a solution are the void ratio - effective stress and hydraulic conductivity - void ratio relationships.

\subsubsection{Constitutive relationships}

In finite strain modelling, the two main consolidation controlling components are the void ratio - effective stress relationship, and the hydraulic conductivity - void ratio relationship. Various log-linear or power equations can represent both relationships used in solving finite strain consolidation problems (Seneviratne, 1996; Fox et al., 1997; Fox et al., 2014). UNSATCON uses the following typical mathematical power equations below in representing both relationships:

$$
\begin{aligned}
& e=C_{1}\left(\sigma^{\prime}\right)^{C_{2}} \\
& k=H_{1} e^{H_{2}} .
\end{aligned}
$$

where e = void ratio; $k$ = hydraulic conductivity; $\sigma^{\prime}=$ vertical effective stress and $C_{1}, C_{2}, H_{1}$, and $\mathrm{H}_{2}=$ empirical parameters for compressibility and hydraulic conductivity constitutive relationships. 


\subsubsection{Void ratio-effective stress relationship}

Void ratio-effective stress relationship is also known as compressibility relationship and it is the most researched topic in consolidation of tailings (Ahmed et al, 2013). Compressibility is the ability of a material to reduce in volume (voids reductions) while under stress and is normally plotted as void ratio vs effective stress (Hockley et al., 2018). Figure 2.7 shows a typical void ratioeffective stress relationship with initial void ratios controlling changes in void ratio at smaller effective stress and comparable final void ratio at large effective stress. The compressibility relationship depends on the initial void ratio and shows the existence of aging due to changes in the microstructure of the tailings occurring (Suthaker, 1995; Ahmed, 2013).

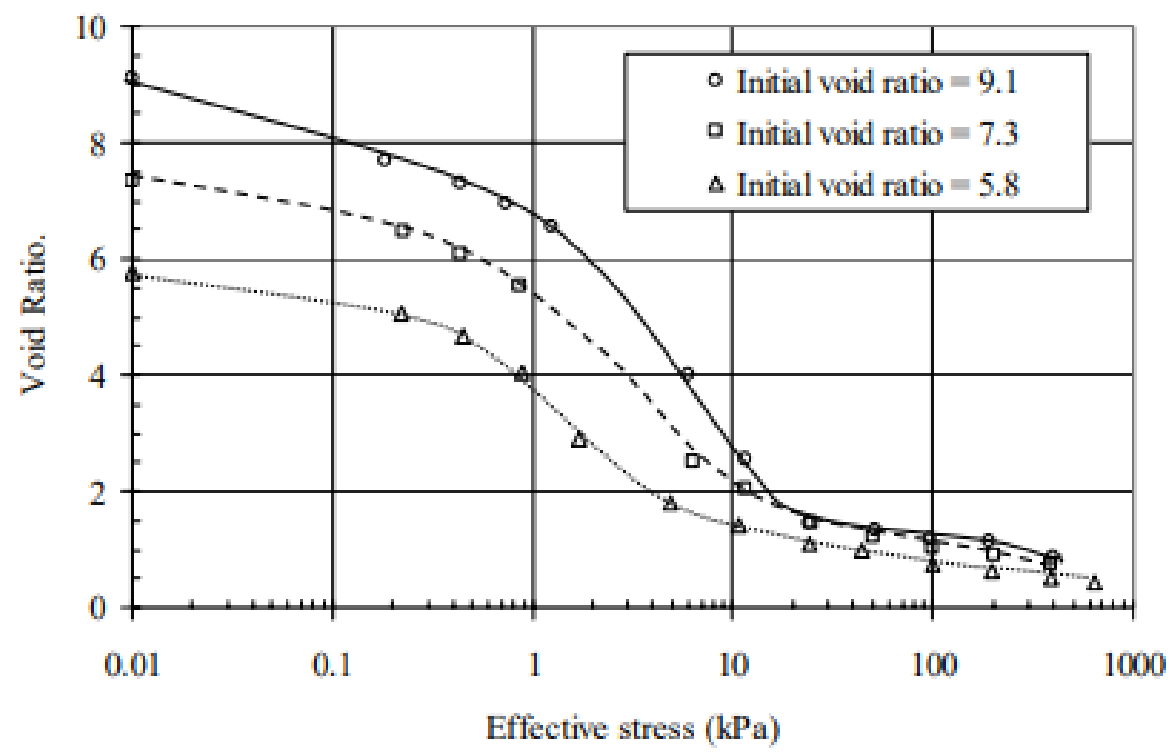

Figure 2.7. Compressibility curves of FFT (modified by Jeeravipoolvarn, 2010, from Suthaker, 1995).

Similarly, Pollock, (1988) showed that initial void ratio increased with fines content and at high effective stress, all samples regardless of fine content had similar void ratios. The correlation between initial void ratio and fines content was explained by the repulsion between clay particles, resulting in a greater electrostatic force between clay particles as fines content increased and at higher effective stresses these forces are surmounted causing the void ratios to be similar regardless of fines content (Pollock, 1980; Hockley, 2018). Both studies seem to agree that at low effective stresses compressibility depends on the initial void ratio and similar void 
ratios regardless of fine content for higher effective stress. Suthaker (1995) concluded a single void ratio and effective stress relationship fails to explain the consolidation behavior in fine tailings.

\subsubsection{Hydraulic conductivity-void ratio relationship}

Hydraulic conductivity is a critical parameter in the consolidation process of oil sands tailings and influences how fast the deposits are reclaimed. The slow dewatering phenomenon in FFT that contributes to their abysmal consolidation behaviour in deep deposits is linked with hydraulic conductivity (Van Olphen 1977; Kessick, 1978; Burchfield et al., 1979). In trying to understand hydraulic conductivity, Suthaker (1995) measured fine tailings flow velocity with time during consolidation test and established that measured flow velocity decreased to a steady state (Figure 2.8). The time taken to achieve this steady state varied from 30 minutes to 15 hours, with hydraulic gradient and void ratio influencing the amount of time taken to reach steady state (Suthaker, 1995).

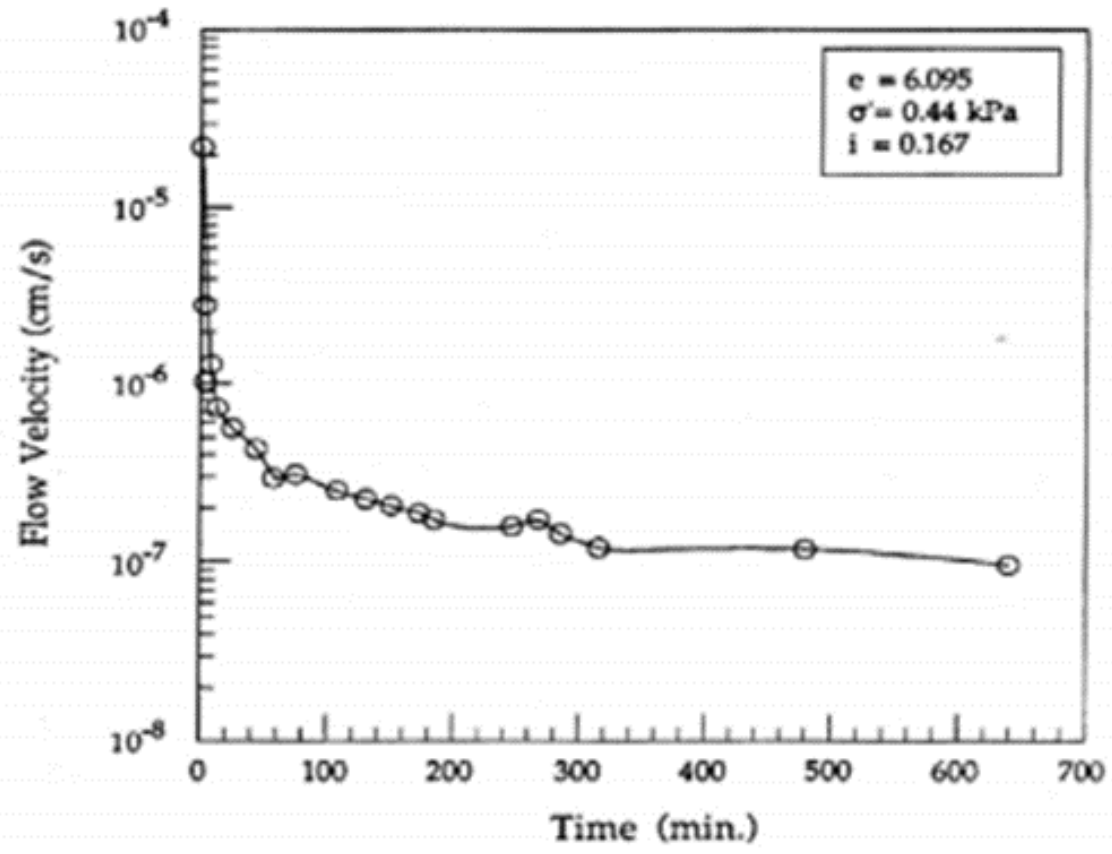

Figure 2.8. Variation of flow velocity with time (modified by Jeeravipoolvarn, 2010, from Suthaker, 1995). 
Further tests on the hydraulic gradient, reported that higher hydraulic gradient would result in lower hydraulic conductivity and at low void ratios $(<1)$ hydraulic gradient effect was negligible (Suthaker, 1995). These results contradict studies by Elnaggar et al., (1973) and Scully et al. (1984) that showed hydraulic conductivity changes were influenced by non-Darcy flow behaviours. Additional studies have shown that laboratory and field hydraulic conductivity measurements do not correlate (COSIA, 2014; Masala et al., 2014; Hockley, 2018). Jeeravipoolvarn (2010) suggested further research on this flow behaviour and Babaoglu (2018) ongoing research is focused on predicting the hydraulic conductivity at higher void ratio and better understanding of the hydraulic conductivity and void ratio relationship. Non-consolidation behaviours such as creep, structuration and thixotropy also affect the long-term settling of the tailings deposits.

\subsubsection{Creep}

Creep or secondary compression refers to any change that takes places in volume over time that is independent of changes to effective stress and is considered the dominant mechanism of aging in soil (Mesri et al., 1990; Schmertmann, 1991). As primary consolidation occurs, the void spaces between soil particles reduces leading to increased contact (bonding) between them; these bonds between soil particles may be broken down leading to a rearrangement of soil particles (Soga, 2005; Sorensen, 2006; Le et al., 2012). This process involves a time dependent rearrangement of particles and the rate of deformation is controlled by viscous friction (Feda, 1989; Kuhn et al., 1993; Le et al., 2012).

Suthaker (1995) listed time, effective stress, preconsolidation and sample thickness as factors influencing creep but several researchers argue that the complexity of clay structure makes the understanding of creep mechanism and factors influencing creep challenging, with Le et al., (2012) proposing a combination of processes at microstructural and macrostructural levels to help with explaining the mechanism of creep (Mesri, 1973; Murakami, 1980; Varatharajan, 2011). At a macrostructural level, creep occurs due to the clay particles trying to reach equilibrium through rearrangement or adjustment of clay particles after interparticle bonds are broken (Taylor, 1942; Soga, 1994; Le et al., 2012). Moreover at the microstructural level, creep mechanism involves viscous flow of water within the clay microstructure leading to the readjustment of clay particles; this readjustment is resisted by the particles due to the double layer of water on the clay particle surface (structural viscosity) (Bjerrum, 1967; Le et al., 2012; Salam, 2020).

Incorporating creep in consolidation settlement of clays calculation can be done have been with two theories namely, hypothesis A and hypothesis B. Hypothesis A assumes that creeps occurs after primary consolidation while hypothesis $B$ proposes that creep takes place during primary consolidation (Jamiolkowski et al., 1985; Fatahi et al., 2013; Le et al., 2015). Consolidation calculation using hypothesis $A$ is less complex and common in geotechnical engineering because 
the void ratio at the end of primary consolidation is unique (Figure 2.9) (Fatahi et al, 2013; Kaczmarek, 2017). Using hypothesis B for settlement calculation is much more complex but several studies have supported this theory and it is currently used in various studies of creep in soils (Degago et al., 2009; Watabe et al., 2012; Fatahi et al, 2013; Le et al, 2015).

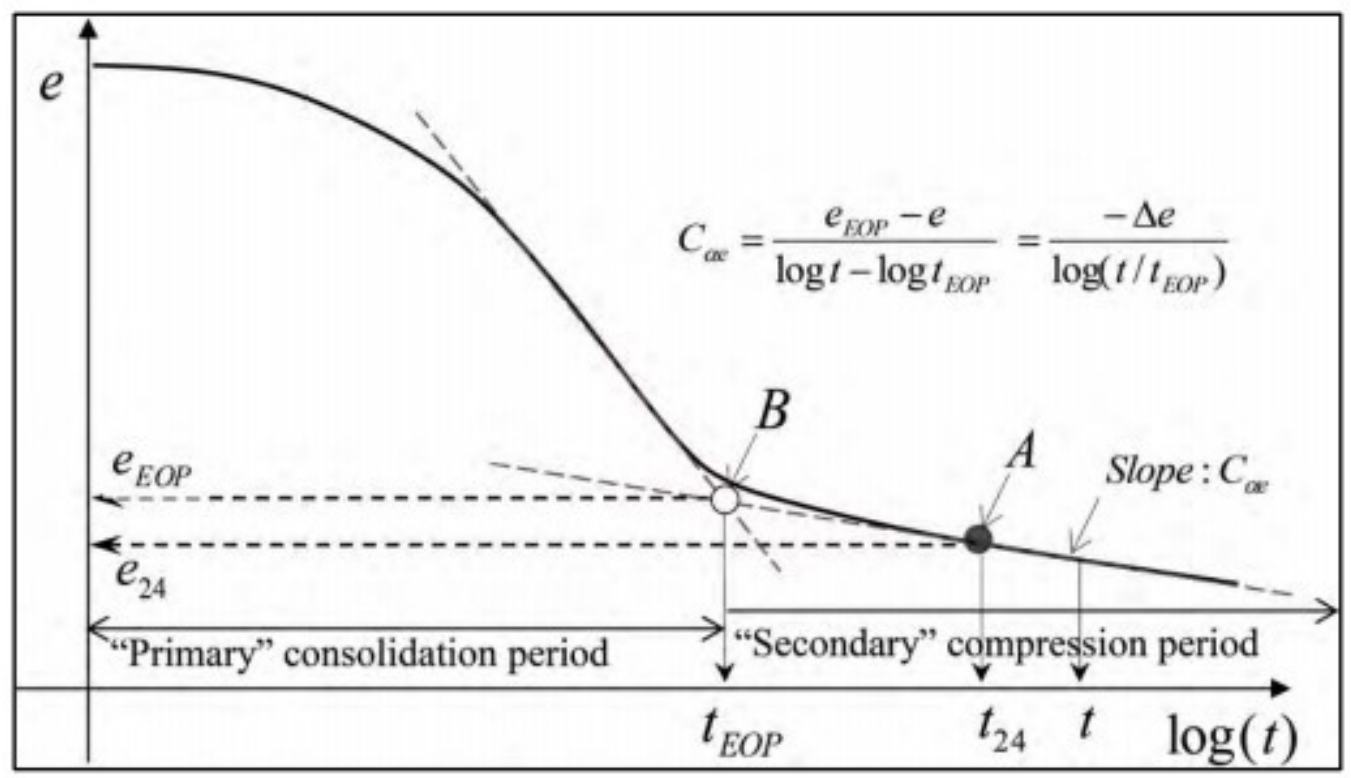

Figure 2.9. The void ratio - log (time) curve showing creep coefficient determination using hypothesis A (Adapted from Yin et al., 2016).

Preconsolidation pressure can be estimated by calculating and plotting the ratio of creep rate $\left(C_{\alpha e}\right)$ /compression index $\left(C_{c}\right)$ for every load increment during an oedometer consolidation test; this ratio is observed to be significantly higher at stresses close to the preconsolidation pressure (Mesri et al., 1977; Graham et al., 1983).

While studying the settlement of Champlain clay in Ottawa, Crawford et al., (1990) observed that the field measurements differed from the laboratory predictions due to consolidation occurring over time at constant effective stresses (secondary compression/creep), making the estimation of the long-term settlement of sensitive clays using laboratory tests problematic (Salam, 2020). Independent research at the University of Alberta conducted on a lab scale with two 10m high, 0.9m diameter standpipes in 1982 filled with oil sands fine tailings in one standpipe and a mix of fine tailings and tailings sand in the other pipe to investigate the long term consolidation behavior of the fine tailings (Jeeravipoolvarn et al, 2009). Jeeravipoolvarn et al., (2009) argued that the settlement which occurred after 20.6 years were because of creep and not consolidation since there was little effective stress development and almost no pore water dissipation. In addition 
to the observed settlement, there was a reduction in void ratio throughout the depth of the standpipe and the settlement occurred at a uniform rate. This observation supports the idea of creep contributing significantly to the settlement thus using finite strain consolidation theory for long term settlement prediction can be difficult and overestimates the consolidation (Jeeravipoolvarn, 2005; Jeeravipoolvarn et al., 2009).

\subsubsection{Thixotropy}

Thixotropy can be defined as a process of softening caused by remolding, followed by a time dependent return to the original harder state at a constant water content and porosity (Mitchell, 1960; Kuhn et al., 1993). In other words, thixotropy deals with the time dependent stiffening of clay particles due to electrochemical forces and it is manifested in time-dependent strength recovery of clay after remolding at constant density (Mitchell, 1960; Jeeravipoolvarn, 2005). Majority of clay-water systems exhibit thixotropic behaviour with evidence seen in natural clay and oil sands tailings (Jeeravipoolvarn, 2009; Miller, 2010; Zhang et al., 2017).

Osipov et al., (1984) and Markgraf et al., (2006) suggested that structured systems experienced thixotropy through strength gain which is linked to the microstructural changes in clays. Skemptom et al., 1952 proposed using the thixotropic strength gain ratio $\left(A_{t}\right)$ in analyzing the thixotropic potential of a soil with the mathematical expression:

$$
A_{t}=\frac{C_{t}}{C_{r}}
$$

where $A_{t}=$ thixotropic strength ratio; $C_{t}=$ Strength at specific time $t$ in the thixotropic process; and $C_{r}=$ strength of the completely disturbed state.

This is quantified as the ratio of undrained shear strength after time $(t)$ to undrained shear strength after remoulding at the same water content and is known as either sensitivity (for saturated clay) or thixotropic strength ratio (for compacted clays) (Skempton et al., 1952; Suthaker et al, 1997). This ratio (thixotropic strength gain or sensitivity) is the preferred method in quantifying thixotropic effects in clays instead of using the actual value of the strength increase because it enables comparison between two samples of the same soil but different water content (Mitchell, 1960; Shahriar et al., 2018).

Undrained shear strength is referred to as the shear strength of soil during undrained loading where water content and volume of clay are constant leading to an increase in pore-water pressure (Wahls, 1983). In clay deposits, undrained shear strength of saturated clay can be correlated to the consolidation history and in FFT deposits undrained shear strength 
development occurred in FFT deposits after substantial dewatering and increase in solids content (Wahls, 1983; Beier et al., 2013). Simple slope stability calculations by Mckenna et al., 2016 using directive 085 guidelines, suggested that than an undrained shear strength greater than $20 \mathrm{kPa}$ is needed to avoid deep seated slope stability failures. Conventional direct shear, unconfined compression and triaxial tests used in geotechnical engineering to estimate undrained shear strength of soils were not applicable for FFT due to their low shear strength, field vane and fall cone devices are some of the alternatives used in calculating undrained shear strength of clays and FFT with low shear strength (Qui et al., 2001; Tanaka et al., 2012; Salam, 2020).

In geotechnical engineering, the relationship between the undrained shear strength $\left(s_{u}\right)$ and the vertical effective stress $\left(\sigma_{v}^{\prime}\right)$ in normally consolidated soils is linear. For overconsolidated soils such as natural clay deposits an empirical relationship between the undrained shear strength $\left(s_{u}\right)$ and the preconsolidation pressure $\left(\sigma_{p}^{\prime}\right)$ was proposed (Mesri, 1975; Terzaghi et al., 1996):

$$
\begin{gathered}
\frac{s_{u}}{\sigma_{p}^{\prime}}=0.22 \text { (For undisturbed samples) } \\
\frac{s_{u}}{\sigma_{p}^{\prime}}=0.27 \text { (for remolded samples) } . .
\end{gathered}
$$

where $s_{u}=$ undrained shear strength, and $\sigma_{p}^{\prime}=$ preconsolidation pressure.

Undrained shear strength and preconsolidation pressure corresponding increase occurs due to similar processes namely thixotropy and structuration effecting changes in the microstructure of the clay (Nagaraj et al., 1990; Salam, 2020). Additionally, Mesri (1975) further linking thixotropic behaviour in remoulded or reconstituted clay to structuration effect with an increase in undrained shear strength (thixotropy) leading to a subsequent increase in preconsolidation pressure (structuration) over time. This established thixotropy-structuration connection is evident in tailings ponds, with thixotropic aging linked with slow dissipation of excess pore water pressure leading to low effective stress development; these low effective stresses contribute to the development of an over-consolidated structure (structuration) that affects dewatering of tailings (Miller, 2010; Somogyi et al., 1977; Jeeravipoolvarn, 2010). Although both phenomena are similar the difference between both is that structuration effect leads to a stiffer clay sample while thixotropy results in strength gain (Qi et al., 2018).

Thixotropy can be approached in two ways, macroscopic and microscopic. Osipov et al., 1984 studied thixotropy at a microscopic level using scanning electron microscopy (SEM) but this study focused on macroscopic level using a fall cone device. The study showed microstructural changes 
in clay correlate with the value of shear strengths and an increase in thixotropic strength with time is directly related to the recovery of the initial microstructure in clays (look at source). Mineralogy of the clay, water content, rate of loading, axial strain, and time are some of the factors that influence thixotropy (Banas, 1991; Suthaker, 1995).

\subsubsection{Structuration/Aging effect}

Leroueil et al., (1990) observed that natural undisturbed clay deposits had different geotechnical properties when compared to reconstituted or remolded samples prepared from the same clays and argued a time dependent behavior called 'structuration' effected changes in the microstructure of these clays through a "bonded structure" developed over time, leading to an increase in the apparent preconsolidation pressure (Crawford, 1968; Leroueil et al., 1990). The combined effect of soil particles arrangement and interparticle bonding resulting from aging is known as 'structure` (Mitchell, 1976; Burland, 1990; Mohamadi et al., 2018).

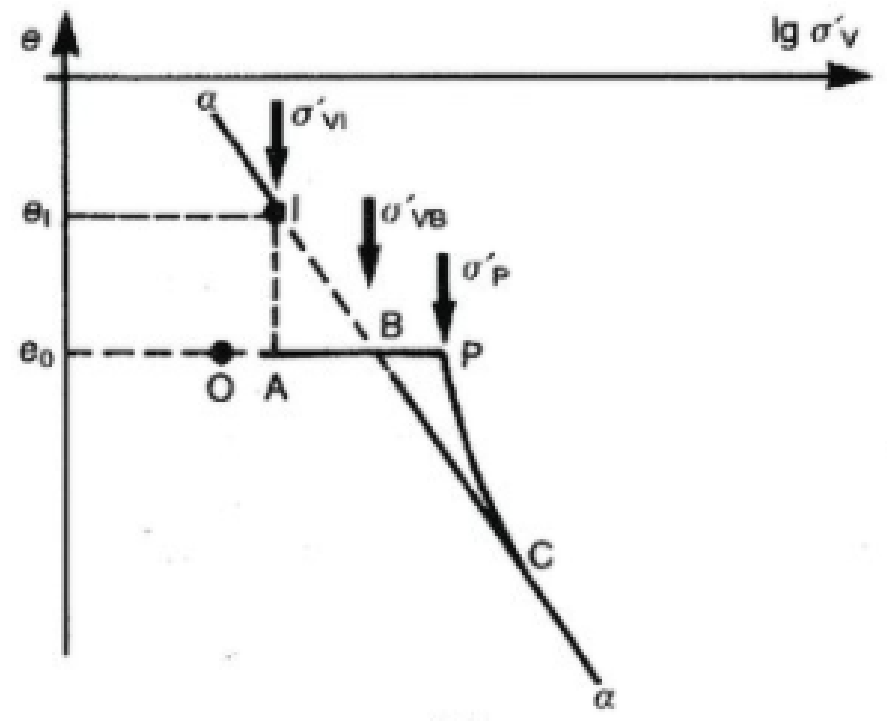

(a)

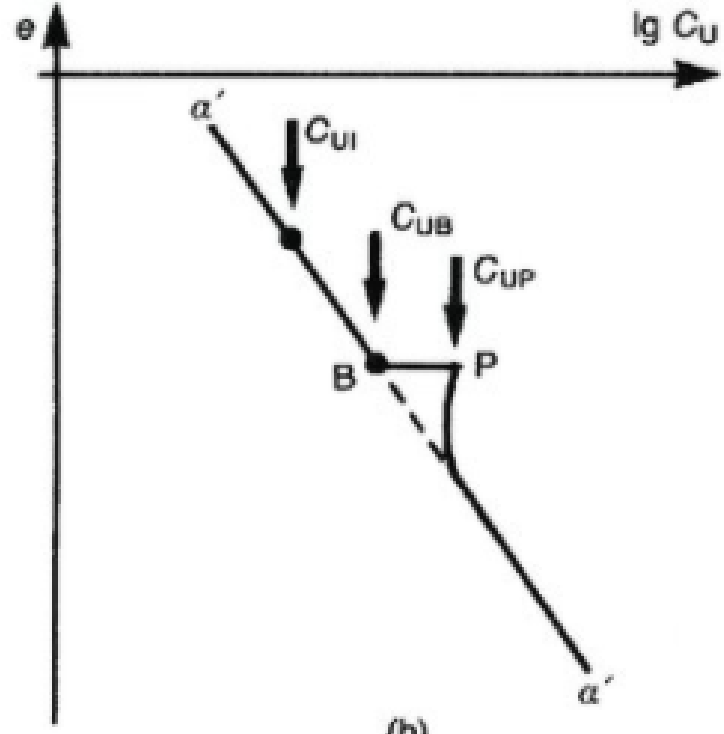

(b)

Figure 2.10. Effect of creep, thixotropy and structuration on (a) compressibility curve for clay soil; and (b) shear strength (undrained) for clay soil (Adapted from Leroueil et al., 1990).

Leroueil et al., (1990) further explained this phenomenon using the compressibility and void ratio - undrained shear strength curves (Figure $2.10 \mathrm{a}$ and b), as the stress on the soil increased $\left(\sigma_{V I}^{\prime}\right)$ during deposition the void ratio decreased $\left(e_{1}\right)$. After the deposition, effective stress remained 
constant but void ratio decreased $\left(\mathrm{e}_{0}\right)$ due to creep. And this decrease in void ratio led to an increase in undrained shear strength $\left(C_{U B}\right)$ and preconsolidation stress $\left(\sigma_{V B}^{\prime}\right)$. Due to the constant rearrangement of the clay particles and closer interparticle bonding as a result of smaller void space (which is linked to thixotropy), the preconsolidation pressure increases $\left(\sigma_{p}^{\prime}\right)$ with the shear strength also increasing $\left(\mathrm{C}_{\mathrm{up}}\right)$. The increase in apparent preconsolidation pressure is a time dependent aging effect that changes the strength, stiffness and compressibility (resistance to compression) of the clay and processes such as cementation, delayed compression (creep), and aging effects (thixotropy) have been found to be responsible for such changes in fine-grained soils (Locat et al., 1986; Burland, 1990; Delage et al., 2010; Mohamadi et al. 2018).

Destructuration refers to the loss of the bonded soil structure due to plastic deformations resulting from straining soil or remoulding through loading or shearing leading to a destructured effect where the soil gains compressibility and decreases in shear strength (Leroueil et al., 1990; Mohamadi et al. 2018; Salam, 2020). Burland (1990) suggested determining the effects of aging using geotechnical properties i.e. compressibility and strength of both natural and reconstituted clay (remoulded clay at water content greater than or equal to the original liquid limit) (Burland, 1990). Results from experiments performed based on Burland proposition showed natural clay samples had a higher void ratio at the same effective stress when compared to reconstituted clay samples (Figure 2.11) (Locat et al., 1985; Burland, 1990; Leroueil, et al., 1990; Liu et al., 1999; Delage, 2010). 


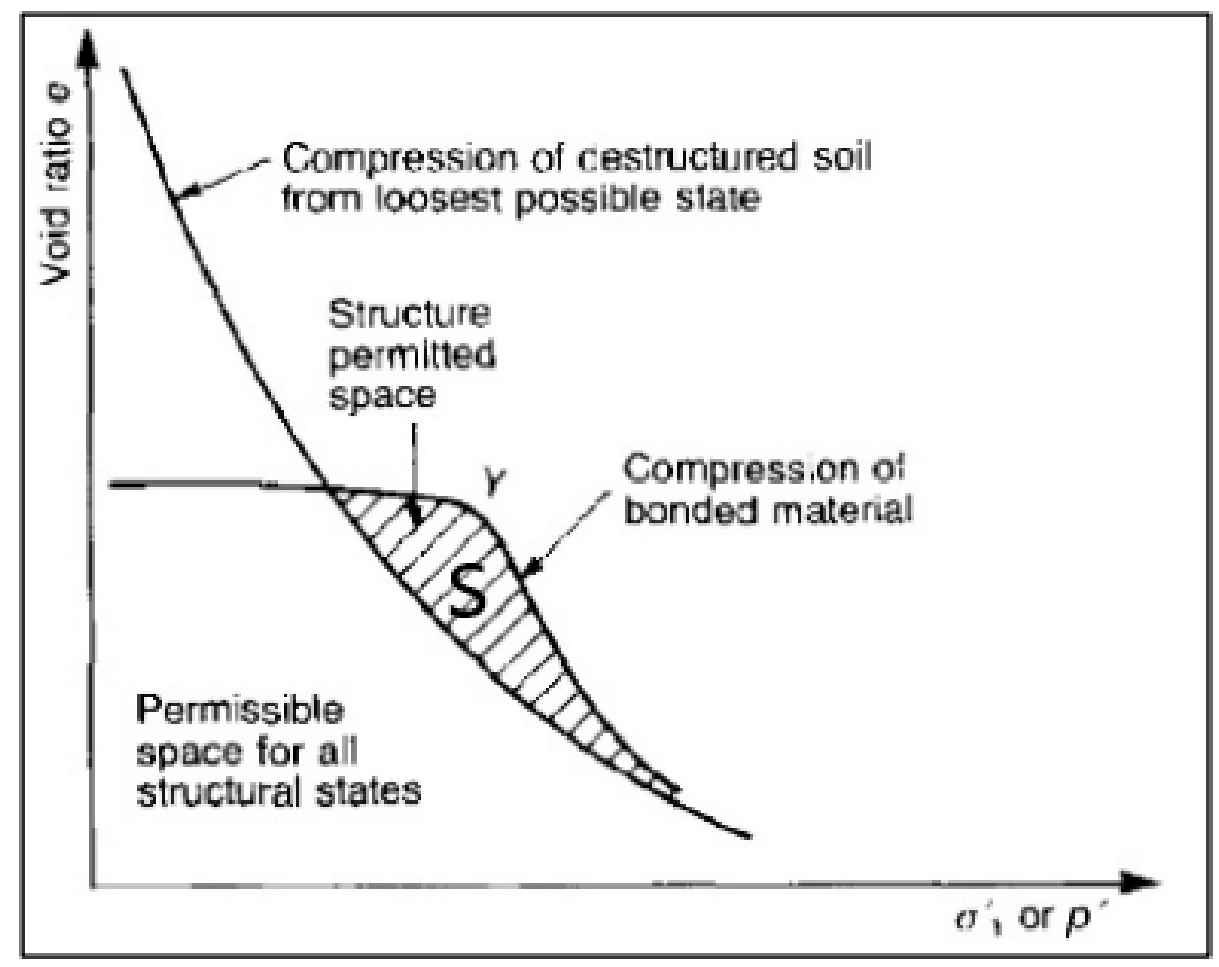

Figure 2.11. Comparison of structured and destructed soil samples compressibility (Adapted from Leroueil et al., 1990).

Figure 2.11 shows the compressibility curves for destructured and structured soil with compression occurring immediately after loading for the destructured/remoulded soil and the structured soil needing the apparent preconsolidation pressure (point $Y$ ) to be exceeded for deformation to begin. The $S$ region (Figure 2.11) shows the area known as 'structure permitted space' where structured soil can exhibit higher void ratios than reconstituted/destructured soil at the same effective stress thereby indicating a stiffer material. Liu et al (1999) argued that structured soil is stiffer than remolded soil especially at low effective stress; results from column dewatering tests on flocculated fluid fine tailings (fFFT) and centrifuged tailings showed structuration effect in both studies with the structured sample stiffer at lower effective stress (Salam et al., 2018; Igbinedion et al., 2019). Developing techniques to predict the degree of structuration in tailings deposits would allow operators mitigate the negative effects of structuration and more accurately predict tailings deposit final settlement (Narges et al., 2019).

\subsection{Temperature effect on consolidation, creep, and aging behaviour}

In northern Alberta, temperature fluctuates between two extremes in the summer and winter which makes the understanding of how temperature influences consolidation or time dependent 
behaviours important. Cho et al. (2000) observed that temperature influenced permeability in clayey soils due to decreased viscosity as temperature increased. Volume change behaviour was also affected by temperature changes both in normally consolidated clay and overly consolidated clays (Abuel-Naga et al., 2005; Jarad, 2017).

Gupta (1964) studied the effect of creep with temperature using triaxial test, the result indicated strain deformation increased with temperature increase due to higher energy of the soil with change in temperature (Jarad, 2017). Figure 2.12 shows the result from Moritz (1995) study using oedometer test to monitor temperature influence on preconsolidation pressure. The result showed that preconsolidation pressure decreased as temperature increased (Jarad, 2017).

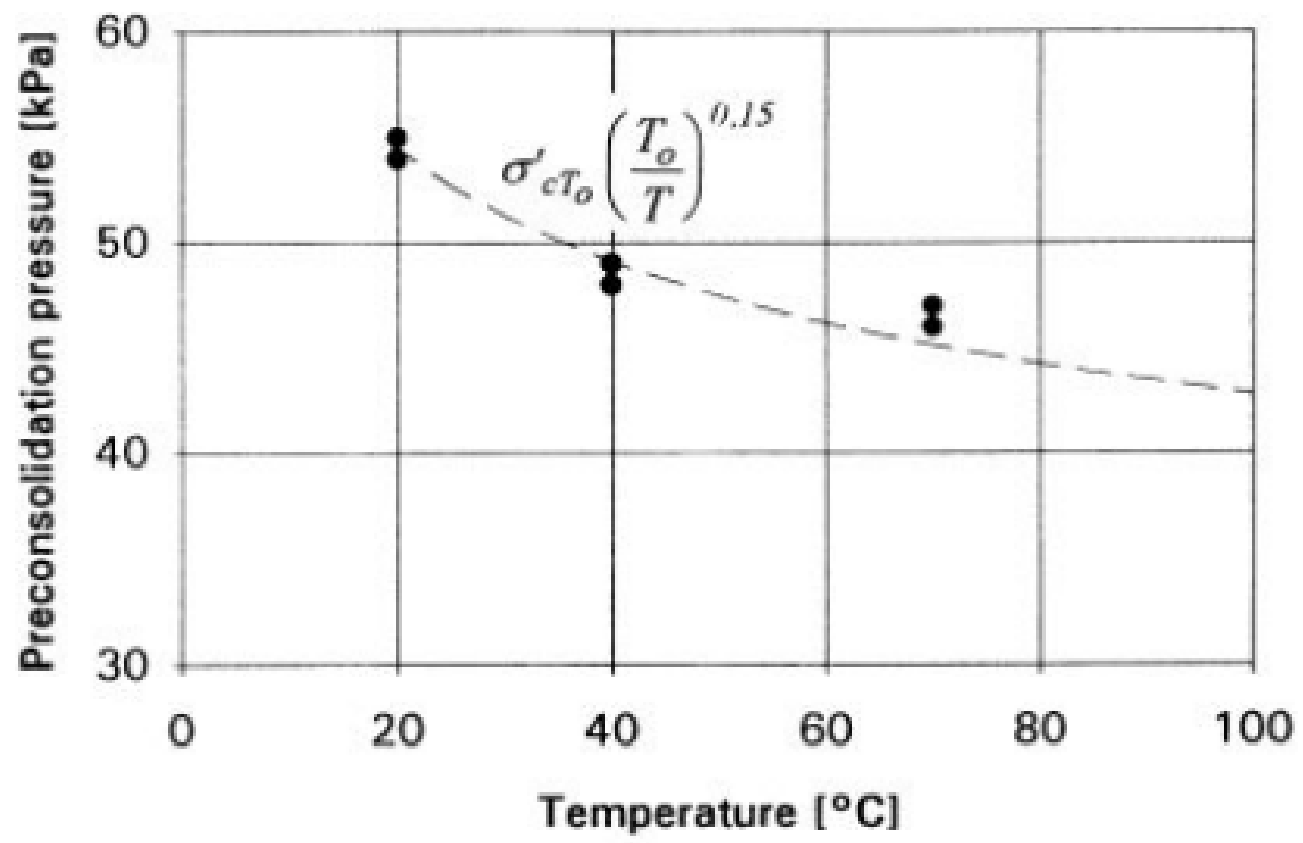

Figure 2.12. Preconsolidation pressure variation with temperature (adapted from Moritz, 1995). 


\section{Chapter 3 : Methods and Materials}

\subsection{Centrifuge cake oil sands tailings characteristics and properties}

Centrifuged oil sands tailings collected in a container $\left(\sim 1 \mathrm{~m}^{3}\right)$, were transported from a bitumen mining operation in Northern Alberta, Canada, and shipped to Carleton University in Ottawa. The tailings originally had a solids content of $46 \%$ by wt and consolidated somewhat during transport to $54 \%$ by wt. A laboratory procedure of remixing the tailings with their bleed water prior to use in both phase I and II of the experimental program was performed to bring them back to their pre-transport condition. Mixing was done in 24 hours intervals using a DLM150VGD, mixer direct drum mixer at an average speed of $120 \mathrm{rpm}$. After the desired solid content was achieved, tailings were transferred to $0.10 \mathrm{~m}$ columns ( $48 \%$ by wt) and steel box ( $54 \%$ by wt) for phase 1 and 2 laboratory investigations, respectively.

A collection of laboratory tests and analyses were performed to determine the physical, mineralogical, and chemical characteristics of the cake. The initial solids content ranged from $50 \%$ to $54 \%$ (by weight) or a gravimetric water content from $83 \%$ to $101 \%$. The specific gravity is 2.34, and the PL and LL are $40 \%$ and $65 \%$ (by fall cone instead of Casagrande cup and glass plate as per deviation from ASTM D4318-17e1). The clay content obtained from the Methylene Blue Index (MBI) analysis was approximately $53 \%$. According to the X-ray diffraction (XRD) results, the composition of the clay fraction was $80 \% \%$ Kaolinite and $16 \%$ Illite. Total Dissolved Solids (TDS) in the pore water collected from the centrifuge cake was $744 \mathrm{mg} / \mathrm{L}$, electrical conductivity was 967 micro-S/cm, while the dominant cations were sodium at $93 \mathrm{mg} / \mathrm{L}$. More detailed pore-water chemistry and mineralogical composition results can be found in Appendix A. The following subsections provide explanation of the laboratory testing conducted on the centrifuge cake tailings.

\subsubsection{Atterberg limits}

In geotechnical engineering, Atterberg limits help quantify clay effects of a material over a range of water contents, with liquid limit (LL) and plastic limit(PL) the two most common test used in analyzing Atterberg limits (Hockley et al, 2018). The moisture contents when clay material changes from liquid to plastic and from plastic to non plastic behaviour are known as $\mathrm{LL}$ and $\mathrm{PL}$, respectively.

The centrifuge cake sample was airdried and a $30^{\circ}$ fall cone device was used in determining the liquid and plastic limit of the centrifuge cake sample. At a known water content, a fall cone 
penetration test is carried out with the displacement penetration recorded, afterwards, water content is increased using distilled water. The $\mathrm{LL}$ and $\mathrm{PL}$ are determined through the semi-log penetration-water content curve with the water content at penetration depth of $20 \mathrm{~mm}$ used in finding $\mathrm{LL}$ and $2 \mathrm{~mm}$ for PL (Figure 3.1).

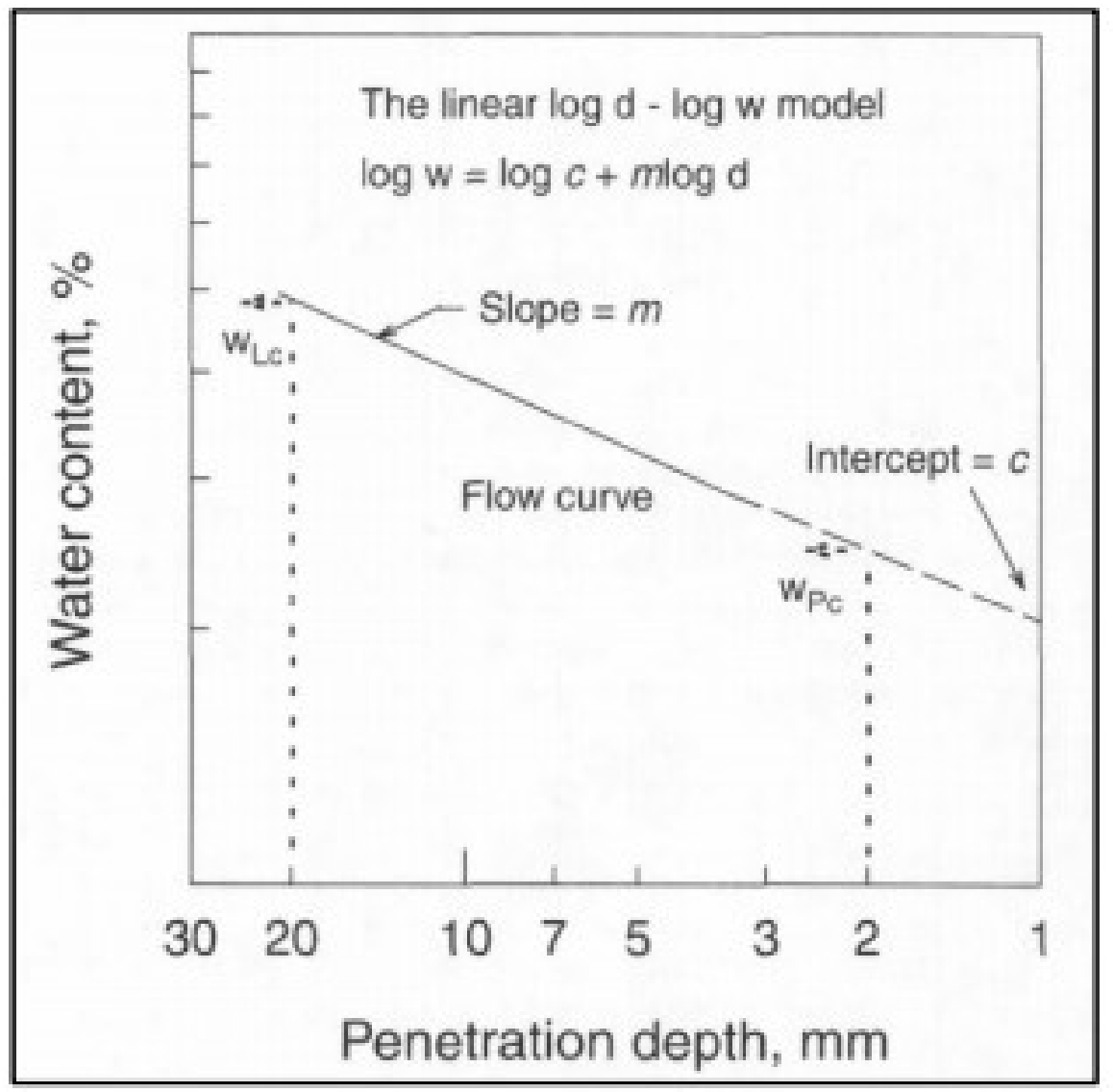

Figure 3.1. Linear log plot of penetration depth vs water content used in calculating plastic limit (Adapted from Feng 2001).

\subsubsection{Clay Content (Methylene blue index test)}

Methylene blue index (MBI) is used in determining the ionic absorption capacity and clay content of a sample. The shipped centrifuge cake samples were tested at AGAT laboratories for clay content using MBI test; this test uses the empirical equation proposed by Sethi, 1995 and is expressed in the empirical relationship below as: 


$$
\% \text { Clay }=\frac{M B I \frac{m e q}{100 g}+0.04}{0.14}
$$

where $\%$ clay = percentage of clay; and $\mathrm{MBI}=$ Milliequivalents of methylene per $100 \mathrm{~g}$ of sample, expressed in meq/100g.

\subsection{Experimental equipment}

\subsubsection{Pore-water pressure sensors}

In this study (both phases), positive pore-water pressure measurement was monitored using UMS Model T5x pore-water pressure sensor called tensiometer (Figure 3.2). The tensiometer measures pore-water pressure within the range of 0 to $100 \mathrm{kPa}$ was connected to DI2e and Sutron 9210 xLite data loggers (Figure $3.3 \mathrm{a}$ and b). The UMS model T5x pore-water pressure sensor consists of a porous ceramic cup connected by an acrylic glass shaft to the sensor body (Figure 3.2). The tensiometer works by the water in the reservoir (tip) equilibrating with the water in the soil through a porous ceramic tip, the pressure of the water in the tip moves a deformable membrane located in the sensor body causing the resistivity of the membrane changing as it is deformed, hence the pore-water pressure is sensed using a simple electric circuit through the membrane. At equilibrium, the water in the soil and within the reservoir are at negative pressure

and since the reference air pressure is assumed to be atmospheric pressure (zero), the measured negative pressure equals the matric suctions of the soil. To maximize the responsiveness of the sensor. The water in the sensor shaft is deaired by cycles of positive and negative pore-water pressure listed below:

1. Collect deionised water into a syringe and remove the air from the syringe.

2. Detach the acrylic shaft from the sensor body and insert both into a vacuum chamber filled with deionised water and deair for at least 30 minutes.

3. Insert the syringe underneath the water and take out and extra air in it.

4. Insert the syringe in the shaft body carefully not to touch the membrane and remove any air bubbles by pushing the deionized water into the shaft body and gently tapping on the sides to let out any trapped air.

5. Insert the syringe inside the shaft carefully repeat the previous step.

6. Check for any trapped bubbles and if any repeat step 4 and 5 .

7. If there are no air bubbles, connect the shaft to the sensor body underneath the water and leave saturated until ready to use. 


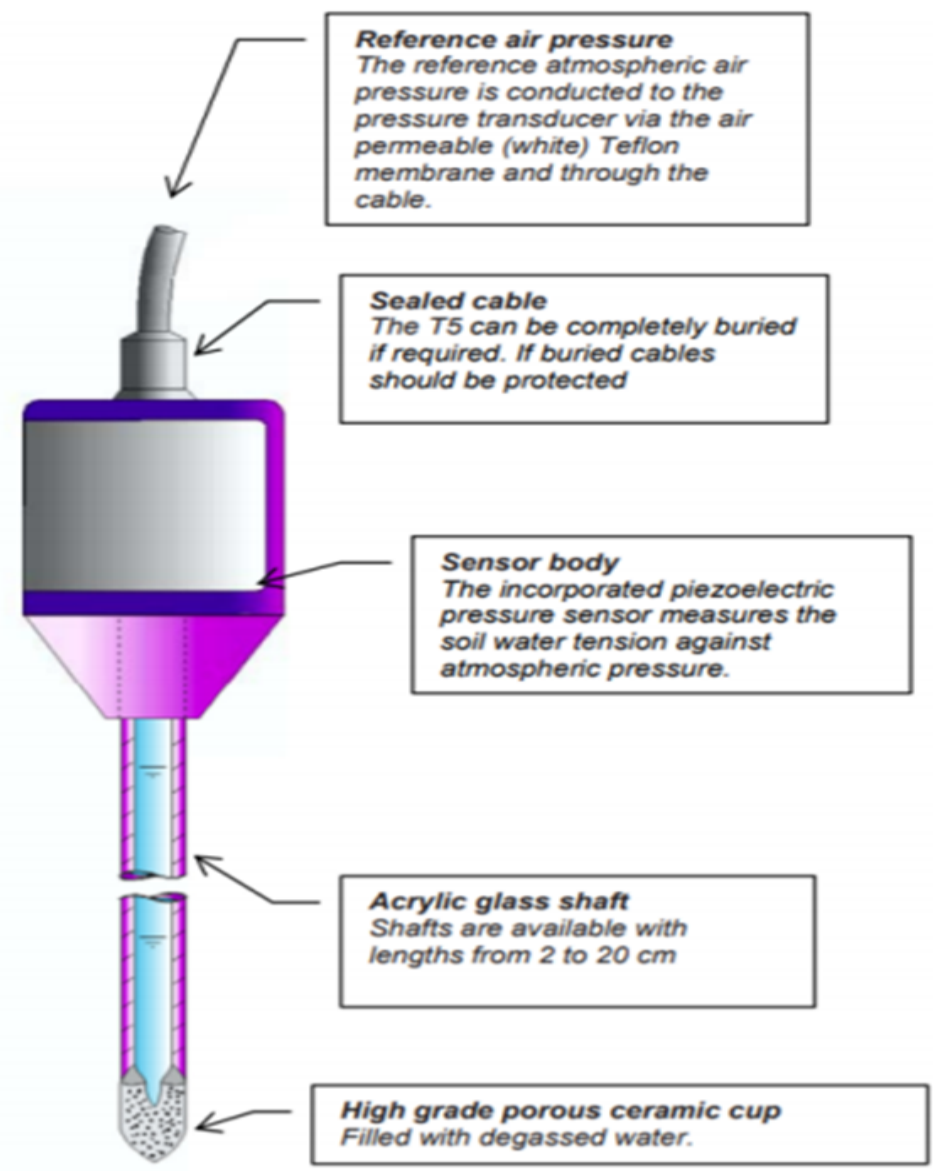

Figure 3.2. Labelled pore-water pressure sensor (UMS T5 tensiometer) (from Meter Environment, 2018). 


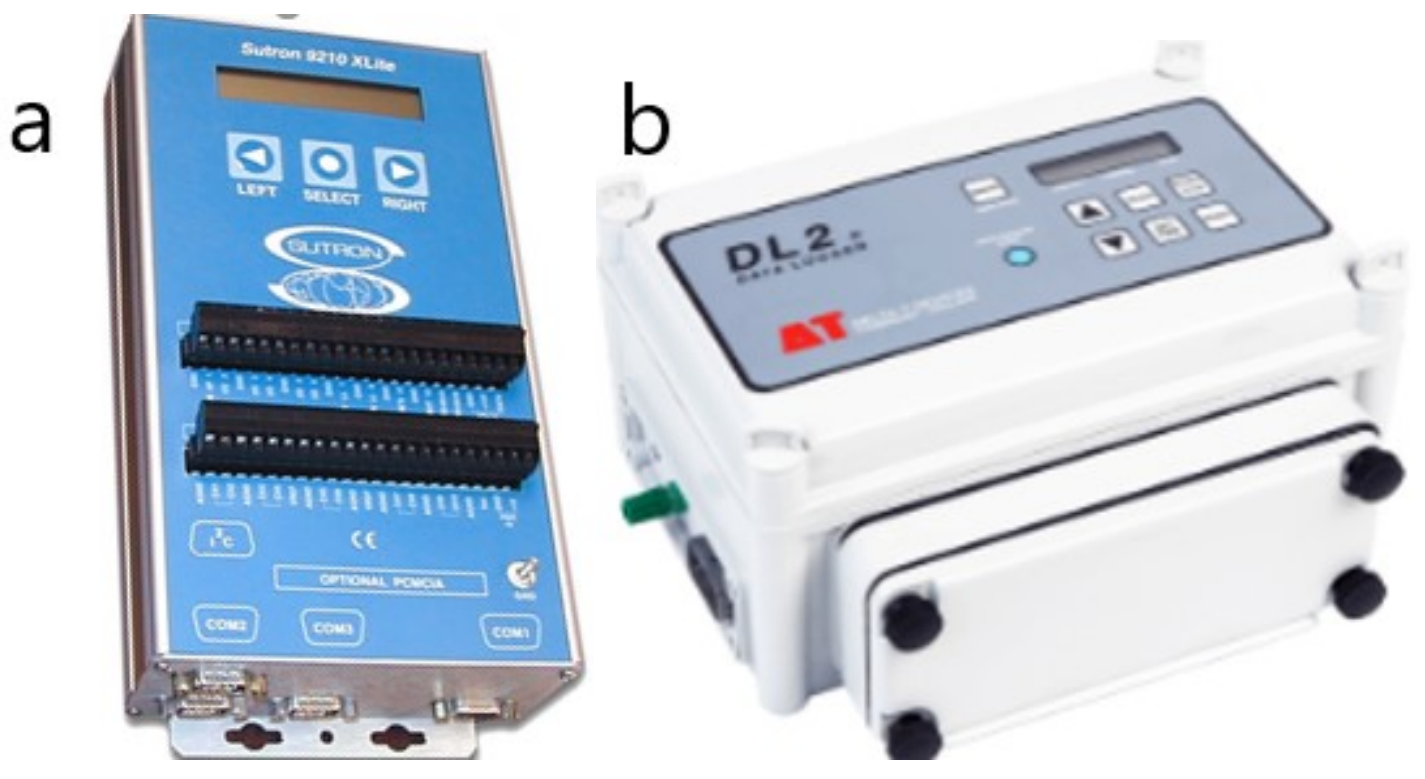

Figure 3.3. (a) Sutron 9210 xLite data logger (https://www.sutron.com/product/xlite-9210b/); and, (b) DI2e datalogger (https://www.delta-t.co.uk/product/dl2e/).

Prior to deposition in both phases, the $5 x$ pore-water pressure sensors were filled with de-aired distilled water and put in a vacuum overnight to remove air bubbles from them. Thereafter, they were tested at different height in a graduated cylinder filled with water and left saturated in a rubber cover. Pore water pressure data for phase 1 oedometer tests were logged with DI2e data logger and Sultron 9210 xLite was utilized in phase 1 column test and phase 2 novel consolidation test in the steel box (Figures $3.3 \mathrm{a}$ and $\mathrm{b}$ )

\subsubsection{Fall cone}

Fall cone test is a testing technique in which a soil sample is penetrated by a cone (Figure 3.4) through self weight and the penetration depth is measured; this test can be used in determining Atterberg limits and undrained shear strength of soil samples (Tanaka et al., 2012). 


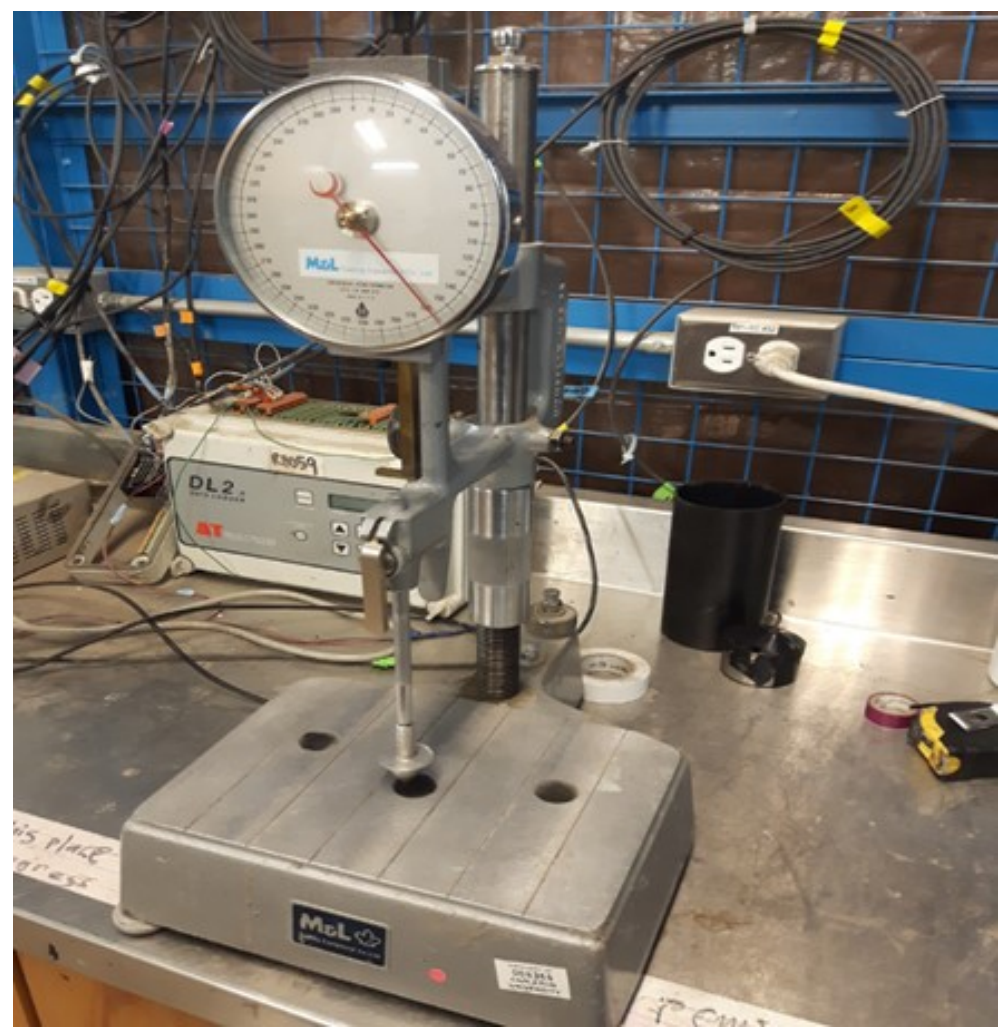

Figure 3.4. A M\&L fall cone testing equipment.

In 1957, Hansbo represented mathematically the relationship between undrained shear strength and cone penetration as:

$$
S_{u}=\frac{k m g}{d^{2}}
$$

where $\mathrm{S}_{\mathrm{u}}=$ undrained shear strength (in $\mathrm{kPa}$ ); $\mathrm{k}=$ cone factor, an empirical constant that depends on the angle of the fall cone tip and whether the sample is undisturbed or remoulded; $\mathrm{m}=$ mass of the cone; $g$ = gravitational acceleration $=9.81 \mathrm{~m} / \mathrm{s}^{2}$; and, $d=$ depth of cone penetration (in mm) (Leroueil et al., 1996; Dimitrova et al., 2011).

The cone factor is the most important variable in the above equation (3.6) and depending on the angle of the fall cone tip, cone surface roughness, the rate of strain during penetration and the deformation of clay around the cone during penetration the cone factor (k) varies (Hansbo, 1957; Koumoto et al., 2001; Hazell, 2008). For the $30^{\circ}$ degrees angle fall cone used in this experiment and the assumption of semi-rough surface for tailings, Koumoto et al., 2001 suggested a cone factor (k) of 1.33 which was used in determining the undrained shear strength. In this study, 
column dewatering test had samples sheared at day 0 and then put in replicates which were "processed" at 1, 3, 7, 14, 21, 28, 42, 56, 70, 84 and 98 days aged samples.

\subsubsection{Oedometer test}

Oedometer test is performed to mimic the one-dimensional compression of a soil in the field with settlement over incremental loading measured and the stress-strain relationship (void ratio vs effective stress plot) for the soil is developed. Figure 3.5 shows the major components of the oedometer apparatus consists of a cylindrical cell, fulcrum, and weights. The cylindrical cell contained the saturated soil sample enclosed in a metal ring which was approximately $0.055 \mathrm{~m}$ in diameter and $0.020 \mathrm{~m}$ in thickness and porous stone placed on the top and bottom of the sample. The sample was kept saturated for the duration of the test and the porous stones facilitated two-way drainage. Loads increments were applied after 24 hours due to the assumption that excess pore-water pressure dissipated after 24 hours during conventional oedometer test.

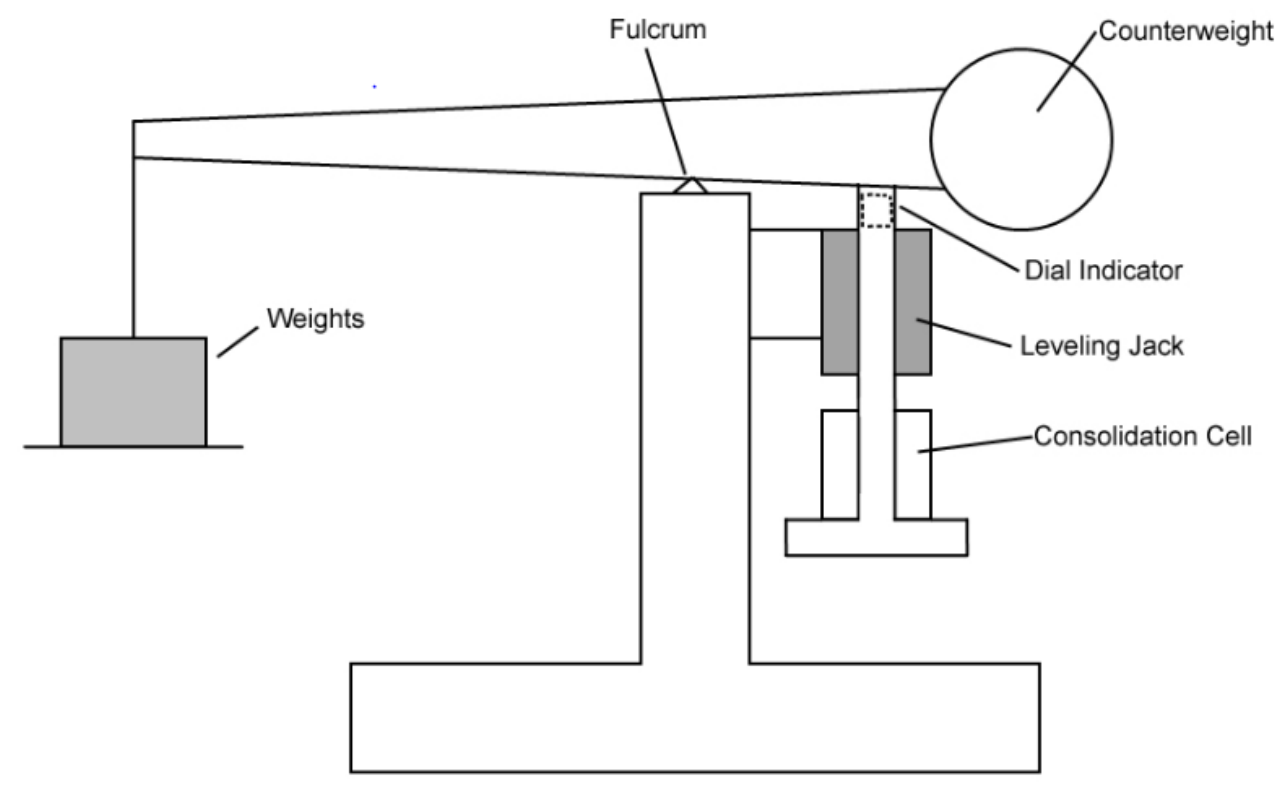

Figure 3.5. Conventional oedometer test frame (Adapted from Salam, 2020).

The conventional oedometer apparatus was modified by making a hole through the bottom cast and bottom porous stone for a UMS Model T5x pore-water pressure sensor to be inserted into the bottom of the sample, so as to enclose the ceramic tip within the tailings $(\sim 0.005 \mathrm{~m}$ intrusion) (Figure 3.6). This sensor monitors the excess pore-water dissipation allowing for a 
better estimate of the magnitude and duration of primary consolidation for this low permeability material (no longer assuming 24 hours). Secondary consolidation (creep) occurrence in the sample can there be better estimated.

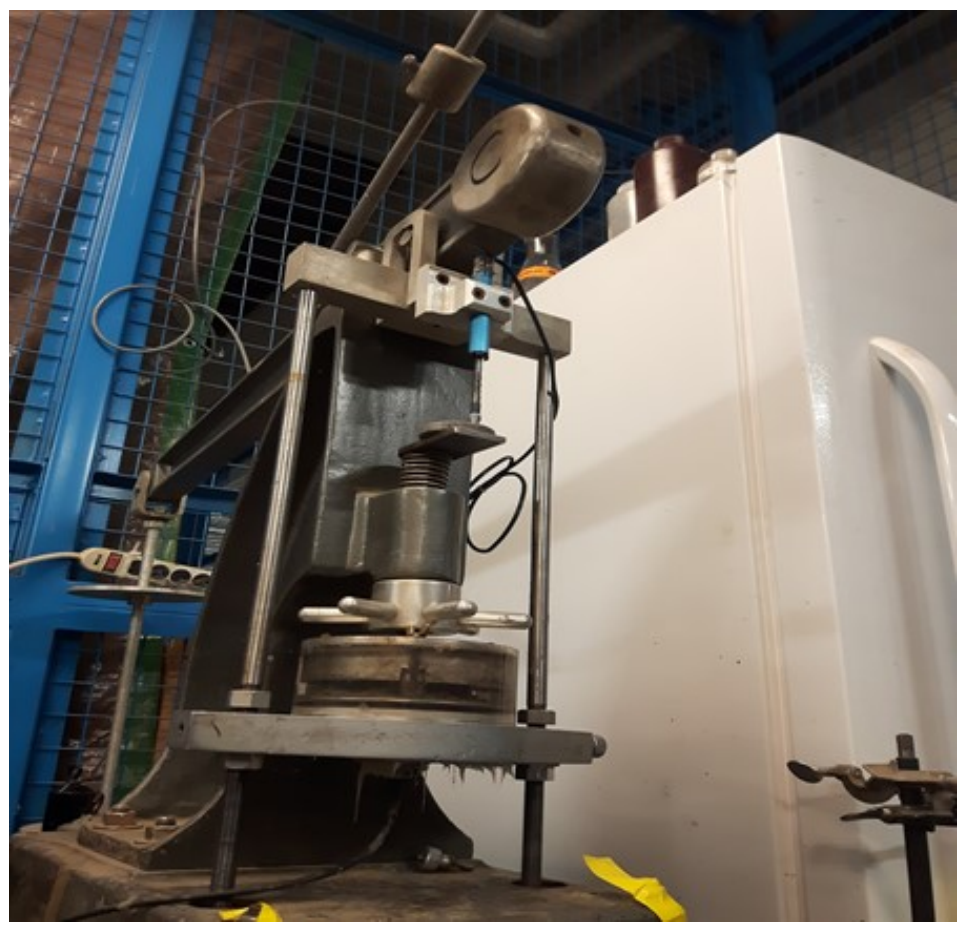

Figure 3.6. Modified oedometer with T5x tensiometers installed in the base and connected to DL 2e data logger.

\subsubsection{Volumetric water content sensors}

The decagon 5TE sensor measures volumetric water content, electrical conductivity, and temperature of soil using a variety of unique methods for each property (Figure 3.7). The 5TE quantifies volumetric water content by measuring the dielectric constant of the soil through a $70 \mathrm{MHZ}$ oscillating probe and relating the measured dielectric permittivity to volumetric constant by Topp equation (Decagon, 2016). Temperature is determined by the thermistor embedded in the sensor while electrical conductivity is estimated using the two-sensor array located on the screw of the 5TE. Decagon (2016) contains detailed information about decagon 5TE methods and operation. 


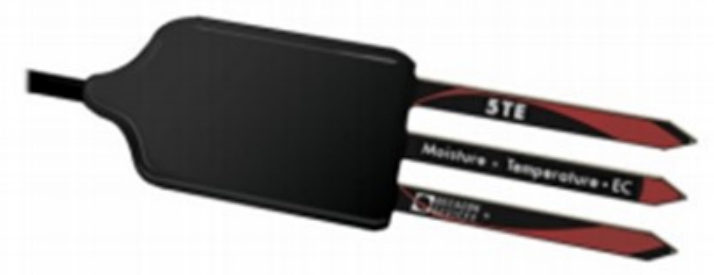

Figure 3.7. Volumetric water content sensor (Decagon, 2016).

Decagon 5TE sensors were used primarily for measuring volumetric water content in the novel consolidation steel box test (phase 2). For this experiment, calibrations were performed using the method proposed by Starr et al. (2002); five air dried clay samples were adjusted to different gravimetric water content and the following calibration curve (Figure 3.8 ) and equation (Equation 3.7) were derived (Abdulrahman, 2019):

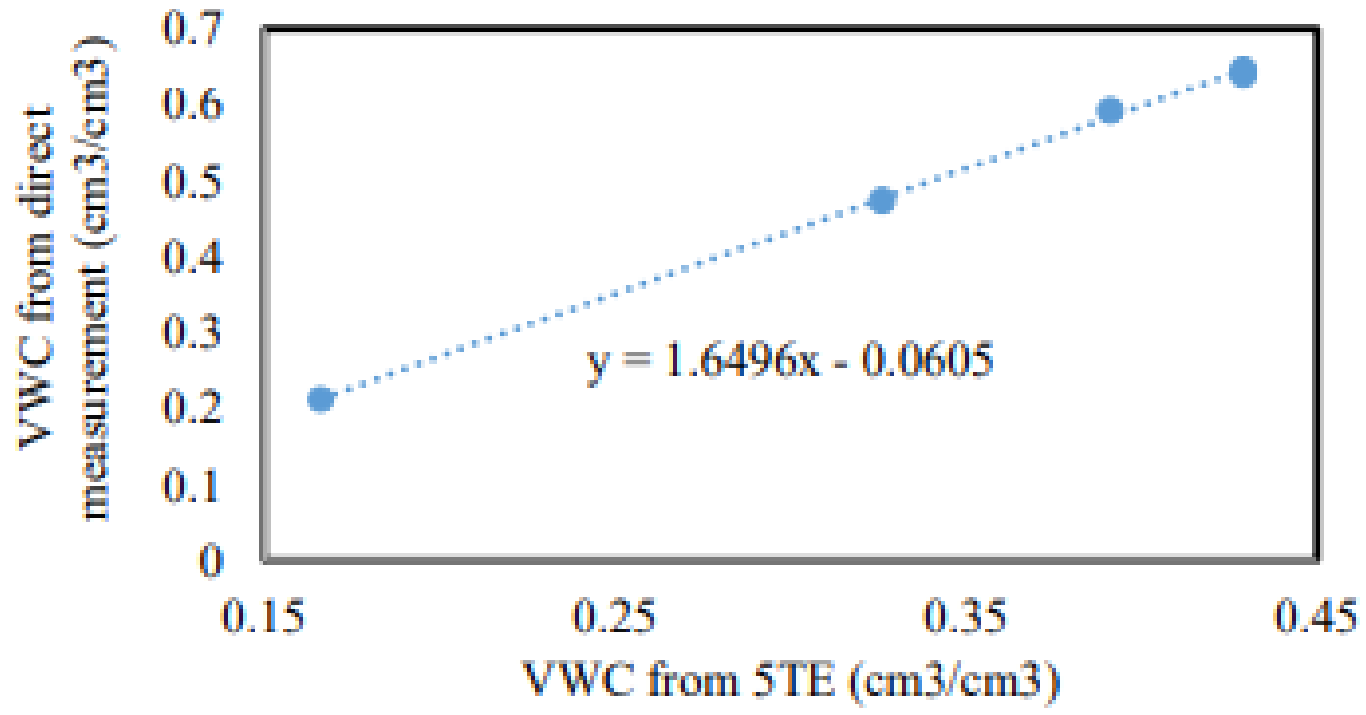

Figure 3.8. Decagon 5TE calibration (from Abdulrahman, 2019).

$$
\mathrm{VWC}_{\text {corrected }}=1.6496 * \mathrm{VWC}_{5 \mathrm{TE}}-0.0605
$$


Abdulrahman (2019) provides a detailed step by step procedure on how the calibration was conducted.

\subsubsection{Load cells}

Load cells measure applied stress (force) by converting the measured stress into an electrical signal. Four Artech 70210-5k load cells (Figure 3.9) were used in balancing the steel box and measuring the mass changes in the box over the duration of the experiment. The load cells had a load carrying capacity of $5000 \mathrm{lb}$, and they were calibrated using varying dead loads to get the correct orientation that summed up to the applied load.

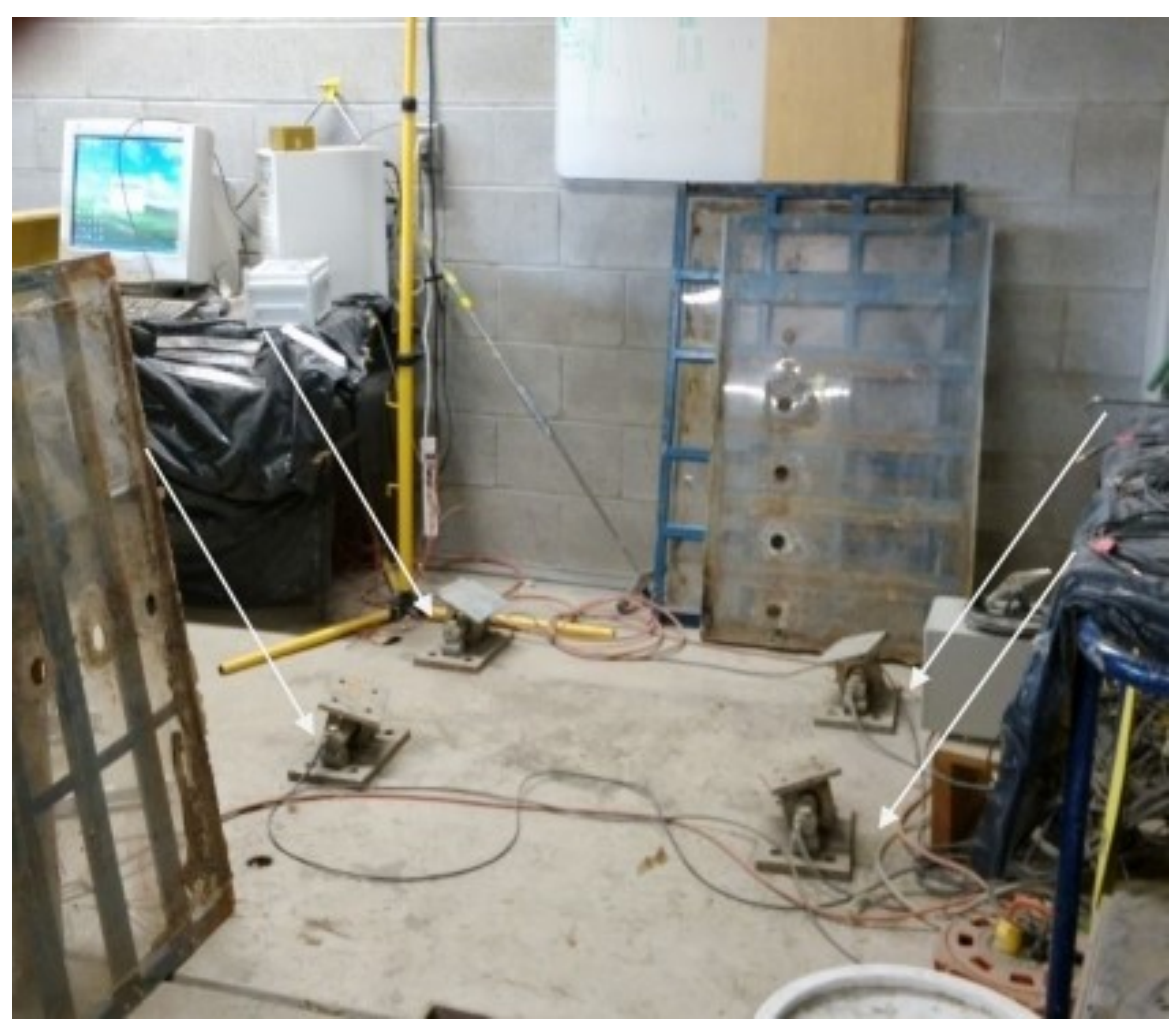

Figure 3.9. Four Artech 70210-5k load cells (from Hurtado, 2018).

\subsubsection{Soil pressure gauge}


Like load cells, soil pressure cells measure stress acting on surfaces by converting the pressure applied on the surface into an electric signal. The soil pressure gauges were used at the bottom of the box to measure pressure acting on the surface and monitor the amount of stress at the bottom of the box. Figure 3.10 shows the three $100 \mathrm{~mm} \mathrm{KDC-200kPa}$ soil pressure gauge used in measuring stress at the bottom of the steel box and their orientation. Two were placed close to the steel wall and one int the middle to investigate wall effect. A universal testing machine (UTM) was used in calibrating the load cells over a wide range of loads.

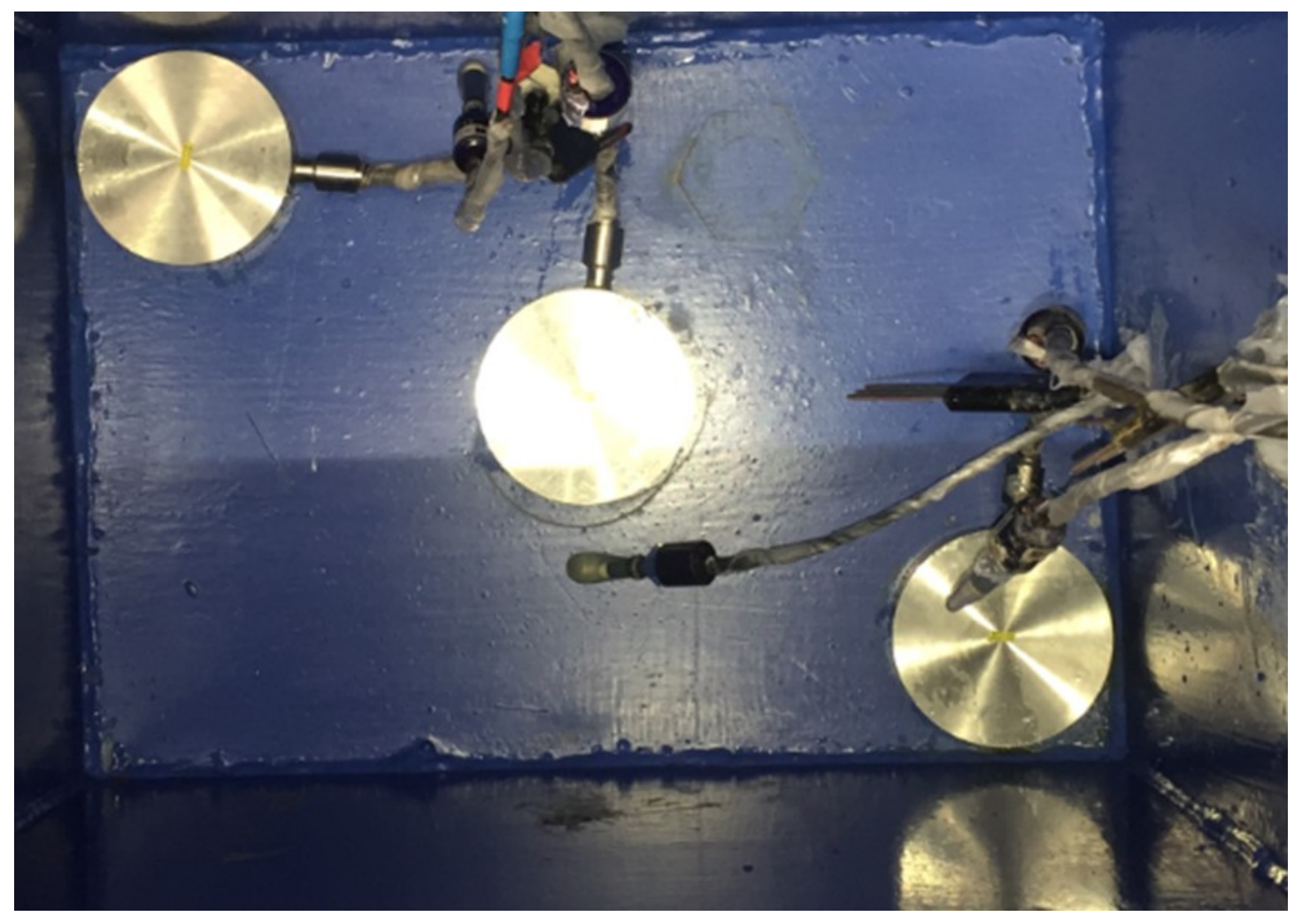

Figure 3.10. KDC-200kPa soil pressure gauge.

\subsubsection{Linear Variable Differential Transformer (LDVT)}

The LDVT sensor measures displacement by converting motion into electrical signal. The LDVT used in this study (phase II) measures up to $150 \mathrm{~mm}$ displacement and was connected to a $12 \mathrm{v}$ dc transmitter and a data logger that is connected to the computer. Figure 3.11 shows the position of the sensor on the lever load transfer plate. 


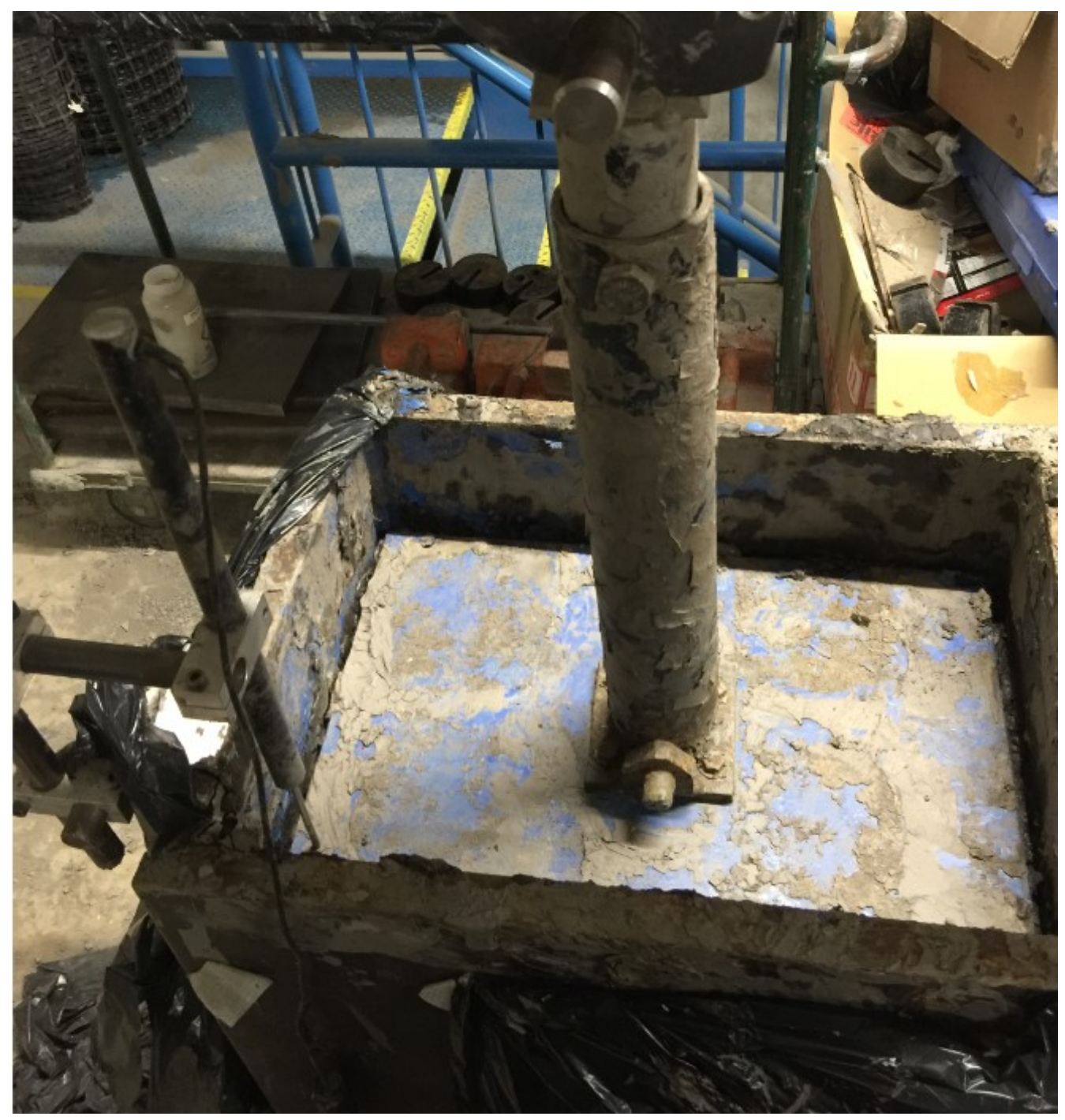

Figure 3.11. LDVT sensor on the load transfer component of the lever arm.

\subsection{Experimental setup}

\subsubsection{Column dewatering test setup (Phase I)}

Twenty-three $0.075 \mathrm{~m}$ diameter "replicate columns" made from polypropylene (PP) were filled with the prepared tailings to heights of $0.10 \mathrm{~m} \mathrm{(+/-} 0.002 \mathrm{~m}$ ) (Figure 3.12). Seven columns were for water content and oedometer testing, eleven columns for water content and fall cone measurement and three columns solely for fall cone measurements (see Table 3-1 for details). 


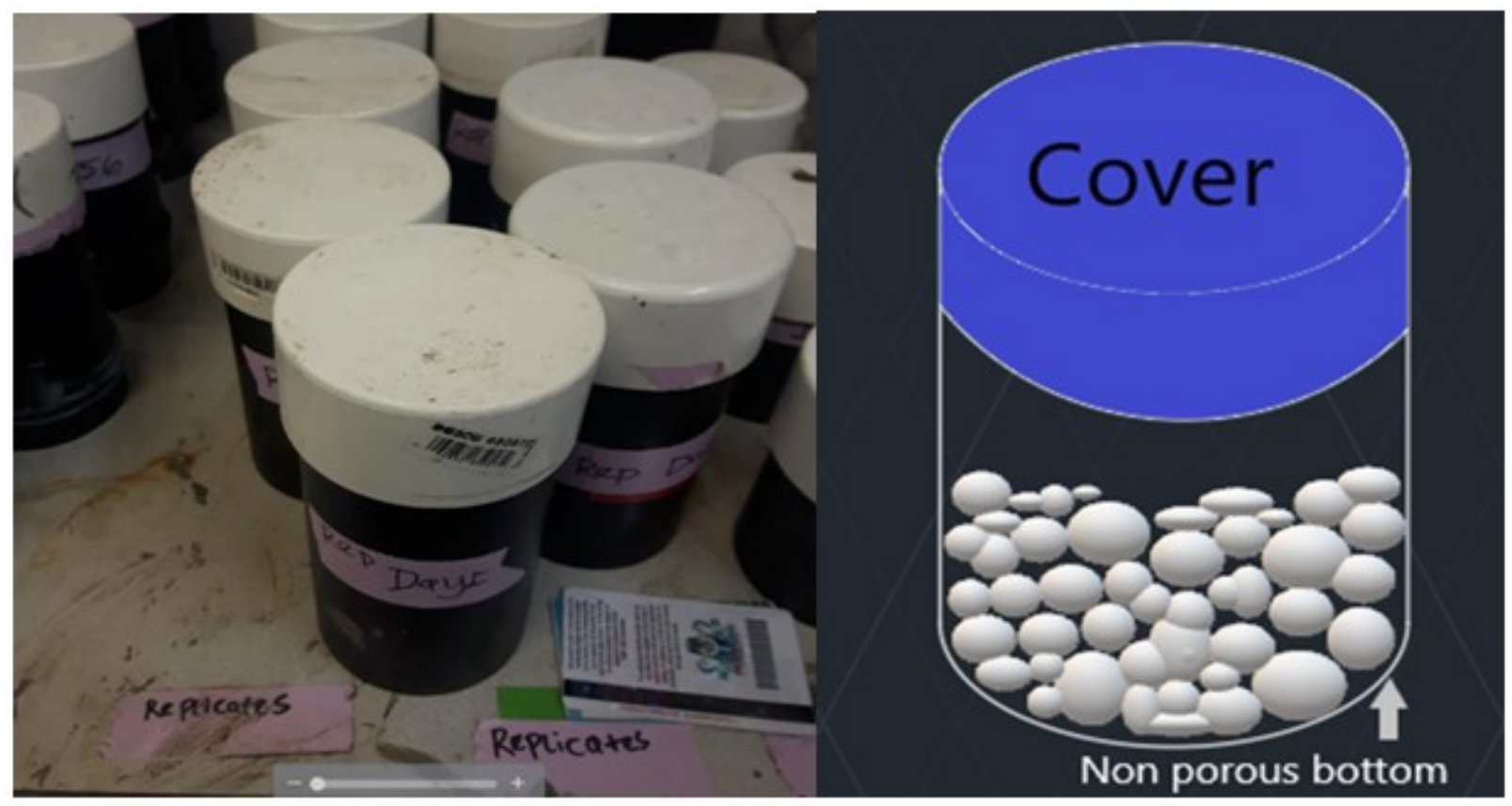

Figure 3.12. Schematic diagram showing replicate columns with $0.10 \mathrm{~m}$ thick tailings.

Table 3-1: Breakdown of columns used in phase I.

\begin{tabular}{|l|l|l|l|}
\hline Procedure & Number of columns & $\begin{array}{l}\text { Average height of } \\
\text { columns }(\mathrm{m})\end{array}$ & $\begin{array}{l}\text { Average height of } \\
\text { tailings in columns } \\
\text { (m) }\end{array}$ \\
\hline $\begin{array}{l}\text { Replicate columns for } \\
\text { oedometer test }\end{array}$ & 7 & 0.15 & 0.1 \\
\hline $\begin{array}{l}\text { Replicate columns (no } \\
\text { oedometer test) }\end{array}$ & 11 & 0.16 & 0.1 \\
\hline $\begin{array}{l}\text { Replicate columns for } \\
\text { pore-water } \\
\text { measurements }\end{array}$ & 2 & 0.11 & 0.1 \\
\hline $\begin{array}{l}\text { Replicate columns for } \\
\text { fall cone measurement }\end{array}$ & 3 & 0.16 & 0.1 \\
\hline
\end{tabular}

Two additional columns were used to monitor pore-water pressure with an UMS Model T5x pore-water pressure sensor. The PWP sensors were installed into each respective column (at 
depths of $0.064 \mathrm{~m}$ and $0.059 \mathrm{~m}$ respectively) (Figure 3.13). The lids were removed periodically to measure the height of accumulated bleed water. These 2 columns were kept under minimal disturbance throughout the pore-water pressure monitoring timeline.
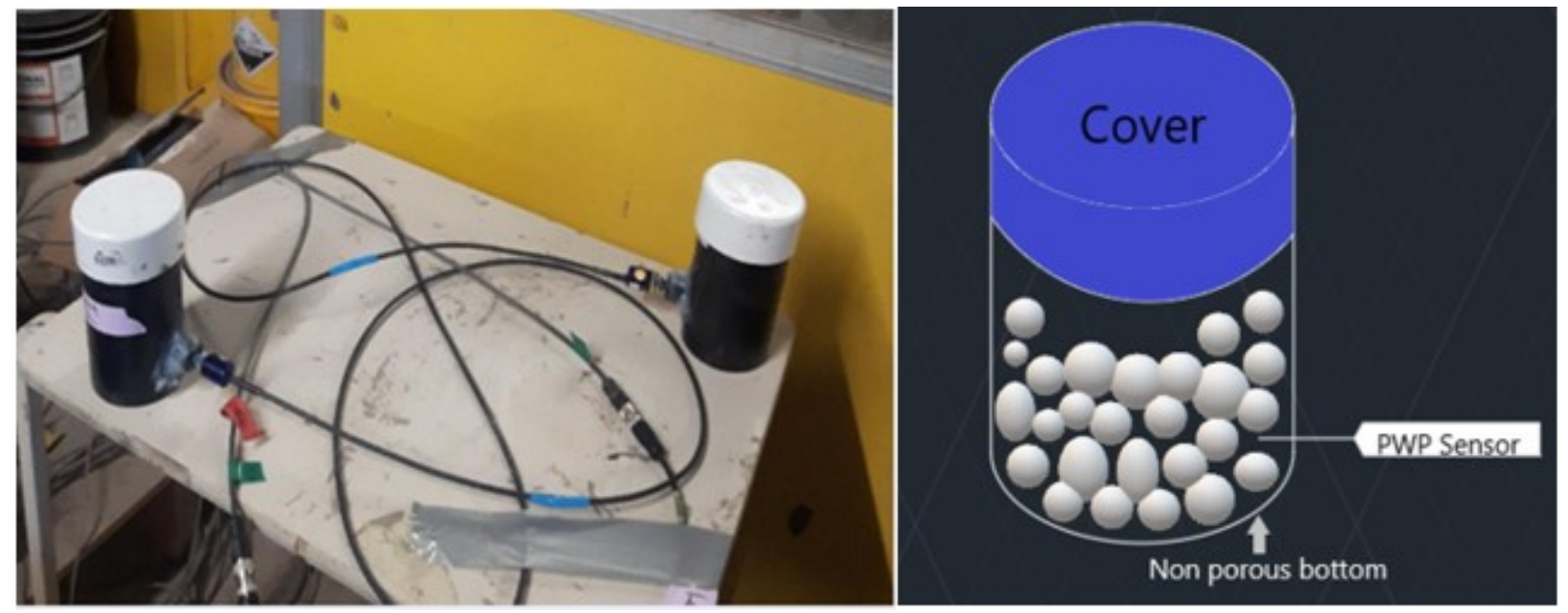

Figure 3.13. Schematic diagram showing replicate column with pore-water pressure (PWP) sensor.

Besides the two pore-water pressure columns all other replicate columns were regularly weighed, covered with airtight lids to keep material saturated and kept on a stable surface with little disturbance over the test period. PP has been shown to be superior to other plastics such as acrylic or PVC, as the latter are hydrophilic and show pronounced sidewall effects, while the PP material shows no detectable sticking of the material to the sides, and no variability in settlement over time occurs when larger diameter experiments are employed (Salam 2020).

\subsubsection{Sampling and monitoring}

The tailings deposited in the eleven replicates columns (no oedometer) and seven replicates columns (oedometer) were processed at different time steps. This processing involved removing and weighing the surface bleed water, and subsequently either destructively sampling the tailings for water content with depth (every $0.01 \mathrm{~m}$ ) or preparing oedometer samples. Table 3-2 shows the procedure carried out on a specific column at a specific day. 
Table 3-2: Scheduled measurements on columns at specific days.

\begin{tabular}{|c|c|c|c|}
\hline Day(s) & $\begin{array}{l}\text { Replicates columns } \\
\text { (no oedometer) }\end{array}$ & $\begin{array}{l}\text { Replicates columns } \\
\text { (oedometer) }\end{array}$ & Fall cone columns \\
\hline 1 & Water content & & Fall cone \\
\hline 3 & Water content & & Fall cone \\
\hline 7 & Water content & & Fall cone \\
\hline 14 & $\begin{array}{l}\text { Water content, Fall } \\
\text { cone }\end{array}$ & $\begin{array}{l}\text { Water content, } \\
\text { oedometer }\end{array}$ & Fall cone \\
\hline 21 & $\begin{array}{l}\text { Water content, Fall } \\
\text { cone }\end{array}$ & & Fall cone \\
\hline 28 & $\begin{array}{l}\text { Water content, Fall } \\
\text { cone }\end{array}$ & $\begin{array}{l}\text { Water content, } \\
\text { oedometer }\end{array}$ & Fall cone \\
\hline 35 & & & Fall cone \\
\hline 42 & $\begin{array}{l}\text { Water content, Fall } \\
\text { cone }\end{array}$ & $\begin{array}{l}\text { Water content, } \\
\text { oedometer }\end{array}$ & Fall cone \\
\hline 56 & $\begin{array}{l}\text { Water content, Fall } \\
\text { cone }\end{array}$ & $\begin{array}{l}\text { Water content, } \\
\text { oedometer }\end{array}$ & Fall cone \\
\hline 62 & $\begin{array}{l}\text { Water content, Fall } \\
\text { cone }\end{array}$ & $\begin{array}{l}\text { Water content, } \\
\text { oedometer }\end{array}$ & Fall cone \\
\hline 79 & $\begin{array}{l}\text { Water content, Fall } \\
\text { cone }\end{array}$ & $\begin{array}{l}\text { Water content, } \\
\text { oedometer }\end{array}$ & Fall cone \\
\hline 107 & $\begin{array}{l}\text { Water content, Fall } \\
\text { cone }\end{array}$ & $\begin{array}{l}\text { Water content, } \\
\text { oedometer }\end{array}$ & Fall cone \\
\hline 119 & & & Fall cone \\
\hline 126 & & & Fall cone \\
\hline 140 & & & Fall cone \\
\hline 518 & & & Fall cone \\
\hline
\end{tabular}

Replicate columns (no oedometer) were "processed" primarily for water content with depth at $1,3,7,14,21,28,42,56,62,79$ and 107 days after deposition (Table 3-2). For days 1, 3 and 7 no fall cone measurements were taken but subsequent time steps included fall cone and water content processing. Fall cone measurements were done on the undisturbed sample before destructive sampling for water content was done. During water content processing, the entire $0.10 \mathrm{~m}$ layer of tailings was destructively samples using up the entire deposited tailings material.

Similarly, the replicate columns (oedometer) were "processed" primarily for oedometer test at 14, 28, 42, 56, 62, 79 and 107 days after deposition (Table 3-2). The processing was involved destructively sampling the top $0.06 \mathrm{~m}$ of tailings for water content column and the last $0.04 \mathrm{~m}$ (bottom sample) used for oedometer testing. The bottom $0.04 \mathrm{~m}$ was preferred for the oedometer test because effective stress is assumed to be most significant at the bottom of the 
column. Two samples were used for the oedometer test with the first sample collected from the undisturbed sample at the bottom and the remaining sample sheared before the second sample (remoulded) is collected. Both conventional and modified oedometer apparatuses were used in testing the two samples collected with the modified oedometer measuring the excess porewater dissipation and dictating the time for load change (complete consolidation) for both setups.

The three replicate columns were solely for fall cone measurements were measured on 1, 3, 7, $14,21,28,35,42,56,62,79,107,119,126$ and 140 days (Table 3-2). The measurement process involved weighing the sample before and after removing the surface bleed water. The fall cone samples were used to track the aging effect of samples (structuration). Due to quasi disturbance of the fall cone samples (Figure 3.14), replicates for water content measurement (beginning from day 14) were used for fall cone test before breaking the column since they were not disturbed. This was done to minimize the disturbance of the sample and compare the results from the undisturbed replicate (no oedometer) sample and the frequently disturbed fall cone sample. On day 518 , two of the replicate columns solely for fall cone measurements had their strength measured at an undisturbed state, then both samples were sheared (remolded) and strength measured after which both columns were processed.

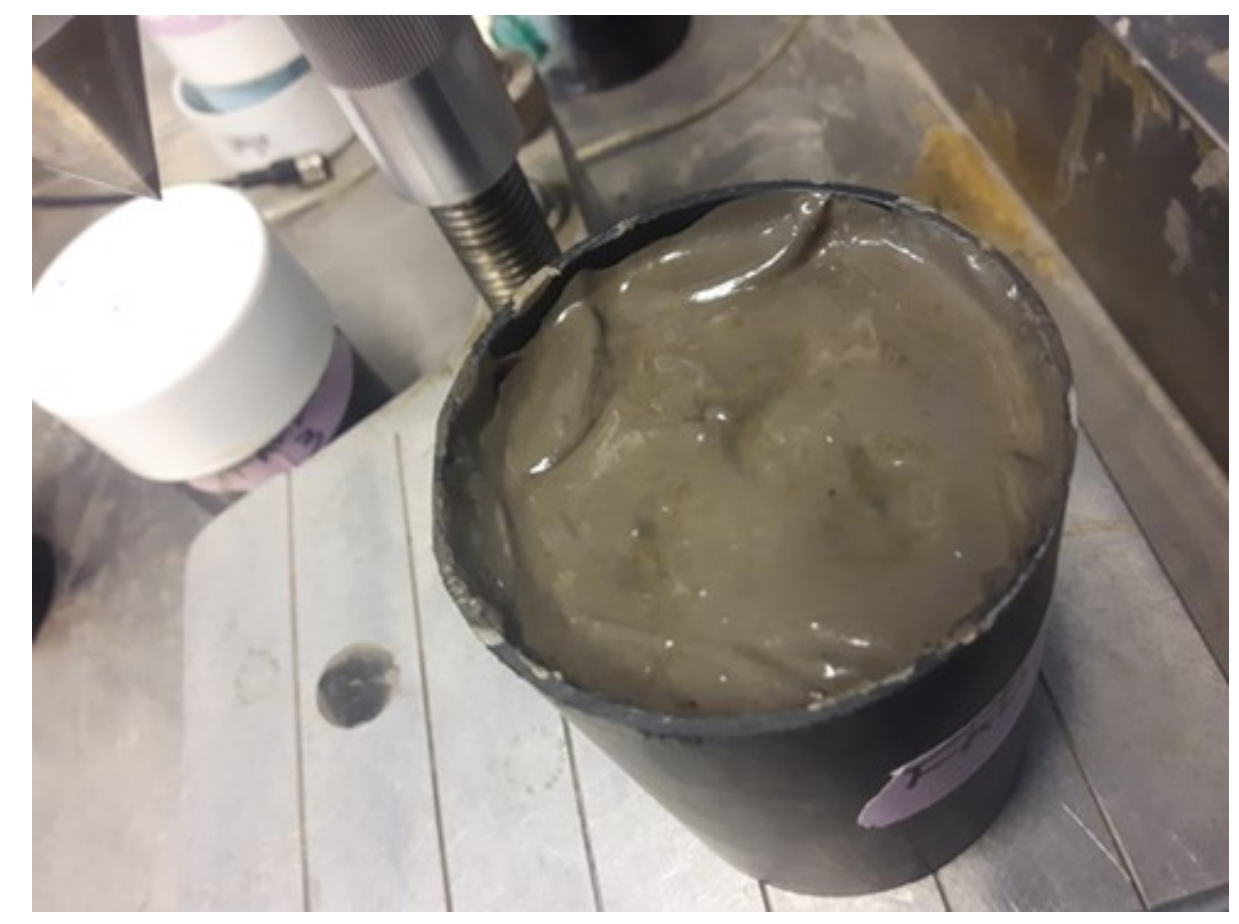

Figure 3.14. Visible marks on tailings from previous measurements.

The two replicate columns used for pore-water pressure monitoring were connected to the computer via the Sutron xLite data logger and had their measurements logged in real time. 
Occasionally the lid was removed, and the settlement or surface bleed water height was measured with a ruler. After 126 days of monitoring the pore-water pressure the replicate samples were dismantled and one was destructively sampled for water content (no oedometer) and the other for water content and oedometer.

An electric oven was used to dry the sample for 24 hours at $105^{\circ} \mathrm{C}$ to measure moisture content of the tailings and at 1 hour at $550^{\circ} \mathrm{C}$ for volatile solids measurement.

\subsubsection{Large-scale consolidation setup (Phase II)}

The large-scale consolidation apparatus used for the test are shown in figures 3.15 and 3.16. Major components of the setup consist of steel box, steel beam, weight, load transfer and loading arm sections. The loading arm was made from steel, $3.69 \mathrm{~m}$ wide and $0.01 \mathrm{~m}$ thick (labelled design diagram for full setup can be found in the appendix D). The weight and load application sections were attached to the loading arm at $0.60 \mathrm{~m}$ and $3 \mathrm{~m}$ from the fulcrum point, respectively. This was done to achieve a mechanical advantage of five times the load applied at the weight section being transferred to the steel box.

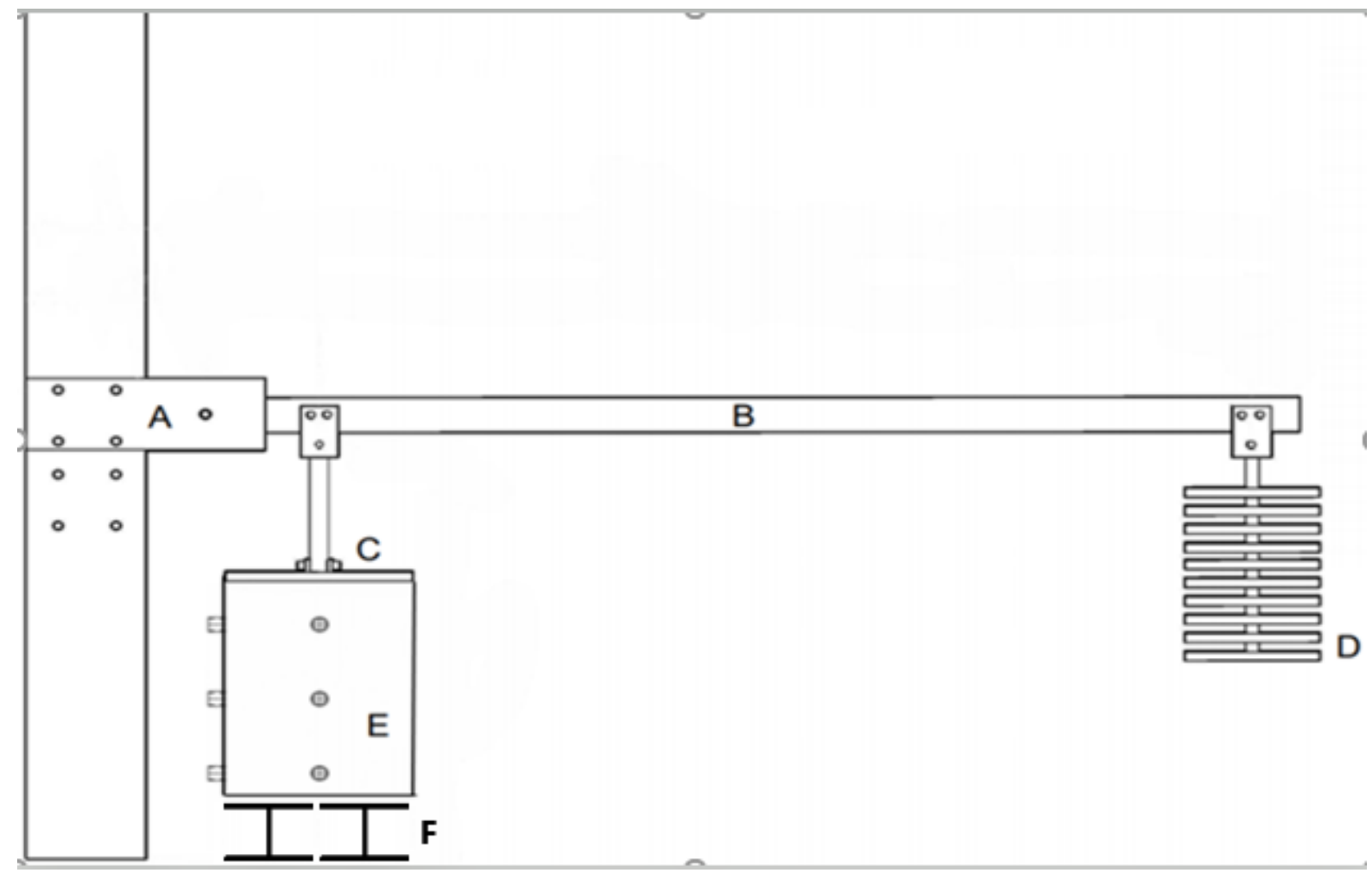

Figure 3.15. Schematic diagram of the large-scale consolidation test apparatus: A: Steel beam; B: Loading arm; C: Load transfer; D: Weights; E: Steel box; F: Load cells. 


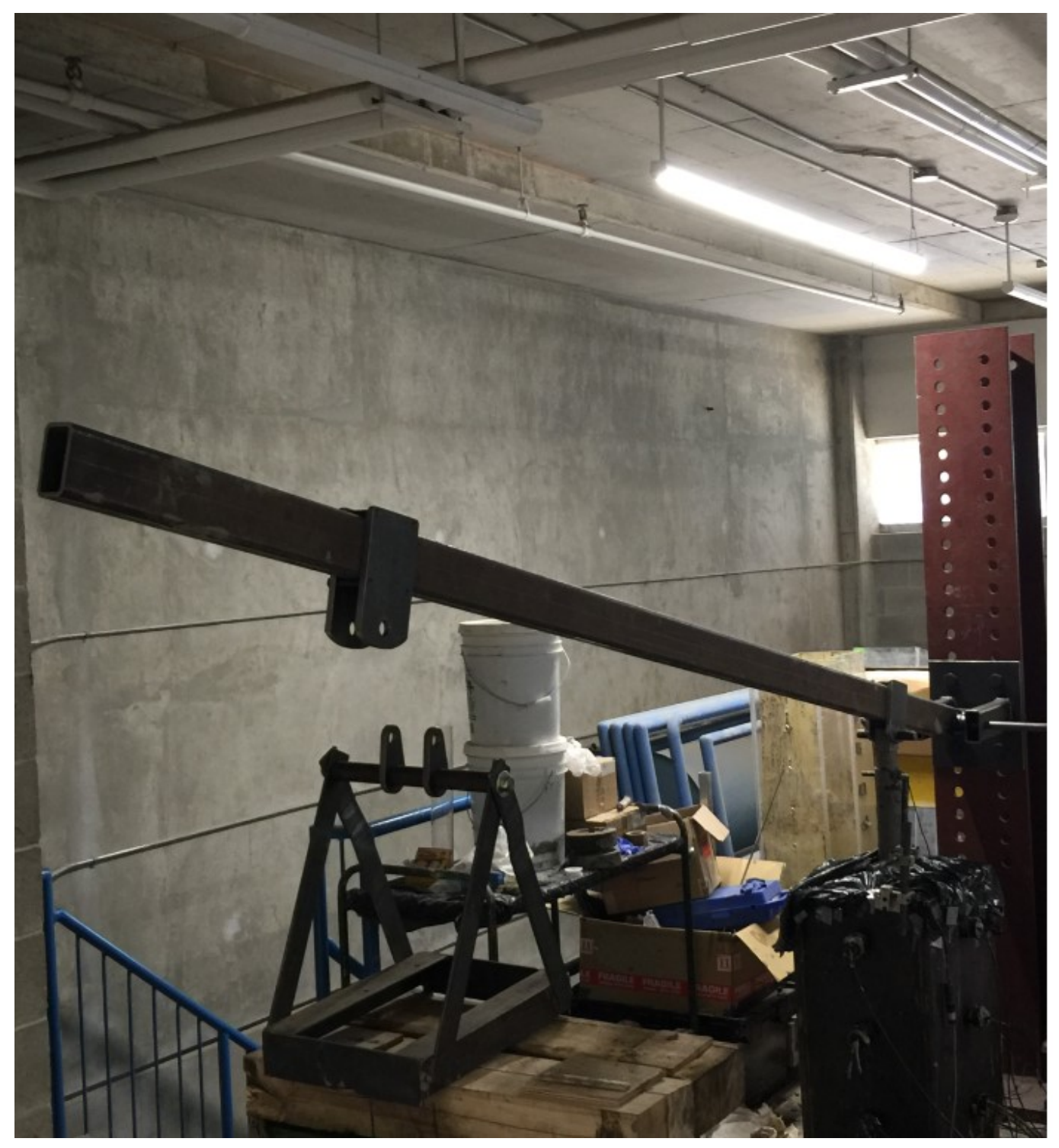

Figure 3.16. Schematic diagram showing large scale setup and sketched design.

The 1-inch thick steel box with a base area of $0.49 \mathrm{~m} \times 0.35 \mathrm{~m}$ and height of $0.72 \mathrm{~m}$ modified with 3 holes at 2 sides for sensors to be inserted into the box for measurement during the experiment. 6 decagon 5TE volumetric water content sensors (at depths of $0.10 \mathrm{~m}, 0.22 \mathrm{~m}, 0.30$ $\mathrm{m}, 0.35 \mathrm{~m}$ and $0.50 \mathrm{~m}$ respectively) and 5 UMS Model T5x pore-water pressure sensors (at depths of $0.12 \mathrm{~m}, 0.31 \mathrm{~m}$ and $0.54 \mathrm{~m}$ respectively) were inserted into the box for measurement during the test (Figures 3.17 and 3.18). Steel was the preferred material used in the box due to the high load bearing capacity of steel. 


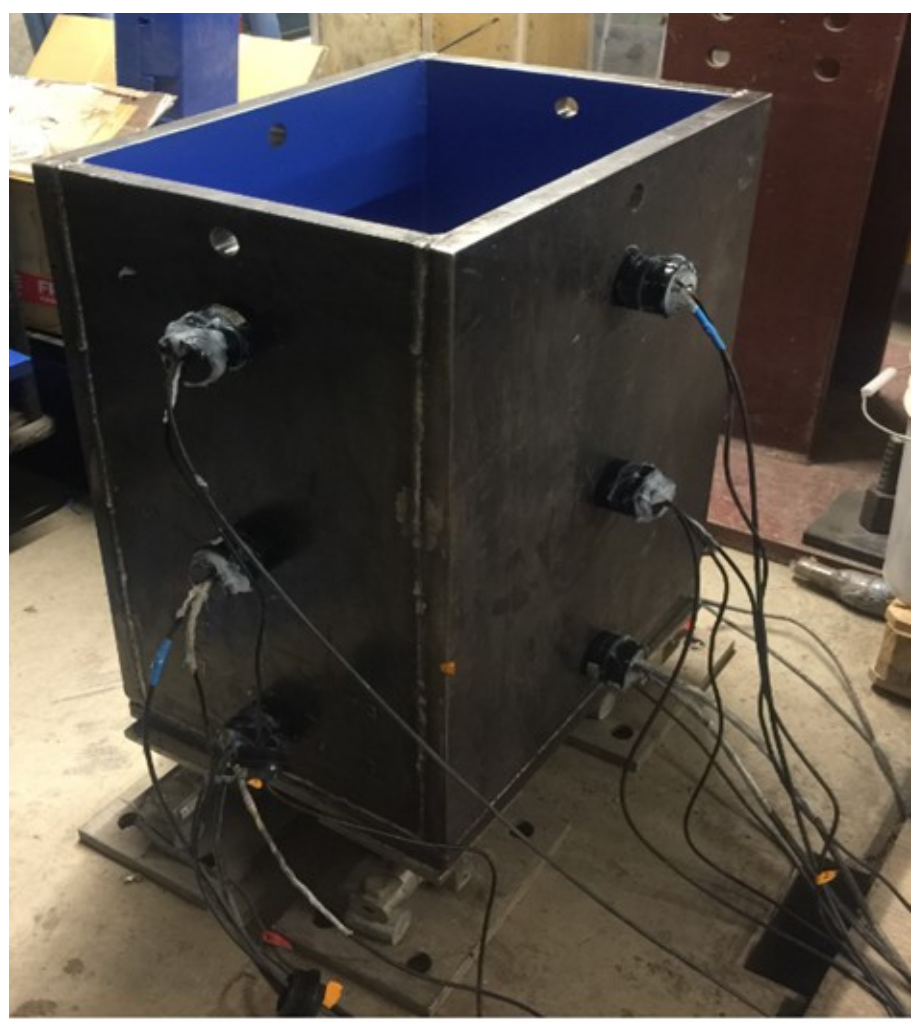

Figure 3.17. Steel box balanced on load cells.

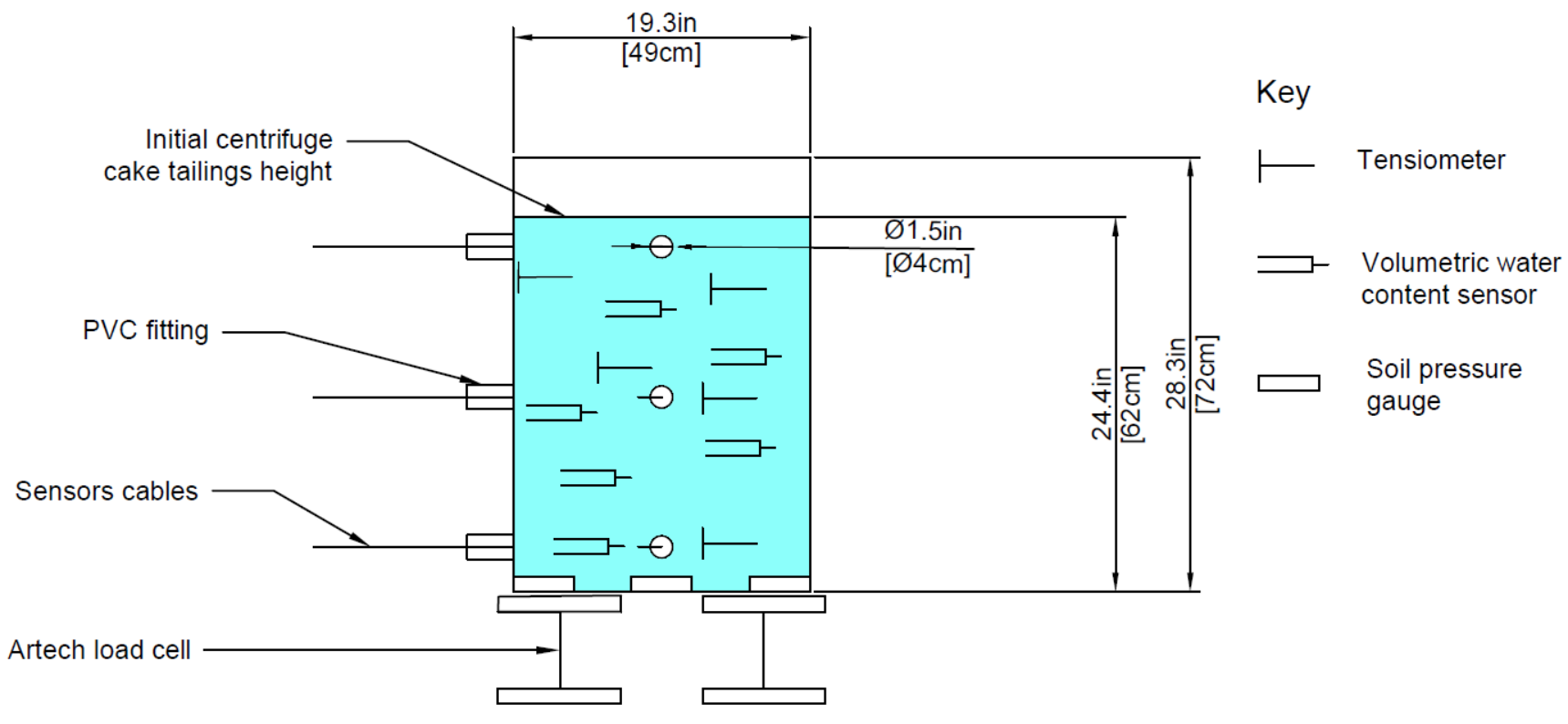

Figure 3.18. Schematic diagram showing pore-water pressure (tensiometer), soil gauge pressure and volumetric water sensors in the box. 
The box was balanced on four Artech 70210 load cells (Figure 3.18) and linear variable differential transformer (LDVT) was attached to the top wall of the box and placed on the load transfer section to monitor tailings displacement over time. The steel box was covered with a plastic sheet and sensor holes sealed with silicone and PVC fittings during the duration of the test to minimize any evaporation.

\subsubsection{Sampling and monitoring}

The steel box was filled with centrifuge oil sands cake tailings to a height of $0.62 \mathrm{~m}(+/-0.01 \mathrm{~m})$ and left to self-consolidate for the first 23 days. Surface sampling was done on a two-day interval starting from day 1 until day 23 and an electric oven was used to dry the collected samples at 105 deg C (solids content), 200 deg C (adsorbed water) and 550 deg C (volatile solids). At the beginning of the test (day 1) and end of self-weight consolidation (day 23) core sampling by depth and water content analysis (GWC) were carried out.

On day 26 (Table 3), $2 \mathrm{kPa}$ load was applied to the sample in the box and left until the excess pore water pressure dissipated. The gravimetric water content at the end of the loading step was measured and the next load is applied. The sample was loaded incrementally at 2, 3, 8 and $16 \mathrm{kPa}$ (Table 3-3) with GWC measurement at the end of loading step.

Table 3-3: Applied loads with corresponding day.

\begin{tabular}{|l|l|l|}
\hline Day(s) load is applied & Applied load (kg) & Effective stress (kPa) \\
\hline 26 & 28 & 2 \\
\hline 44 & 48 & 3 \\
\hline 55 & 124 & 8 \\
\hline 132 & 260 & 16 \\
\hline
\end{tabular}

Sensors inserted in the box tracked volumetric water content (VWC), pore-water pressure (PWP), applied load, displacement, and stress measurements (Table 3-4). 
Table 3-4: Sensors measurement and position in box (Phase II).

\begin{tabular}{|l|l|l|}
\hline Sensor & Measurement & Position \\
\hline $\begin{array}{l}\text { Volumetric water content } \\
\text { sensor }\end{array}$ & Volumetric water content & $\begin{array}{l}\text { Inside the box }(0.10 \mathrm{~m}, 0.10 \\
\mathrm{m}, 0.4 \mathrm{~m}, \text { and } 0.52 \mathrm{~m})\end{array}$ \\
\hline Tensiometer & Pore-water pressure & $\begin{array}{l}\text { Inside the box }(0.10 \mathrm{~m}, 0.11 \\
\mathrm{m}, 0.25 \mathrm{~m}, 0.3 \mathrm{~m}, \text { and } 0.54 \mathrm{~m} \\
\text { depths }\end{array}$ \\
\hline Load cell & Mass changes in box & Underneath the box \\
\hline $\begin{array}{l}\text { Linear variable differential } \\
\text { transformer (LVDT) }\end{array}$ & Displacement & Top of the box \\
\hline Soil pressure gauge & Stress at the bottom of box & Inside box (at the bottom) \\
\hline
\end{tabular}

\subsection{UNSATCON}

Detailed procedure on modelling with UNSATCON software is shown in this sub-section using phase II experimental conditions with a total run time of 200 days (Figures 3.19 to 3.25). The UNSATCON user is required to input four categories of variables namely, deposition scheme, materials, numerical parameters, and boundary conditions. 


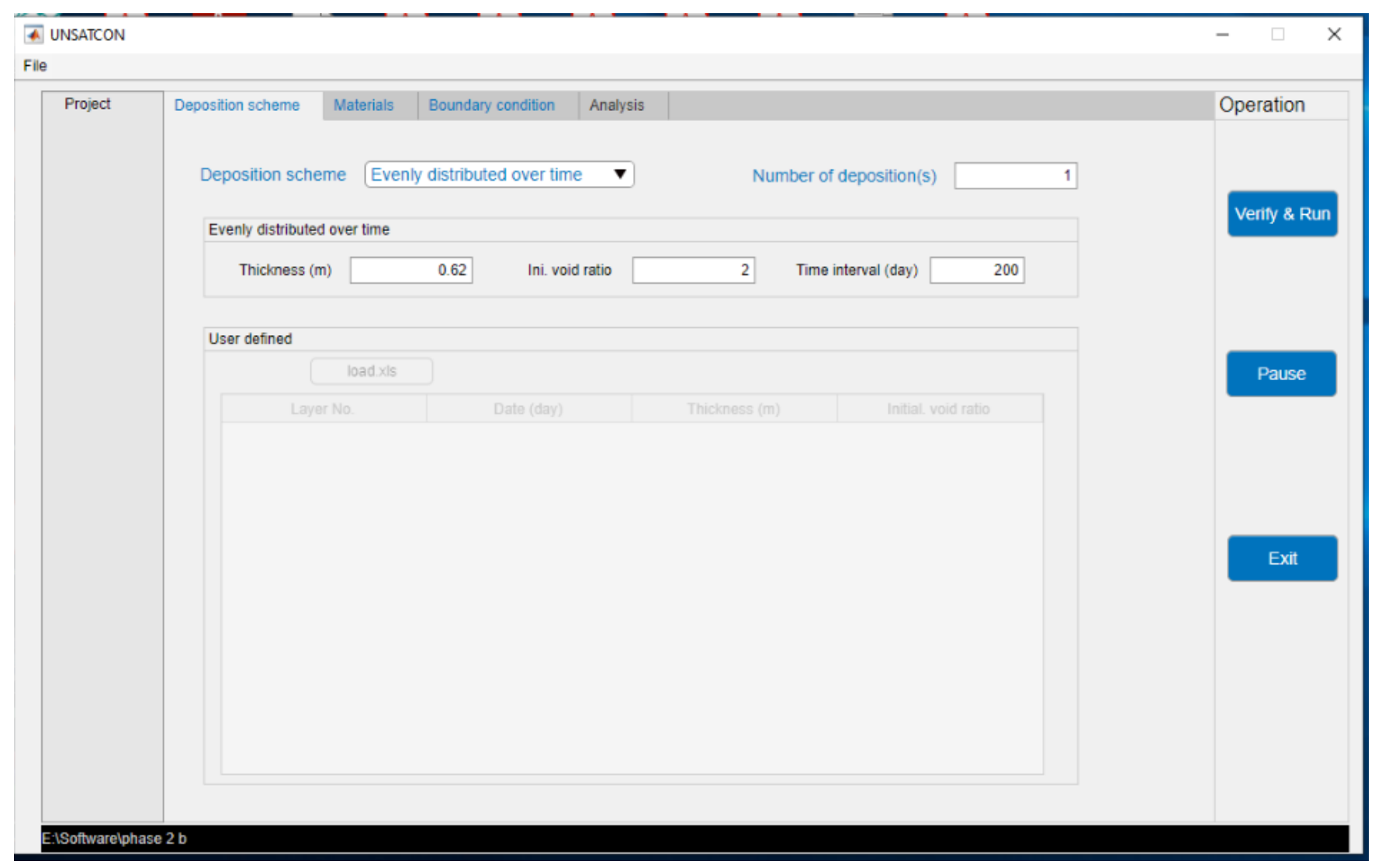

Figure 3.19. Screenshot of the deposition scheme window in UNSATCON.

The deposition scheme inputs entail defining the thickness of the deposited sample, number of deposition(s), initial void ratio and time interval between depositions (Figure 3.19). The user can choose from distributed over time option (homogenous material properties) or user defined option (heterogenous material properties i.e. multi-layer deposition for layers having varying void ratios, thickness, and deposition time) (Figure 3.29). Evenly distributed over time option was chosen in the UNSATCON model done in this study. 


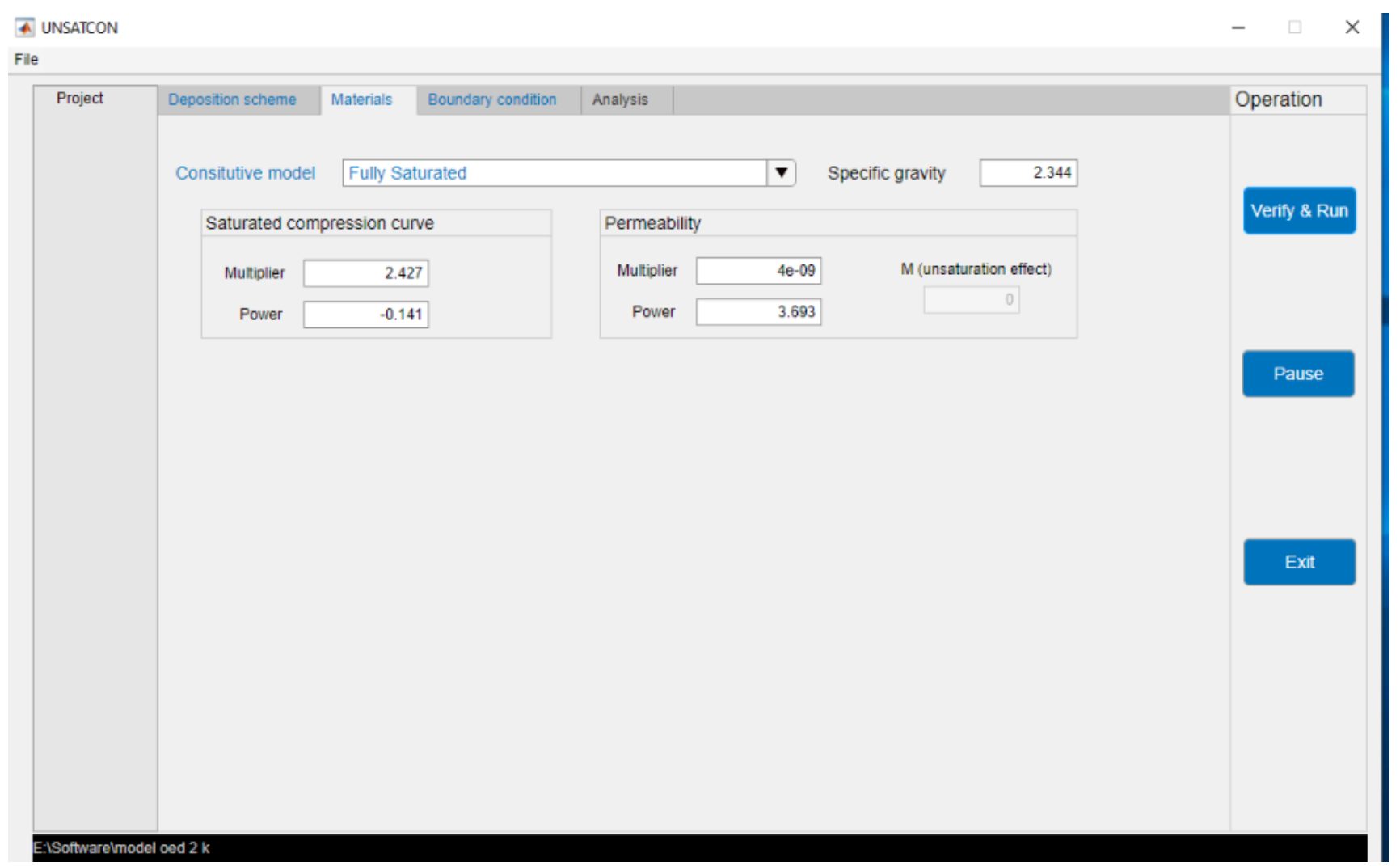

Figure 3.20. Materials window in UNSATCON.

The material category focuses on the compressibility and hydraulic conductivity - void ratio relationships (constitutive relationships) of the material used as well as the specific gravity of the material (Figure 3.20). These properties include specific gravity, empirical constants from fitting compressibility and hydraulic conductivity - void ratio curves. Depending on the analysis being done the user inputs the constitutive model to use (fully saturated, State surface model, Glasgow coupled model). Both phases were modeled under the assumption of fully saturated conditions. 


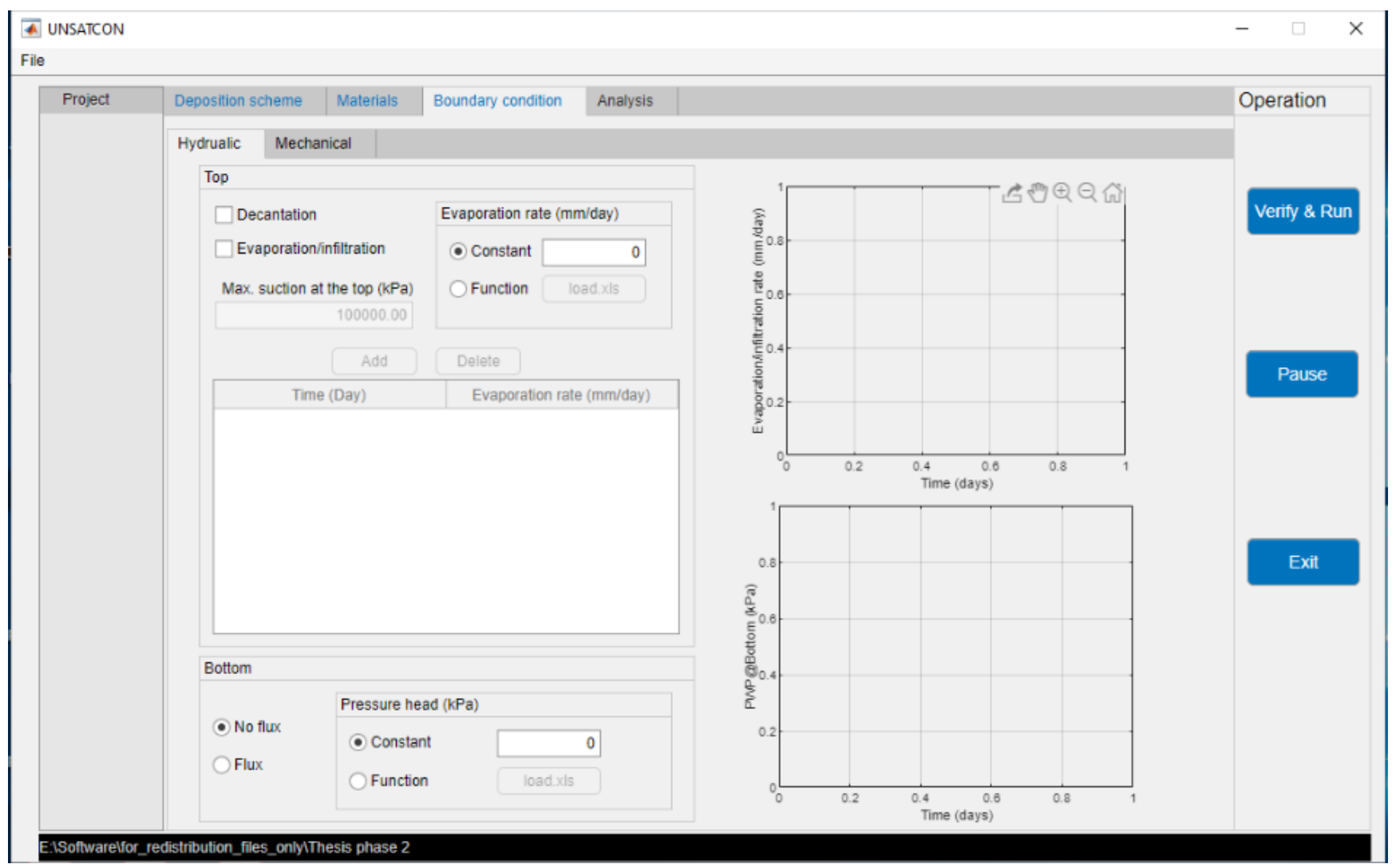

Figure 3.21. Hydraulic - boundary condition window in UNSATCON.

Boundary conditions are required from the user to define the constraints of the experiment. Evaporation rate, decantation and bottom flux rate are some of the hydraulic property to be defined in this window (Figures 3.21). Due to saturated conditions and no drainage out of the box of this experiment all three parameters were set to zero. 


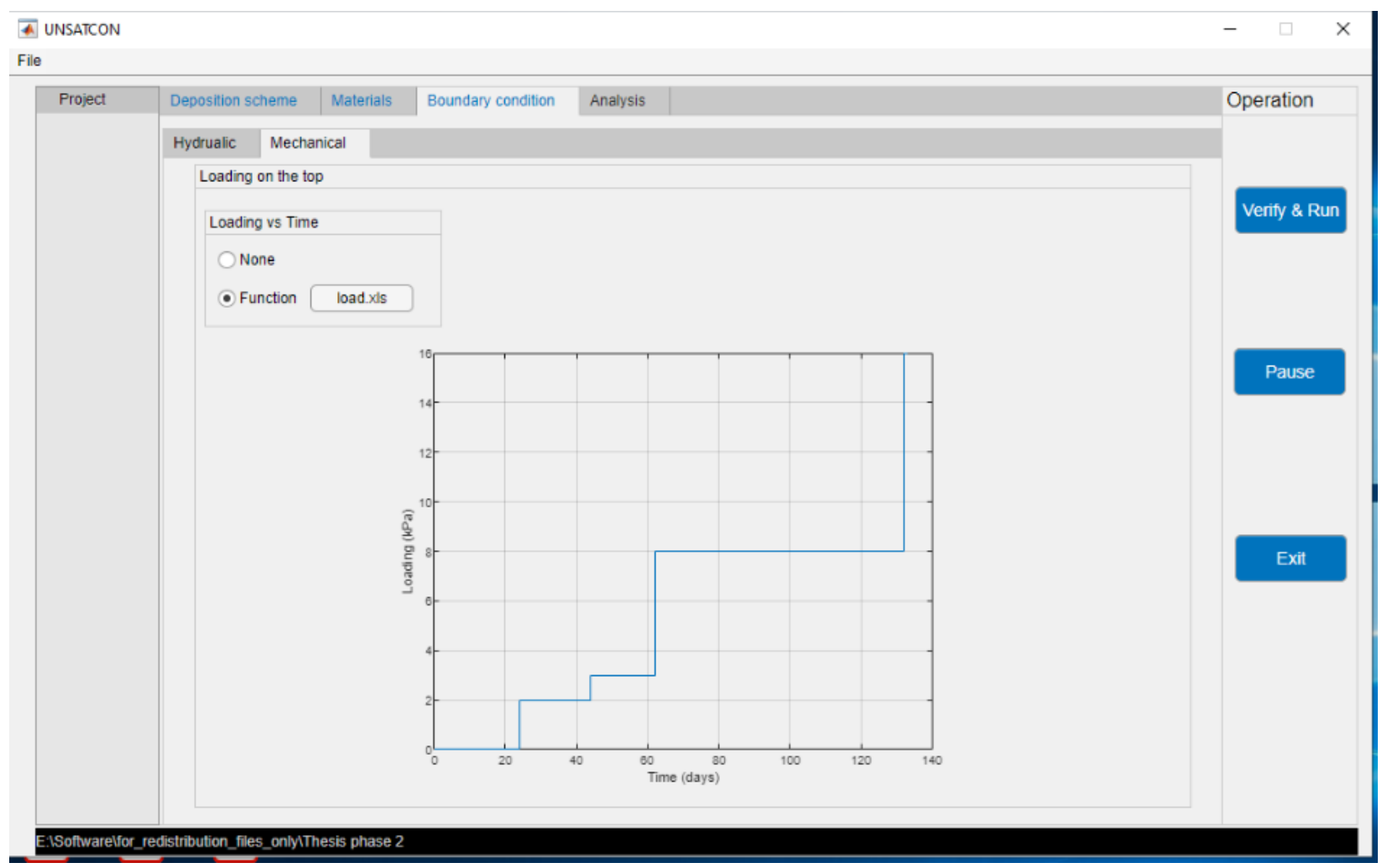

Figure 3.22. Mechanical - boundary condition window in UNSATCON.

The loading rate input is the other input required in the boundary condition window (Figure 3.22). The user uploads an excel file containing details on the load applied ( $\mathrm{kPa}$ ) and the time of application (day). For this study, the phase I had no loads applied while phase II had 2,3, 8 and $16 \mathrm{kPa}$ loads applied. 


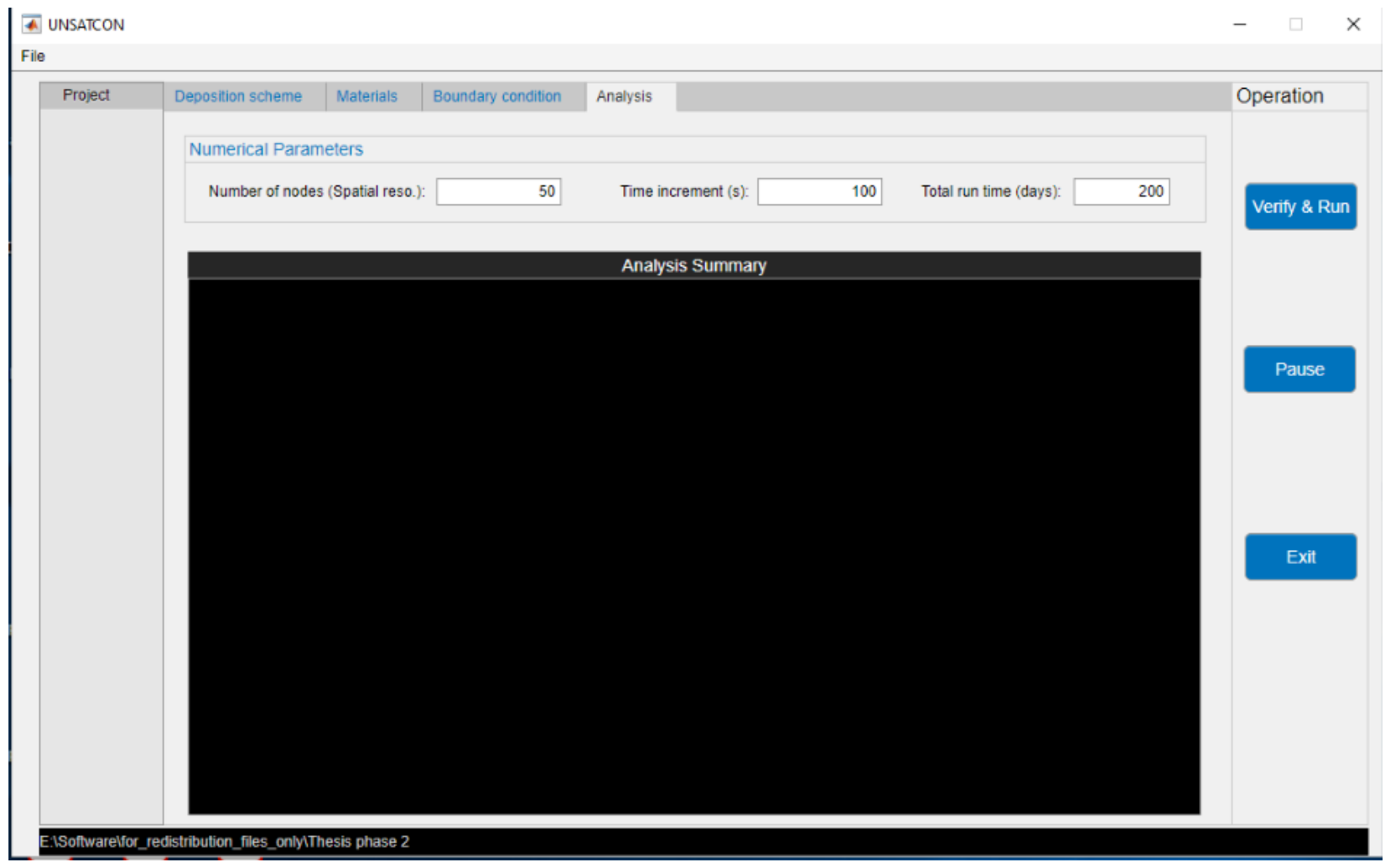

Figure 3.23. Numerical parameter window in UNSATCON.

Spatial nodes (number of elements) and time steps needed for a numerical solution as well as analysis run time are requested from the user in the numerical parameter category (Figure 3.23). 


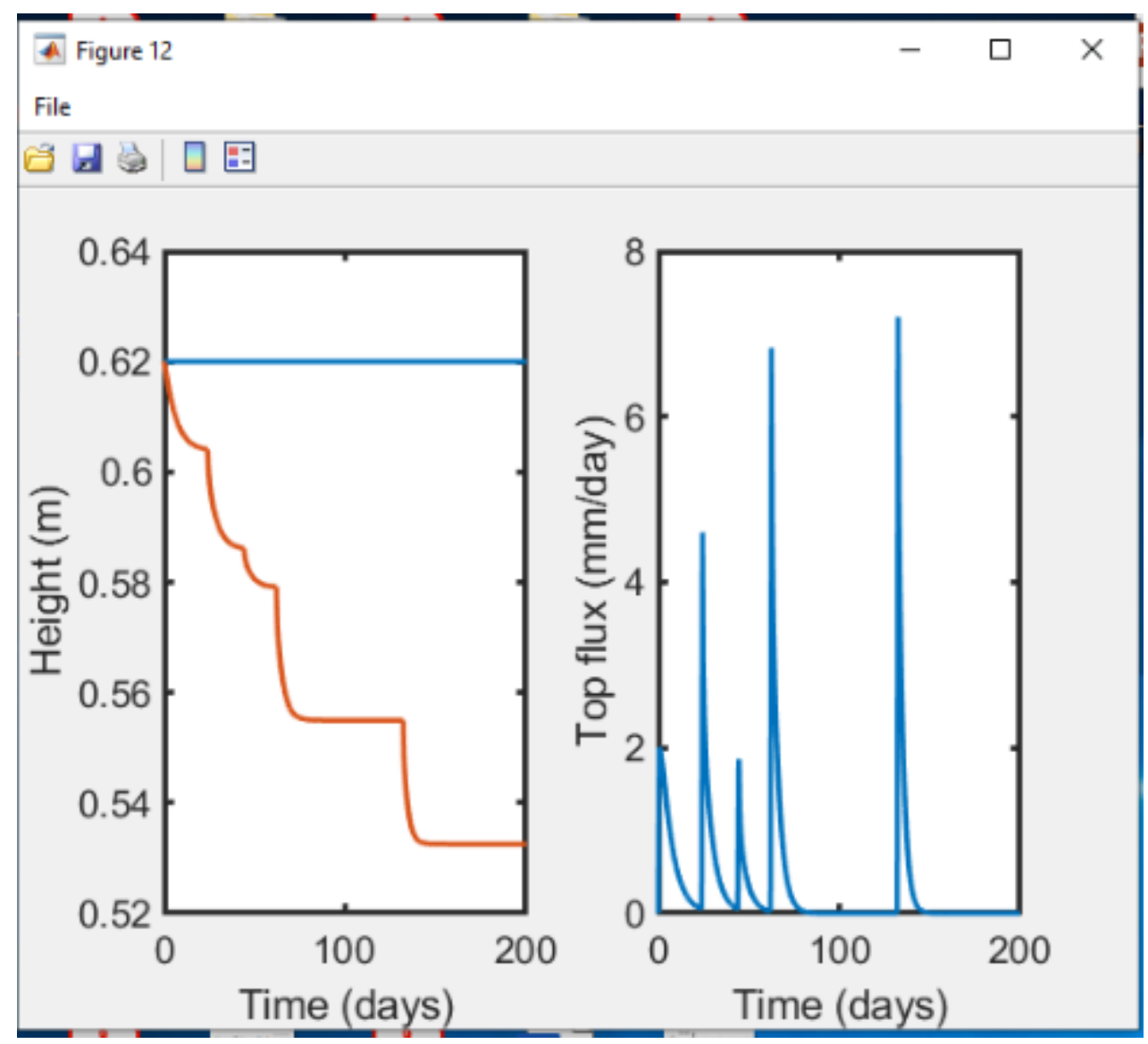

Figure 3.24. Overall settlement versus time plot generated by UNSATCON for steel box using oedometer calculated hydraulic conductivity.

The user has the option of plotting and visualizing the results when the runtime is over with the settlement vs time plot and elevation vs void ratio some of the plot generated by request at the end of the analysis (Figure 3.24 and 3.25). The output generated by the software are stored in a predetermined folder when the runtime is over. 

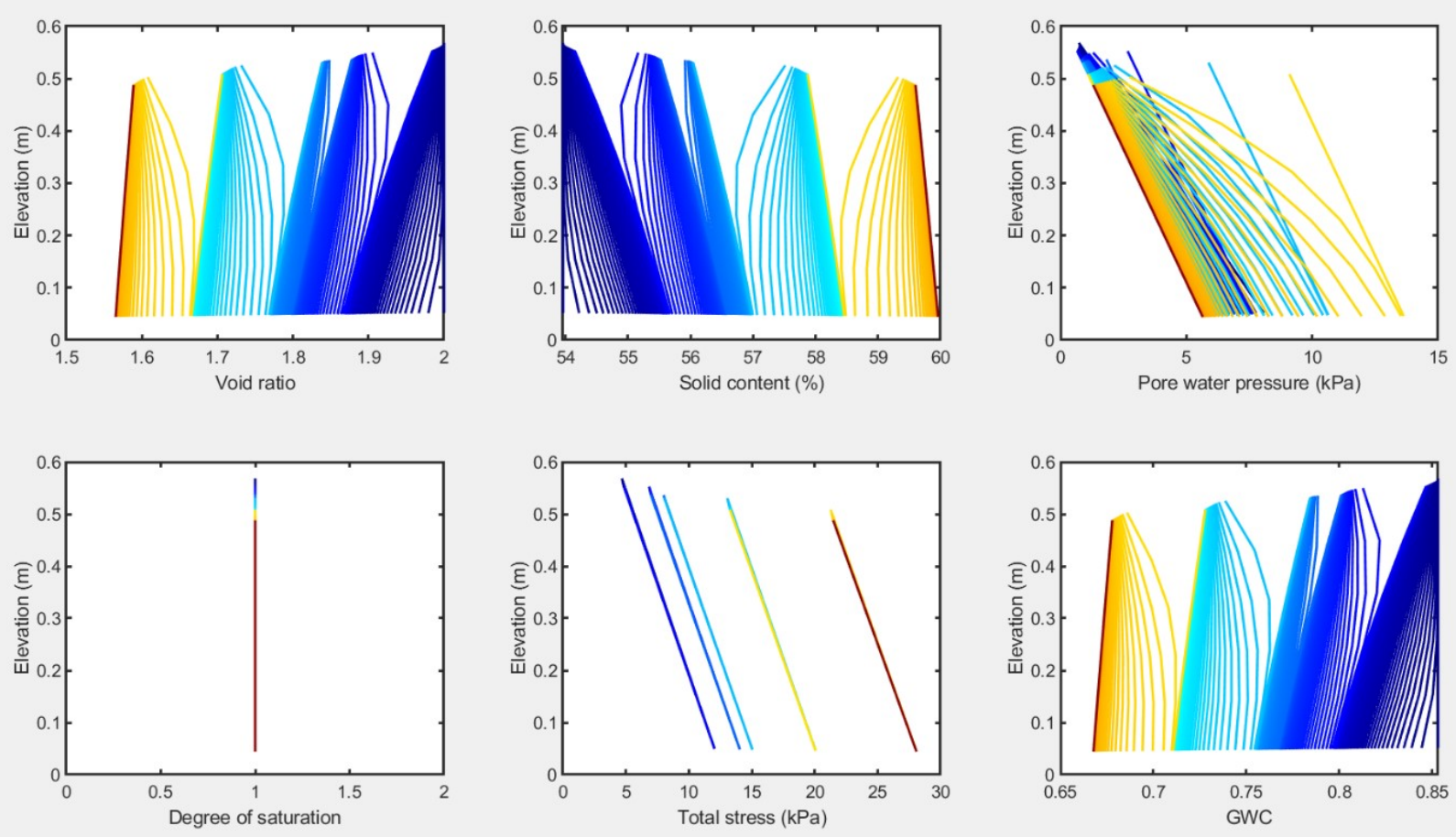

Figure 3.25. Overall results from UNSATCON with plotted geotechnical properties for steel box using oedometer calculated hydraulic conductivity. 


\section{Chapter 4 : Results (Phase I)}

\subsection{Phase I (0.10 $\mathrm{m}$ column) results}

After mixing of tailings for 2 weeks, tailings were deposited in the $0.075 \mathrm{~m}$ diameter columns (twenty-three) on the March 26 ${ }^{\text {th }}, 2019$ using a plastic cup until a layer of $0.10 \mathrm{~m}$ thickness was achieved. The initial average gravimetric water content was $106 \%$ by wt ( $48 \%$ solids content). Additional details on the deposition can be found in the Appendix B.

\subsubsection{Pore-water pressure and water content}

Table 4-1 shows the amount of settlement in both columns is negligible after 67 days ( $30^{\text {th }}$ May) and 126 days ( $30^{\text {th }}$ July). The first and second replicate columns had a settlement of less than $0.01 \mathrm{~m}$ after 67 days. By 127 days, the settlement was still same as 67 days for both replicate columns.

Table 4-1: Height of tailings in the two replicates columns with tensiometers at the beginning of deposition, 65 days after deposition and 126 days after deposition.

\begin{tabular}{|l|l|l|l|l|}
\hline Tensiometer \# & Day & Date & $\begin{array}{l}\text { Height to } \\
\text { water from } \\
\text { top of } \\
\text { column (m) }\end{array}$ & $\begin{array}{l}\text { Height to } \\
\text { Tailings } \\
\text { from top of } \\
\text { column (m) }\end{array}$ \\
\hline 1 (T5) & 1 & $26-$ Mar-19 & 0.05 & 0.05 \\
\hline $2(\mathrm{T7})$ & & & 0.04 & 0.04 \\
\hline & & & & \\
\hline $1(\mathrm{~T} 5)$ & 65 & $30-$ May-19 & 0.05 & 0.05 \\
\hline $2(\mathrm{T7})$ & & & 0.04 & 0.04 \\
\hline & & & & \\
\hline $1(\mathrm{~T} 5)$ & 126 & $30-\mathrm{Jul}-19$ & 0.05 & 0.5 \\
\hline $2(\mathrm{~T} 7)$ & & & 0.04 & 0.05 \\
\hline & & & & \\
\hline
\end{tabular}

For both replicate columns with tensiometers, there was an initial sharp decrease in pore-water pressure and gradual decrease over time (Figures 4.1 and 4.2). At day 8 the pore water pressure for both tensiometers was $9.65(\mathrm{hPa})$ and decreased to $8.13(\mathrm{hPa})$ by day 41 . This gradual 
decrease continued until day 99 when the pore water pressure measured 6.4 (hPa) and 5.8 (hPa) for replicate 1 and 2 respectively (hydrostatic pressure values).

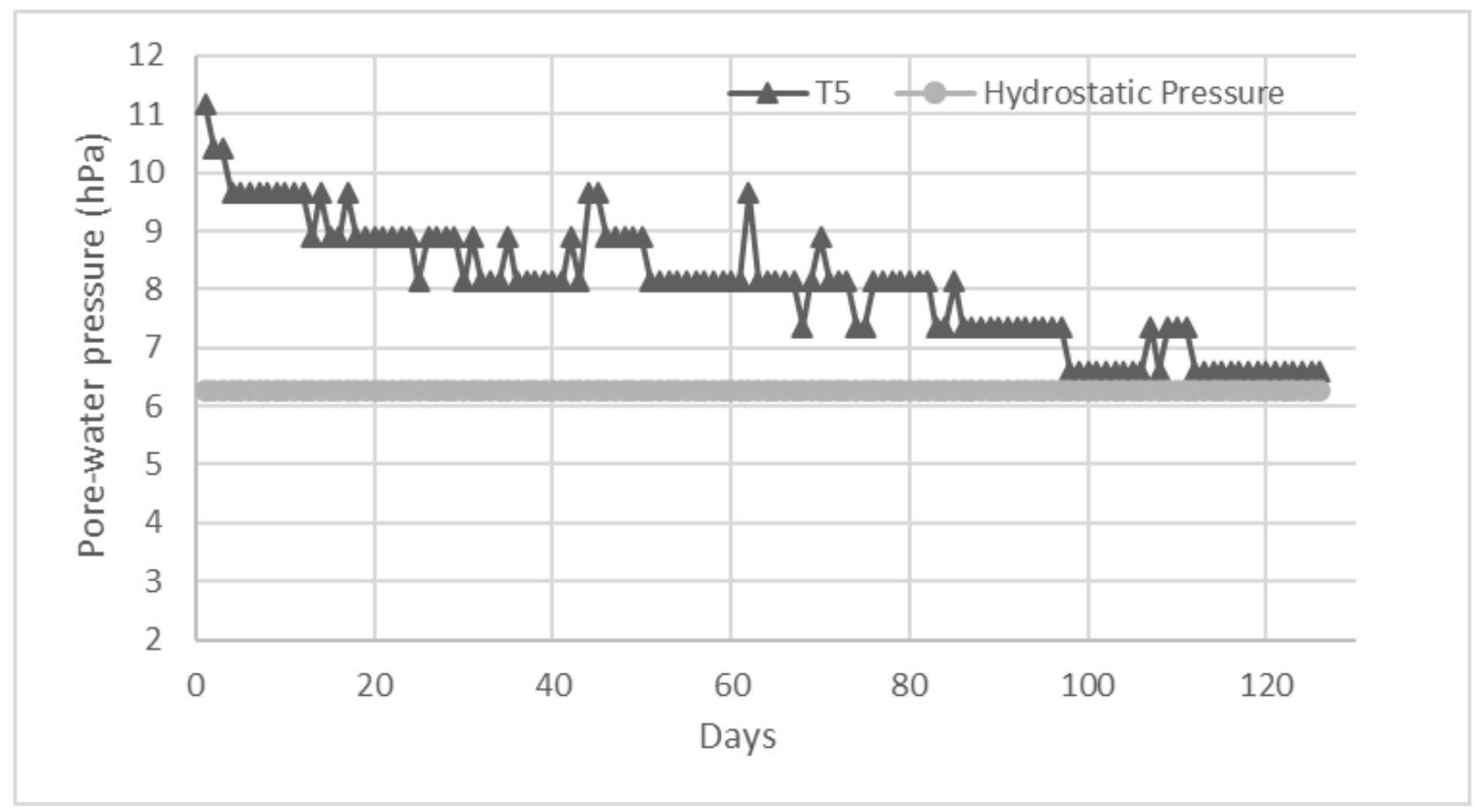

Figure 4.1. Pore-water pressure (hPa) at $0.064 \mathrm{~m}(\mathrm{T5})$ depth from the top of the tailings at room temperature. 


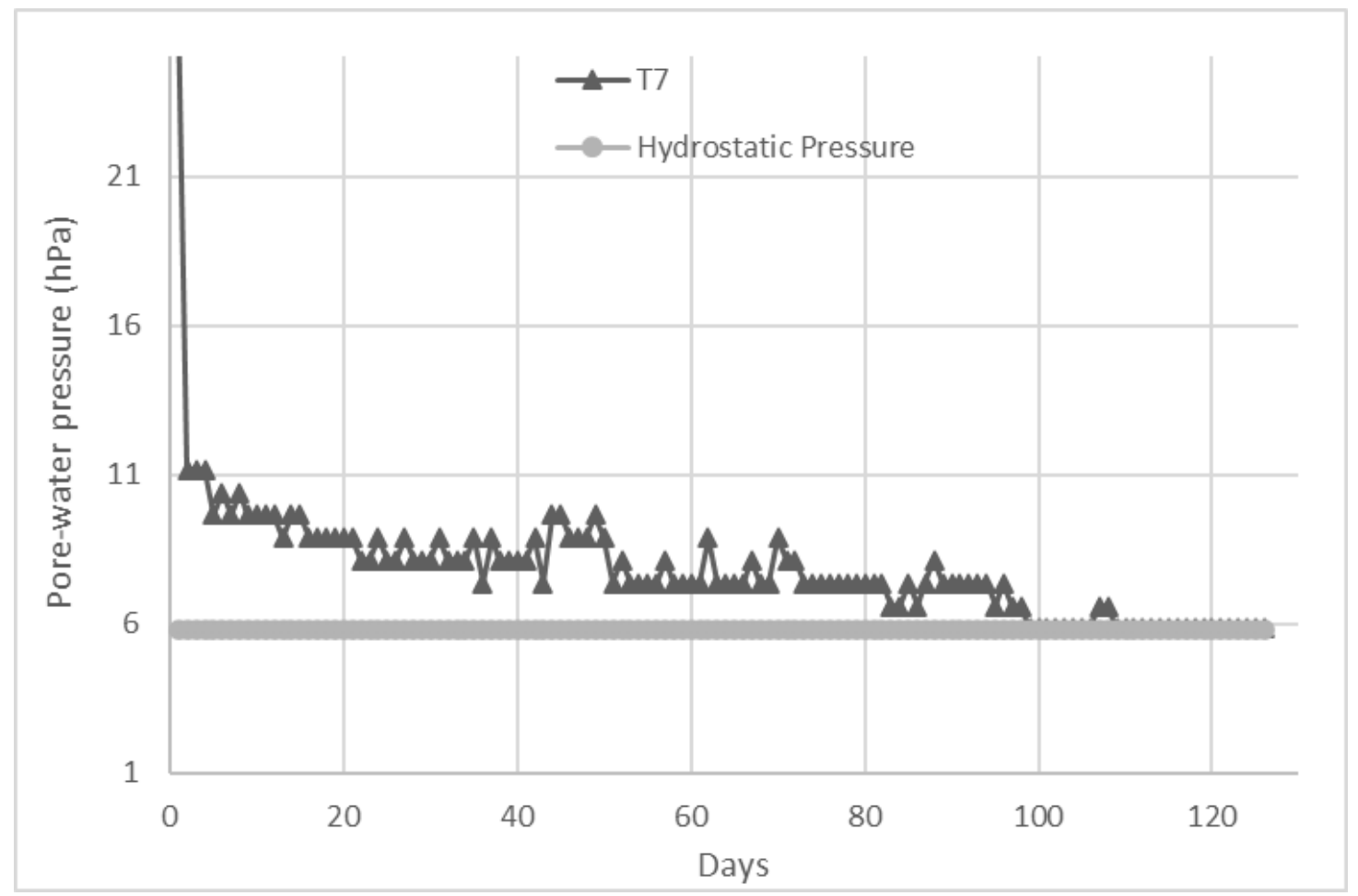

Figure 4.2. Pore-water pressure (hPa) at $0.056 \mathrm{~m}(\mathrm{~T} 5)$ depth from the top of the tailings at room temperature.

The water content in the replicate columns saw the most significant changes in the bottom half occur within the first 42 days thereafter deformation occurred in the top half of the column (Figure 4.3). This seems to correlate with the pore-water pressure measurements where most of the pore-water pressure (Figure 4.2 ) equilibrated by 42 days. 


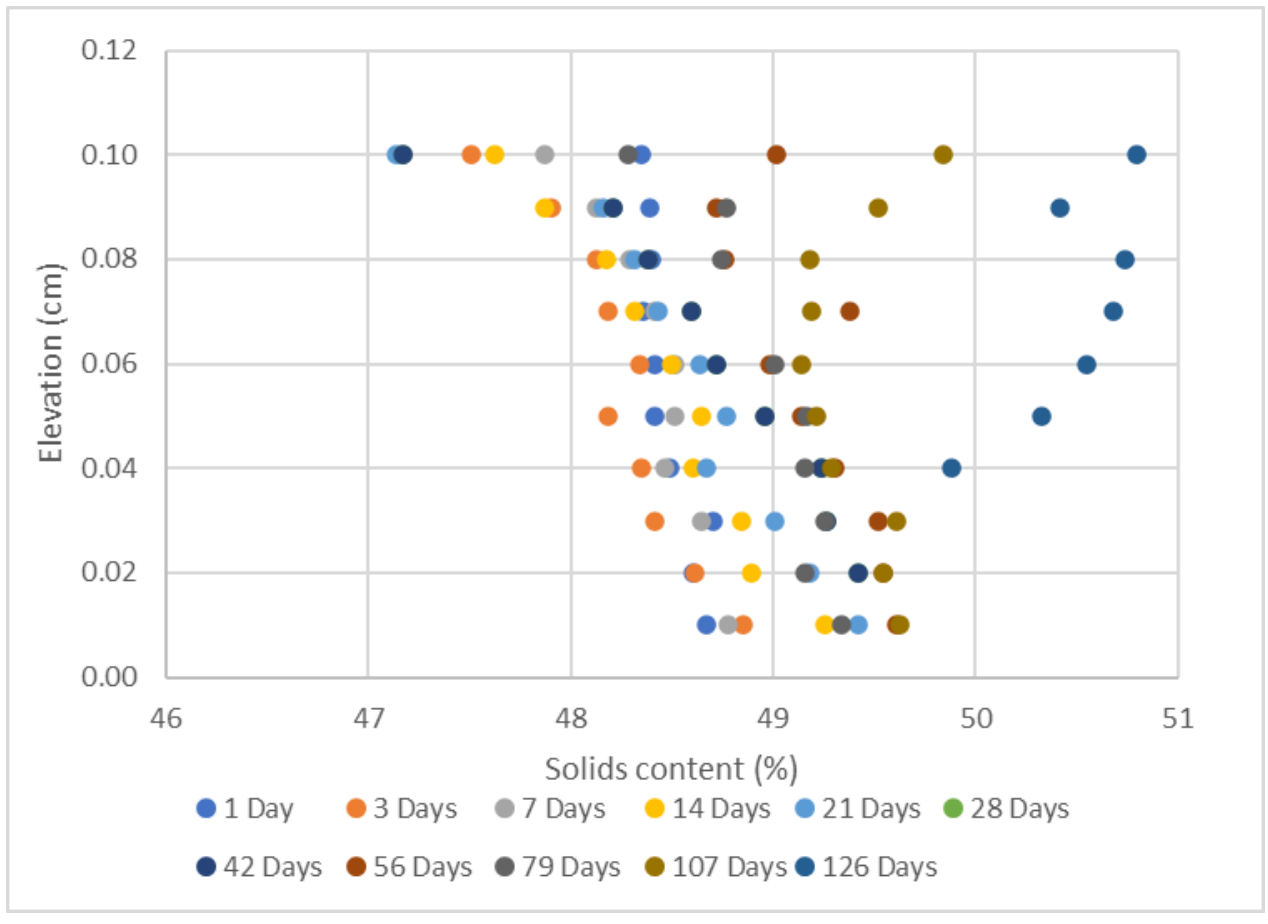

Figure 4.3. Depth profile of water content in the replicate columns.

\subsubsection{Fall cone and oedometer tests}

Figure 4.4 shows an increase in strength with sample age in both the fall cones and replicate columns. This strength gains may be due to a variety of reasons ranging from changes in density as the sample dewaters with time to structuration occurring in the microstructure of the sample. Changes in water content between days 42 and 126 determined by processing columns at different days were negligible whereas the magnitude of the strength increase within that period was greater than $2 \mathrm{kPa}$. This shows that although change in density might be contributing to the increasing strength in the sample, structuration effect is also a mechanism contributing to this behavior. 


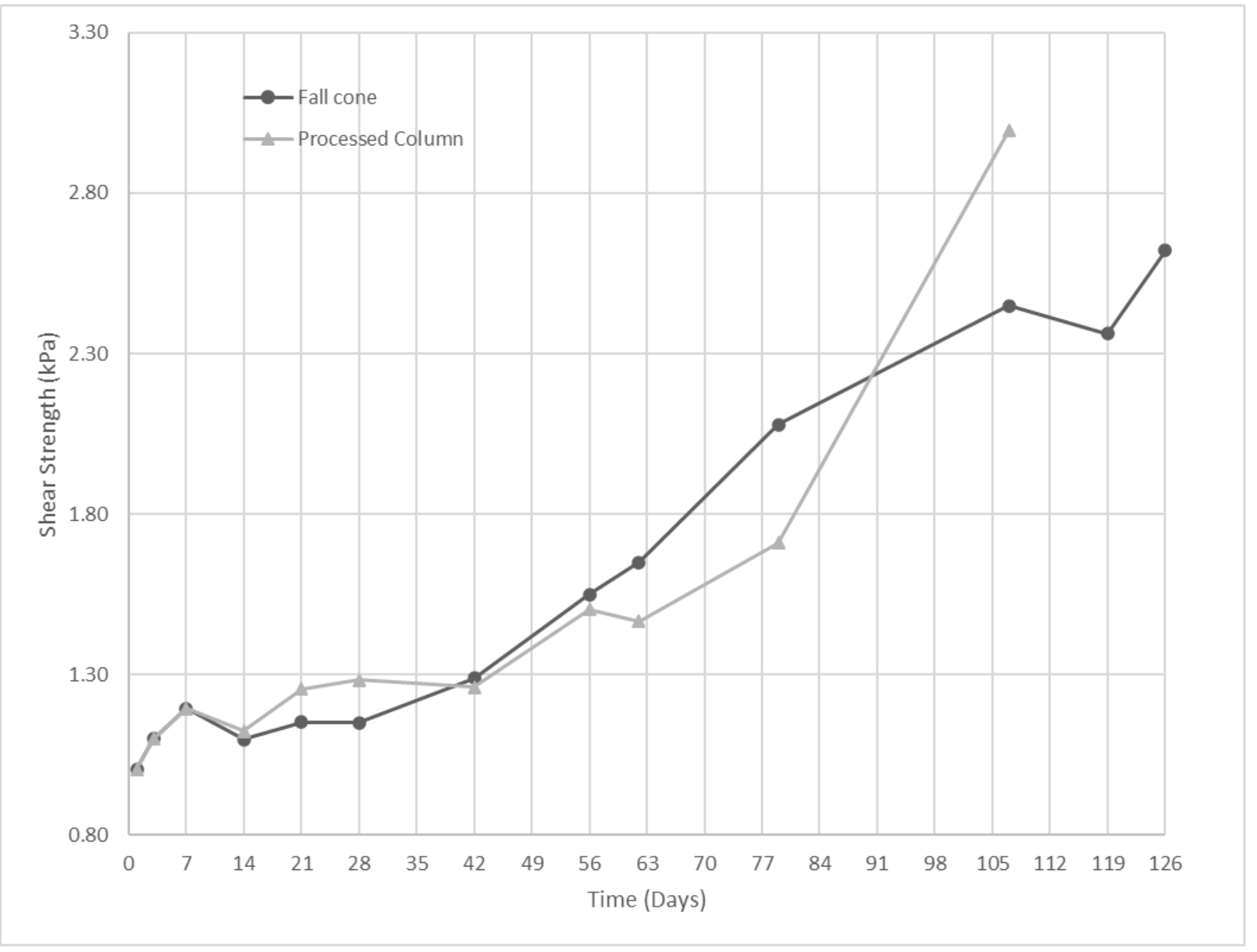

Figure 4.4. Undrained shear strength of the three-fall cone and the water content replicate columns over recorded over different days.

Strength increased significantly after day 42 ( $2 \mathrm{kPa}$ ) compared to between days 0 and $42(0.3$ $\mathrm{kPa}$ ) (Figure 4.5). This period of significant increase coincides with the period after most of the changes in PWP (Figure 4.2) and water content (Figure 4.3) occurred. This suggests that structuration occurs after primary consolidation rate has reduced or at the end of primary consolidation. 


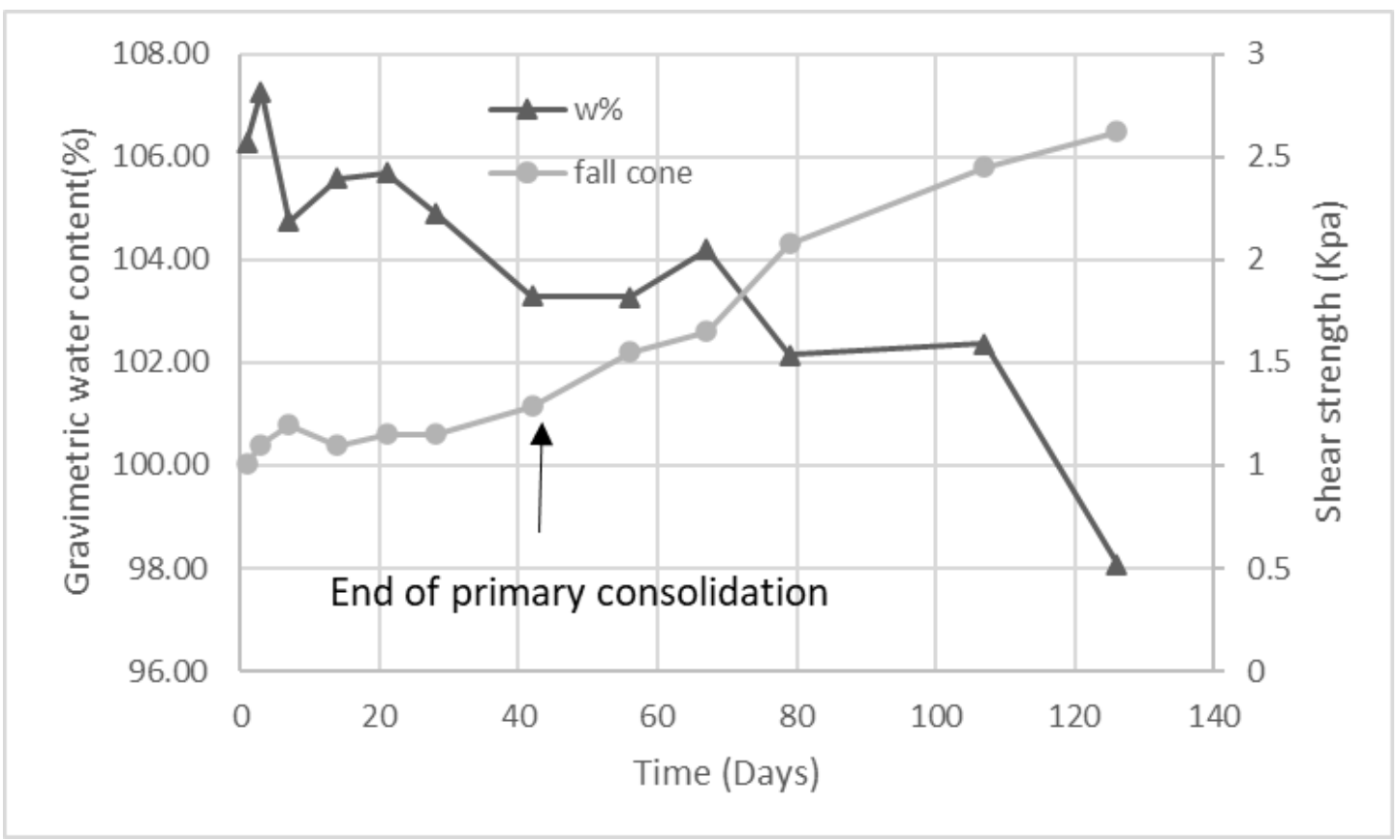

Figure 4.5. Water content over time in columns plotted with undrained shear strength development.

Table 4-2: Replicate column thixotropy strength gain

\begin{tabular}{|l|l|l|l|l|}
\hline Time (days) & $\begin{array}{l}\text { Strength at } \\
\text { time }(\mathrm{t})(\mathrm{kPa})\end{array}$ & $\begin{array}{l}\text { Strength at } \\
\text { disturbed/remolded } \\
\text { state }(\mathrm{kPa})\end{array}$ & $\begin{array}{l}\text { Thixotropic } \\
\text { strength gain }\left(\mathrm{A}_{\mathrm{t}}\right)\end{array}$ & $\begin{array}{l}\text { Average water } \\
\text { content }(\%)\end{array}$ \\
\hline 518 & 2.82 & 1 & 2.82 & 100 \\
\hline
\end{tabular}

Fall cone measurement conducted on an undisturbed replicate column at day 518 showed a strength of $2.82 \mathrm{kPa}$, after which the column was sheared at the same water content and an undrained shear strength was $1 \mathrm{kPa}$ was recorded (Table 4-2). This thixotropic strength gain of 2.82 indicates that the centrifuge cake gained strength (aged) over time and supports the idea that thixotropy is an aging mechanism in tailings.

For the oedometer test, samples were gotten from the bottom $0.04 \mathrm{~m}$ of the replicate columns since total and effective stress are maximum at the bottom of column. At the beginning i.e. day 0 , the initial void ratio of the sample was 2.91 which reduces at days $28,62,79$ and 126 (Table 4-3). This validates the assumption that void ratio decreases with time as sample dewaters. 
Table 4-3: Initial void ratios for remolded and undisturbed samples at different days.

\begin{tabular}{|l|l|l|}
\hline Day\{s) & $\begin{array}{l}\text { Remolded } \\
\text { sample initial void ratio }\end{array}$ & $\begin{array}{l}\text { Undisturbed } \\
\text { sample initial void ratio }\end{array}$ \\
\hline 0 & 2.92 & \\
\hline 28 & & \\
\hline & 2.76 & \\
\hline 62 & & 2.23 \\
\hline & 2.23 & \\
\hline 79 & & 2.18 \\
\hline & 2.12 & \\
\hline 126 & & 2.02 \\
\hline
\end{tabular}

For days 79 and 126, two samples (one sheared and the other undisturbed) were used in the oedometer test to investigate if the strength increase noticed in the fall cone measurement after 42 days (Figure 4.5) was linked to structuration (development of apparent preconsolidation pressure). Figure 4.6 shows the compressibility curves for days 79 and 126 indicating a development of preconsolidation pressure by both days.

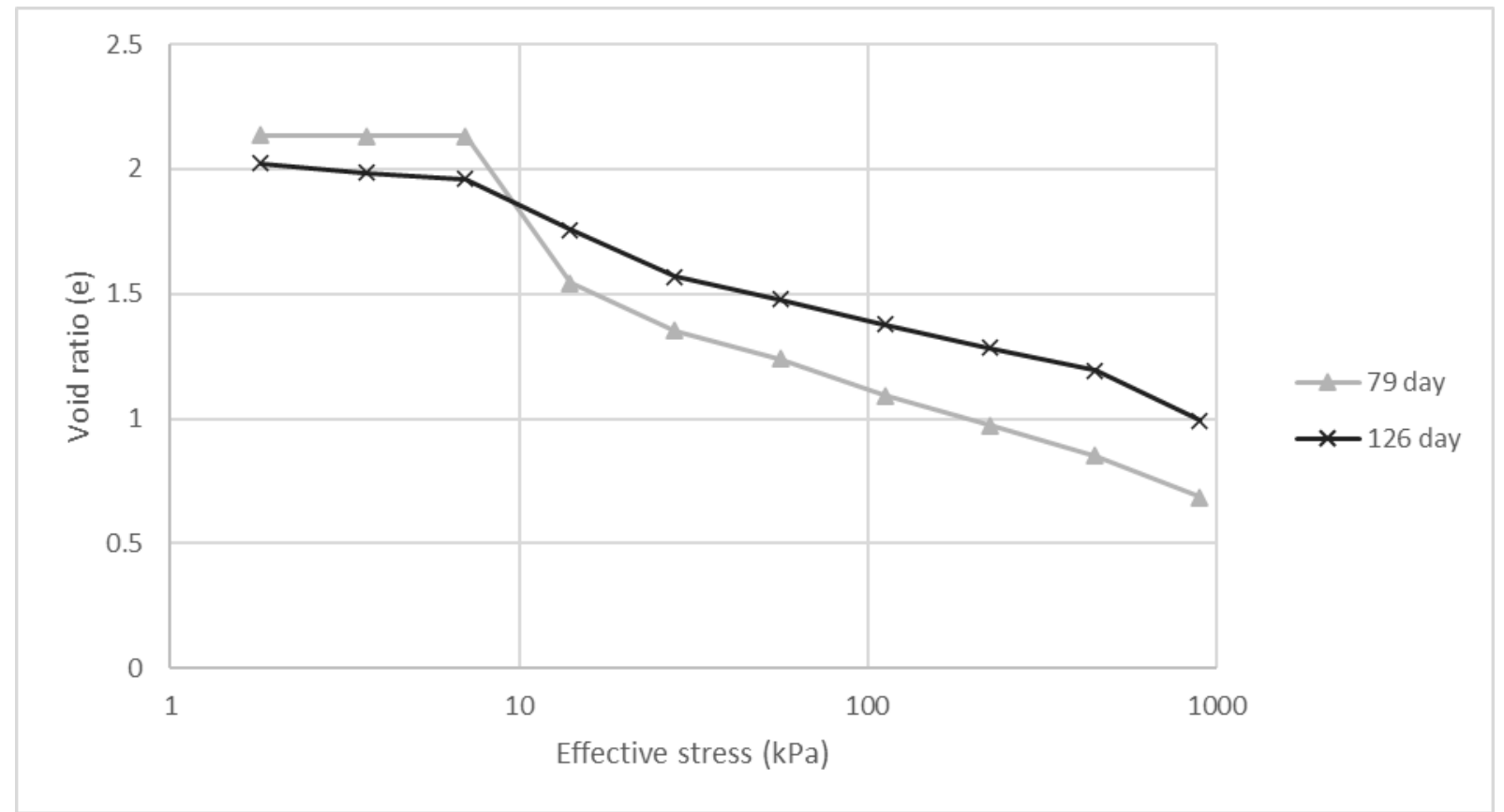

Figure 4.6. The compressibility curves for undisturbed column samples at 79 and 126 days. 
Plotting the creep rate/compression index ratio vs effective stress graph for days 79 and 126 (Figures 4.7 and 4.8) indicates that the maximum ratio (which indicates the preconsolidation pressure) occurred around $10 \mathrm{kPa}$ for both days. This correlates with the void ratio - effective stress graph (Figure 4.6) for both days where the preconsolidation pressure is approximately 10 $\mathrm{kPa}$.

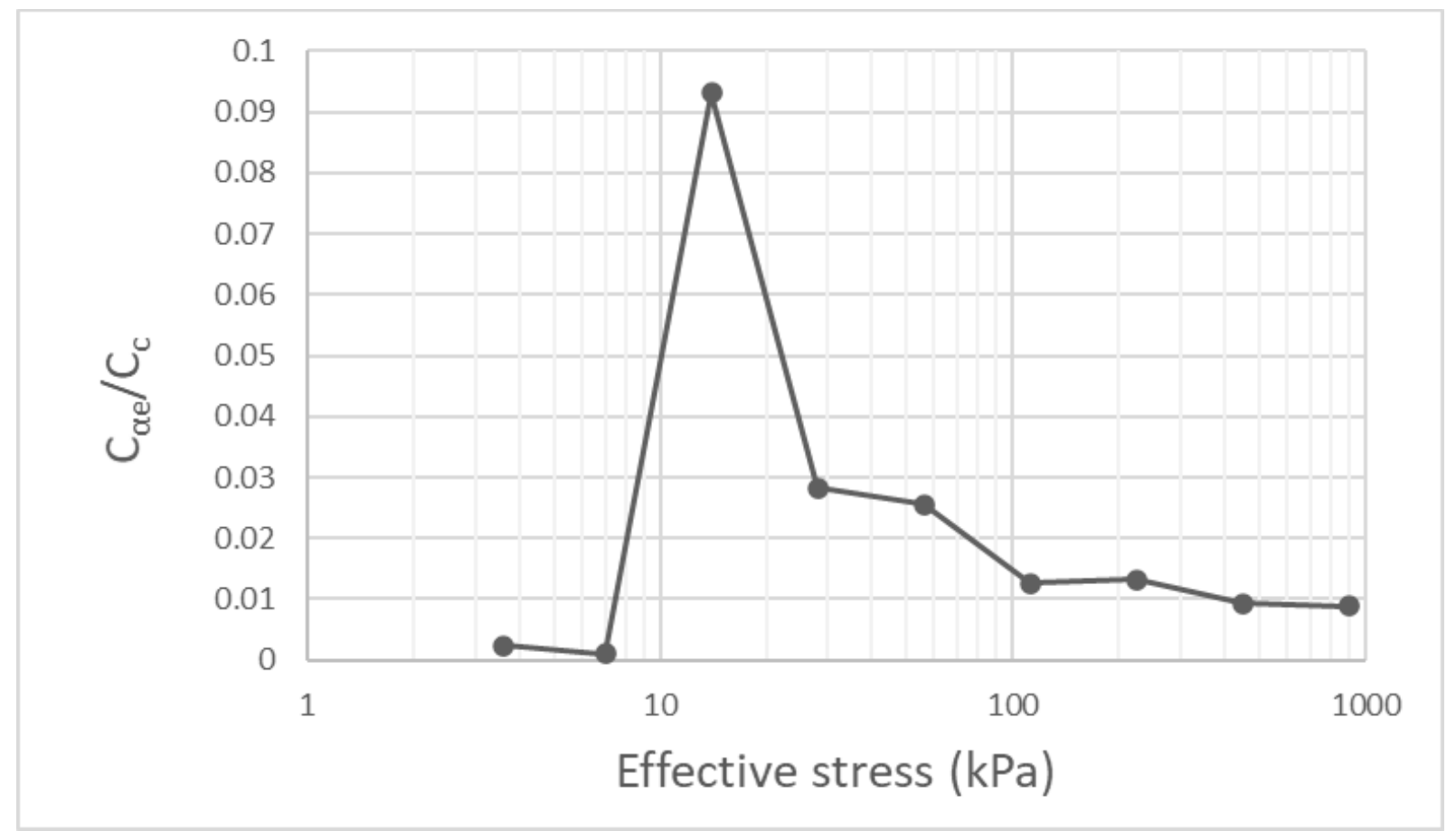

Figure 4.7. Plot of creep rate $\left(C_{\alpha e}\right)$ /compression index $\left(C_{c}\right)$ ratio for day 79. 


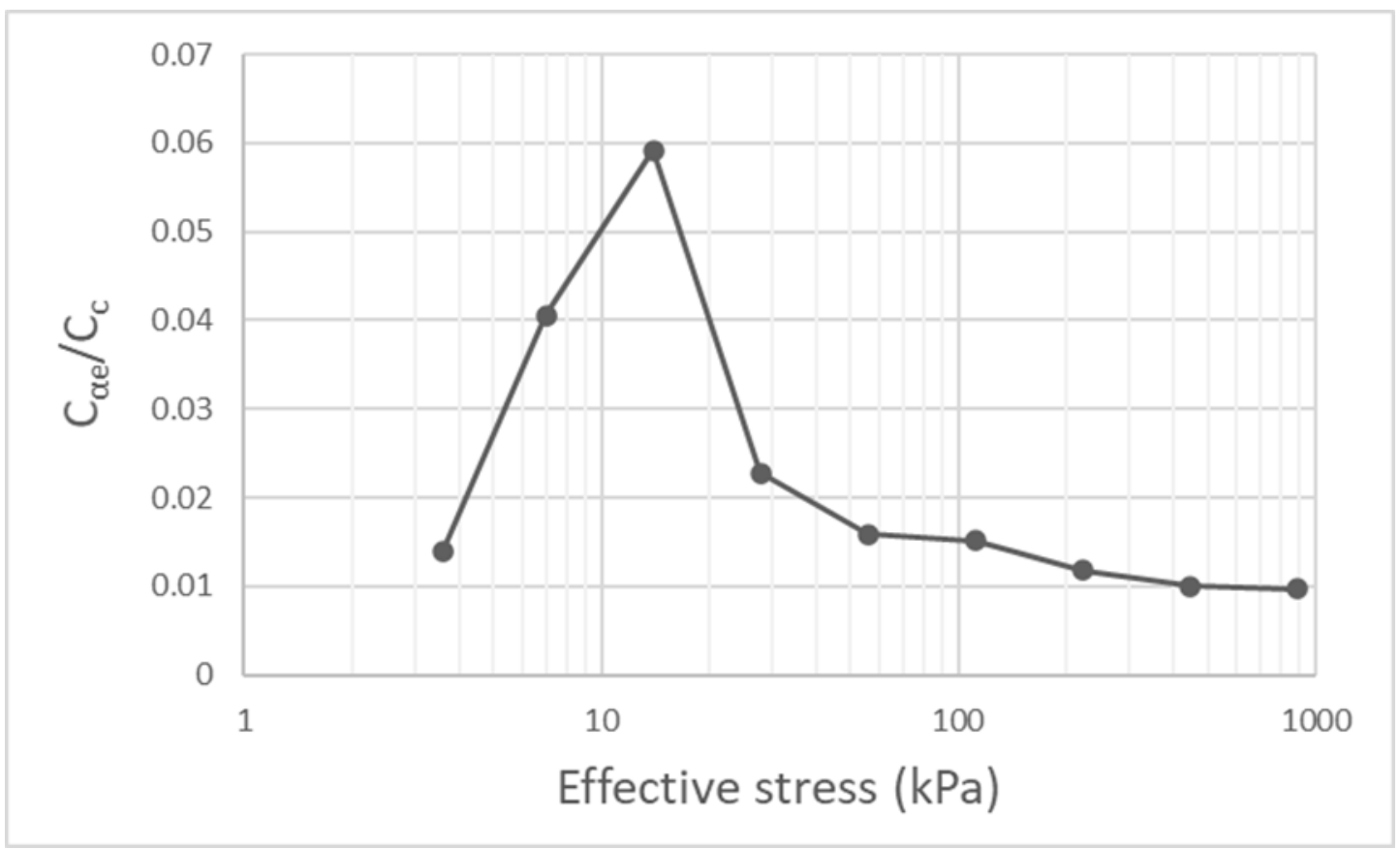

Figure 4.8. Plot of creep rate (Cae)/compression index (Cc) ratio for day 126.

Comparing the sheared and undisturbed sample compressibility curves for day 79 shows the development of preconsolidation pressure in the undisturbed sample whereas the day 79 remolded sample (sheared) had none (Figure 4.9). This development of preconsolidation pressure confirmed in Figures 4.6, 4.7 and 4.9 indicate that structuration mechanism occurred in the centrifuge cake columns. 


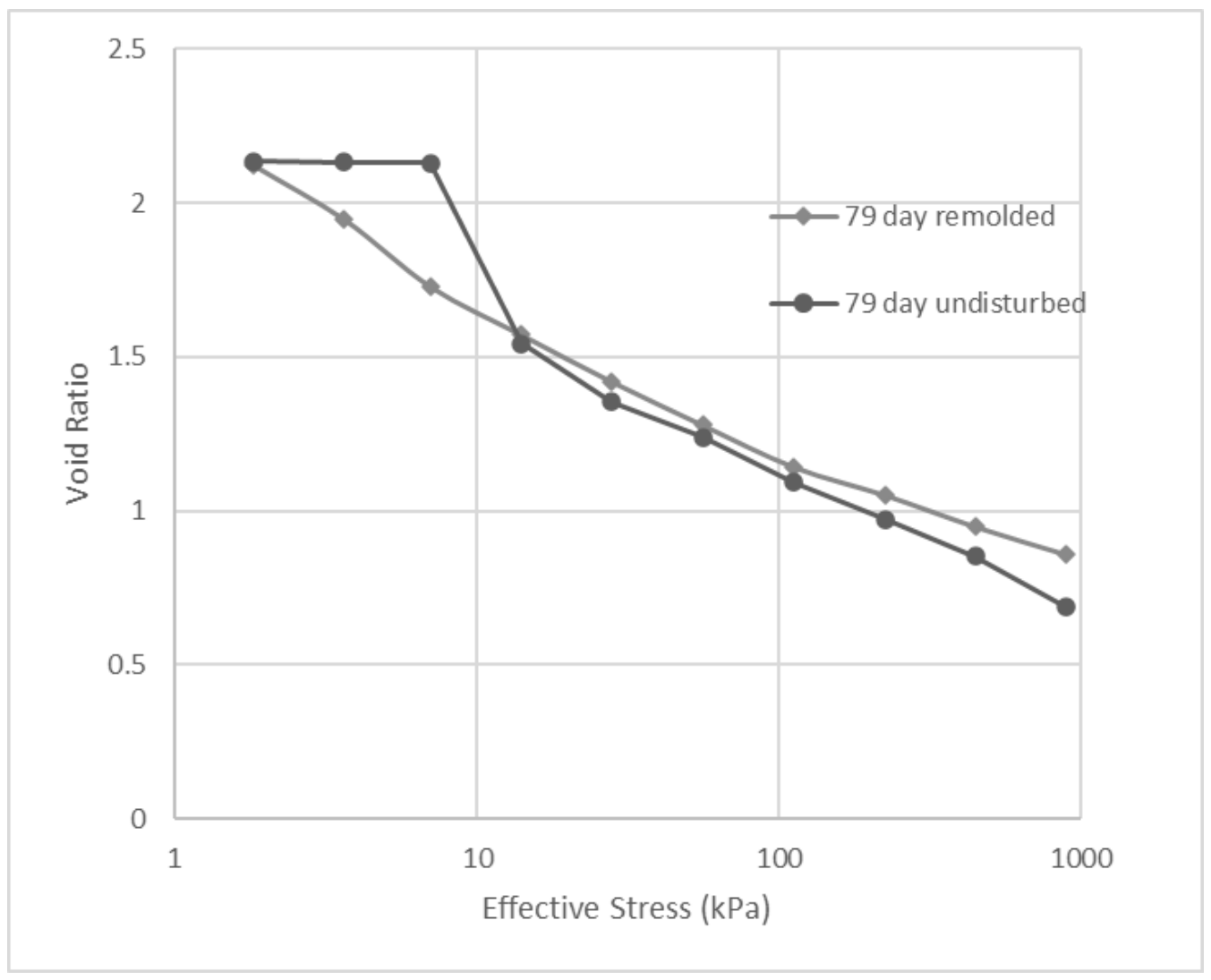

Figure 4.9 Change in compressibility curve in centrifuge cake tailings from replicate $0.10 \mathrm{~m}$ tall columns at day 79 .

For both the undisturbed samples and remolded samples the initial void ratio at the first loading step decreased with sample age (Figures 4.6 and 4.10). This observation was expected as void ratio decreases with time due to decrease in void space as water drain out of soil pores and can be linked to creep since this void ratio changes occurred at low effective stresses. 


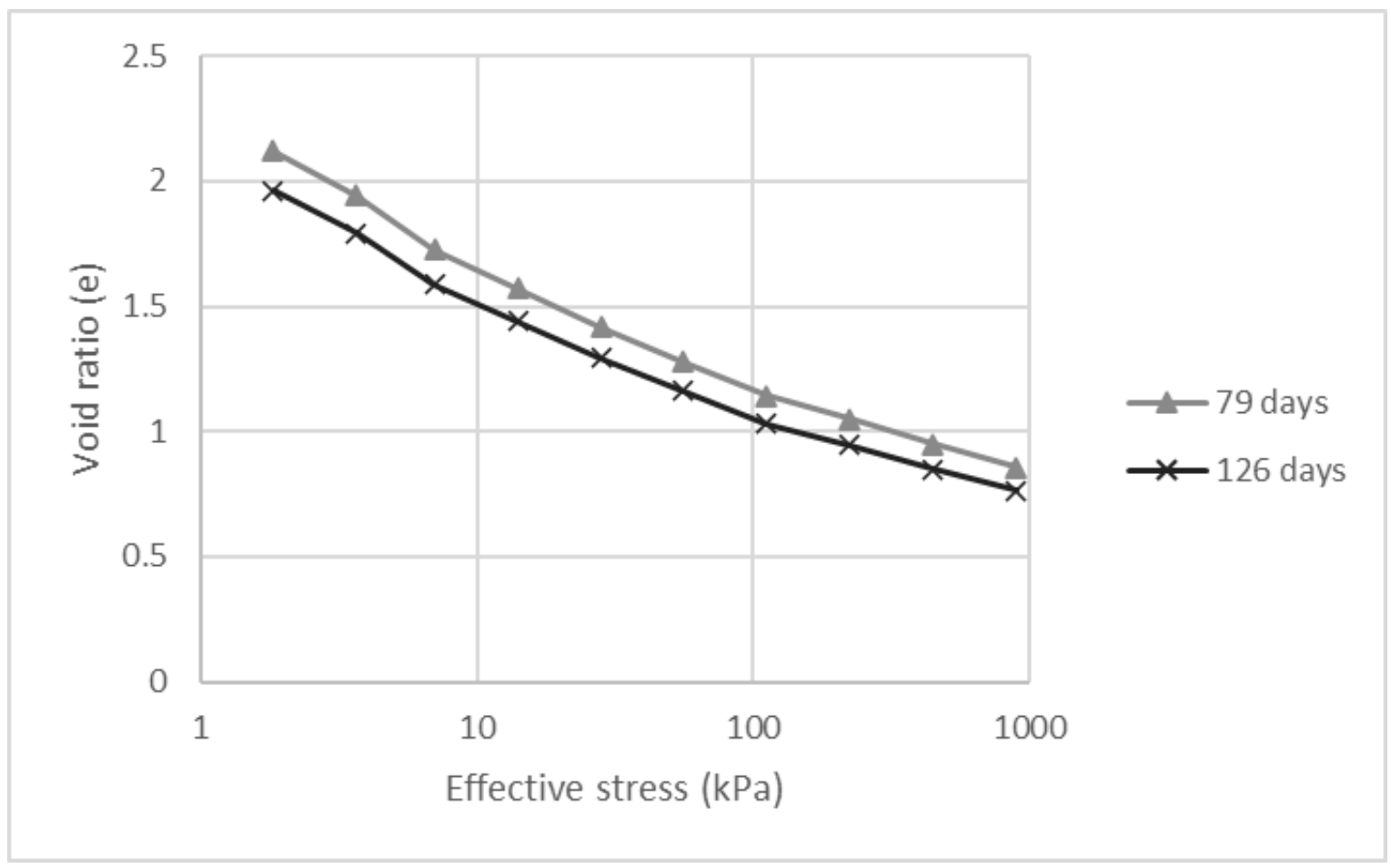

Figure 4.10. Comparing compressibility of remolded days 79 and 126 samples.

Figures 4.11 and 4.12 shows the maximum ratio of the creep coefficient/compression in the remolded days 79 and 126 samples occurred at the initial effective stress, followed by a steady decrease as effective stress increased. This observation was expected as days 79 and 126 remolded samples compressibility curves (Figure 46) showed no development of preconsolidation (Figure 4.10). 


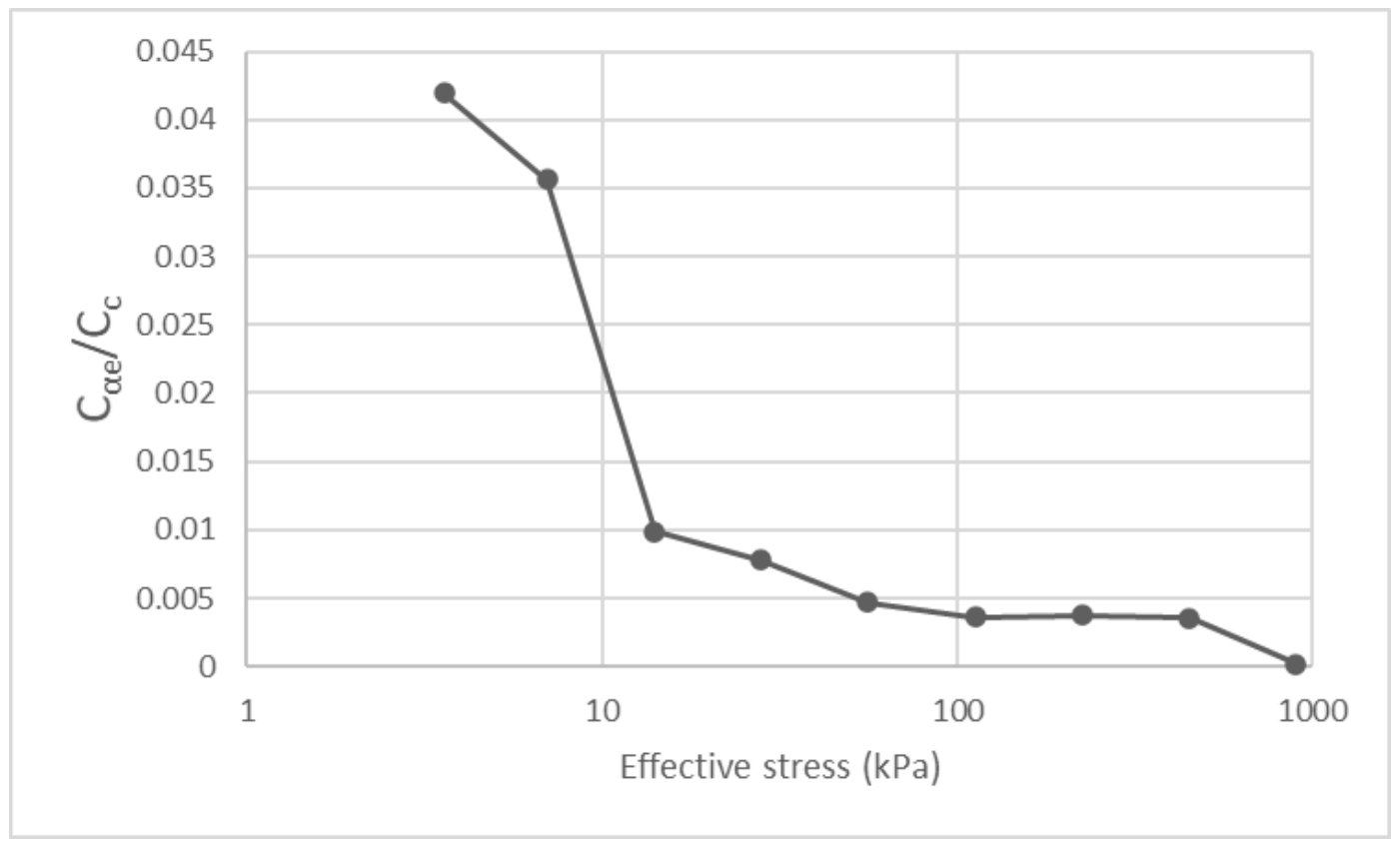

Figure 4.11. Plot of creep coefficient $\left(C_{\alpha}\right) /$ compression index ratio $\left(C_{c}\right)$ for remolded day 79

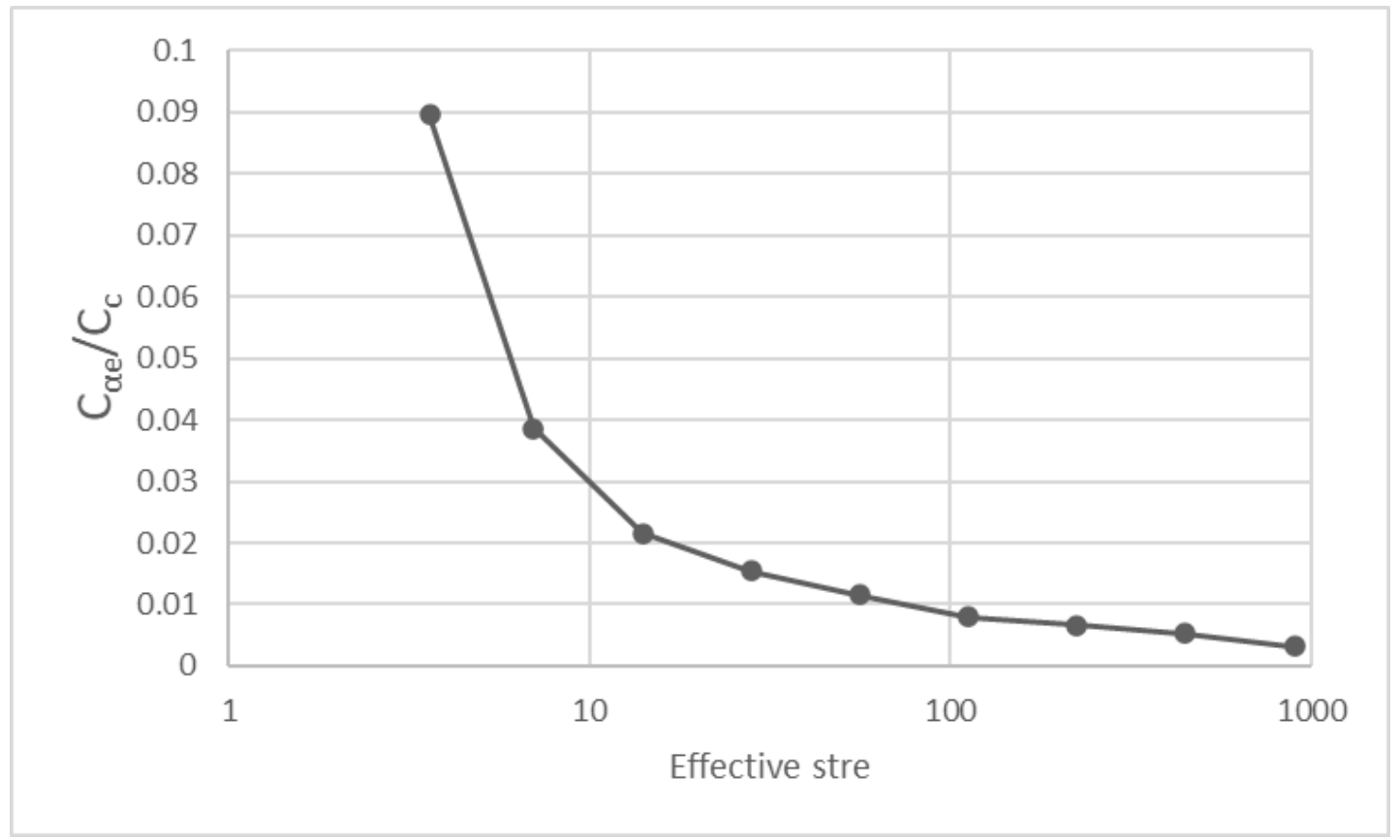

Figure 4.12. Plot of creep coefficient $\left(C_{\alpha}\right) /$ compression index $\left(C_{c}\right)$ ratio for remolded day 79

Comparing days 0 and 28 compressibility curves showed day 28 more stiffness (reduced volume change) for each load step when compared to day 0 (Figure 4.13). For example, the load 
increment from $55 \mathrm{kPa}$ to $110 \mathrm{kPa}$ showed day 0 had a lower decrease in voids when compared to day 28. This stiffness can be linked to aging effects in the centrifuge cake.

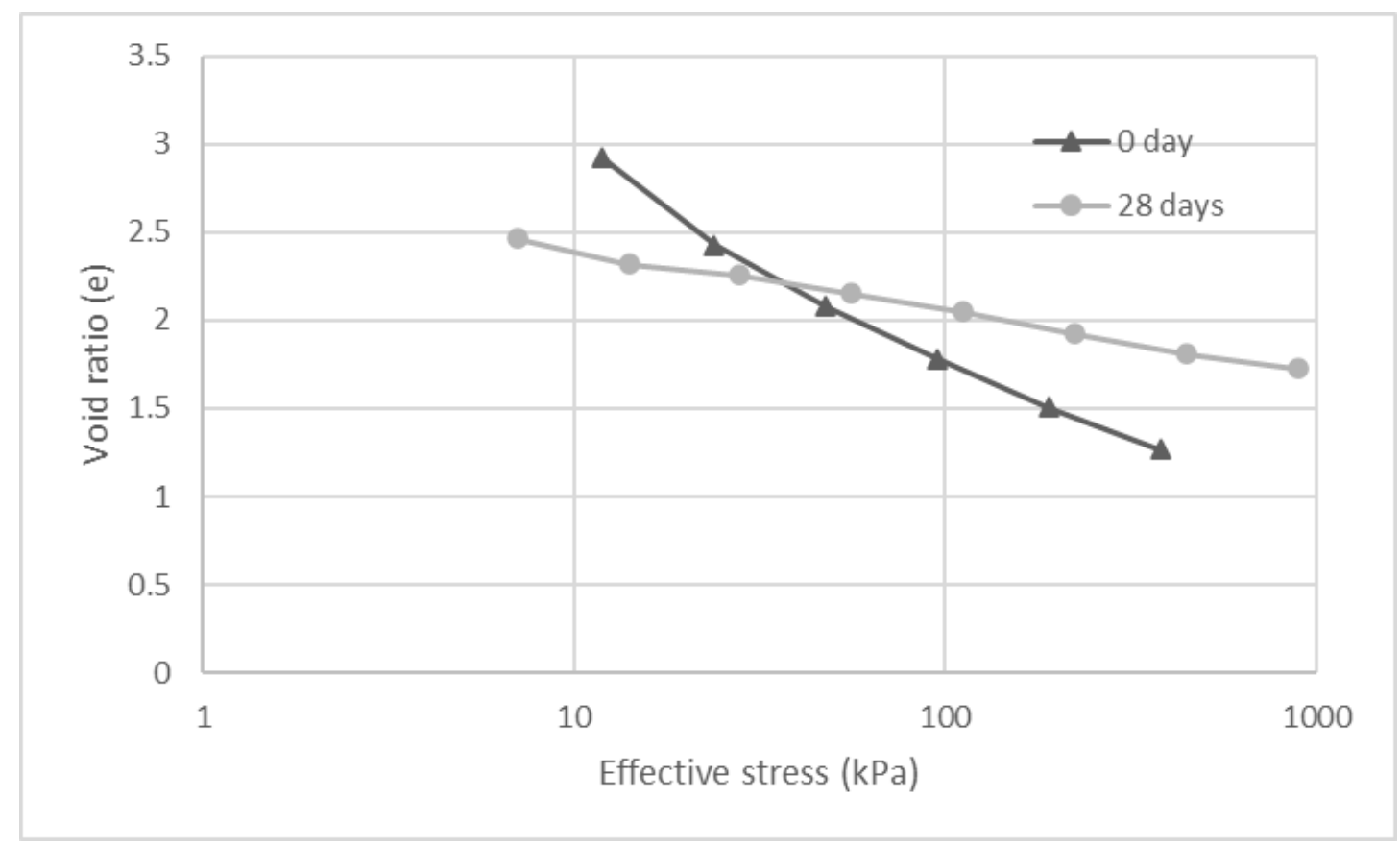

Figure 4.13. Compressibility curve from oedometer tests started at 0 day and 28 days.

Tracking excess pore-water pressure dissipation using a tensiometer inserted through the base of the oedometer cell (Figure 3.6) showed settlement occurred after excess PWP dissipated. Three examples at the load increment for $220 \mathrm{kPa}$ are shown from days 28, 79 and 126 oedometer tests in Figures 4.14, 4.15 and 4.16. In these plots, settlement after the complete dissipation of excess PWP was observed. This behaviour is linked to classical secondary compression (creep). 


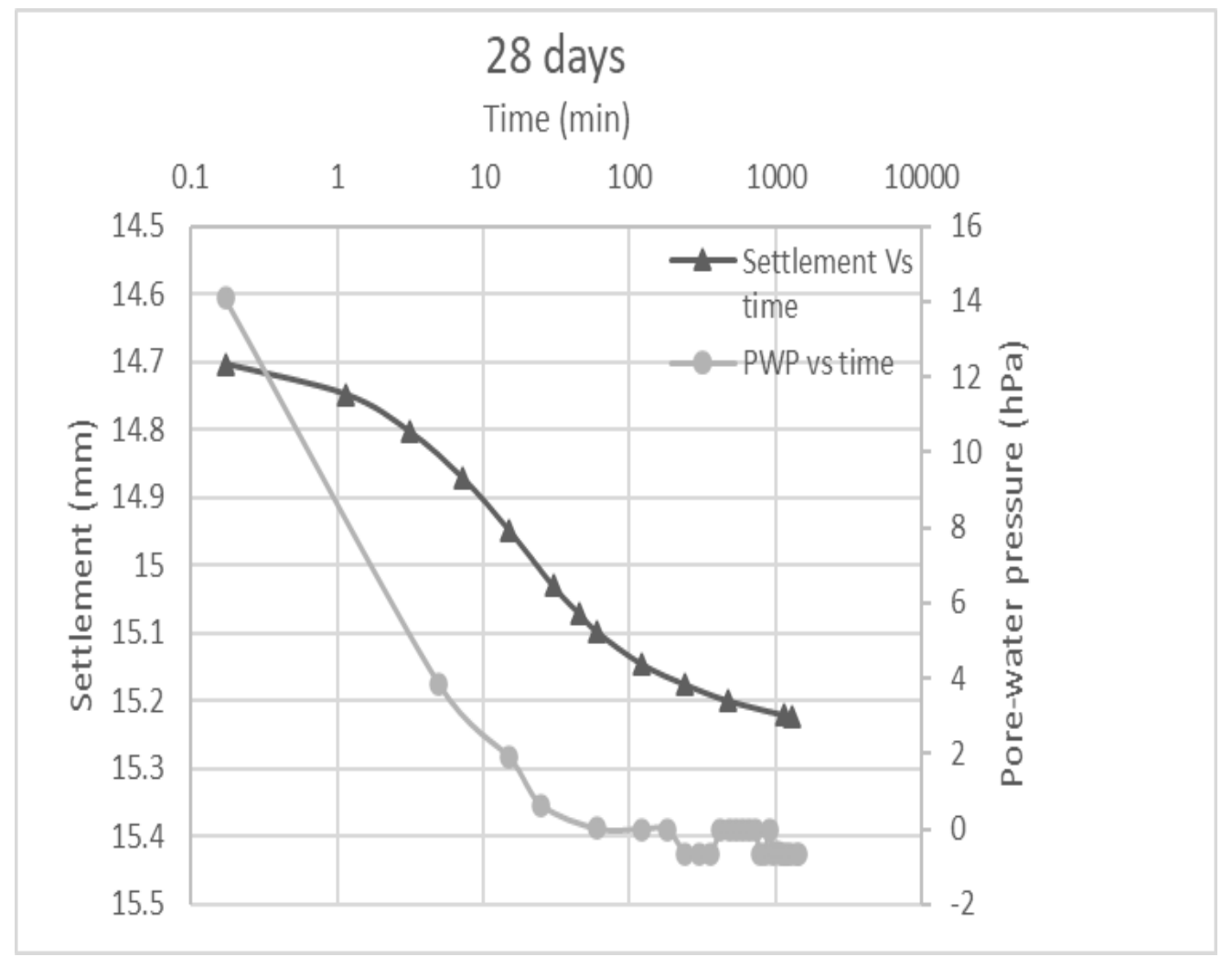

Figure 4.14. Settlement vs time plot showing pore-water pressure dissipation for the $220 \mathrm{kPa}$ loading step for the 28 days sample. 


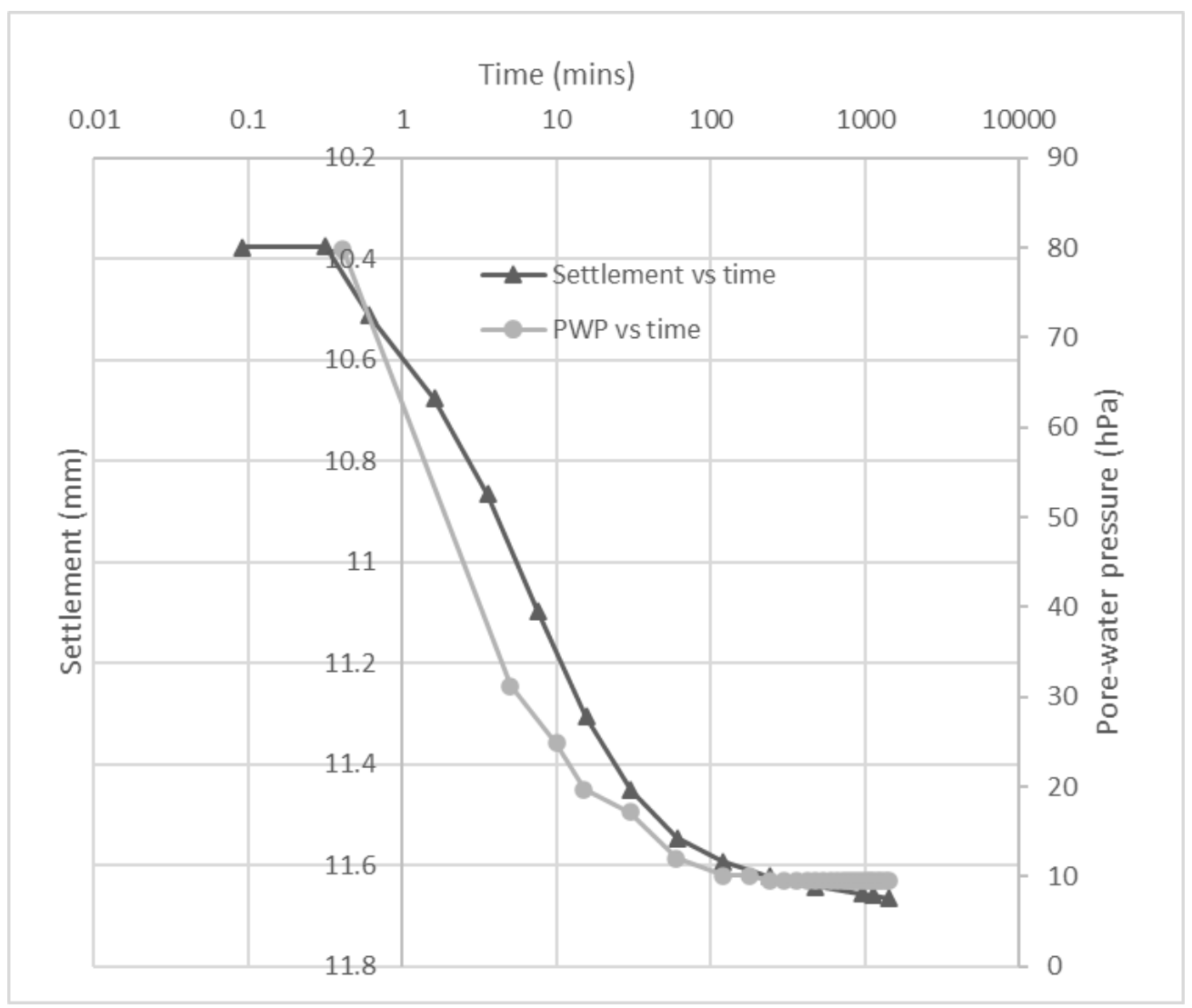

Figure 4.15. Settlement vs time plot showing pore-water pressure dissipation for the $220 \mathrm{kPa}$ loading step for the 79 days sample. 


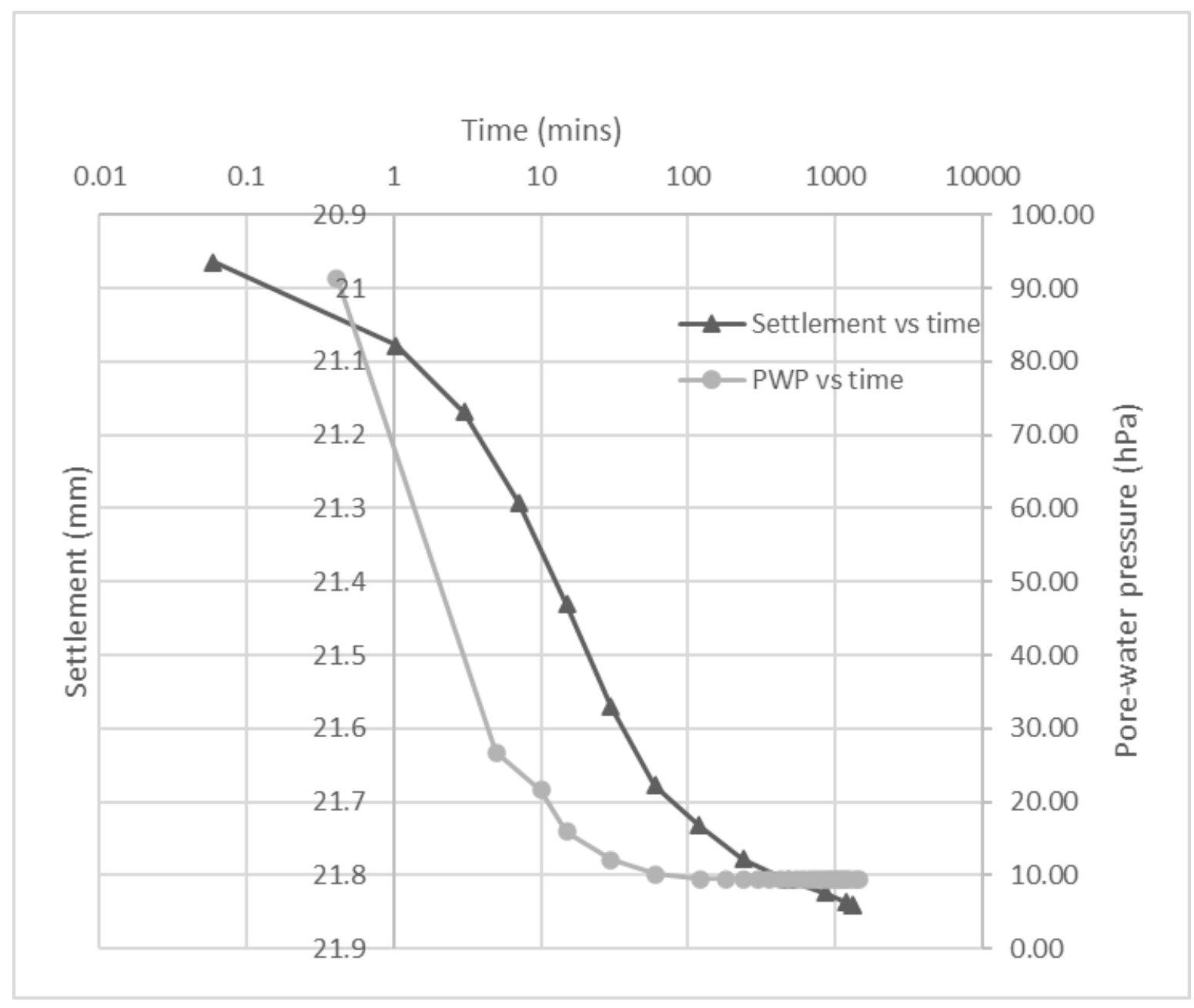

Figure 4.16. Settlement vs time plot showing pore-water pressure dissipation for the $220 \mathrm{kPa}$ loading step for the 126 days sample.

\subsection{Comparison to modelled results}

Numerical modelling of the measured results was carried out using UNSATCON tool to verify the accuracy of large strain consolidation models in analyzing the centrifuge cake dewatering behaviour. Using the hydraulic conductivity derived from oedometer test and calibrated hydraulic conductivity, two models runs were stimulated. 
The deposition scheme parameters (Figure 4.17) used in both model runs are derived from the $0.10 \mathrm{~m}$ column experiment, with the model generated plots for both runs attached in appendix E (Figures $\mathrm{E}-1$ to $\mathrm{E}-4)$.

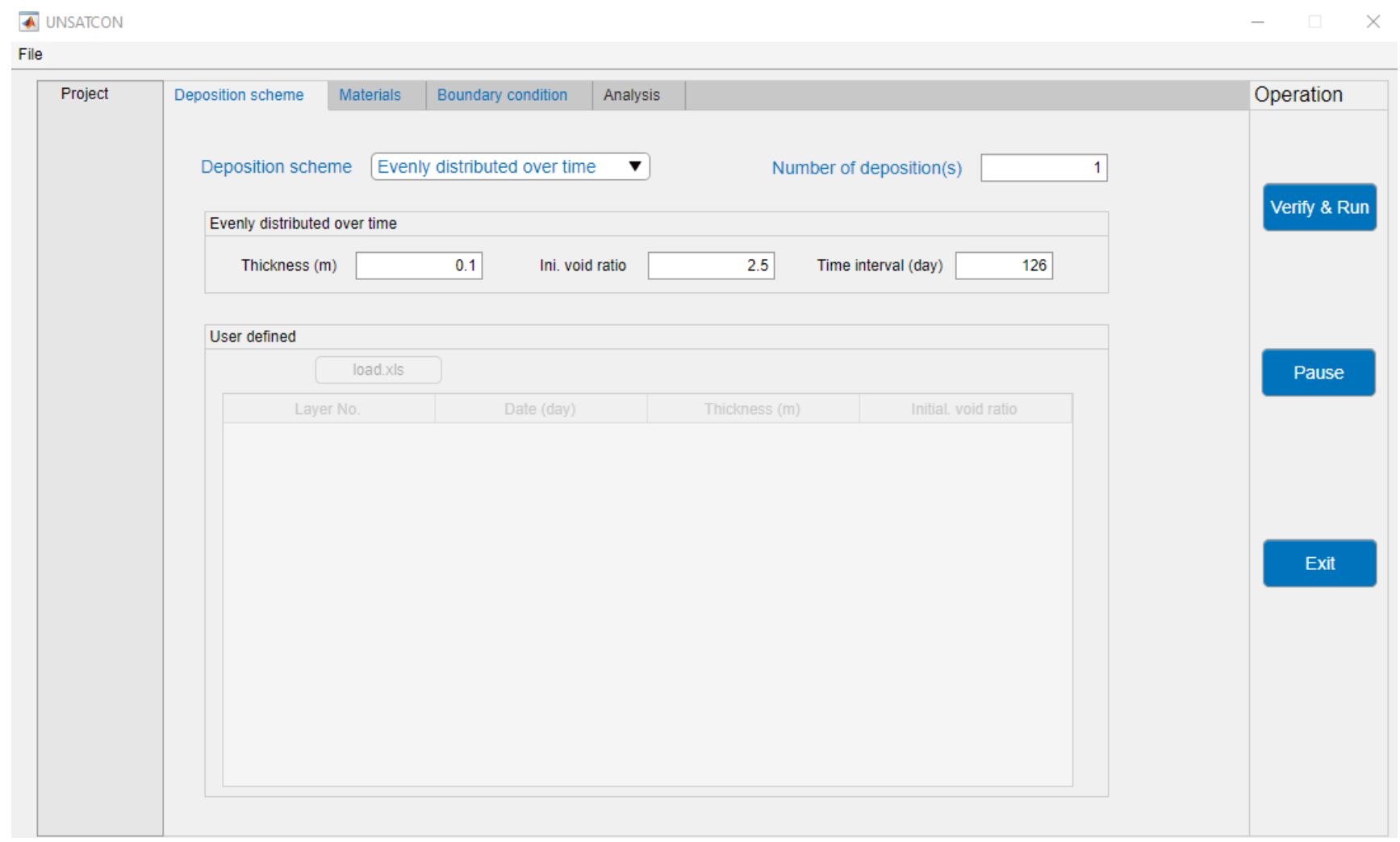

Figure 4.17. UNSATCON deposition scheme parameter window.

Materials parameters used in UNSATCON modelling (Figure 4.21) were initially selected by fitting the compressibility and hydraulic conductivity - void ratio plots derived from the experimental consolidation data. 


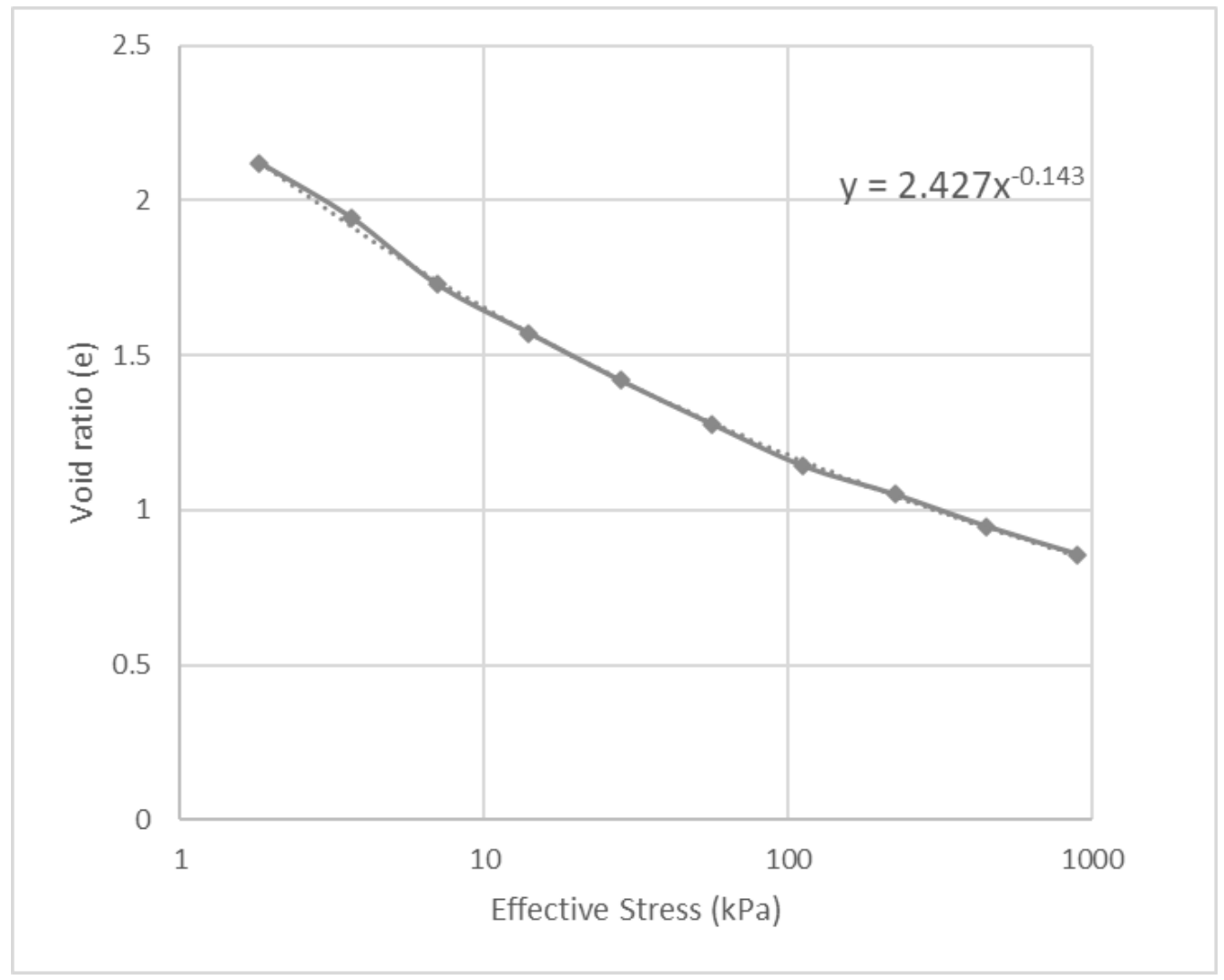

Figure 4.18. Fitted 79-day remolded plot used in developing volume compressibility relationship for the UNSATCON model. 


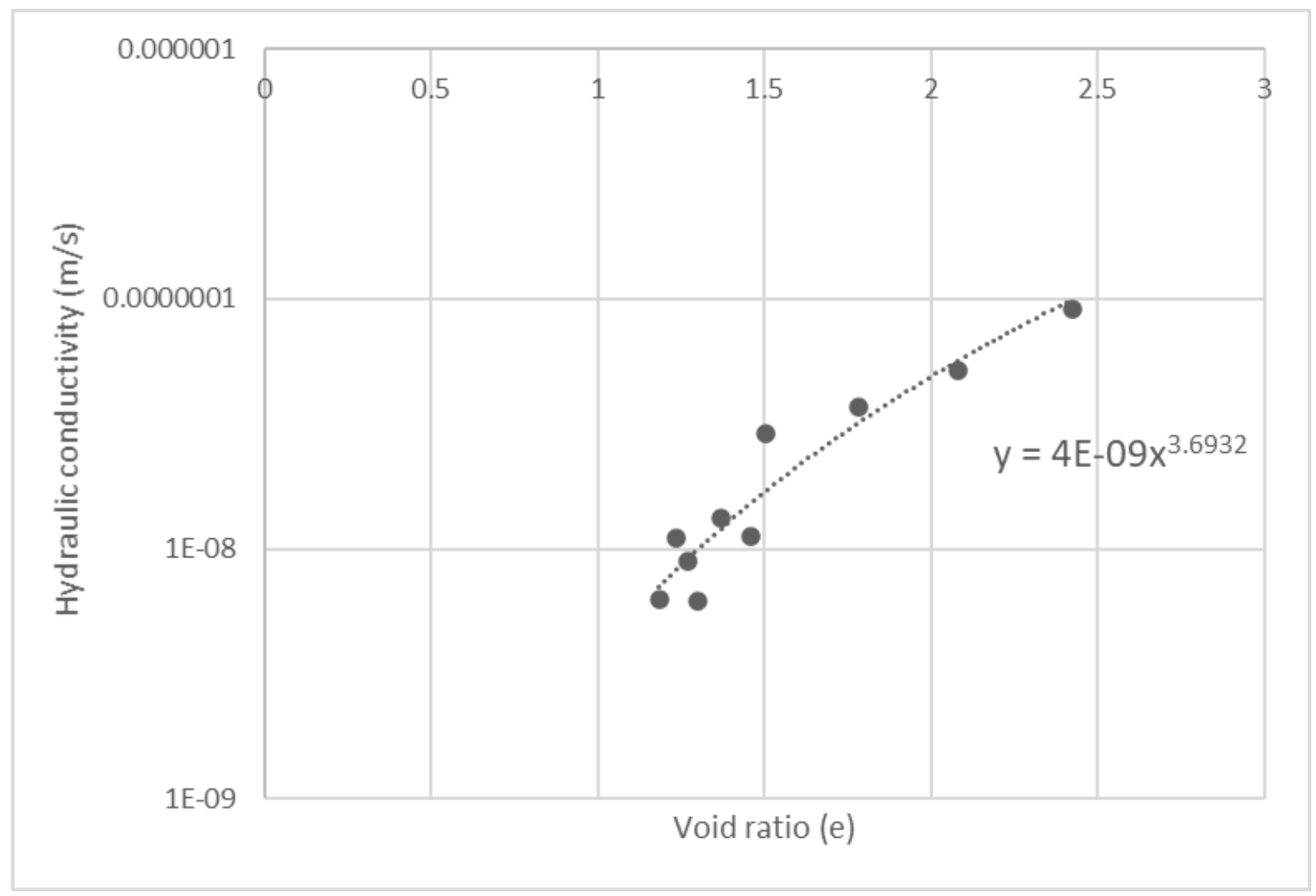

Figure 4.19. Oedometer calculated day-0 hydraulic conductivity-void ratio data used in developing constitutive relationship for the UNSATCON model.

Fitting the compressibility curve (Figure 4.18) and hydraulic conductivity determined from oedometer test (Figure 4.19), the constitutive relationships used in the first UNSATCON model run were developed (Table 4-4).

Table 4-4: Constitutive relationship used in original $0.10 \mathrm{~m}$ column model prediction.

\begin{tabular}{|l|l|l|}
\hline Constitutive relationship & Effective stress - e & Hydraulic conductivity - e \\
\hline Multiplier & 2.43 & $4 \mathrm{e}-09$ \\
\hline Power & -0.14 & 3.69 \\
\hline
\end{tabular}

Calibration was carried out on the model developed constitutive relationship by dividing the calculated hydraulic conductivity for each corresponding void ratio by 20 . This calibration was performed on the hydraulic conductivity to get a better fit for the PWP prediction without changing the other initial parameters. 


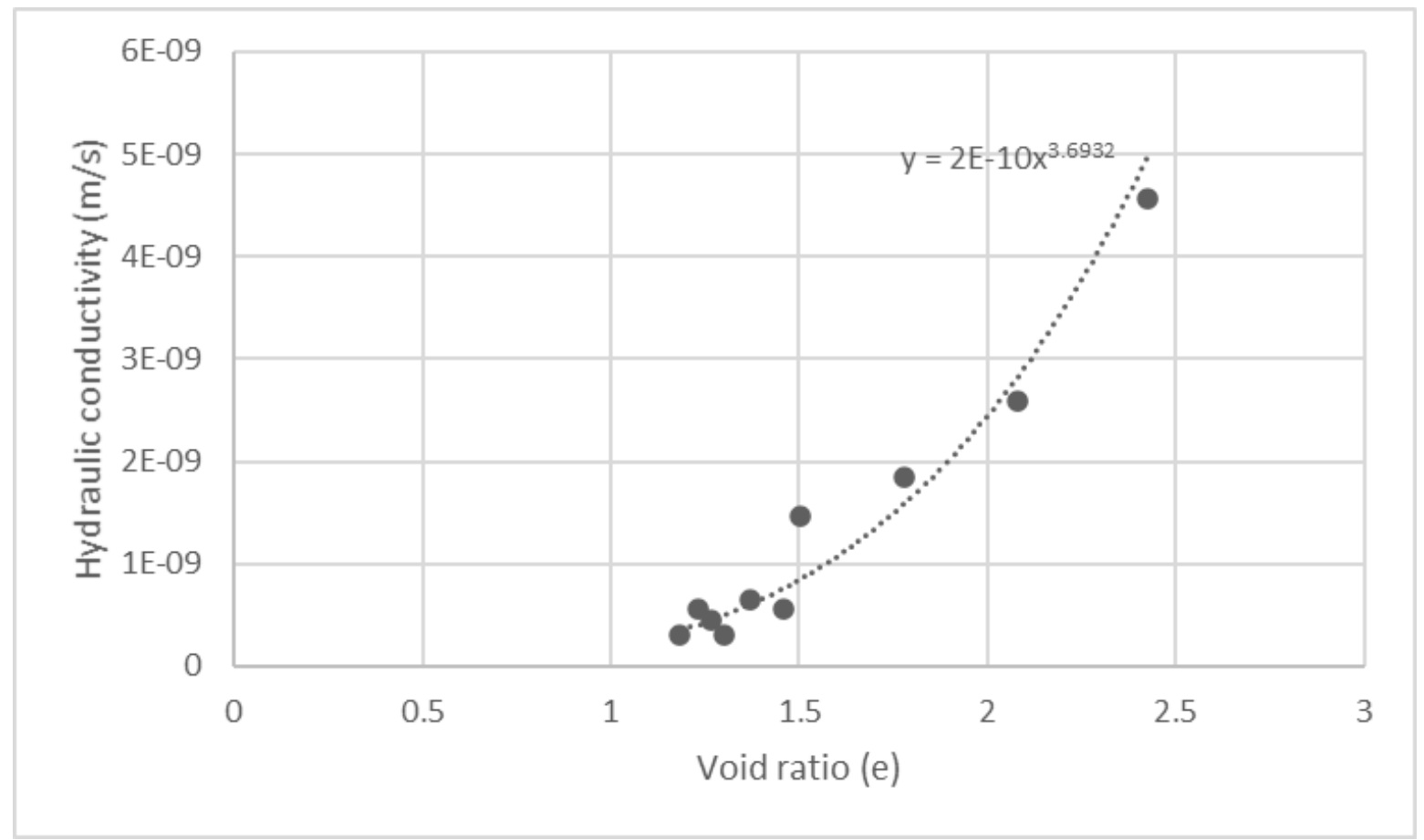

Figure 4.20. Calibrated oedometer day-0 hydraulic conductivity-void ratio data used in developing constitutive relationship for the UNSATCON model.

Fitting the calibrated hydraulic conductivity values (Figure 4-20) and compressibility curve (Figure 4.18), the constitutive relationships used in the second UNSATCON model run were developed (Table 4-5).

Table 4-5: Constitutive relationship used in $0.10 \mathrm{~m}$ column calibrated model prediction.

\begin{tabular}{|l|l|l|}
\hline Constitutive relationship & Effective stress -e & Hydraulic conductivity - e \\
\hline Multiplier & 2.43 & $2 \mathrm{e}-10$ \\
\hline Power & -0.14 & 3.69 \\
\hline
\end{tabular}




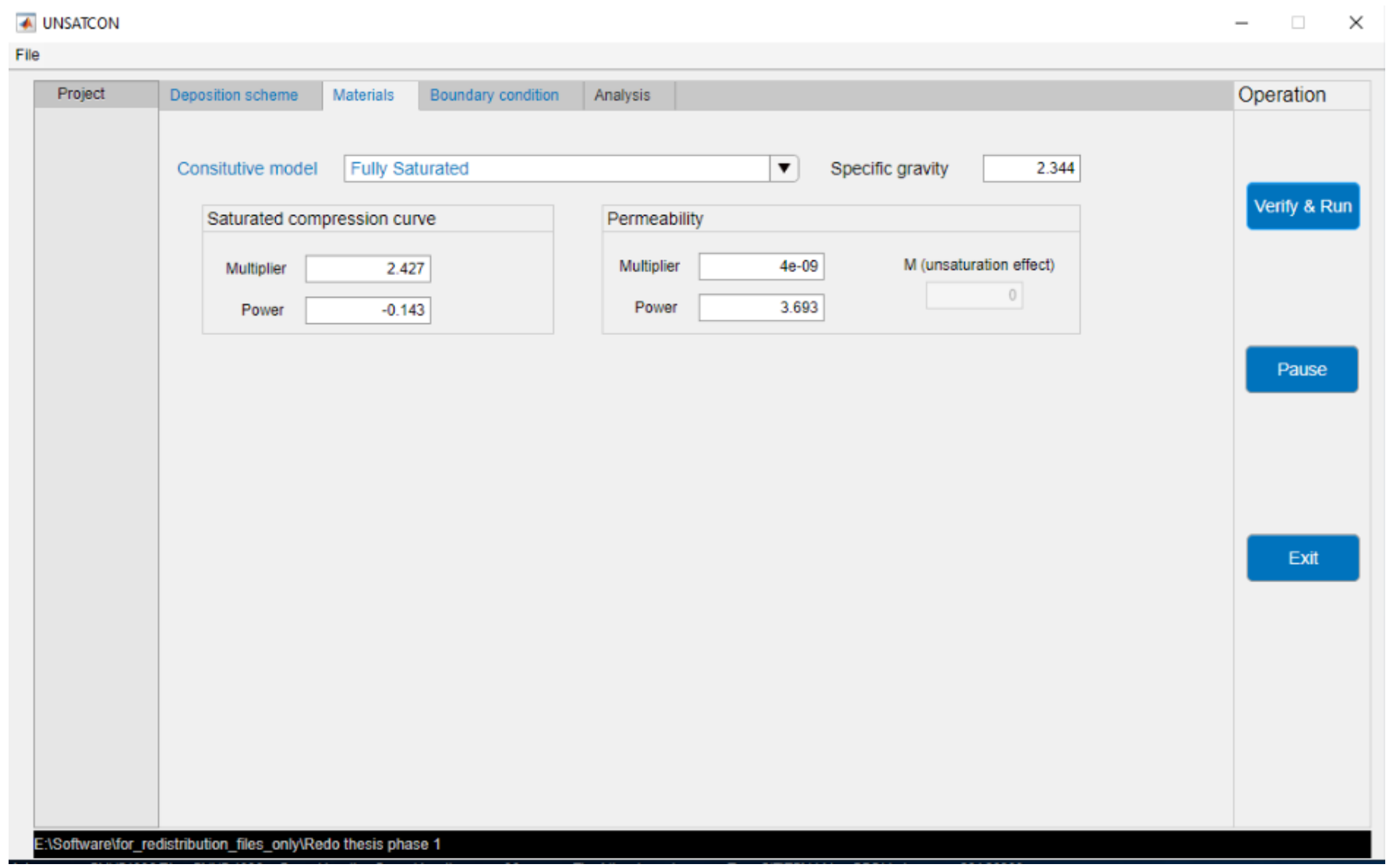

Figure 4.21. UNSATCON materials parameter window showing the oedometer calculated hydraulic conductivity model run.

Both hydraulic and mechanical boundary condition parameters (Figures 4.22 and 4.23 ) were derived from the $0.10 \mathrm{~m}$ column setup. The tailings were kept saturated (no evaporation), flux at the bottom was non-existent (zero) and no loading applied on the columns. 


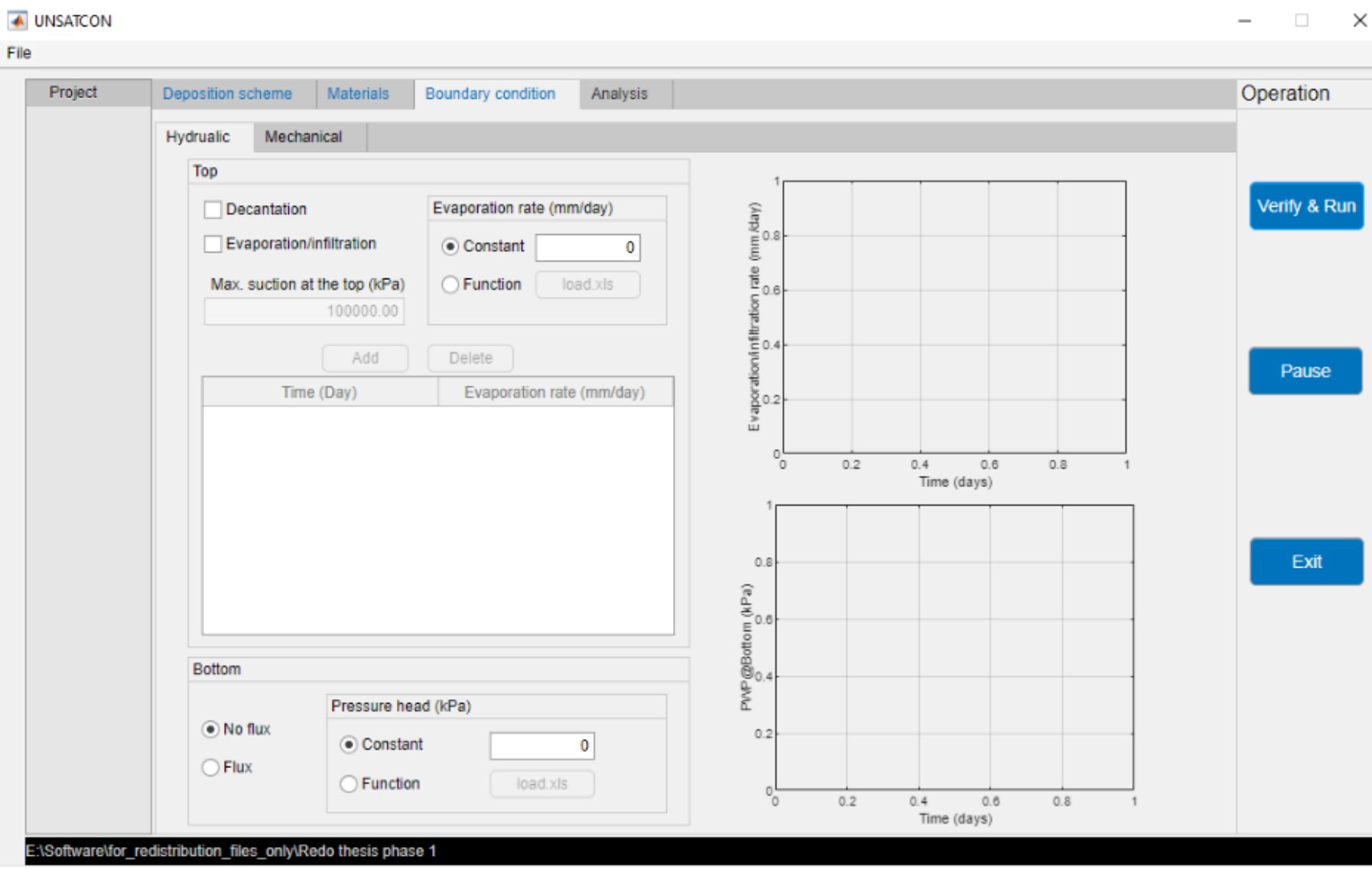

Figure 4.22. UNSATCON boundary conditions - hydraulic parameter window. 


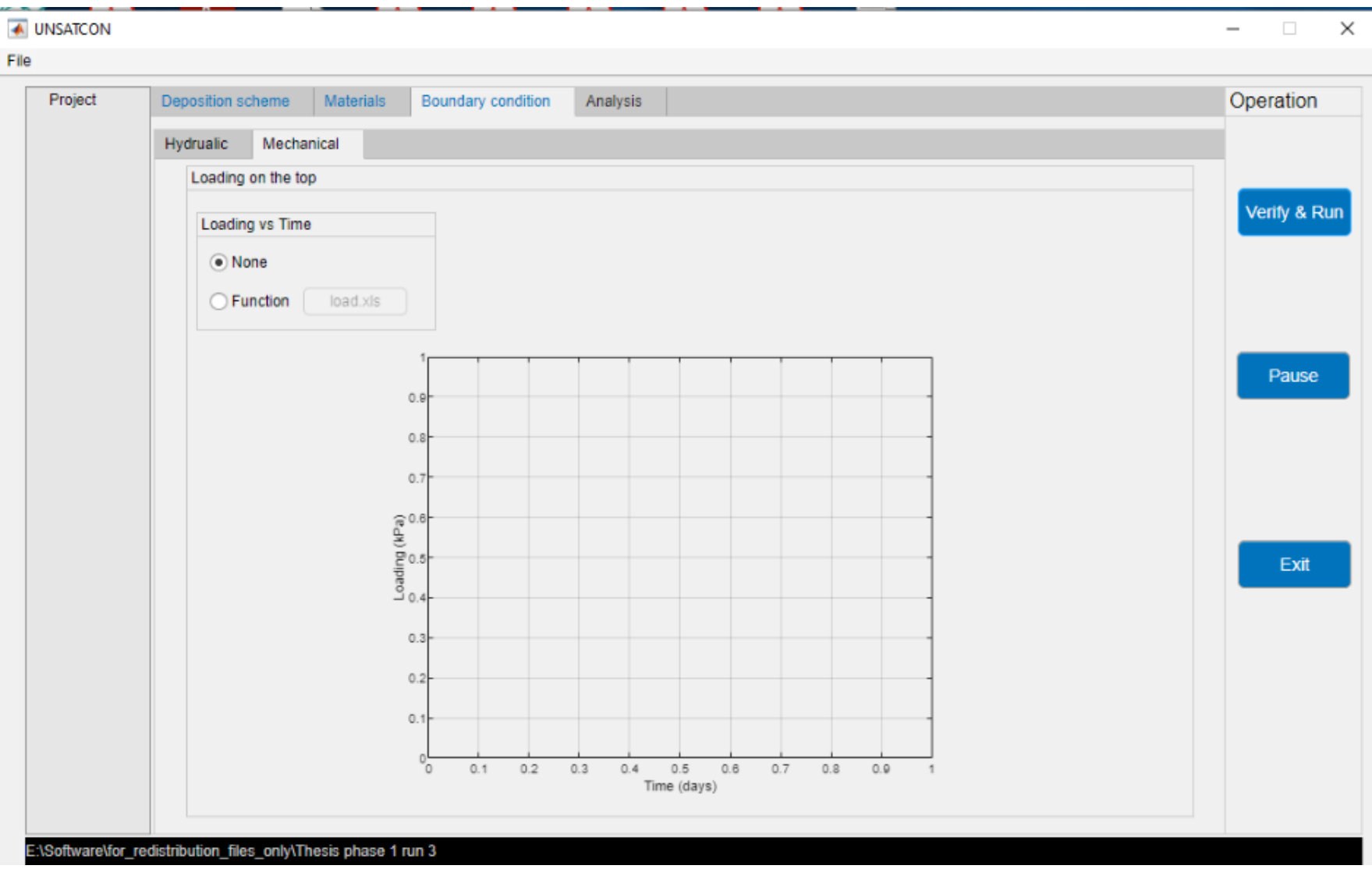

Figure 4.23. UNSATCON boundary conditions - mechanical parameter window.

The spatial (50) and time discretization (10) parameters (Figure 4.24) used in phase I model run were selected by adjusting one parameter while keeping the other parameter constant and the combination with the best comparison to the measured results was chosen; the settlement vs time plot using the chosen parameters is shown in Figure E-3. Sensitivity analysis was performed by adjusting the numerical parameters (time step - 20 and mesh size - 50) and comparing the settlement vs time plot (Figure E-7) to the Figure E-3. The comparison showed the result had minimal sensitivity to the changes in time step and mesh size. 


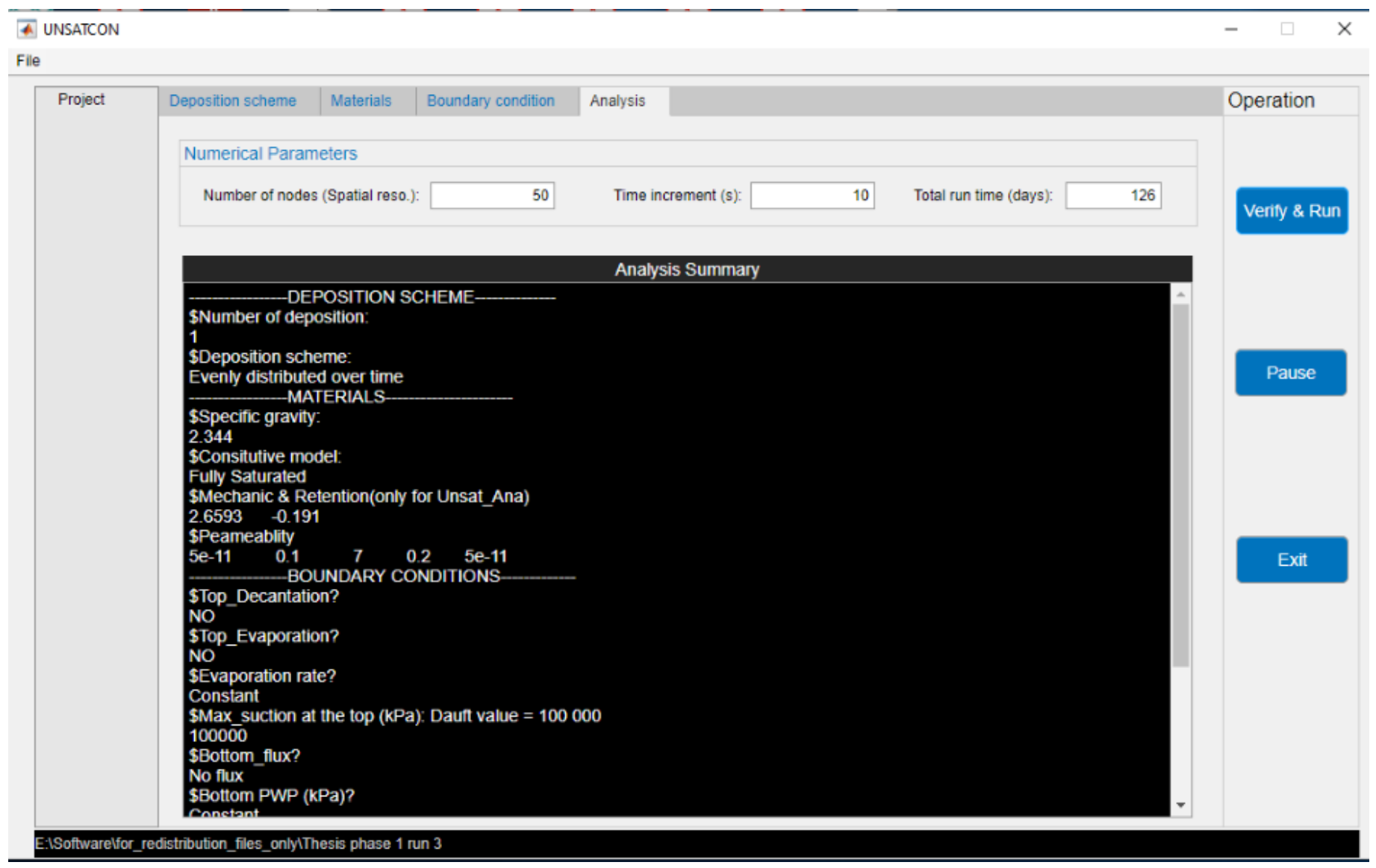

Figure 4.24. UNSATCON numerical parameter window.

\subsubsection{Average gravimetric water content with time}

The average gravimetric water content (GWC) prediction using the oedometer calculated hydraulic conductivity started at a similar water content as the experimental measurement and had most of it's change ( 2\%) within the first 5 days while the average gravimetric water content from the columns show a much higher change ( 10\%) in gravimetric water content over the experiment (Figure 4.25). 


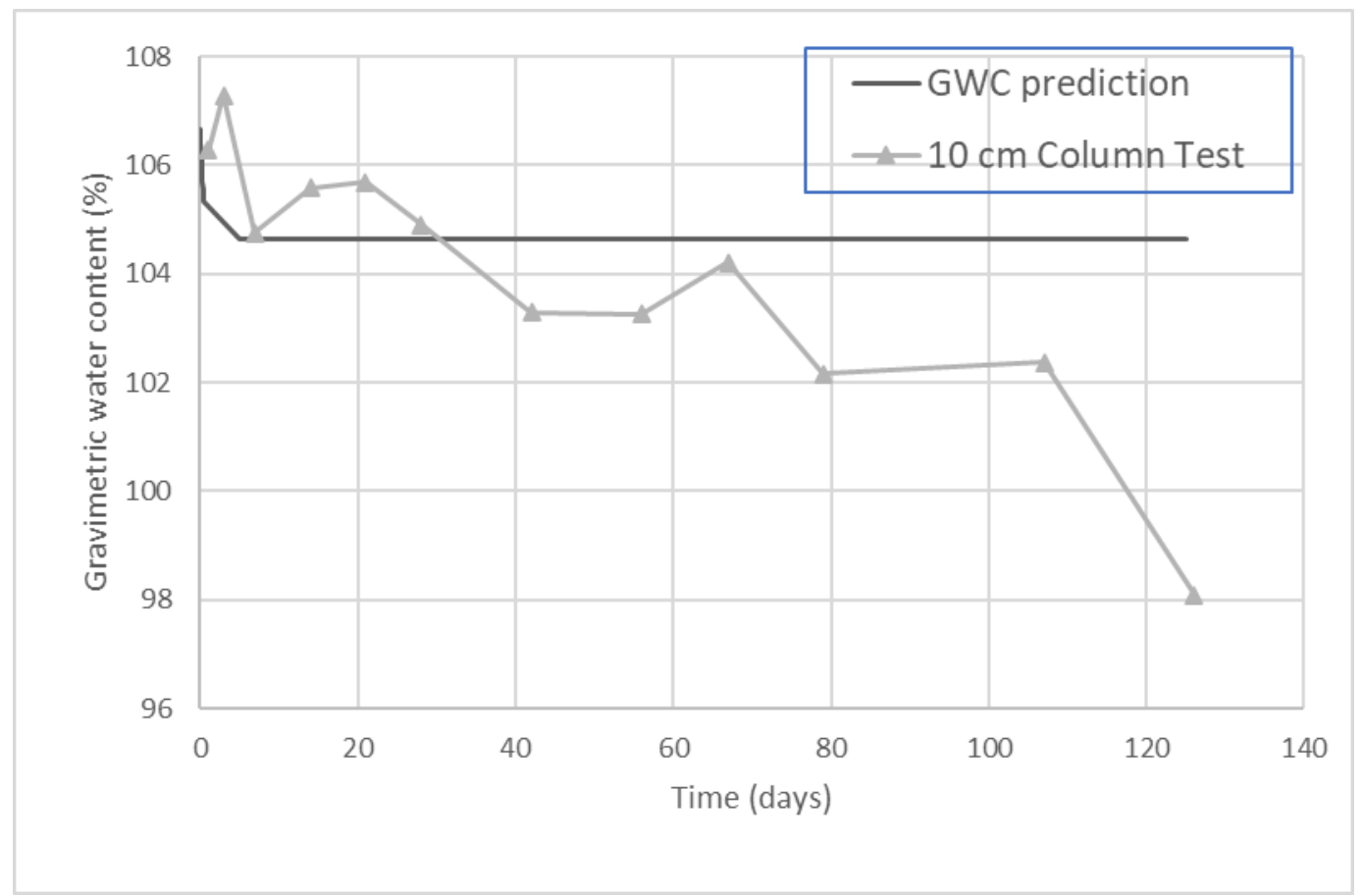

Figure 4.25. Average gravimetric water content with time modelled using oedometer calculated hydraulic conductivity.

The calibrated model had a better prediction for gravimetric water content in the first 30 days when compared to the previous model prediction (Figure 4.26). This is expected since the previous hydraulic conductivity value is estimated from compressibility curve which underestimates the $\mathrm{k}$ value hence using a lower hydraulic conductivity value gives a better correlation with the measured data. 


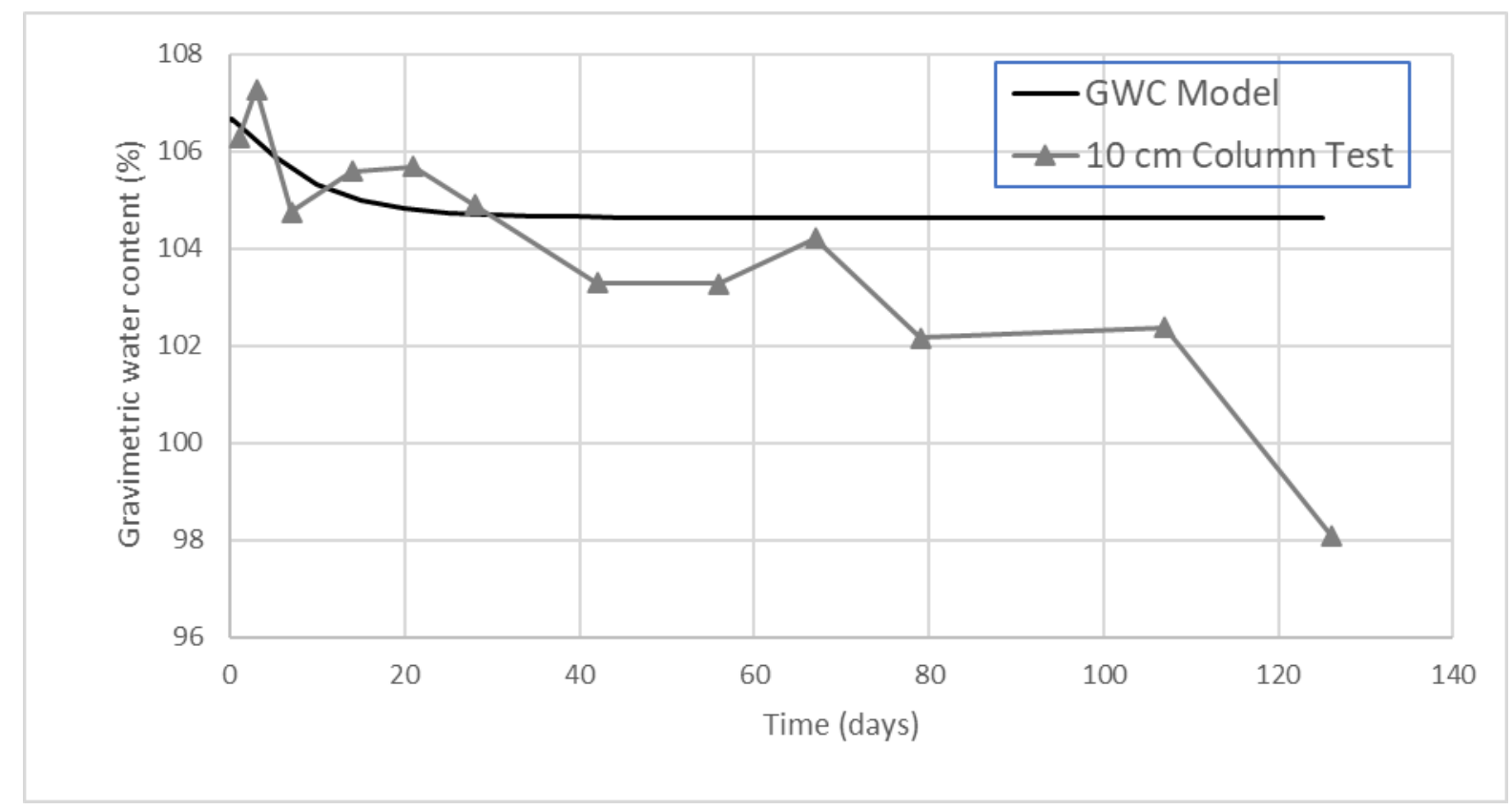

Figure 4.26. Average gravimetric water content with time modelled using calibrated hydraulic conductivity.

\subsubsection{Solids content with depth profile}

Model prediction using the oedometer calculated hydraulic conductivity showed most of the changes in solids content with depth happened in a shorter time frame ( $\sim 5$ days) when compared to the measured solids content profile ( $\sim 56$ days). There is correlation between the predicted model and measured final solids content with both showing deformation in the bottom layer over time as expected due to settlement occurring in the $0.10 \mathrm{~m}$ column (Figure 4.27). 


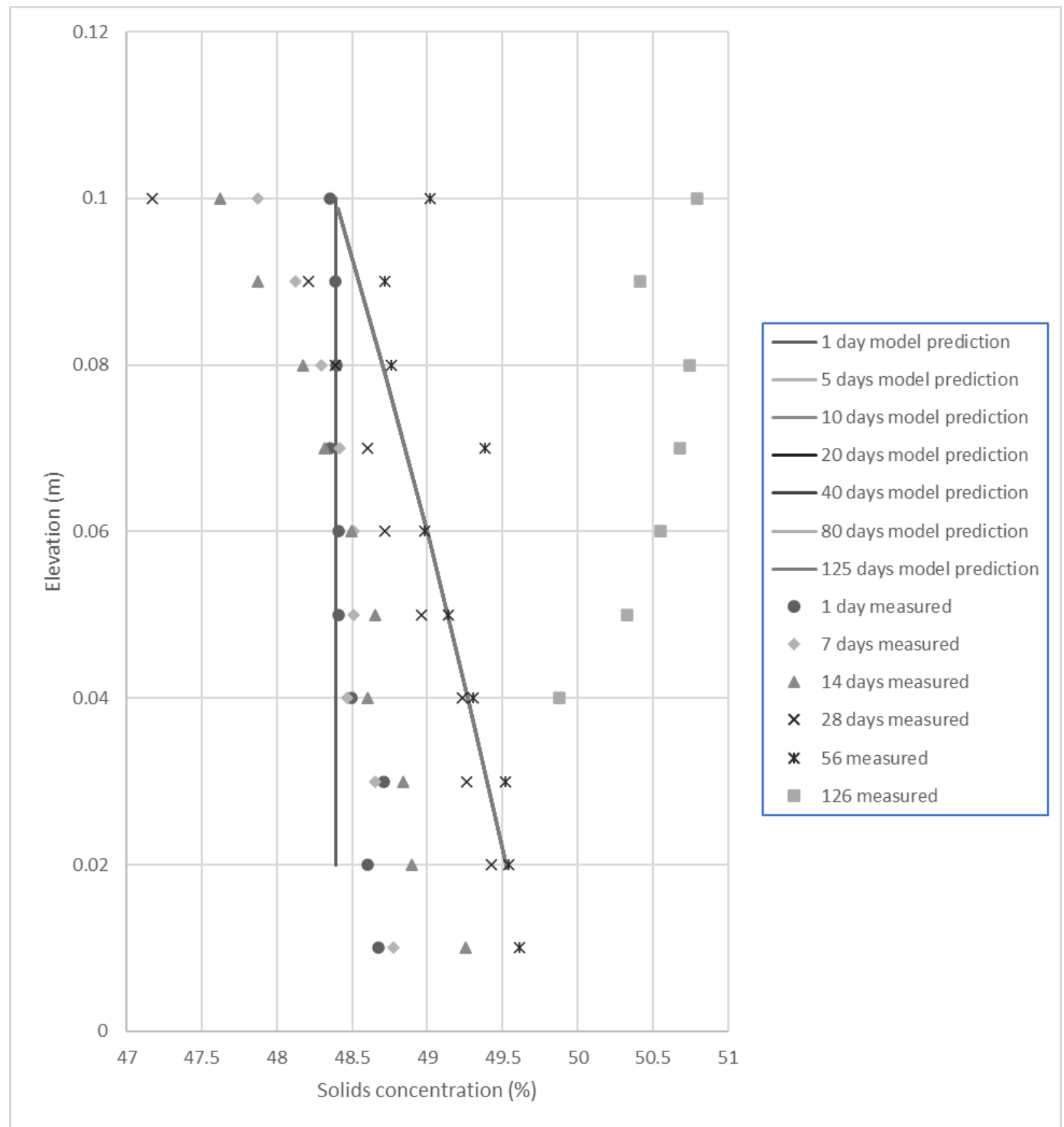

Figure 4.27. Measured and predicted solids content profile model using oedometer calculated hydraulic conductivity for 0.10 m columns.

The predicted solids content profile using the calibrated hydraulic conductivity had a better correlation with the experimental data with most of the changes occurring within the first 40 days (Figure 4.28). 


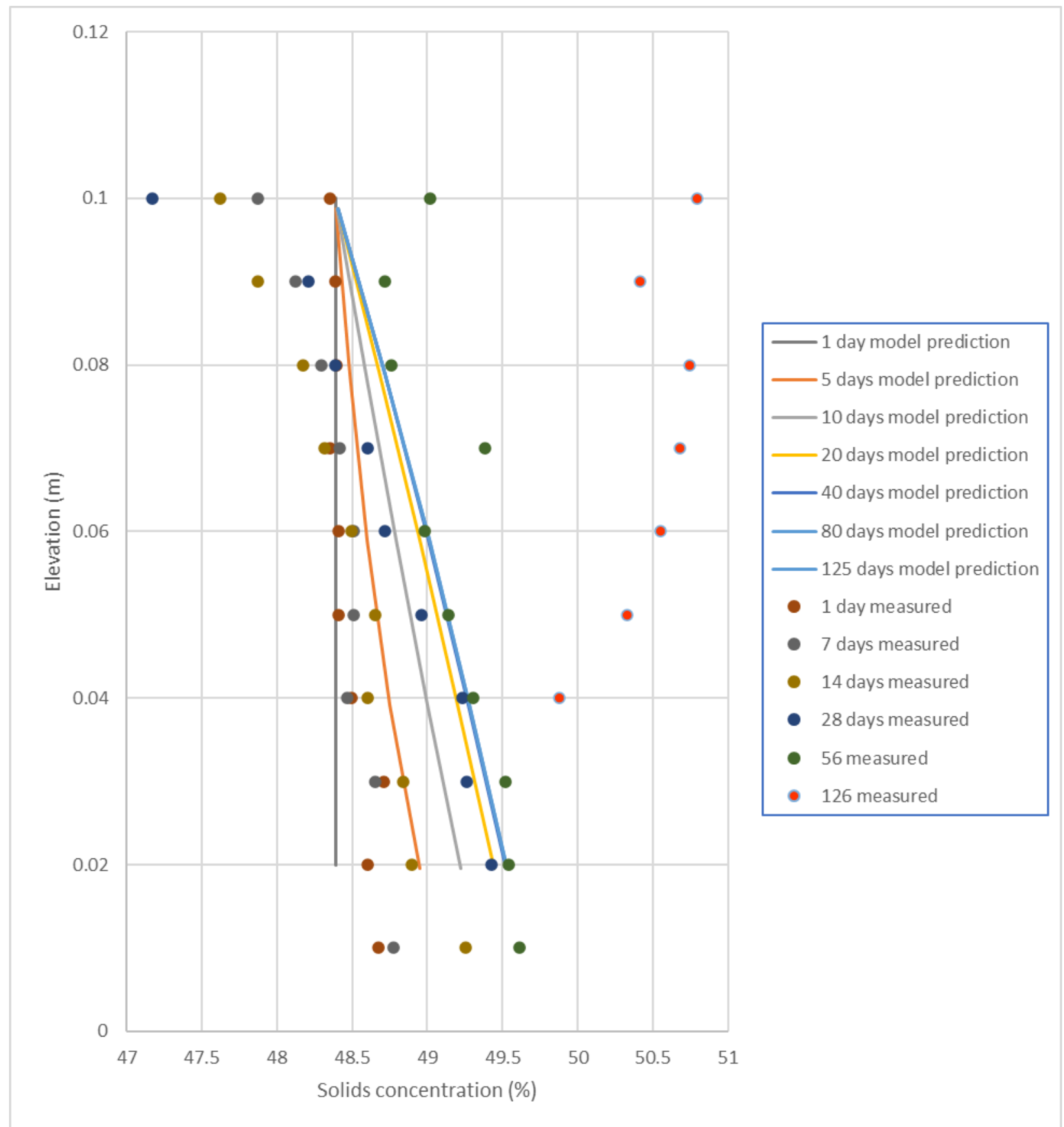

Figure 4.28. Measured and predicted solids content profile model using calibrated hydraulic conductivity for 0.10 m columns.

\subsubsection{Pore-water pressure with time}

The predicted PWP using the oedometer calculated hydraulic conductivity was comparable for the first 80 days with the measured PWP results at both elevations. Most of the changes in the 
model prediction occurred rapidly within the first 5 days whereas the measured PWP changed slowly over time (Figure 4.29).

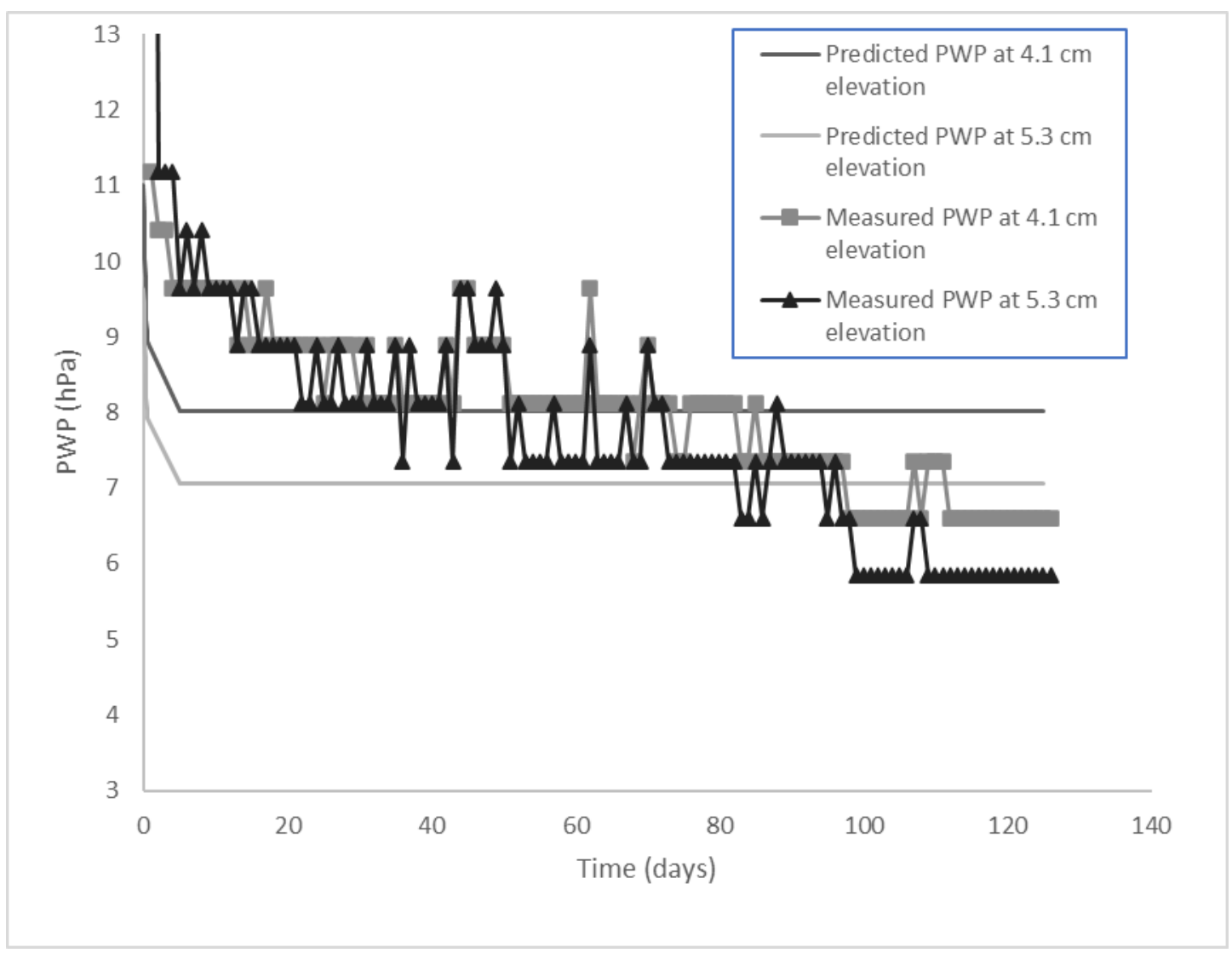

Figure 4.29. Measured and predicted PWP using oedometer calculated hydraulic conductivity for 0.10 m columns.

Changes in the calibrated model PWP occurred less rapidly ( $~ 30$ days) and the dissipation of excess PWP for the first 80 days showed better agreement with the measured data when compared to the other model prediction (Figure 4.30). 


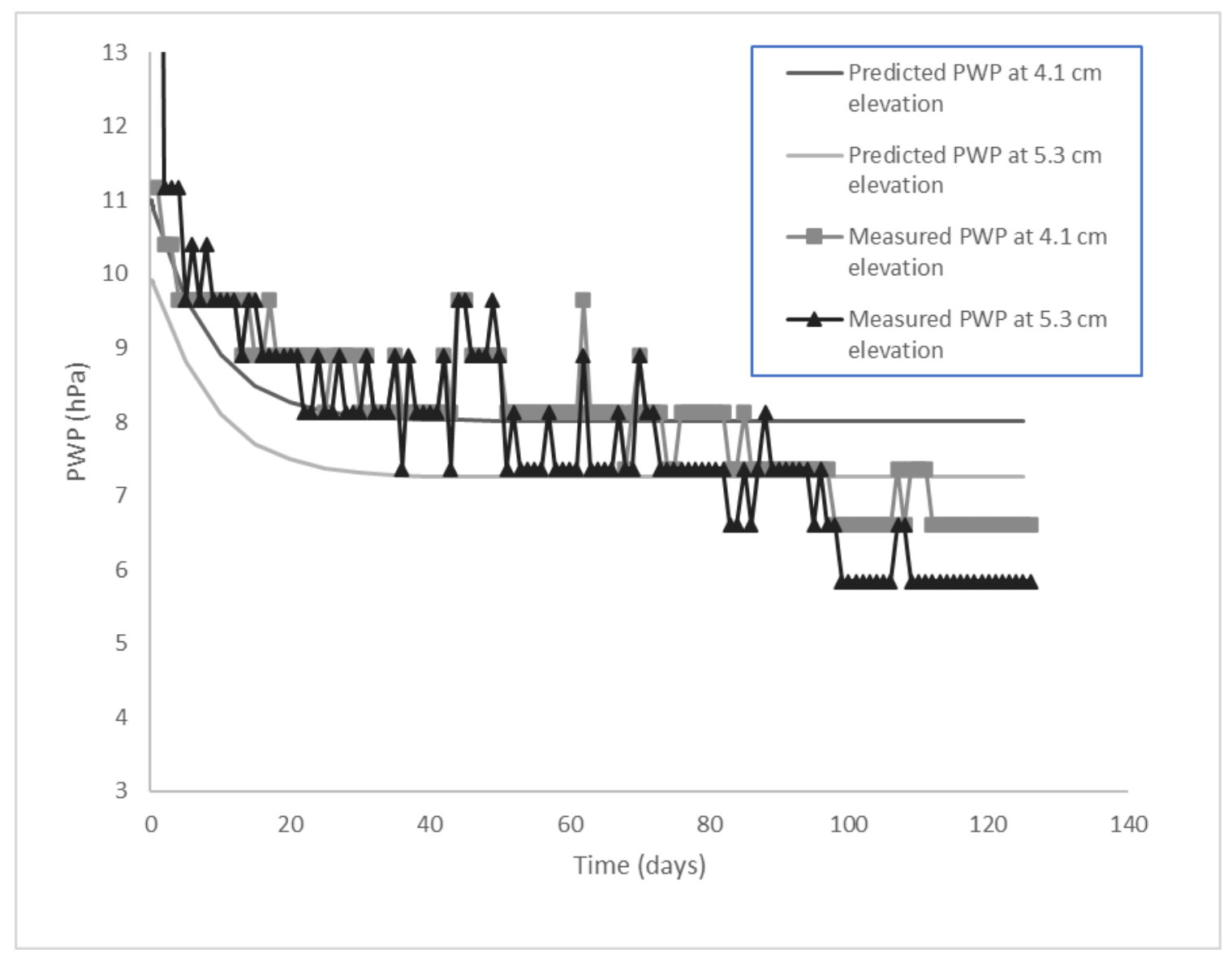

Figure 4.30. Measured and predicted PWP using calibrated hydraulic conductivity for $0.10 \mathrm{~m}$ columns.

\subsubsection{Settlement over time}

There was a correlation between the model prediction and measured data indicating very little changes $(<0.003 \mathrm{~m}$ ) in tailings height over 126 days (Figure 4.31). Predicted settlement using the oedometer calculated hydraulic conductivity showed rapid settlement ( 5 days) occurring in the column when compared with the measured data ( 60 days). The difference between the model and measured settlement may be due to structuration effects which are not incorporated in this model. 


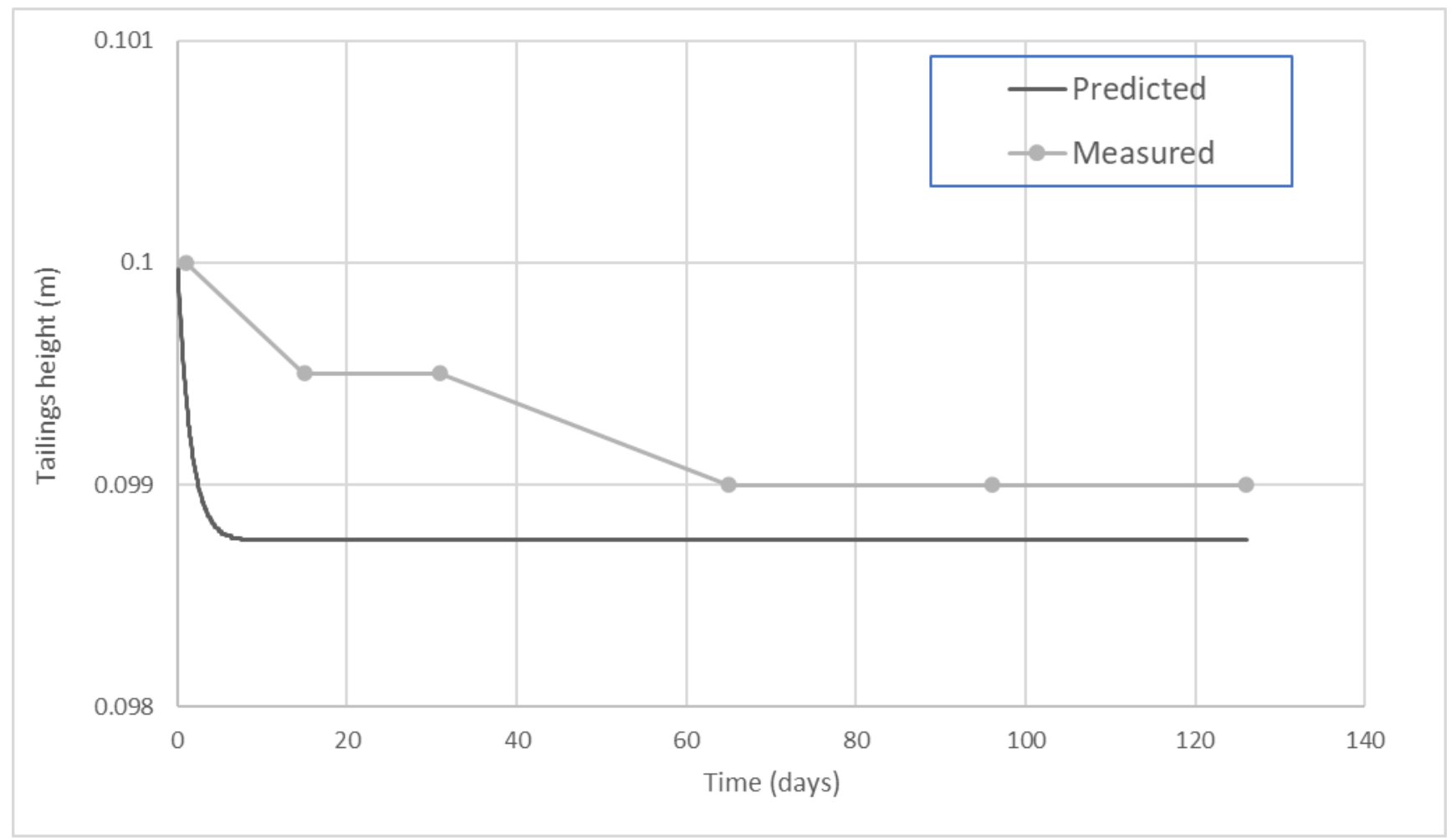

Figure 4.31. Measured and predicted tailings height over time using oedometer calculated hydraulic conductivity for $0.10 \mathrm{~m}$ columns.

Settlement occurred over a longer period ( 30 days) in the calibrated model which was comparable to the measured data ( 60 days). Also, there was correlation between the calibrated model and measured data on very small settlement occurring in the columns (Figure 4.32). The final height of tailings for the calibrated model was higher (lower settlement) and deformation occurred over a longer period when compared to the previous model. This is expected since the calibrated model is modelled using a lower hydraulic conductivity. 


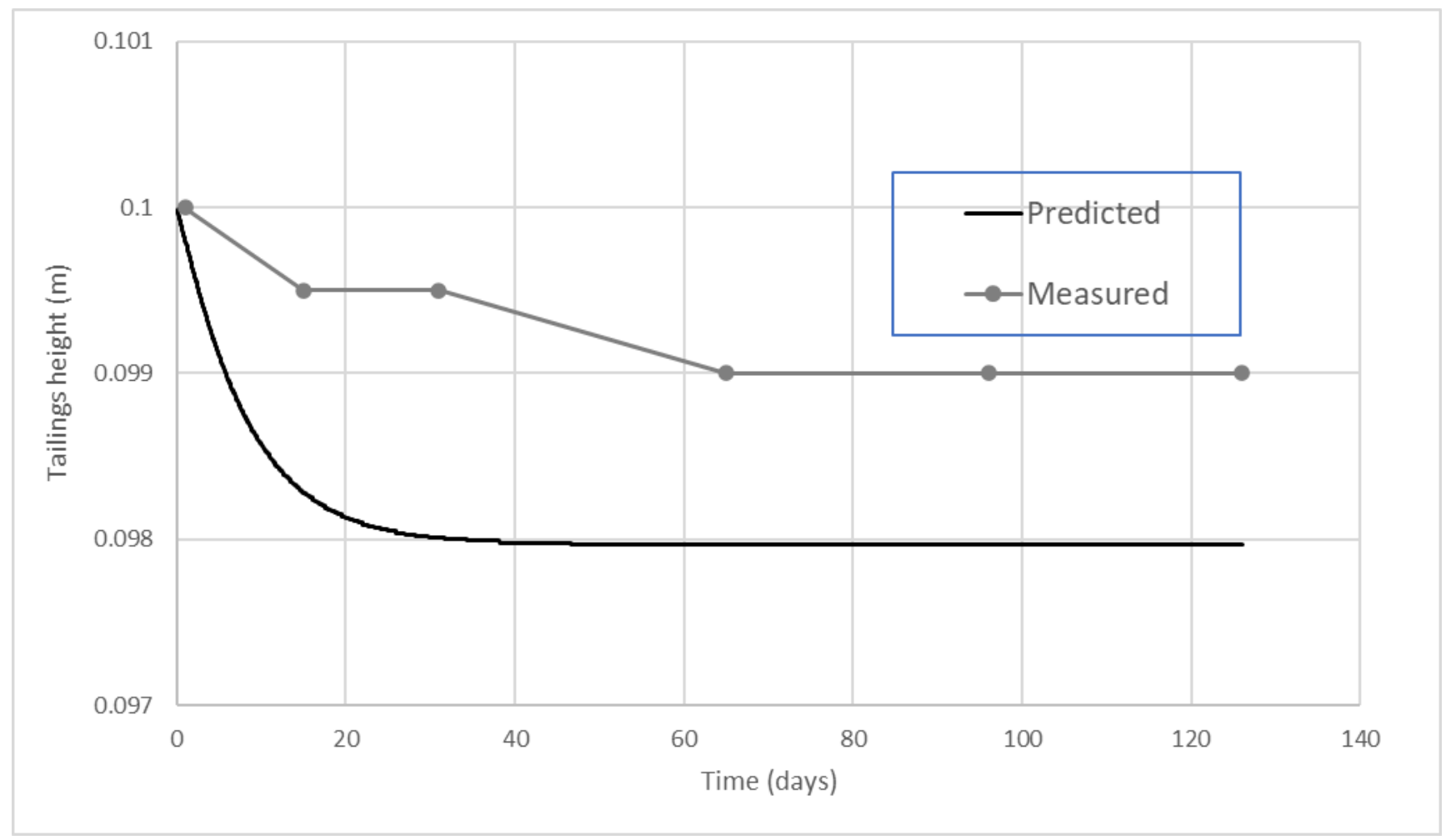

Figure 4.32. Measured and predicted tailings height over time using calibrated hydraulic conductivity for $0.10 \mathrm{~m}$ columns.

\subsection{Comparison to literature results}

\subsubsection{Hydraulic conductivity}

Figure 4.33 shows the hydraulic conductivity vs void ratio (k-e) plots for different oil sand tailings. Miller (2010) and Jeervipoolvarn (2010) used similar constant head testing method in deriving their k-e plot while Owolagba (2013) utilized the falling head test. For this study, the ke plot is estimated from the oedometer test and is comparable to other tailings within two orders of magnitude. 


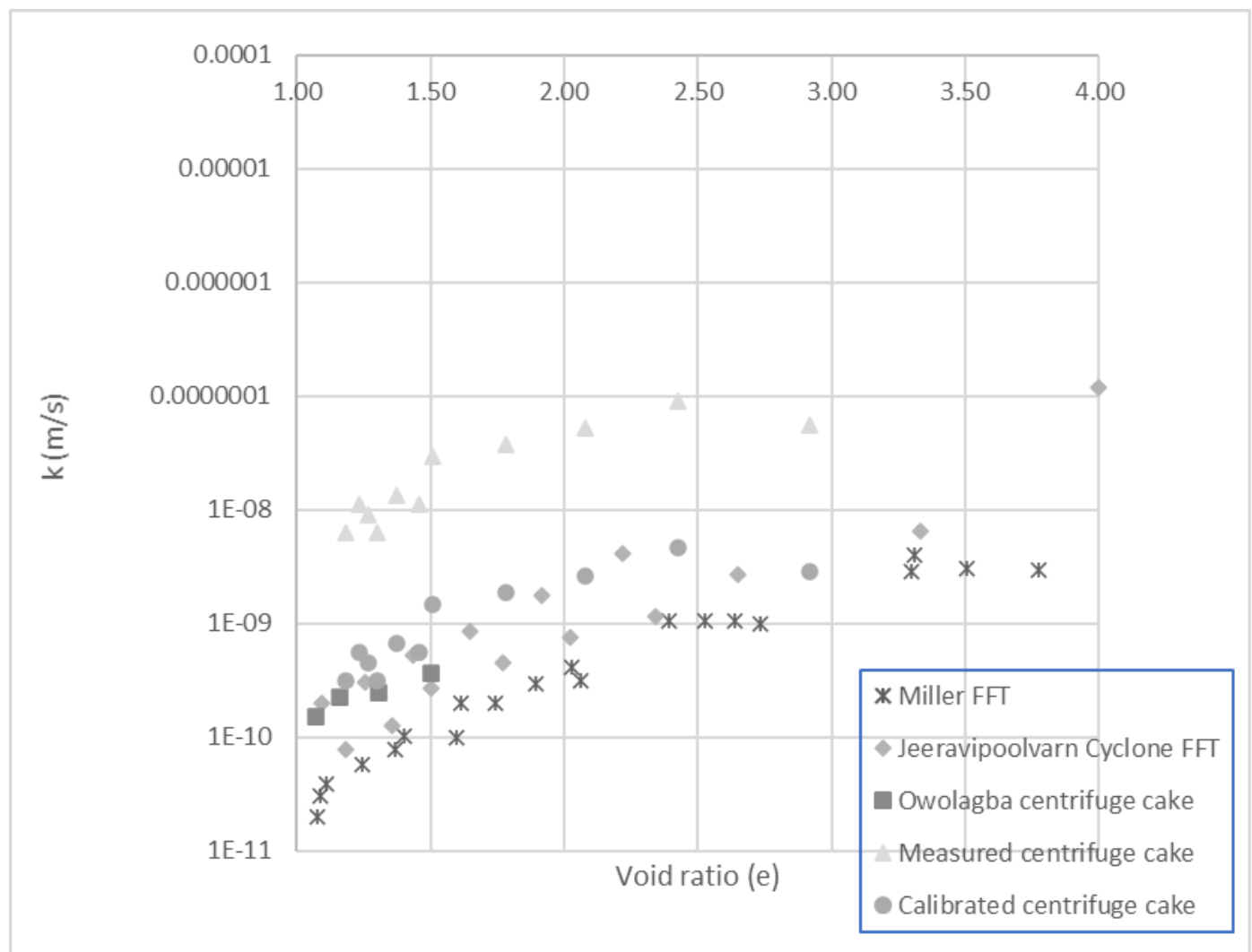

Figure 4.33. Hydraulic conductivity of different oil sand tailings within the void ratio range of 1 to 4 (Adapted from Liu, 2017).

The calibrated hydraulic conductivity k-e plot shows a better comparison with the other tailings and is within less than one order of magnitude to the centrifuge cake hydraulic conductivity measurement from Owolagba (2013) study (Figure 4.33).

\subsubsection{Ratio of creep coefficient to compression index vs effective stress}

Comparing creep coefficient to compression index ratio $\left(C_{\alpha e} / C_{c}\right)$ vs effective stress in centrifuge cake to Winnipeg lacustrine and Belfast estuarine clays shows the similar trend where the highest $\mathrm{Cae} / \mathrm{Cc}$ ratio occurs close to the preconsolidation pressure (Figure 4.34). 


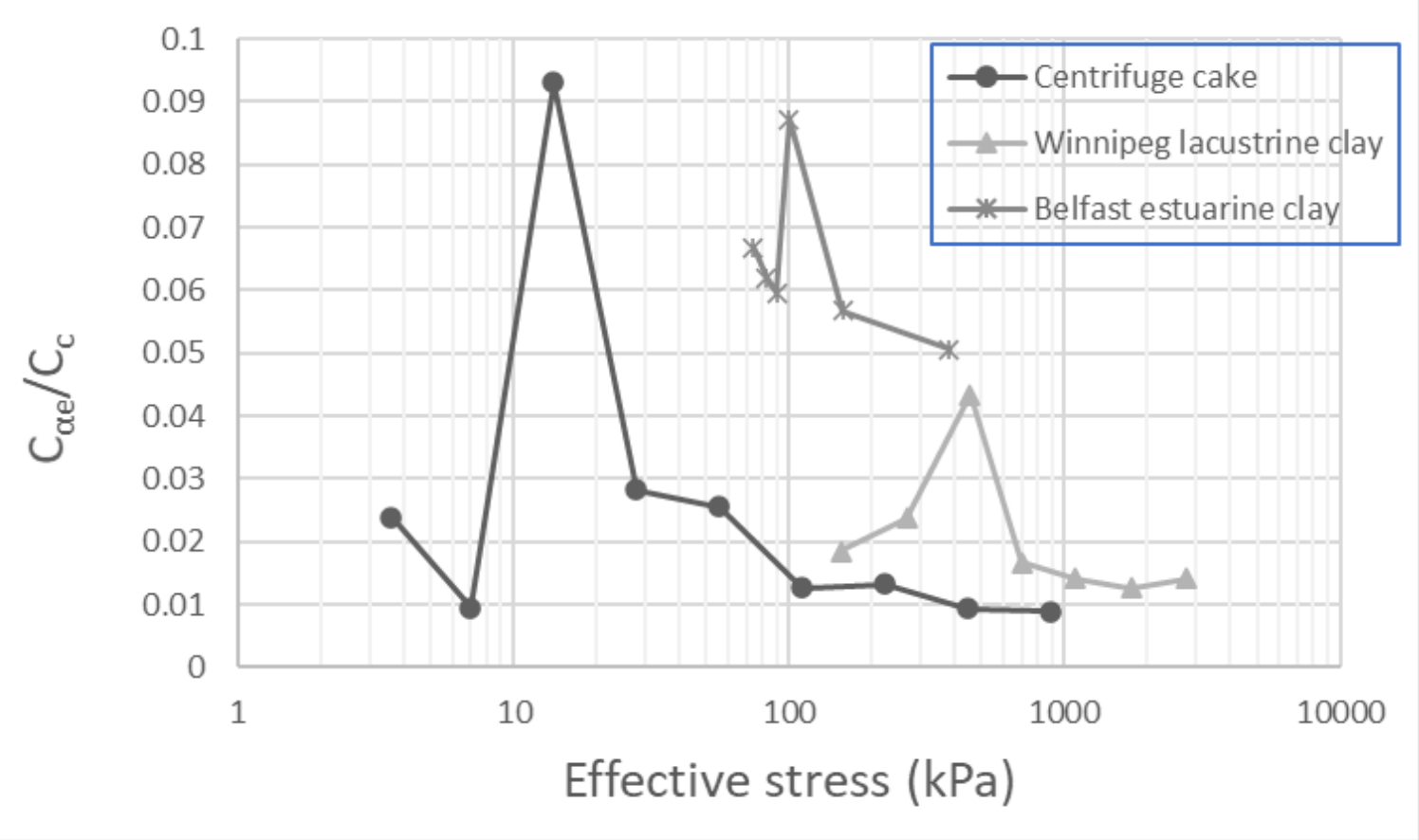

Figure 4.34. Comparison of $C_{\alpha e} / C_{c}$ ratio vs effective stress for clays and centrifuge cake (Adapted from Graham et al., 1983).

\subsubsection{Undrained shear strength with time}

Salam (2020) performed similar $0.10 \mathrm{~m}$ column test on in-line flocculated FFT and observed that after the end of primary consolidation shear strength increased significantly (Figure 4.35). This behaviour is also observed in the centrifuge cake $0.10 \mathrm{~m}$ column test where shear strength increased substantially after primary consolidation ended (Figure 4.5). 


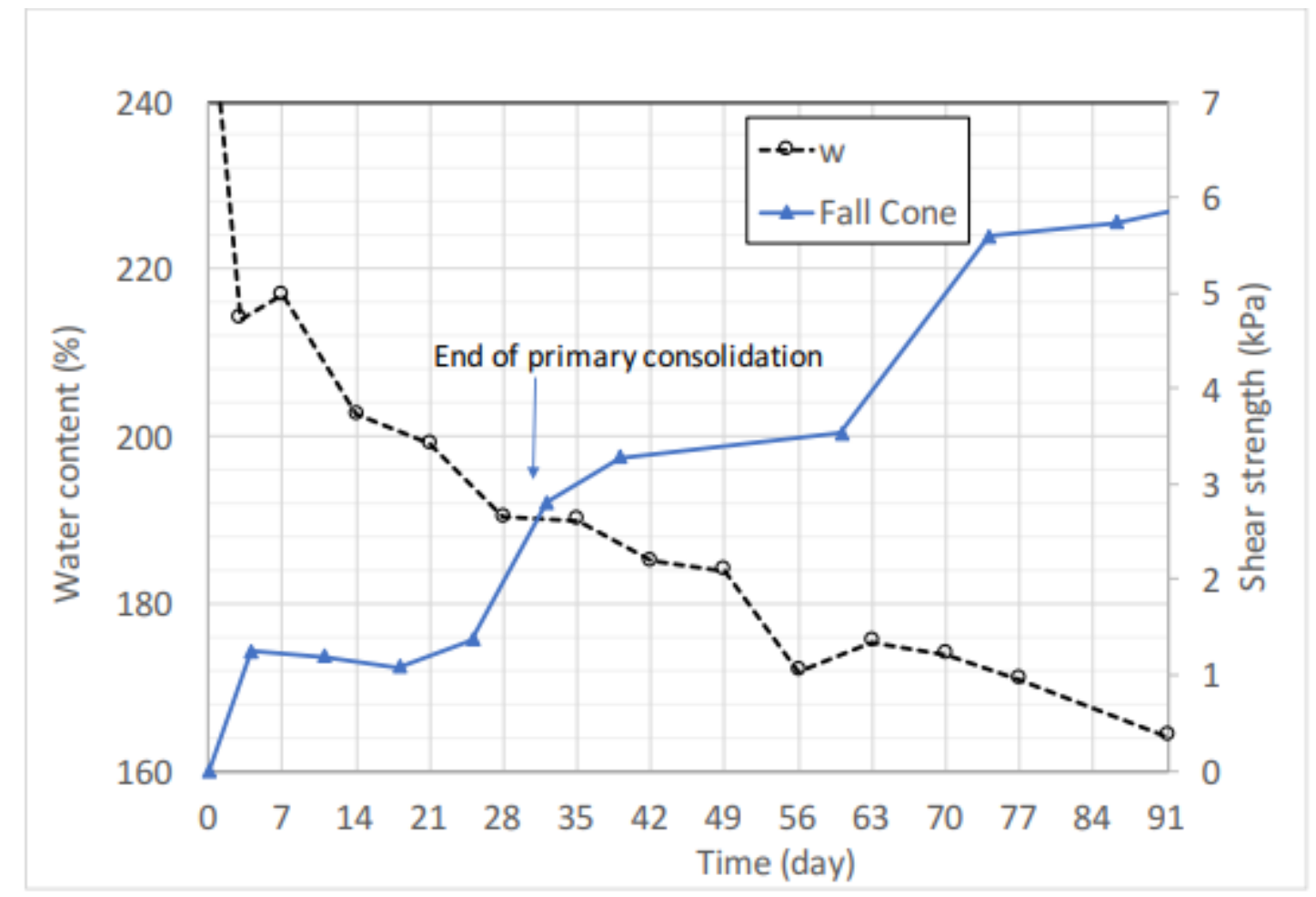

Figure 4.35. Dewatering and fall-cone strength in replicate $0.10 \mathrm{~m}$ tall columns of in-line flocculated FFT (Adapted from Salam, 2018). 


\section{Chapter 5 : Results (Phase II)}

\subsection{Steel box large scale consolidation test}

After mixing of tailings in a 1000L tote for 2 weeks, tailings were deposited in the $0.49 \mathrm{~m} \times 0.35$ $\mathrm{m} \times 0.72 \mathrm{~m}$ steel box on the March $2^{\text {nd }}, 2020$ using a plastic bucket until a layer of $0.62 \mathrm{~m}$ thickness was achieved. The initial average gravimetric water content was $83 \%$ by wt ( $54 \%$ solids content). Additional details on the deposition can be found in the Appendix C.

\subsubsection{Self weight consolidation}

For the first 23 days (March $2^{\text {nd }}-$ March 24 ${ }^{\text {th }}, 2020$ ), the tailings were left to consolidate by selfweight, a settlement of about 0.002 m occurred within this period (Figure 5.1). Core sampling taken at the beginning and end of the self weight consolidation period showed a small change $(<1 \%)$ in tailings water content during this period (Figure 5.2).

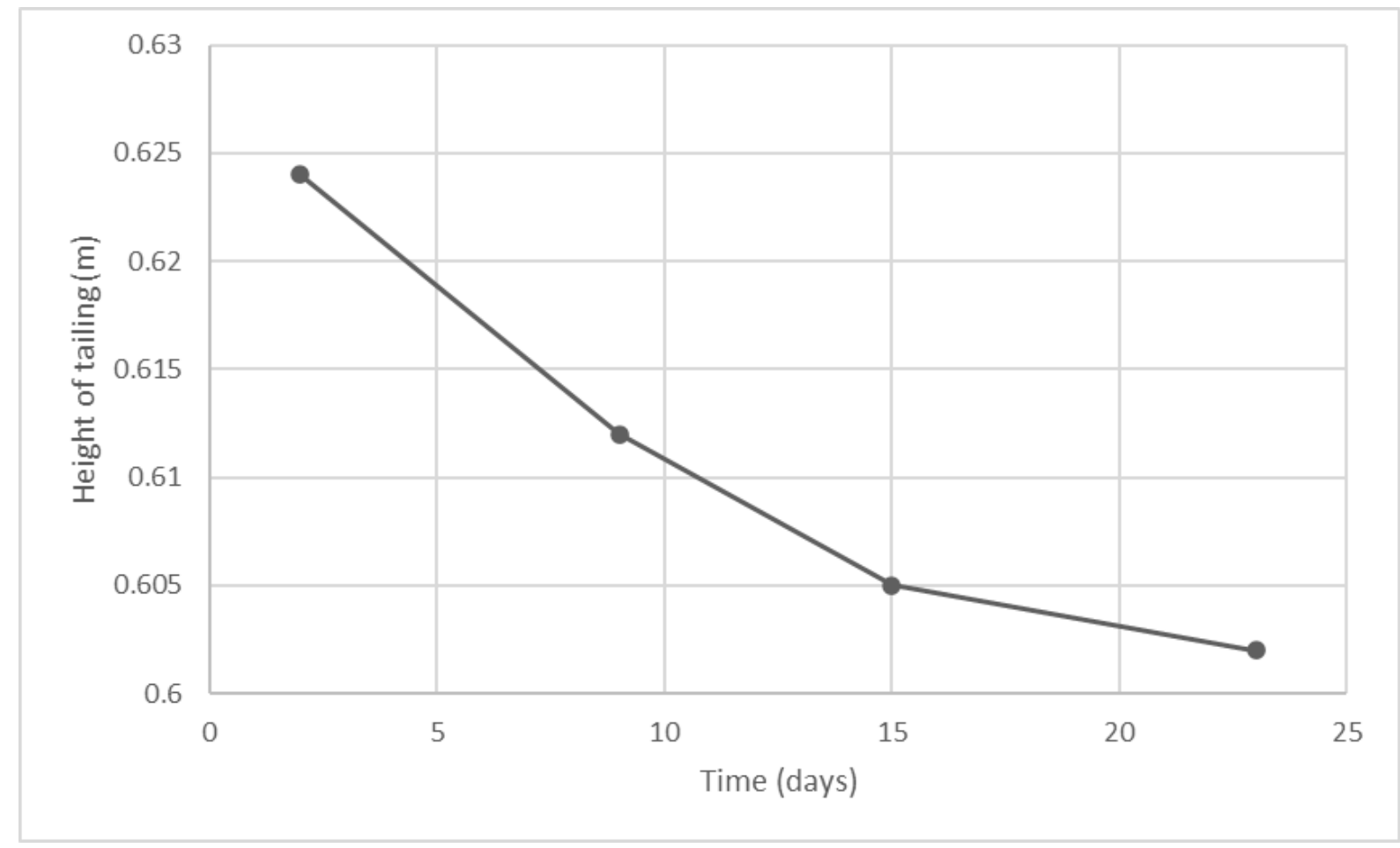

Figure 5.1. Displacement measurement from steel box test during first 23 days of self-weight consolidation. 


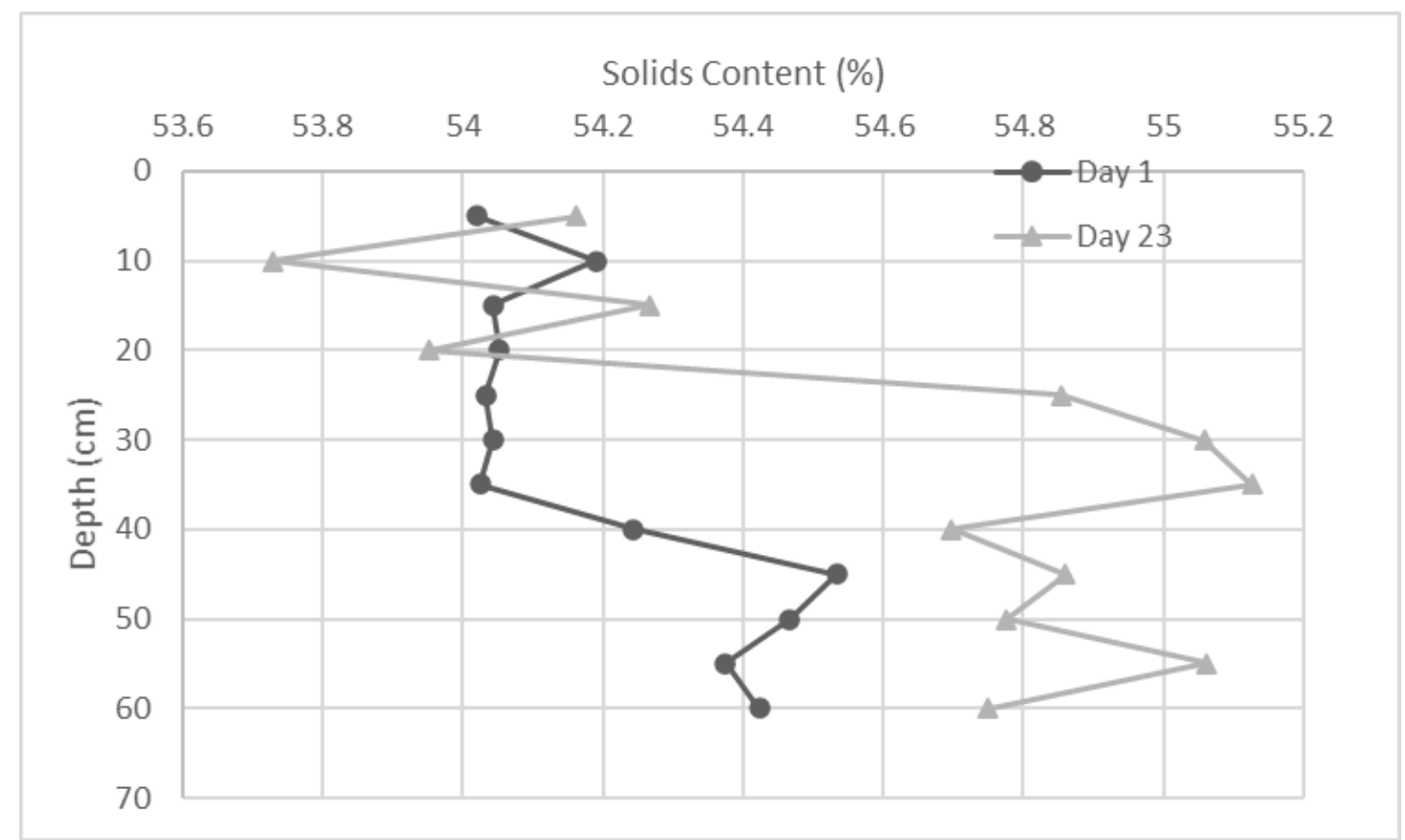

Figure 5.2. Water content by depth at day 1 and day 23 during self-weight consolidation.

Pore-water measurement at different depths showed an increase after pouring followed by gradual decrease over time and PWP measurement by depth increased as expected (Figure 5.3). By day 23 most of the excess pore-water pressure had dissipated indicating primary consolidation occurred in the steel box within the first 23 days of self-weight consolidation. The water content by depth changes (Figure 5.2) can be linked to primary consolidation occurring in the box. 


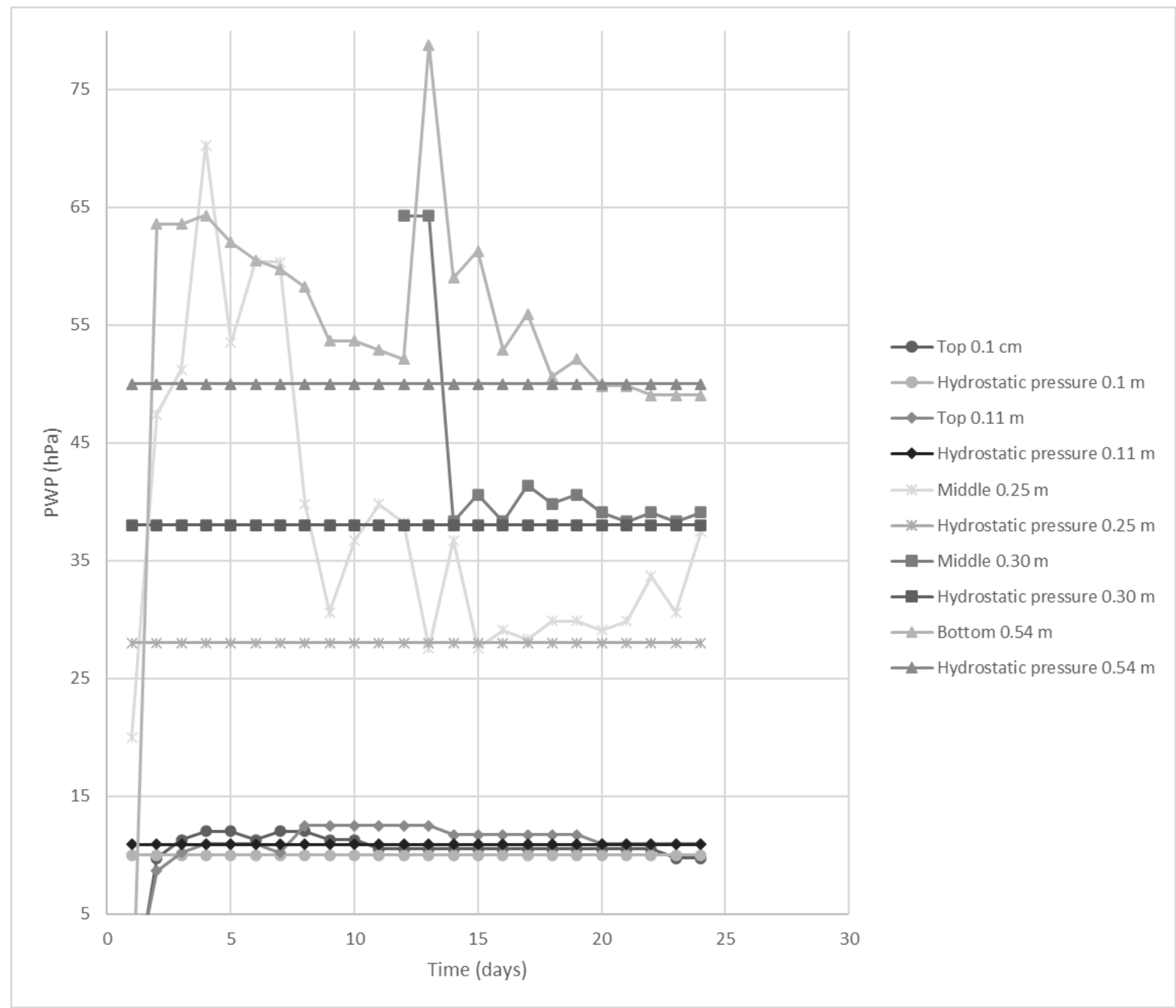

Figure 5.3. PWP readings at different depths.

The volumetric water content profile at different depths shows a gradual increase in water content at the top, middle and bottom layers (Figure 5.4). This could be linked to increase in the degree of saturation of the tailings during the self consolidation stage (Table C-3). As settlement occurs, entrapped air bubbles move out of the void space and water saturates the voids hence the recorded increase. 


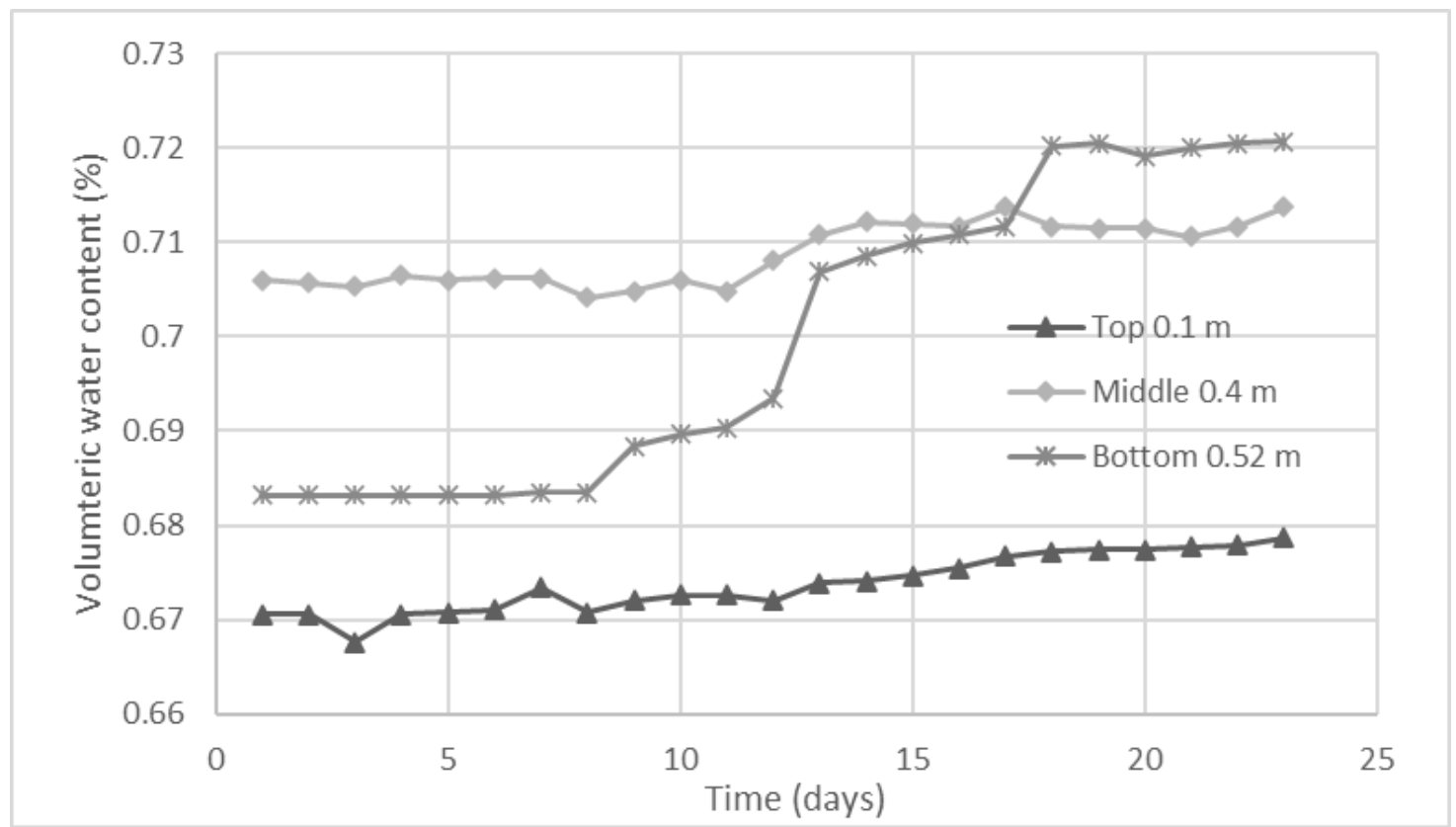

Figure 5.4. Volumetric water content profile at the top, middle and bottom layer.

The weight of the empty steel box before pouring $(327 \mathrm{~kg})$ and the sharp increase after pouring $(462 \mathrm{~kg})$, followed by little or no fluctuation in mass for the period of self weight consolidation (Figure C-1). The little fluctuation in mass was expected since the box was covered with plastic to minimize evaporation. Similarly, pressure gauge cells at the bottom gave a good approximation of the stress at the bottom of the box although the 2 sensors positioned close to the wall, at the right hand side (RHS) and left hand side (LHS) had lower readings than the sensor positioned at the middle (Figure C-2). This could be due to wall effect since both sensors are close to the walls of the box with some of the stress transferred to the wall.

\subsubsection{2 kPa loading step}

On day 26 (March $27^{\text {th }}, 2020$ ), $2 \mathrm{kPa}$ load was applied to the tailings and left for 18 days for excess pore-water pressure to dissipate. The initial loading saw an increase in pore-water pressure in the top, middle and bottom layers of the box, this was followed gradual dissipation of the excess pore-water pressure and as expected the PWP increased with depth (Figure 5.5). The tensiometer at $0.3 \mathrm{~m}$ appeared to give values out of range which could be due to varying reason including cavitation or air bubbles from tailings getting into the membrane. 


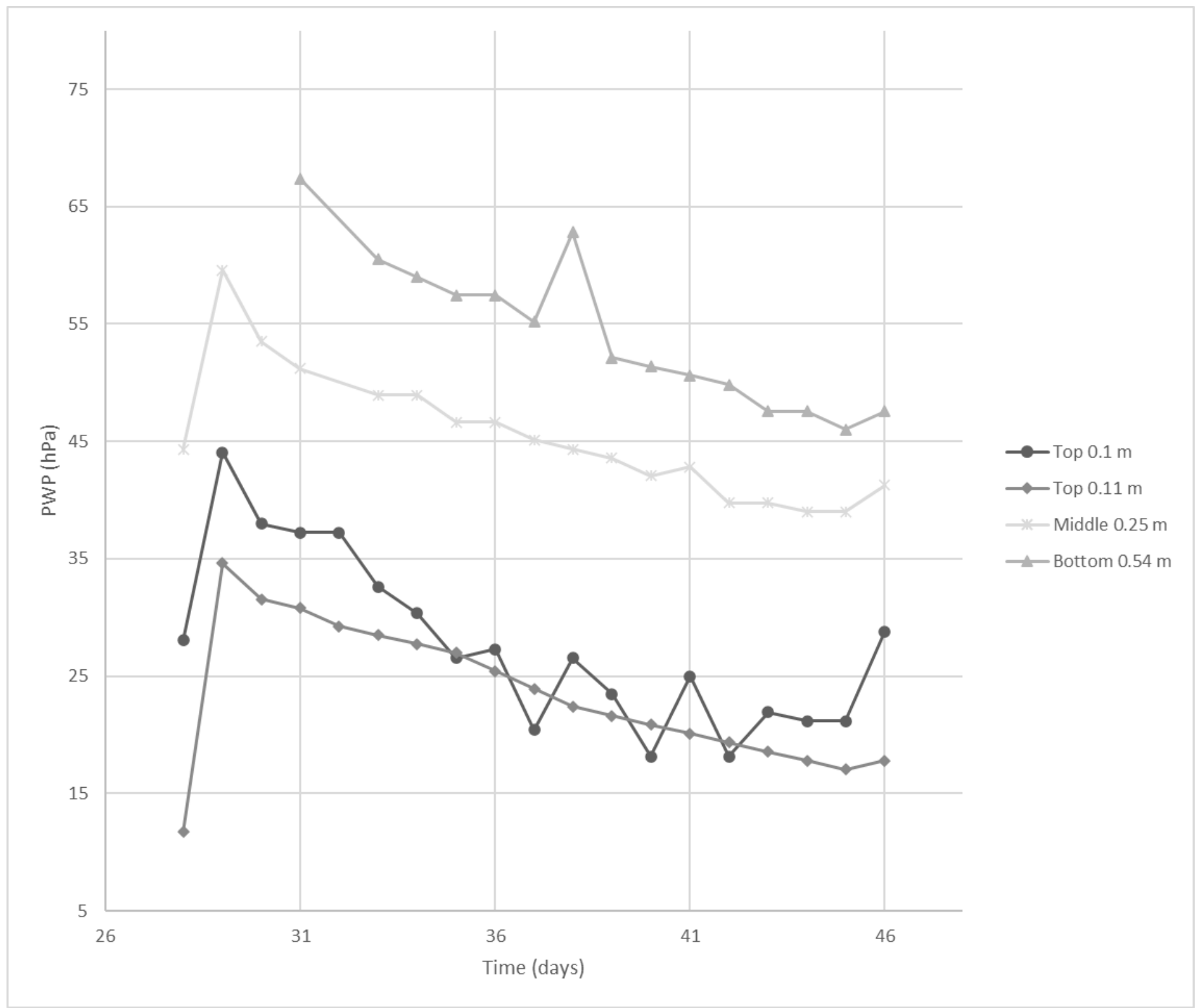

Figure 5.5. PWP readings at different depths for $2 \mathrm{kPa}$ loading step.

Figure 5.6 shows very small settlement $(<0.001 \mathrm{~m})$ occurred in this loading step with the excess pore-water pressure dissipating (complete primary consolidation occurred). The estimated coefficient of secondary compression is approximately zero for this loading step. 


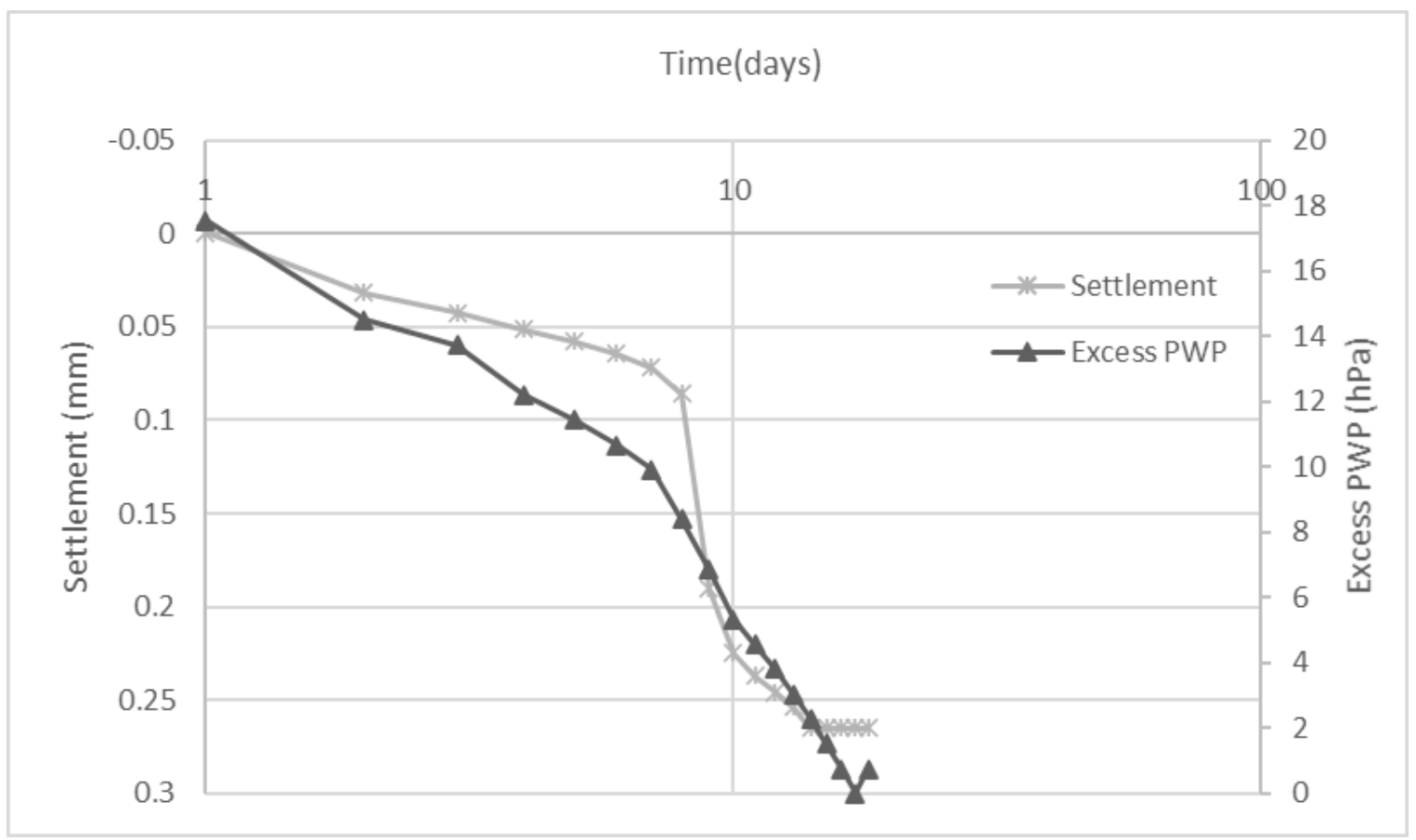

Figure 5.6. Settlement vs time plotted with excess pore-water pressure vs time for $2 \mathrm{kPa}$ loading step using the $0.11 \mathrm{~m}$ PWP sensor.

The volumetric water content sensors for the top, middle and bottom layer showed barely any changes for majority of the experiment with the top and middle layers have similar readings (Figure 5.7). Considering the settlement recorded for this loading step the slight change recorded is expected. 


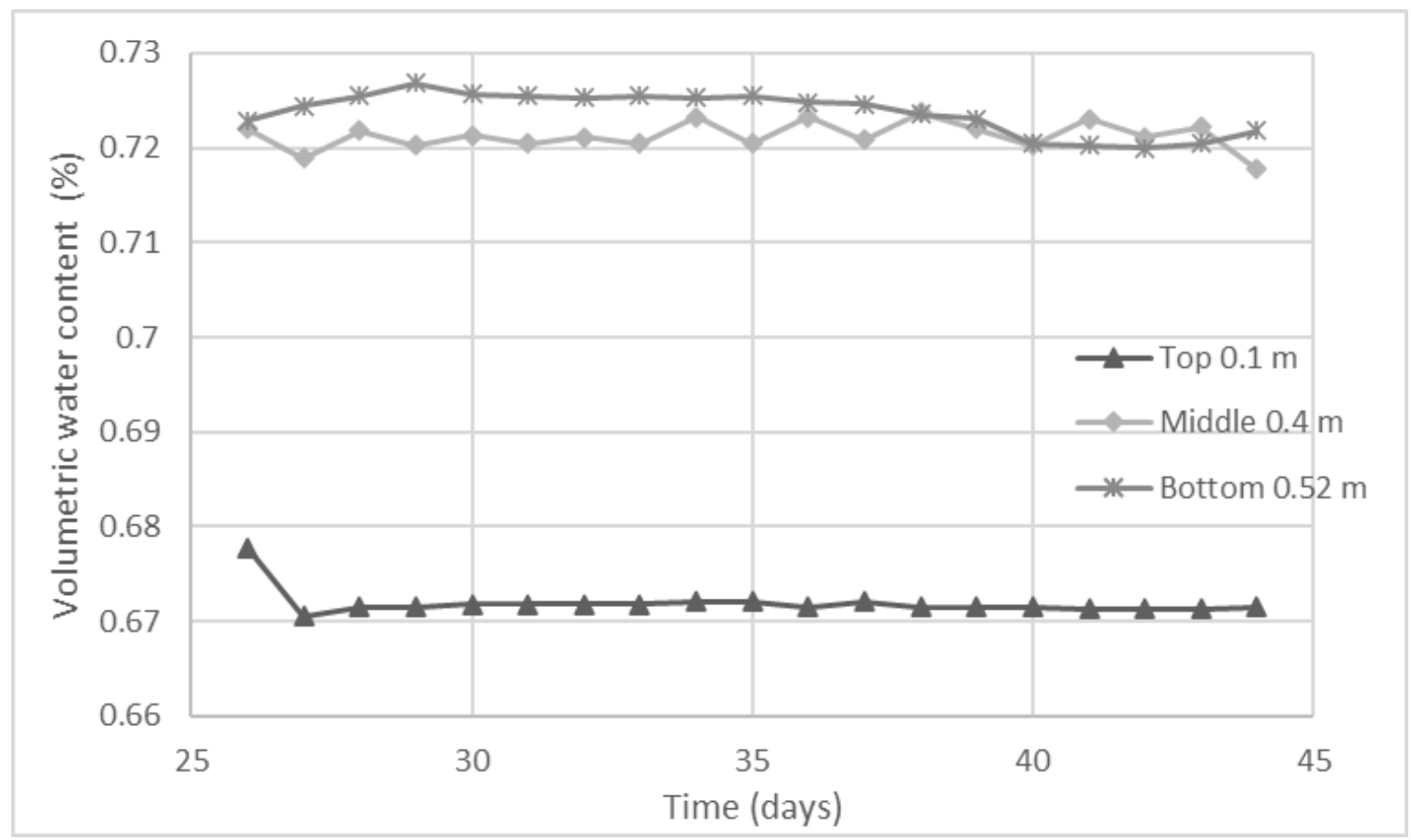

Figure 5.7. Volumetric water content at different depth for 2 kPa loading step.

Figure $\mathrm{C}-3$ shows the initial loading of the box which saw an increase of about $26 \mathrm{~kg}$ followed by little or no fluctuations in mass which indicates little or no evaporation. Likewise, pressure gauge cells at the bottom showed the presence of wall effect in the box with the cell farthest from the wall (middle gauge) having the most accurate load tracking during this loading step (Figure C-4).

\subsection{3 $3 \mathrm{kPa}$ loading step}

On day 44 (April 14 ${ }^{\text {th }}, 2020$ ), $3 \mathrm{kPa}$ load was applied to the tailings and left for 10 days for excess pore-water pressure to dissipate. The PWP sensors located at the top layer $(0.1$ and $0.11 \mathrm{~m})$, middle layer $(0.25 \mathrm{~m})$ and bottom $(0.54 \mathrm{~m}$ depth) recorded an increase in pore-water pressure after loading which was followed by a gradual dissipation of excess PWP as expected (Figure 5.8). The other tensiometer located in the middle layer $(0.3 \mathrm{~m})$ recorded out of range values and is linked to sensor cavitation due to air bubbles or membrane disturbance (Figure 5.8). 


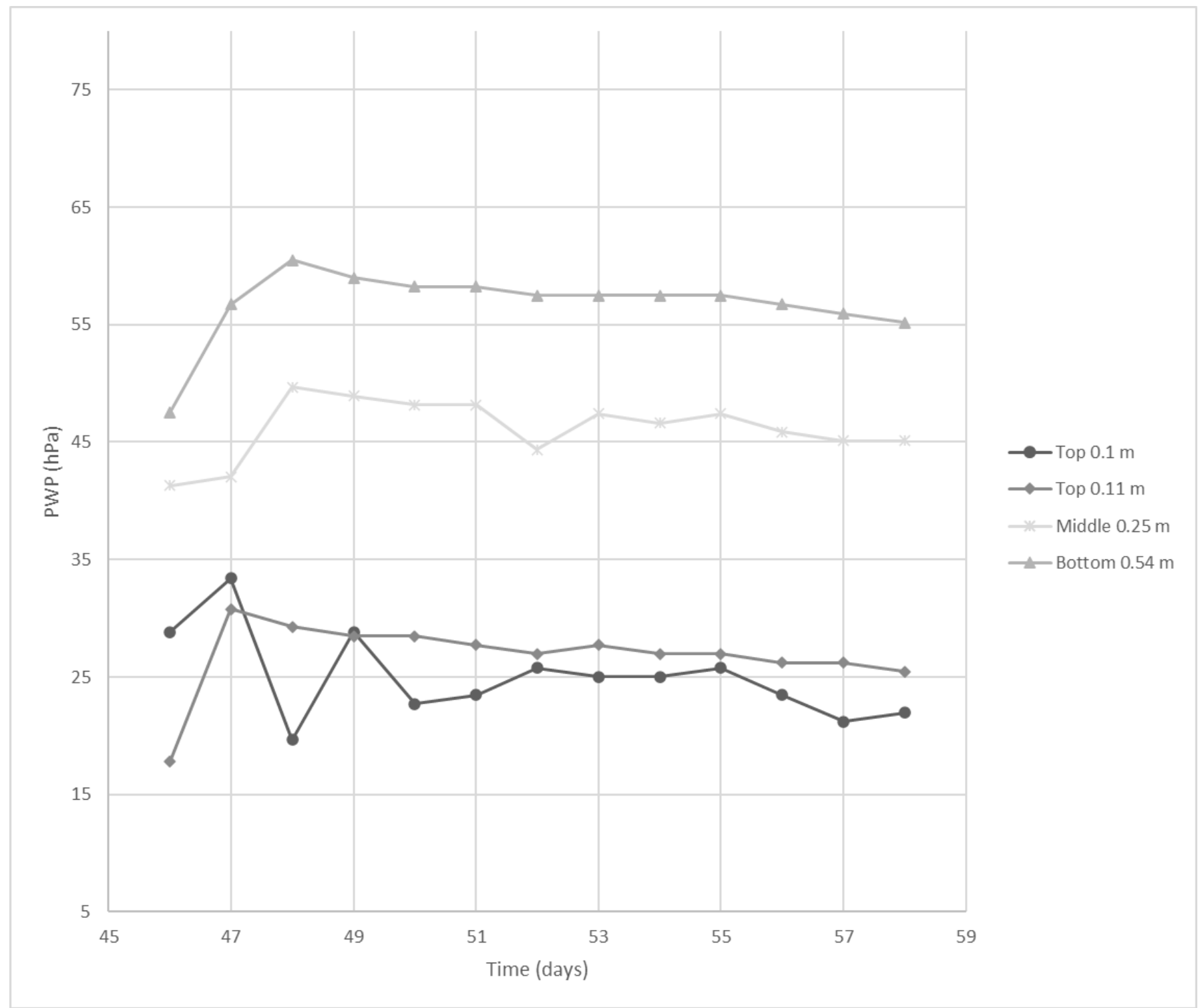

Figure 5.8. PWP readings at different depths for $3 \mathrm{kPa}$ loading step.

This total settlement for this loading step was less than $0.001 \mathrm{~m}$ this may be due to excess porewater pressure barely dissipated before load was changed (Figure 5.9). The estimated secondary compression coefficient is approximately zero for this loading step. 


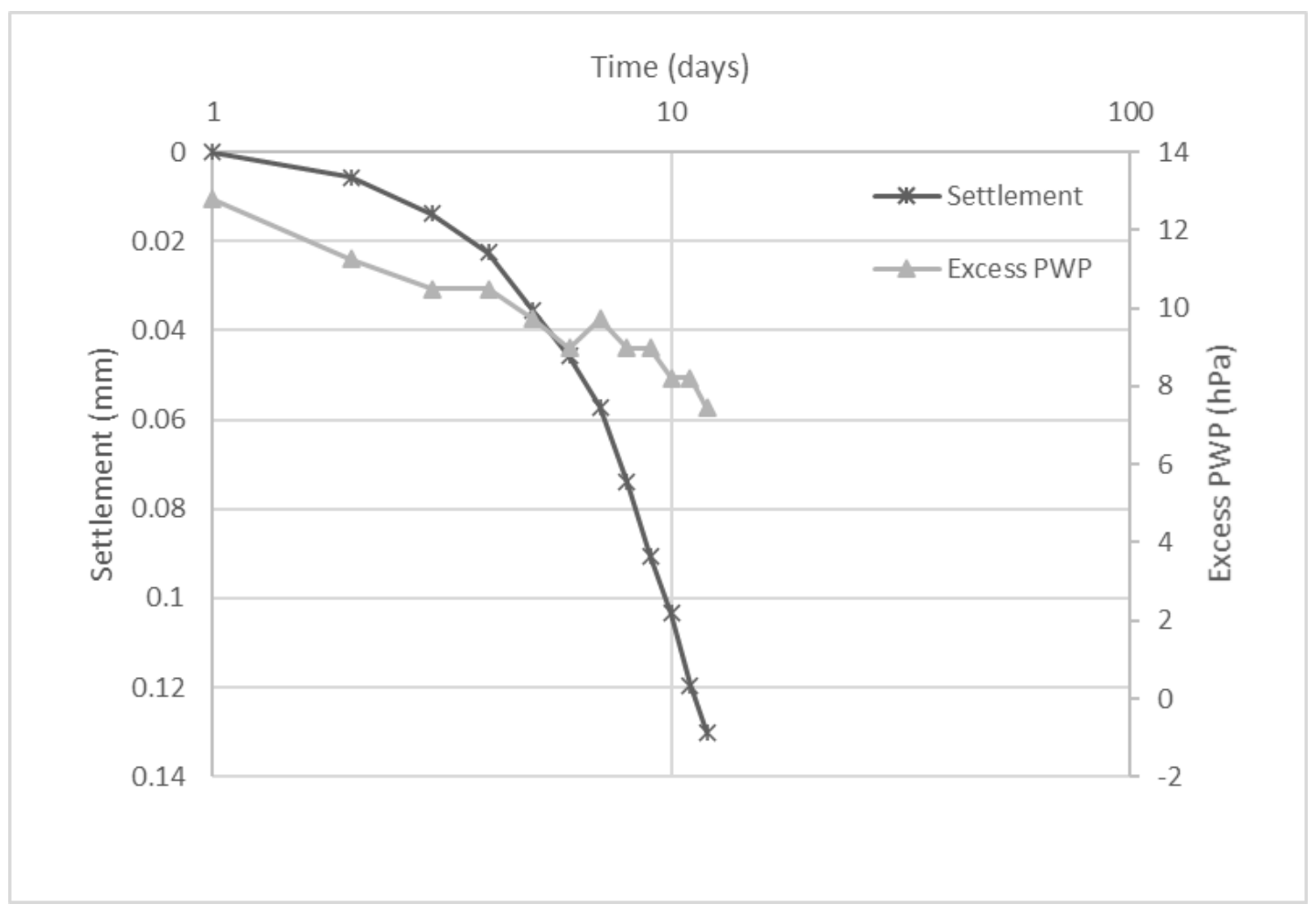

Figure 5.9. Settlement vs time plotted with excess pore-water pressure vs time for $3 \mathrm{kPa}$ loading step using the $0.11 \mathrm{~m}$ PWP sensor.

The volumetric water sensor barely changed in this loading step which is expected considering the very small settlement recorded for this loading step (Figure 5.10). 


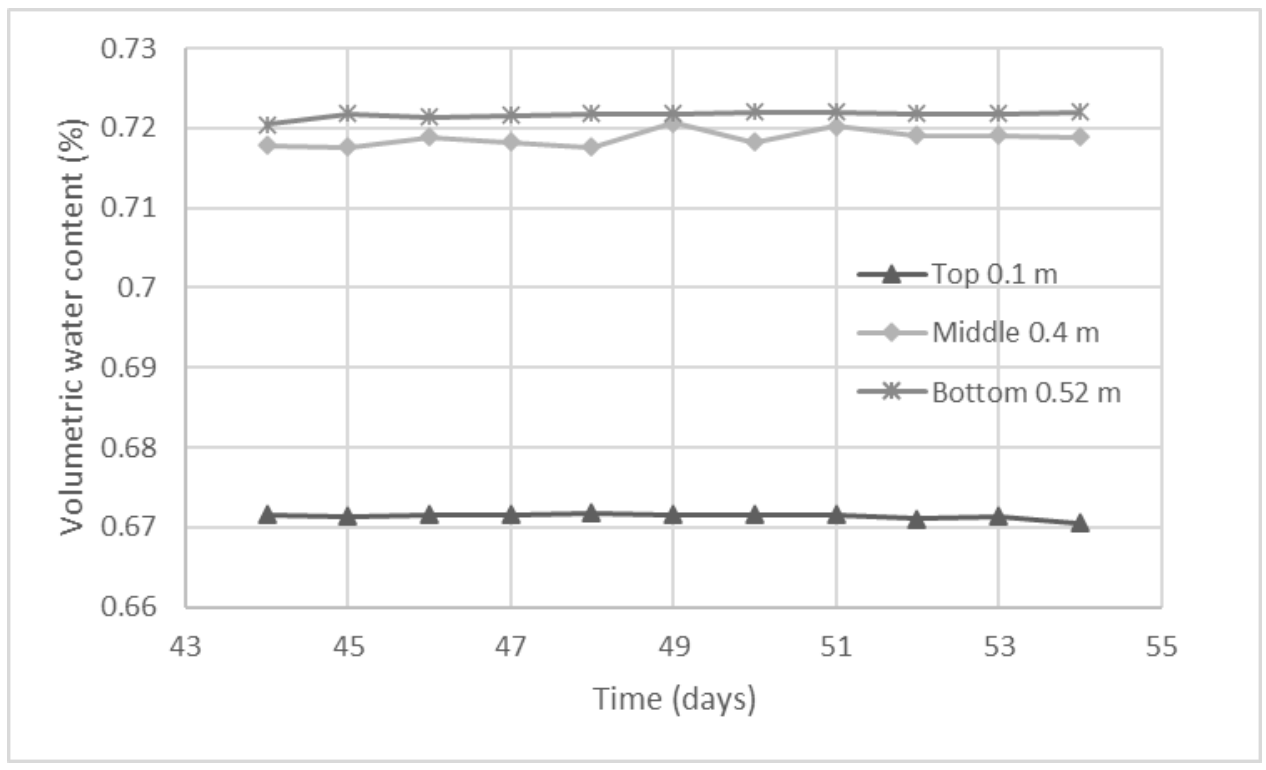

Figure 5.10. Volumetric water content at different depths for $3 \mathrm{kPa}$ loading step.

The initial additional loading for this loading step was $21 \mathrm{~kg}$ which was followed by little or no fluctuations indicating minimal mass loss in the box (Figure C-5). The three pressure gauges located at the bottom of the box seem to confirm the presence of wall effect with the sensor farthest from the wall (positioned at the middle) have the most accurate reading among the three sensors (Figure C-6).

\subsection{4 $8 \mathrm{kPa}$ loading}

On day 62 (May $1^{\text {st }}, 2020$ ), $8 \mathrm{kPa}$ load was applied to the tailings and left for 60 days for excess pore-water pressure to dissipate. The two tensiometer located at the top layer ( 0.1 and 0.11 $\mathrm{m})$, middle layer $(0.25 \mathrm{~m})$ and bottom layer $0.54 \mathrm{~m}$ recorded an increase in PWP pressure after loading followed by gradual dissipation of excess PWP as expected (Figure 5.11). Complete dissipation of excess PWP did not occur during this loading step for all sensors. The tensiometer located at $0.30 \mathrm{~m}$ depth (middle) recorded PWP readings that were out of the expected range may be due to cavitation or air bubbles travelling into the sensor (Figure 5.12). 


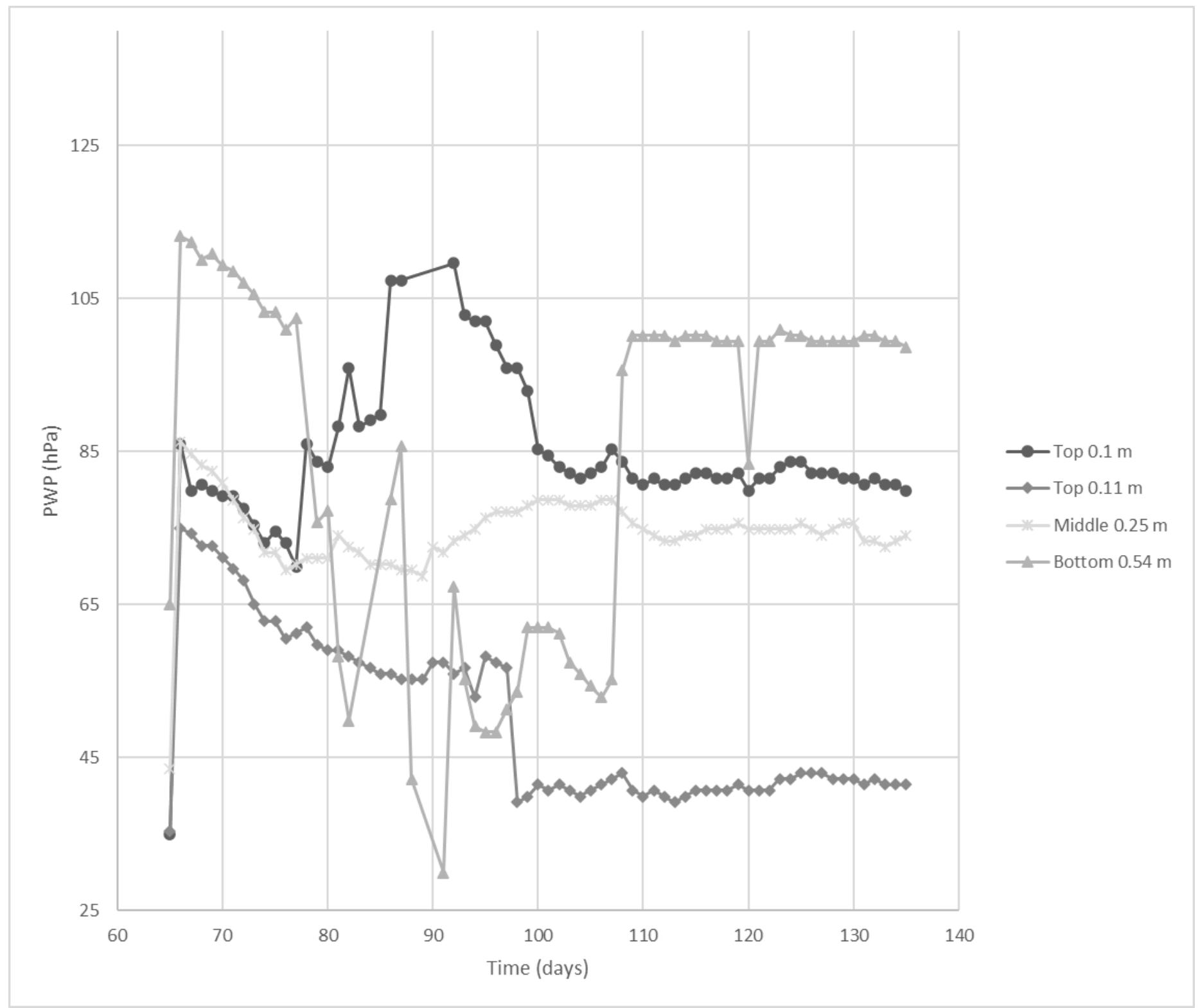

Figure 5.11. PWP readings at different depths for $8 \mathrm{kPa}$ loading step.

The deformation over the course of this loading was about $0.01 \mathrm{~m}$. The PWP reached a constant value around the $30^{\text {th }}$ day of the applied load and settlement continued after this constant value was reached till the end of the loading step (Figure 5.12). This behaviour is linked to secondary compression occurring at a substantial rate and controlling deformation in the box while keeping the PWP at a constant value. The estimated secondary compression coefficient for this loading step is approximately 0.11 . 


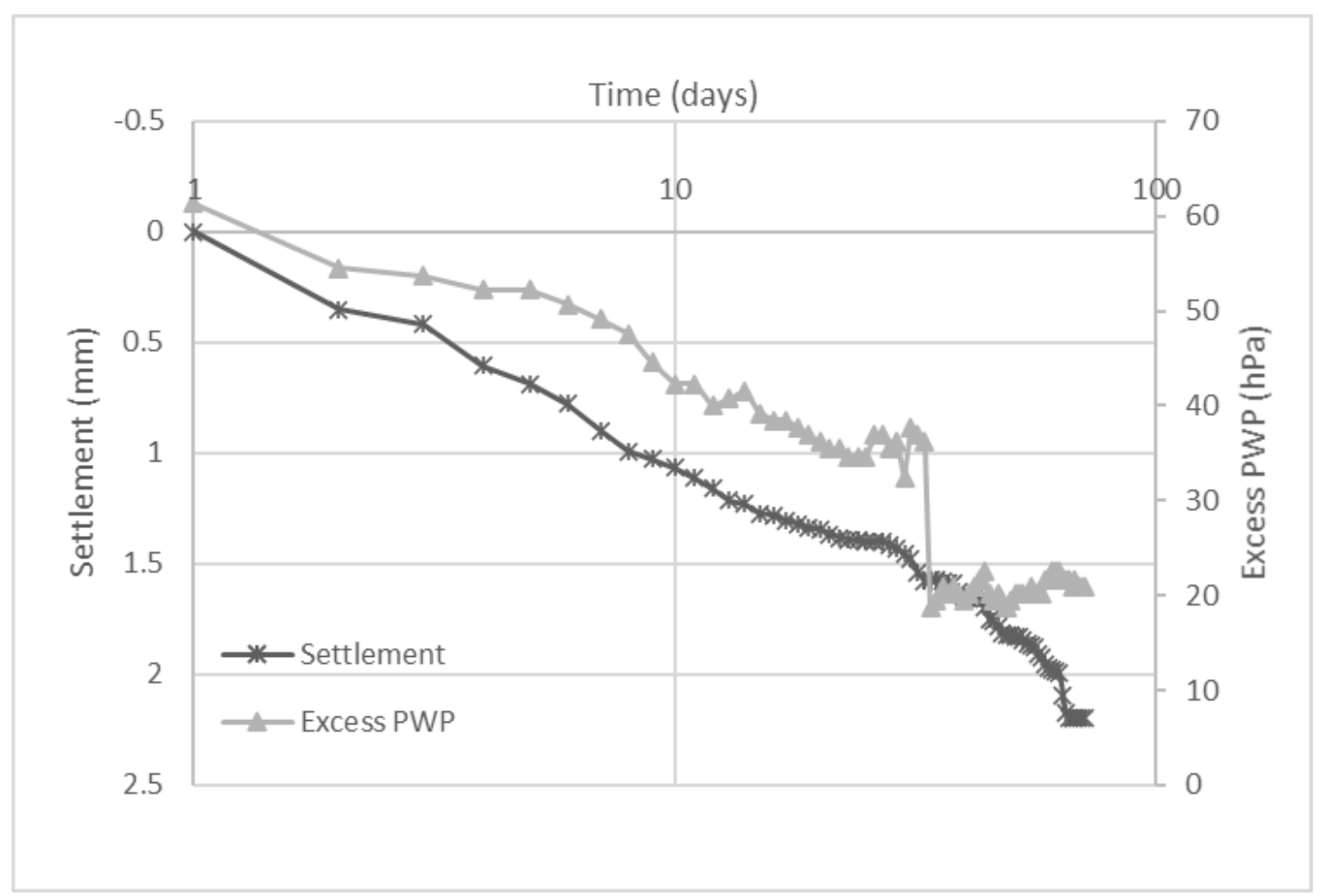

Figure 5.12. Settlement vs time plotted with excess pore-water pressure vs time for $8 \mathrm{kPa}$ loading step using the $0.11 \mathrm{~m}$ PWP sensor.

There is a noticeable increase and decrease in the volumetric water content during the $8 \mathrm{kPa}$ loading step (Figure 5.13). The increase between day 70 and 80 is due to battery change in the data logger thereafter, there was constant decrease in all three layers which was expected due to the large deformation during this loading step. 


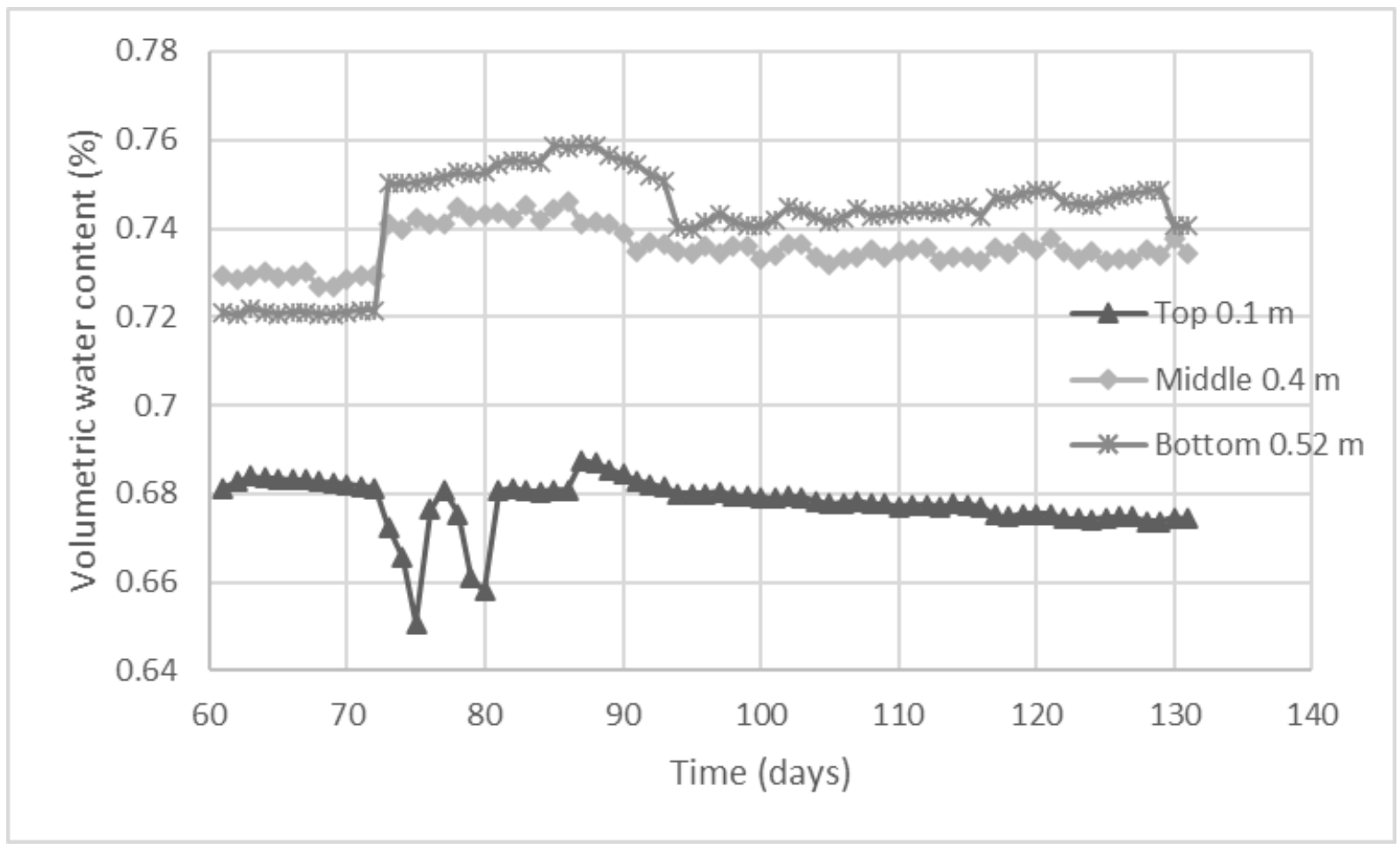

Figure 5.13. Volumetric water content at different depth during the $8 \mathrm{kPa}$ loading step.

The load increment in this loading step was about $75 \mathrm{~kg}$ with the little or no mass fluctuations occurring during the load duration (Figure C-7). Similar wall effect was noticed from the pressure gauge sensors with the sensor positioned at the middle giving the most accurate stress measurement (Figure C-8).

\subsection{5 $16 \mathrm{kPa}$ loading}

On day 132 (July 9th, 2020), $16 \mathrm{kPa}$ load was applied to the tailings and left for 62 days for excess pore-water pressure to dissipate. The tensiometer located at a depth $0.11 \mathrm{~m}$ (top layer) recorded an increase in PWP after loading, followed by a gradual dissipation which was expected (Figure 5.14). Like in the $8 \mathrm{kPa}$ step the PWP equilibrated at a constant value over time with excess PWP not completely dissipating. The other tensiometer at $0.10 \mathrm{~m}$ depth appears to be cavitated with measured PWP readings out of the expected range (Figure 5.14).

The tensiometer located at $0.30 \mathrm{~m}$ depth (middle) appears to record out of range values (Figure 5.14). This maybe due to cavitation or air bubbles travelling into the sensor. The tensiometer at the $0.25 \mathrm{~m}$ depth initially had an increase in PWP after loading, followed by gradually dissipation of excess PWP (Figure 5.14). 28 days after the load application, the sensor appeared to record out of range measurements from days 165 to 184 which was followed by a return to 
values within expected range. This behaviour may have been due to air bubbles from the soil interfering with the sensor measurement. As seen in the $8 \mathrm{kPa}$ loading step for same sensor, PWP values reached a constant value without complete dissipation of excess PWP.

The tensiometer at the bottom had the highest PWP increase after loading followed by gradual dissipation of excess PWP (Figure 5.14). The PWP appears to slightly increase or equilibrate at constant values without complete dissipation of excess PWP occurring. This also appears to be the trend for other sensors $(0.10 \mathrm{~m}$ and $0.25 \mathrm{~m})$ over the duration of the 16 and $8 \mathrm{kPa}$ loading steps.

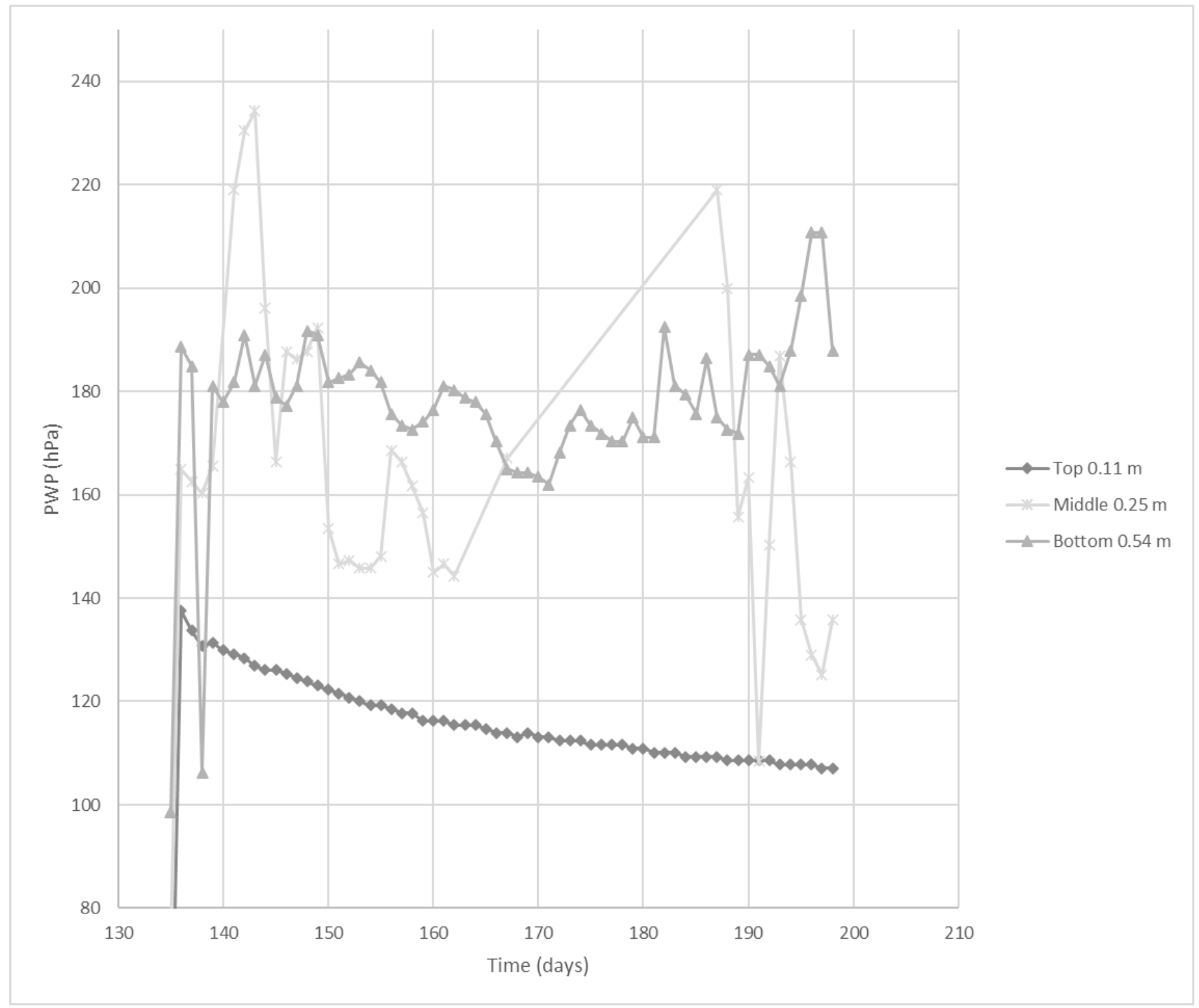

Figure 5.14. PWP readings at different depths for $16 \mathrm{kPa}$ loading step. 
The deformation over the course of this loading was about $0.10 \mathrm{~m}$ with the excess PWP not fully dissipated by the $62^{\text {nd }}$ day of the applied load (Figure 5.15). The largest deformation occurred during this loading step and the secondary compression coefficient was estimated to be about 0.48 .

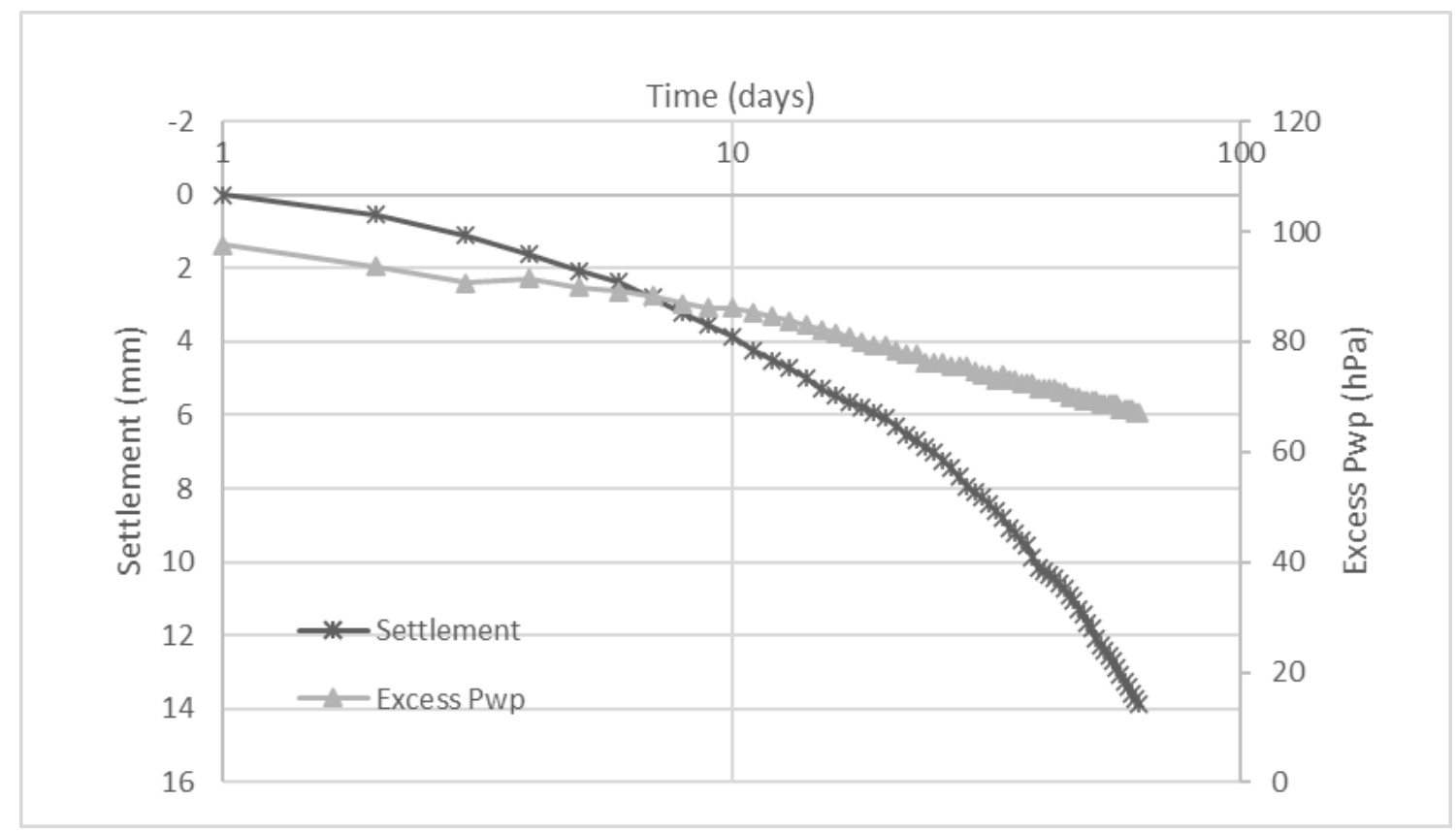

Figure 5.15. Settlement vs time plotted with excess pore-water pressure vs time for $16 \mathrm{kPa}$ loading step using the $0.11 \mathrm{~m}$ PWP sensor.

There is a noticeable decrease in the volumetric water content immediately after the $16 \mathrm{kPa}$ loading is applied and over the loading step (Figure 5.16). This was expected due to the large deformation during this loading step. 


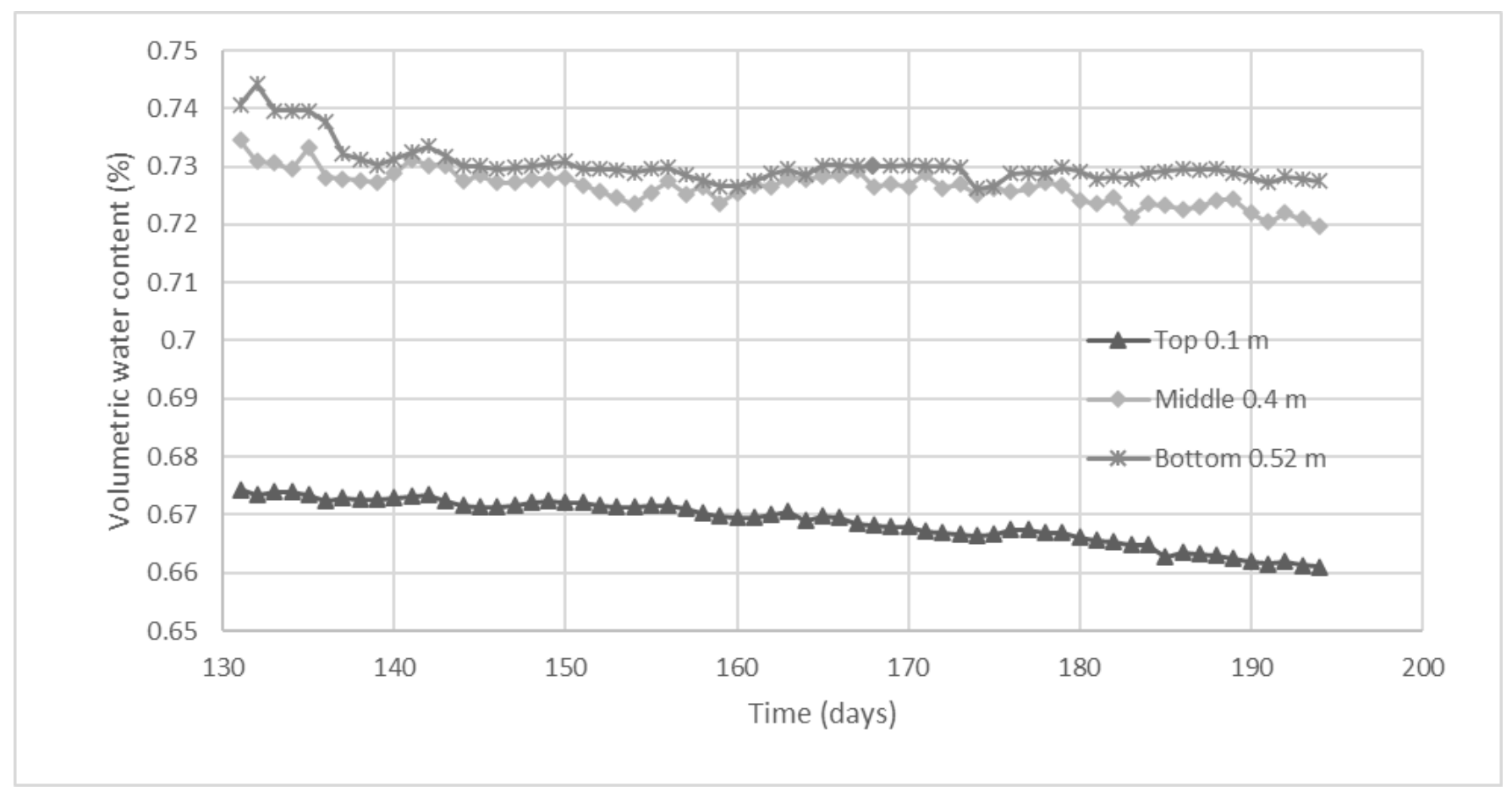

Figure 5.16. Volumetric water content at different depth during the $16 \mathrm{kPa}$ loading step.

The load increment in this loading step was about $140 \mathrm{~kg}$ with the little or no mass fluctuations occurring during the load duration (Figure C-9). Similar wall effect was noticed from the pressure gauge sensors with the sensor positioned at the middle giving the most accurate stress measurement (Figure $\mathrm{C}-10$ ). The higher than expected reading for the middle sensor can be explained by tailings settling on either side of the pressure plate.

\subsubsection{Combined results (self weight consolidation and $2 \mathrm{kPa}, 3 \mathrm{kPa}, 8 \mathrm{kPa}$, and $16 \mathrm{kPa}$ loading steps)}

PWP initially increased and decreased due to self weight consolidation, followed by sharp increase and excess PWP dissipation at 2, 3, 8 and $16 \mathrm{kPa}$. The tensiometers located at $0.10 \mathrm{~m}$ and $0.3 \mathrm{~m}$ depth stopped working during the test hence the distorted values recorded (Figures 5.17 to 5.21). The $10 \mathrm{kPa}$ yellow line between days 55 and 61 represent a failed loading step of $10 \mathrm{kPa}$. 


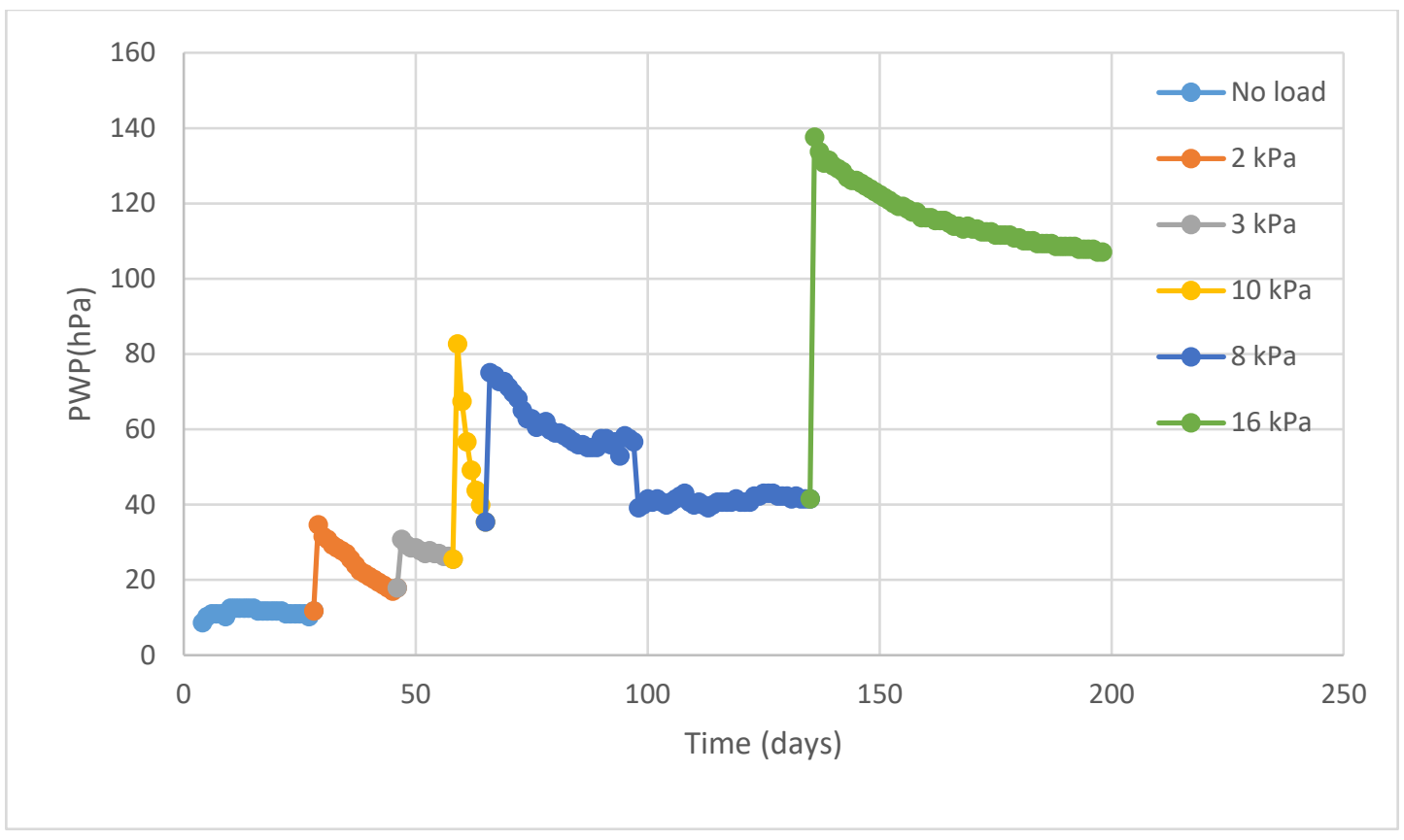

Figure 5.17. Tensiometer located at $0.11 \mathrm{~m}$ depth PWP reading over the period of test.

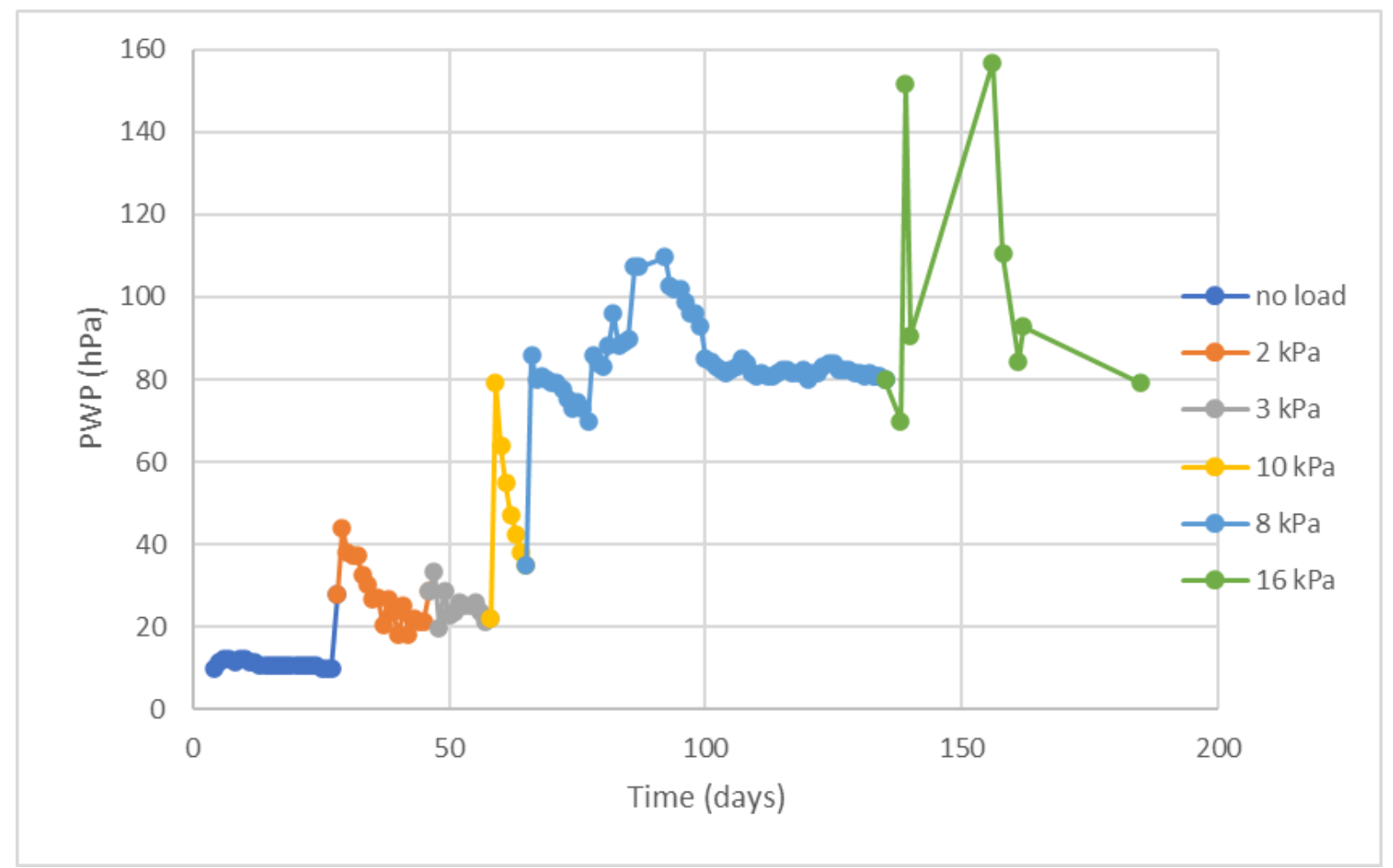

Figure 5.18. Tensiometer located at $0.10 \mathrm{~m}$ depth PWP reading over the period of test. 


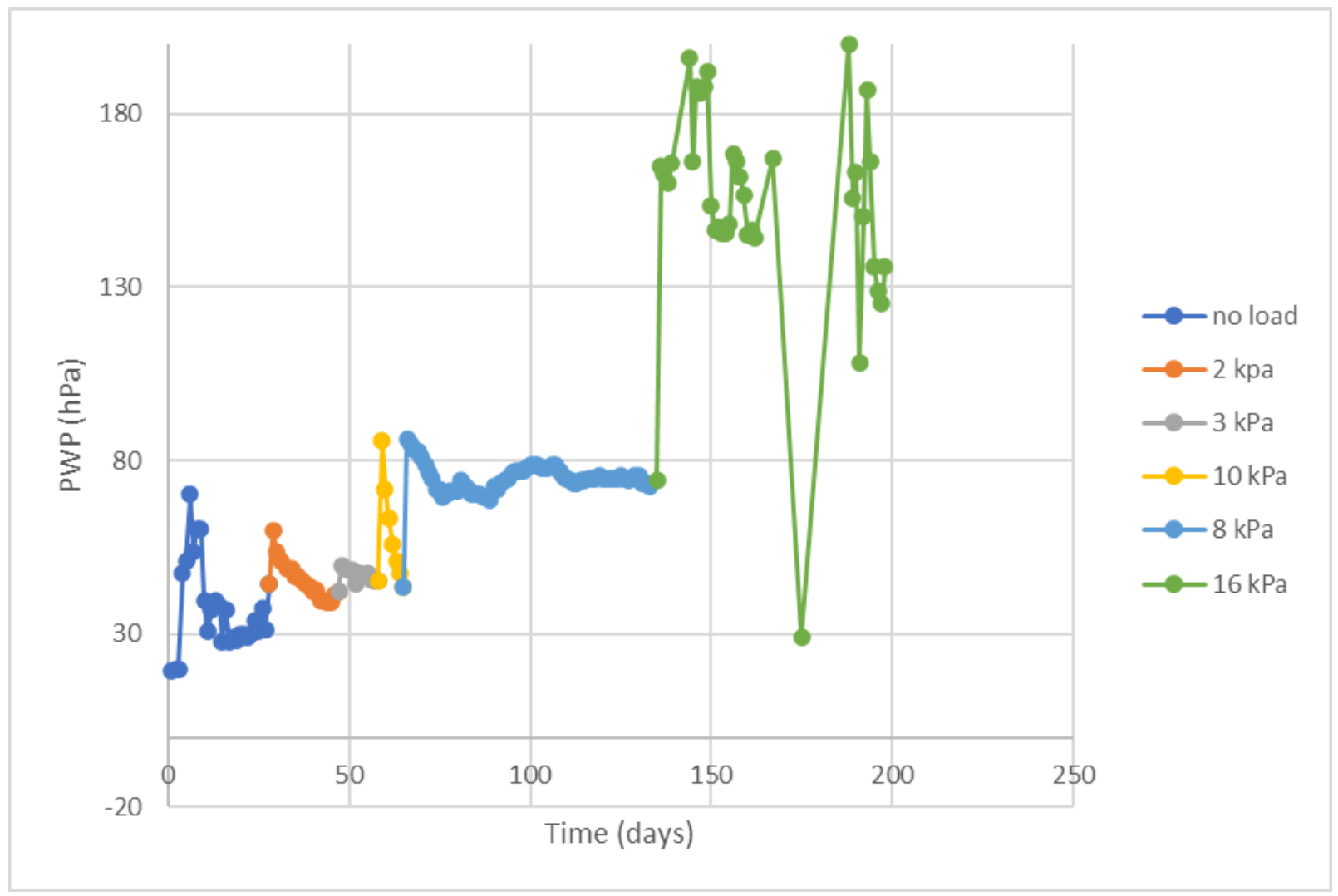

Figure 5.19. Tensiometer located at $0.25 \mathrm{~m}$ depth PWP reading over the period of test. 


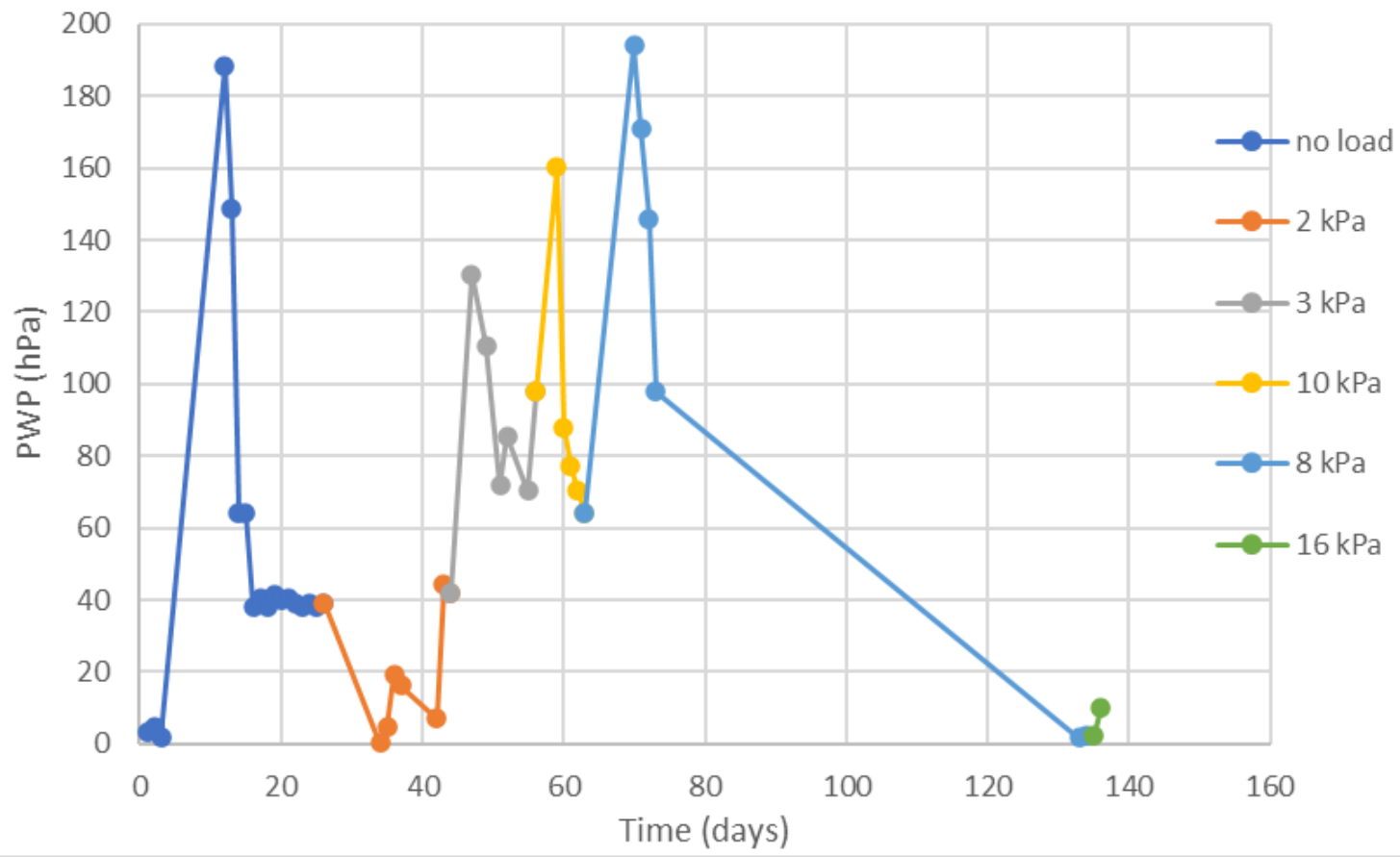

Figure 5.20. Tensiometer located at $0.30 \mathrm{~m}$ depth PWP reading over the period of test. 


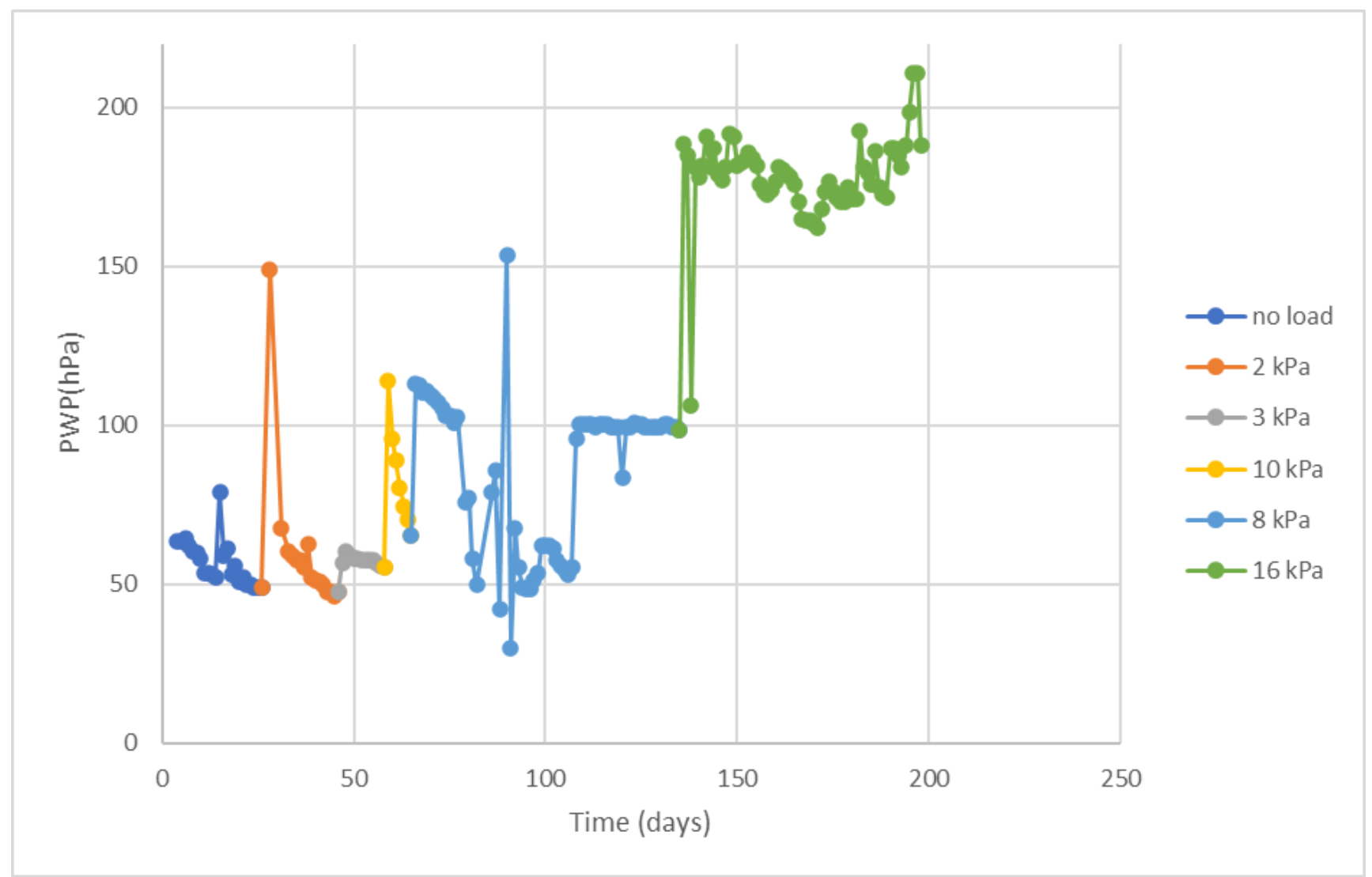

Figure 5.21. Tensiometer located at $0.54 \mathrm{~m}$ depth PWP reading over the period of test.

Initially after pouring there was an increase in volumetric water content followed by a slow decrease (Figure 5.22). This increase can be linked to changes in the chemistry of the samples and saturating happening over time with water filling the void spaces where air pockets were previously present. The changes between days 50 and 60 are due to the failed loading step of $10 \mathrm{kPa}$. The spike noticed between days 70 and 80 is attributed to the battery change in the volumetric water content data logger. After day 125, the water content decreases steadily. Solids content by depth from core samples at the end of the test (Figure C-13) indicated the solids content at the bottom was lower when compared to the top and middle layer. This correlates the results gotten from the water content sensor (Figure 5.22) where the sensor located at top $(0.10 \mathrm{~m})$ showed showing a lower water content than the bottom $(0.52 \mathrm{~m})$. 


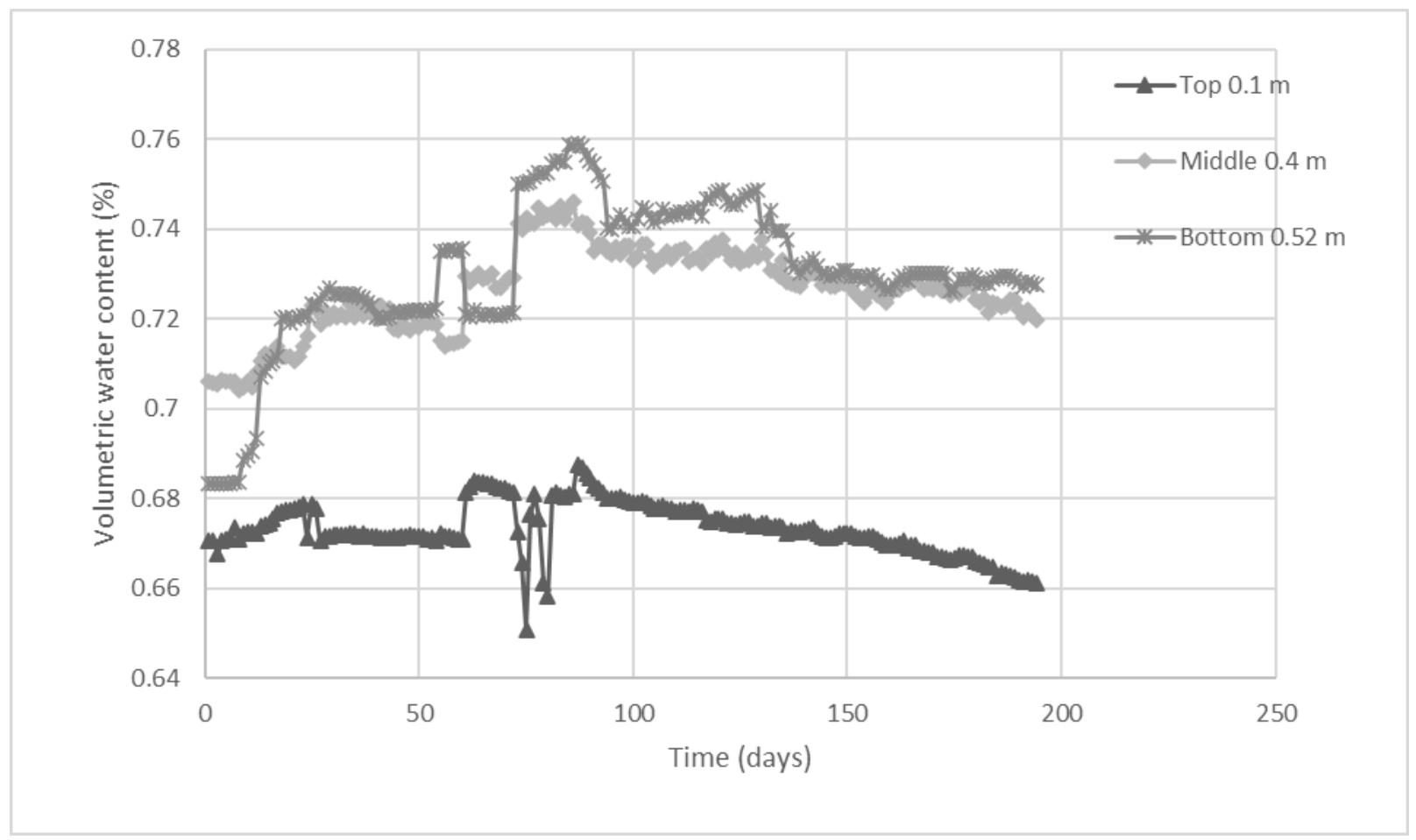

Figure 5.22. Volumetric water content over the test period.

The load applied over the period of the test and the stress at the bottom of the box were tracked by both the load cell and pressure gauge cells (Figures C-11 and C-12). The load cell monitored the mass changes in the box and showed little or no changes over the duration of the box for each loading step (Figure C-12). The pressure gauge cell looked far from the wall had the most accurate reading (Figure $\mathrm{C}-12$ ).

Using average PWP gotten from tensiometers, the effective stress was estimated for the box and the void ratio was estimated from the box settlement data. Figure 5.23 shows the estimated steel box compressibility compared to the oedometer day 79 remolded and undisturbed samples. The estimated steel box compressibility curve is much closer to the undisturbed day 79 from the oedometer test with both showing the development of preconsolidation pressure over time. 


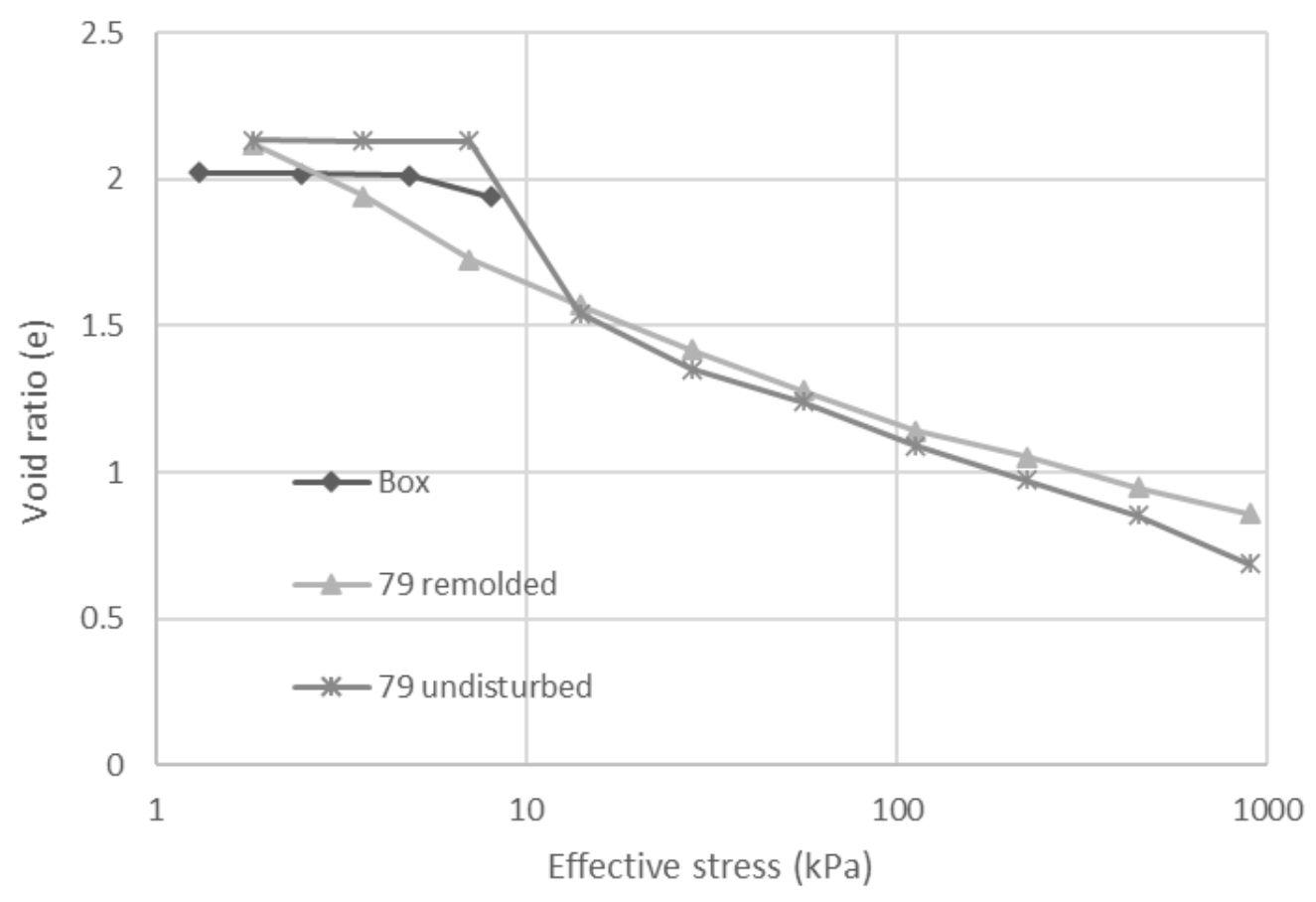

Figure 5.23. Comparison between the oedometer and steel box compressibility curves.

\subsection{Comparison to modelled results}

Similarly, to phase I two model runs were stimulated using the hydraulic conductivity derived from oedometer test and calibrated hydraulic conductivity. Deposition scheme and hydraulic and mechanical boundary condition parameters were derived the steel box experimental setup. The loads are applied as follows, $2 \mathrm{kPa}$ - day 26, $3 \mathrm{kPa}$ - day 44, $8 \mathrm{kPa}$ - day 66 and $16 \mathrm{kPa}$ - day 132.

The materials parameters were selected by fitting compressibility and hydraulic conductivity void ratio plots from day 79 and 0 respectively (Figures 4.18 and 4.19). The parameters used in the initial UNSATCON analysis (Table 5-1) and software generated plots are shown in the UNSATCON methods sub-section (Figures 3.19 and 3.23).

Table 5-1: Constitutive relationship used in original steel box model prediction.

\begin{tabular}{|l|l|l|}
\hline Constitutive relationship & Effective stress - e & Hydraulic conductivity - e \\
\hline Multiplier & 2.43 & $4 \mathrm{e}-9$ \\
\hline Power & -0.141 & 3.69 \\
\hline
\end{tabular}


Using similar calibration to phase I the hydraulic conductivity function was reduced by dividing the oedometer calculated hydraulic conductivity value by 20 . Other parameters were left unchanged for the second analysis (Table 5-2).

Table 5-2: Constitutive relationship used in steel box calibrated model prediction.

\begin{tabular}{|l|l|l|}
\hline Constitutive relationship & Effective stress -e & Hydraulic conductivity -e \\
\hline Multiplier & 2.43 & $2 \mathrm{e}-10$ \\
\hline Power & -0.141 & 3.69 \\
\hline
\end{tabular}

For the calibrated model run the generated plots are attached in the appendix E (Figures 164 and 165).

The spatial (50) and time discretization (100) parameters (Figure 3.23) used in both model runs were selected by adjusting one parameter while keeping the other parameter constant and the combination with the best comparison to the measured results was chosen.

\subsubsection{Solids content by depth profile}

The solids content by depth profile predicted using the oedometer calculated hydraulic conductivity shows some correlation with the measured solids content from core sampling at the beginning and end of self-weight consolidation (Figure 5.24). 


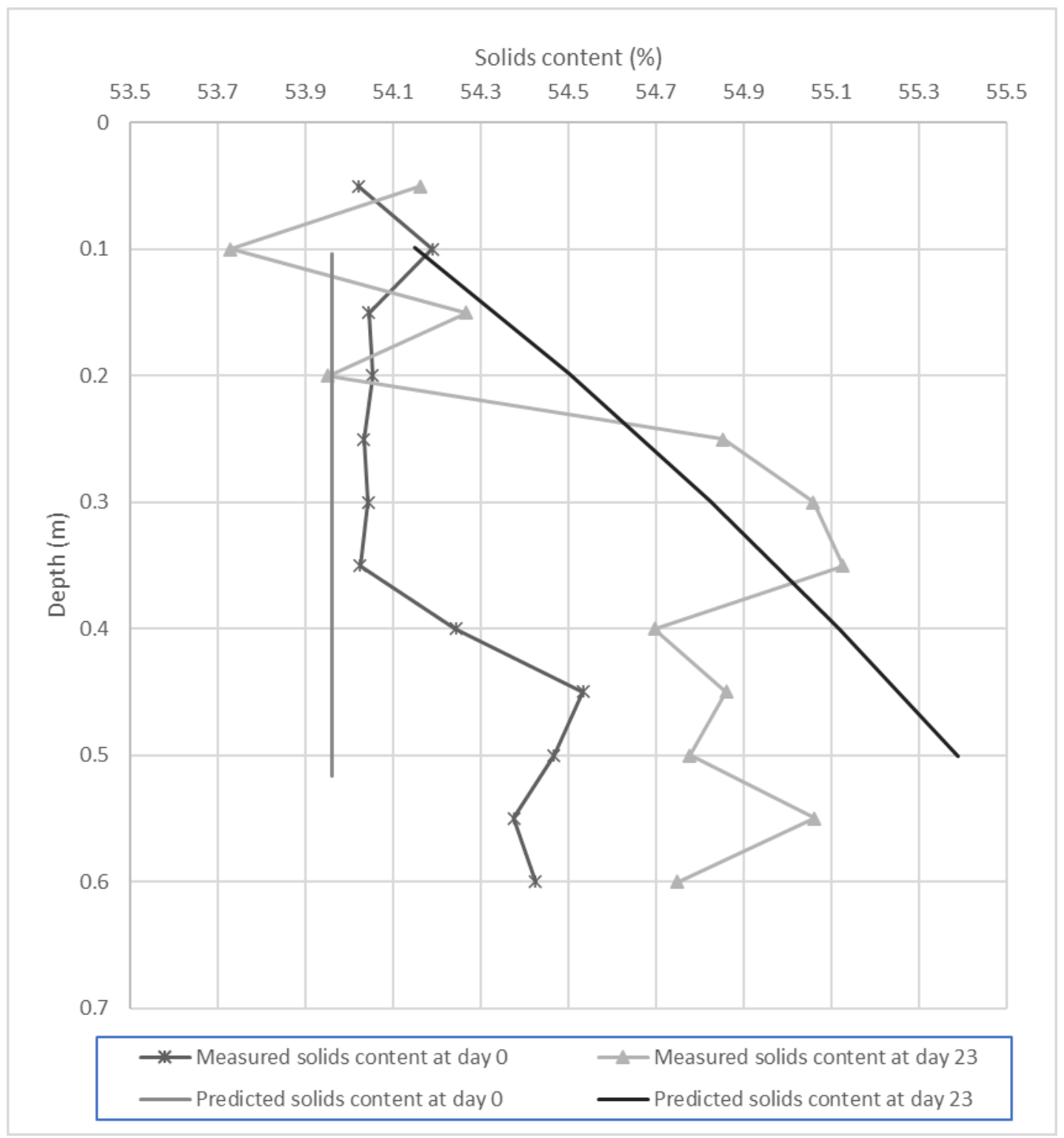

Figure 5.24. Measured and predicted solids content by depth profile using oedometer calculated hydraulic conductivity.

The calibrated hydraulic conductivity predicted a smaller change in solids content by depth profile in comparison to the oedometer calculated hydraulic conductivity model (Figure 5.25). This is expected since the calibrated hydraulic conductivity is lower. 


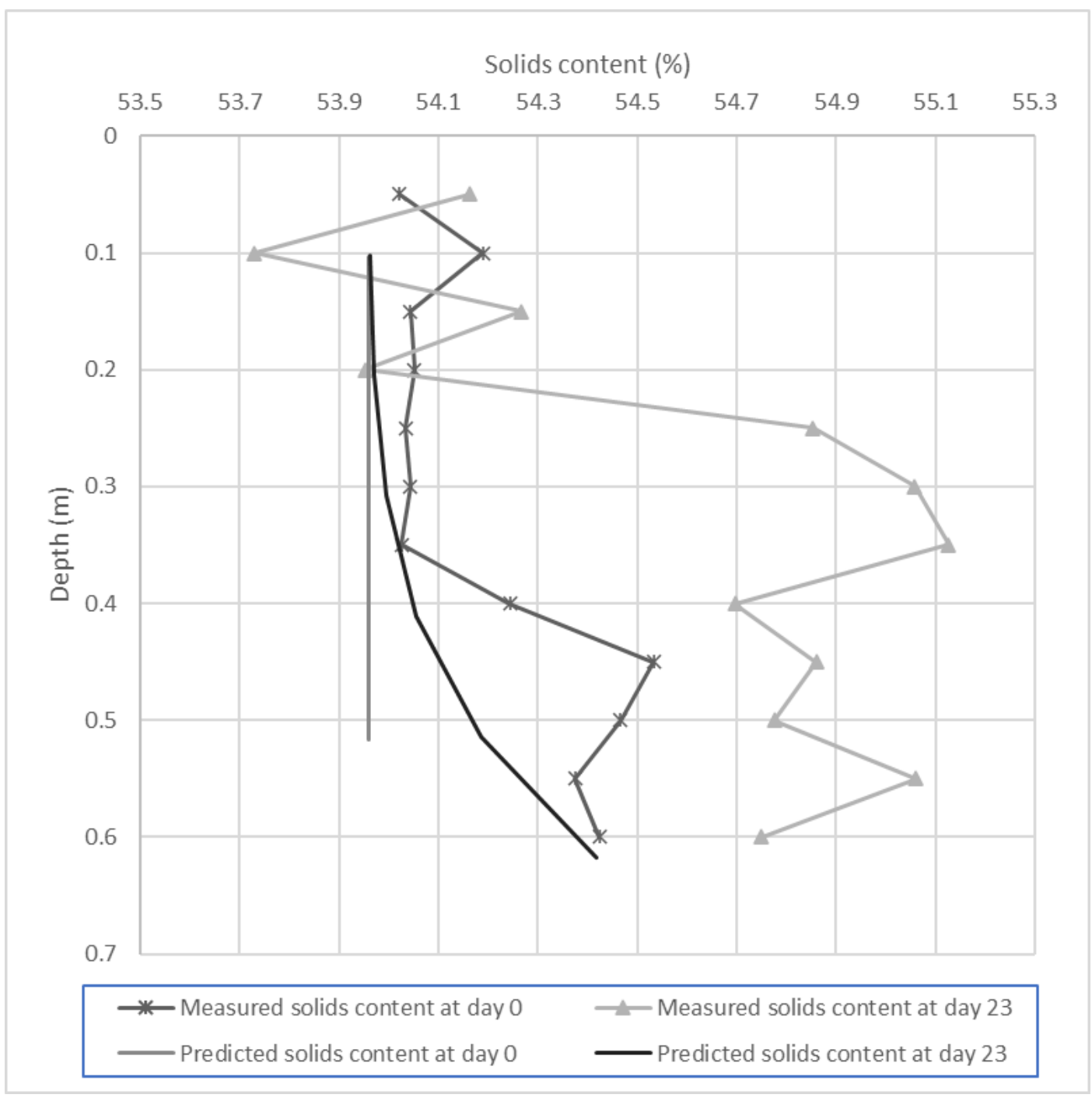

Figure 5.25. Measured and predicted solids content by depth profile using calibrated hydraulic conductivity.

Similar to phase I model run, sensitivity analysis was performed by adjusting the time step (20) and mesh size (10) parameters. Comparing the solids content vs depth plot generated using the adjusted numerical parameters (Figure E-8) to Figure 5.25 indicated negligible changes in the solids content vs depth profile.

\subsubsection{Pore-water pressure with time}


The predicted PWP using oedometer calculated hydraulic conductivity compares well with the measured PWP at smaller loading steps (Figures 5.26-5.28). The predicted PWP dissipation occurred quickly at all three sensor locations.

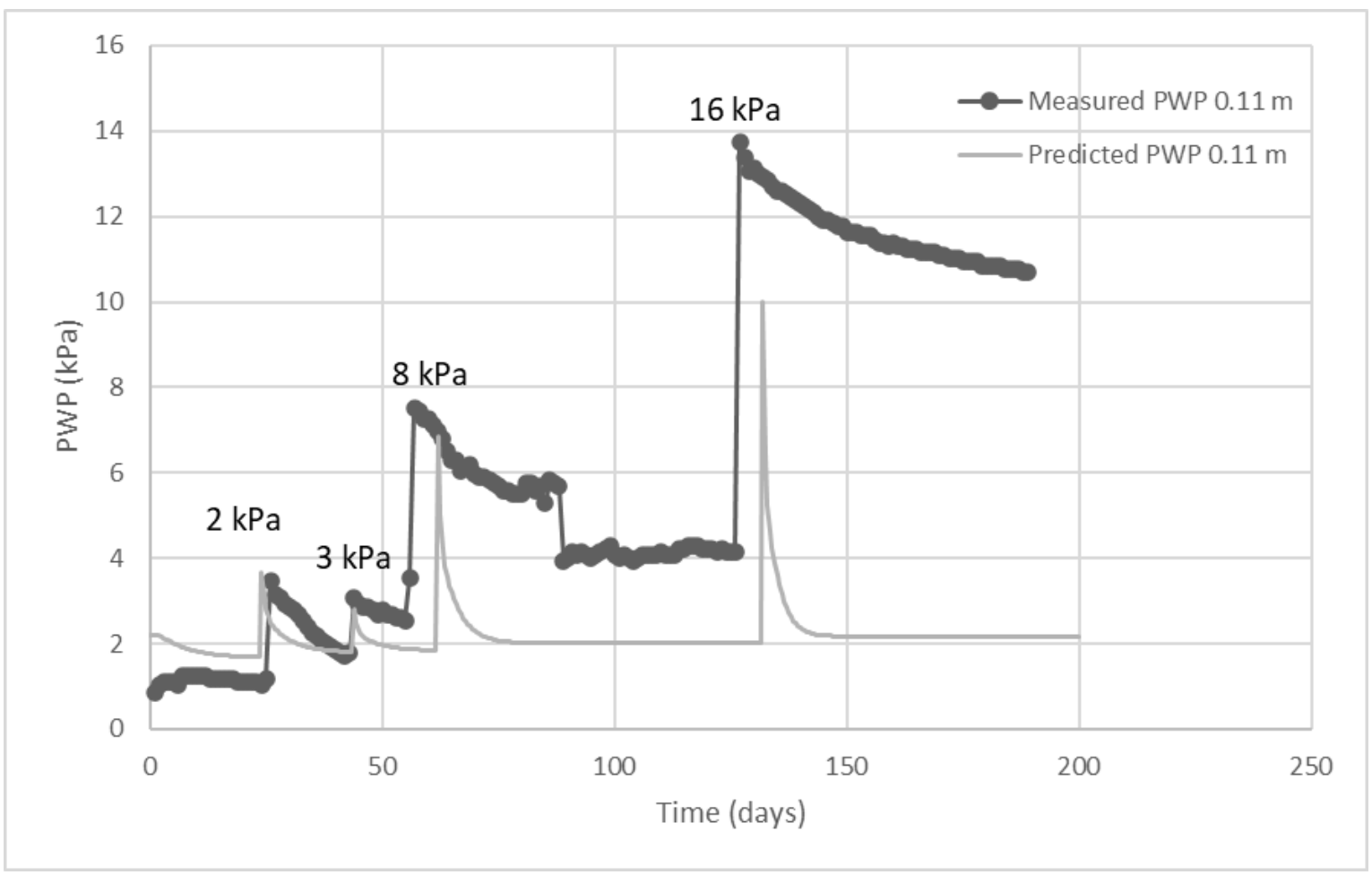

Figure 5.26. Measured and predicted PWP profile at $0.11 \mathrm{~m}$ depth using oedometer calculated hydraulic conductivity. 


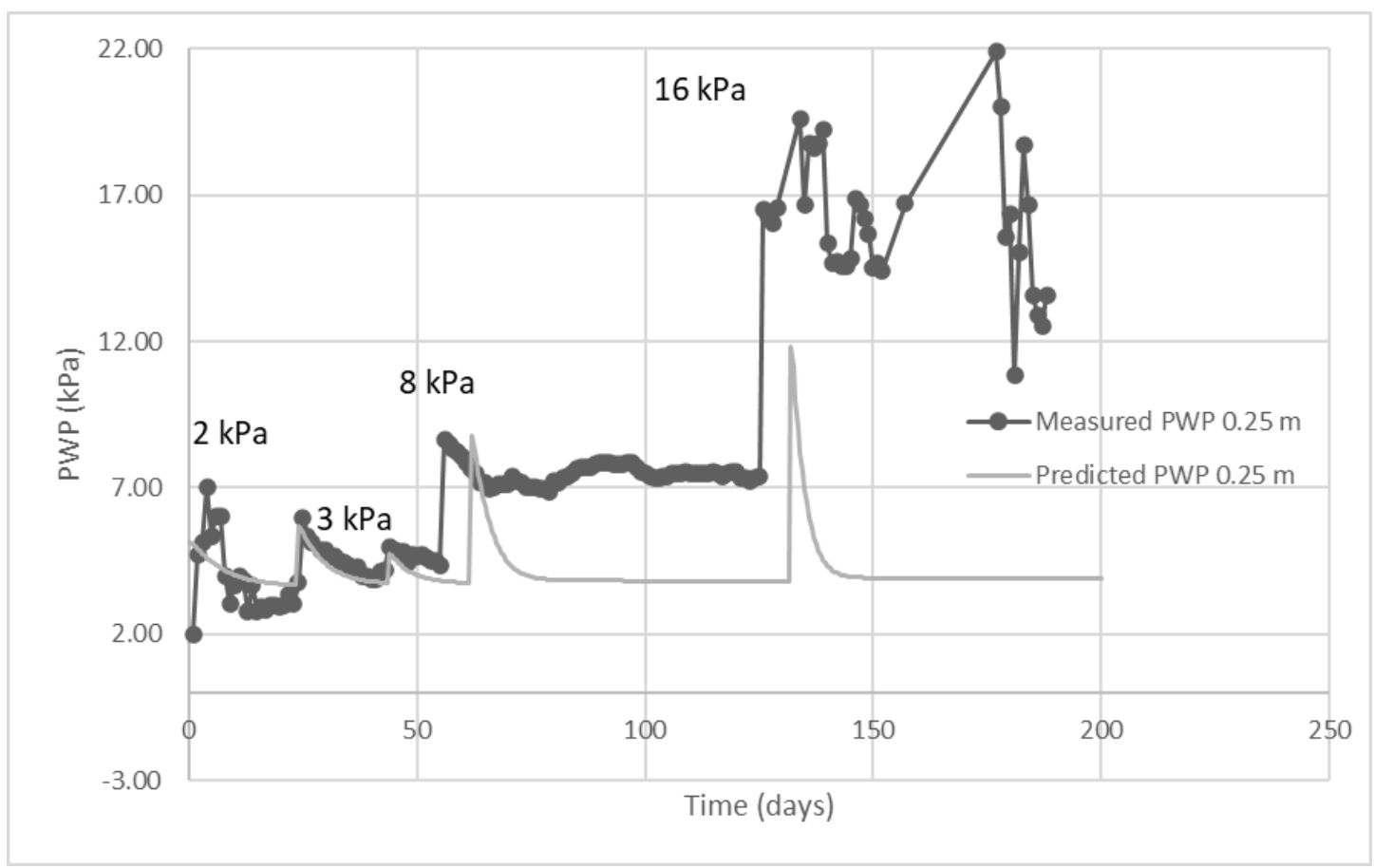

Figure 5.27. Measured and predicted PWP profile at $0.25 \mathrm{~m}$ depth using oedometer calculated hydraulic conductivity. 


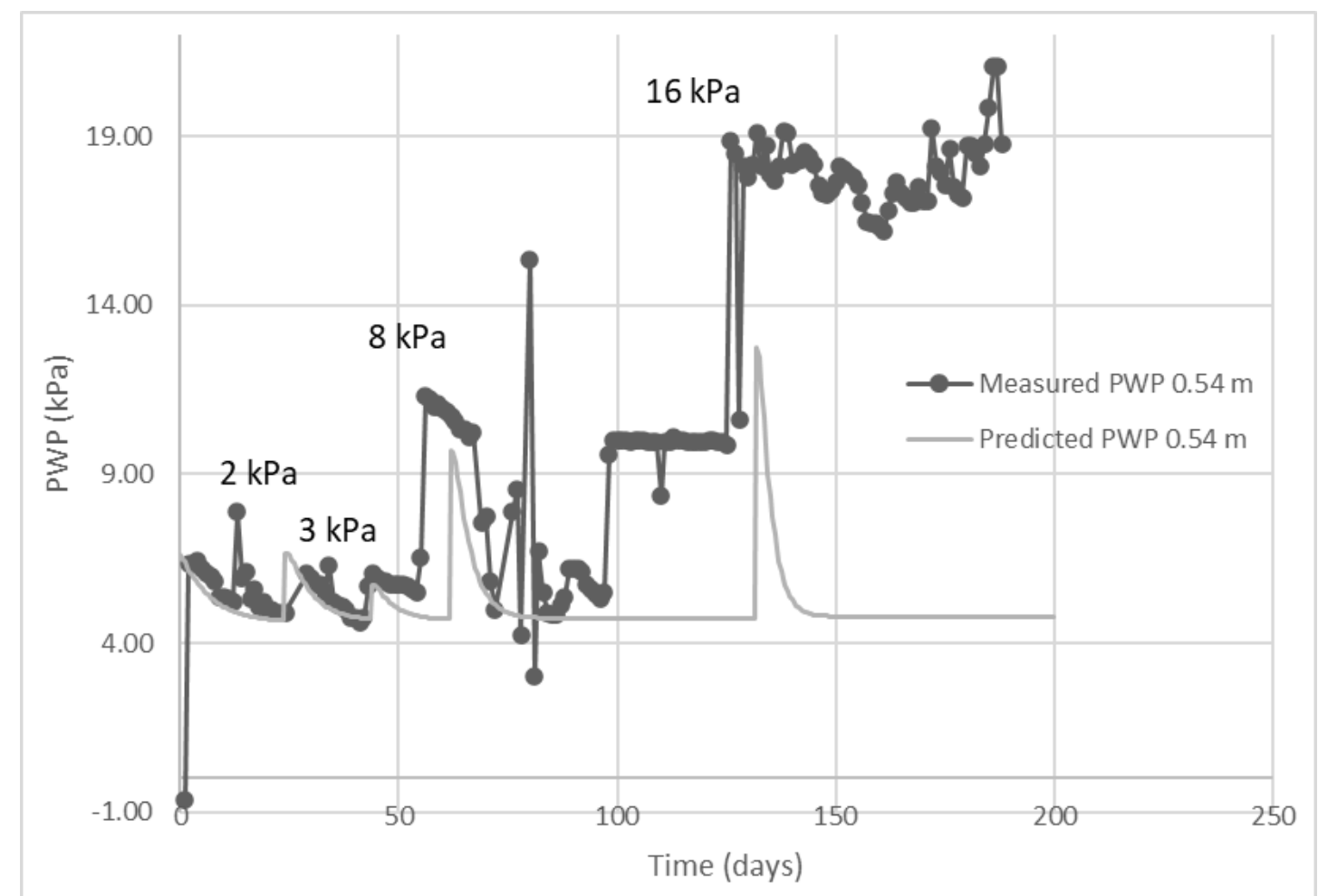

Figure 5.28. Measured and predicted PWP profile at $0.54 \mathrm{~m}$ depth using oedometer calculated hydraulic conductivity.

The calibrated model shows similar trend as the measured data for all three sensors with the predicted PWP slightly overestimated. The model showed a slower dissipation of excess PWP when compared to previous prediction derived from the original permeability function (Figures $5.29-5.31$ ). For 8 and $16 \mathrm{kPa}$ load steps the model predicted complete dissipation of excess PWP whereas from measured data showed a steady decrease and stabilizing. This behaviour may be explained by creep occurring thereby preventing the excess PWP from reaching complete dissipation. This expected since creep rate is higher at or just above the preconsolidation pressure (Graham et al, 1983) 


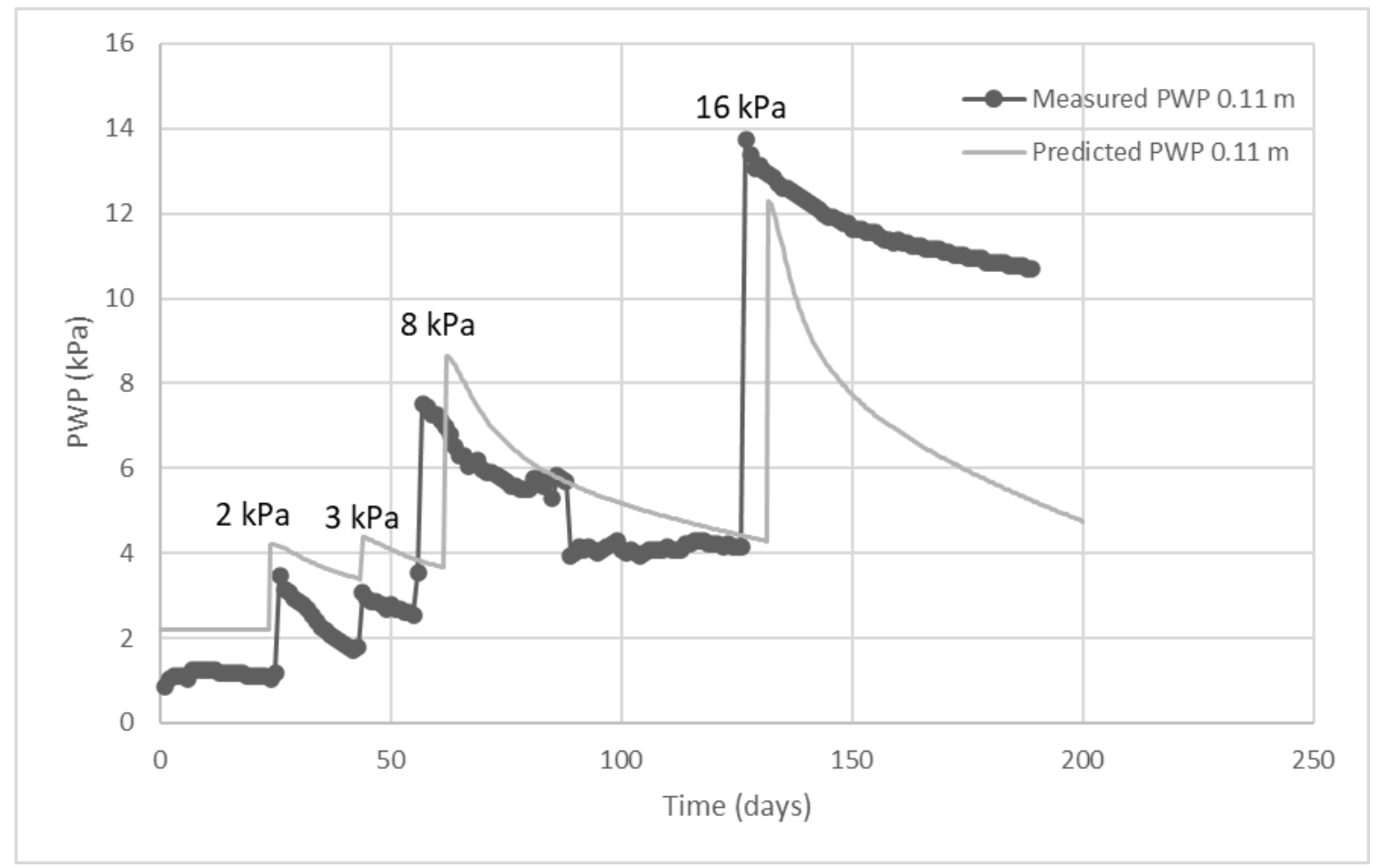

Figure 5.29. Measured and predicted PWP profile at $0.10 \mathrm{~m}$ depth using calibrated hydraulic conductivity.

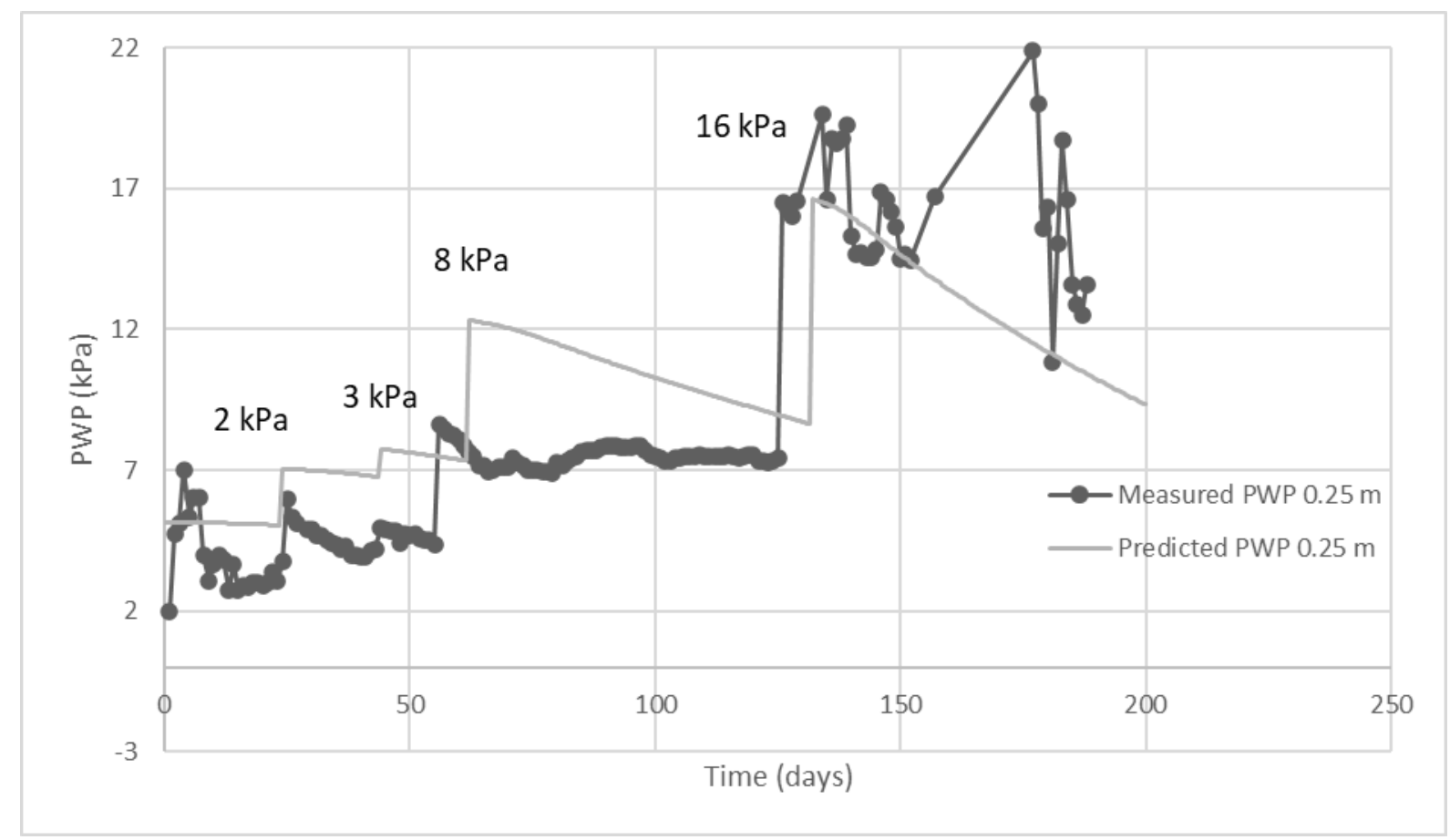

Figure 5.30. Measured and predicted PWP profile at $0.25 \mathrm{~m}$ depth using calibrated hydraulic conductivity. 


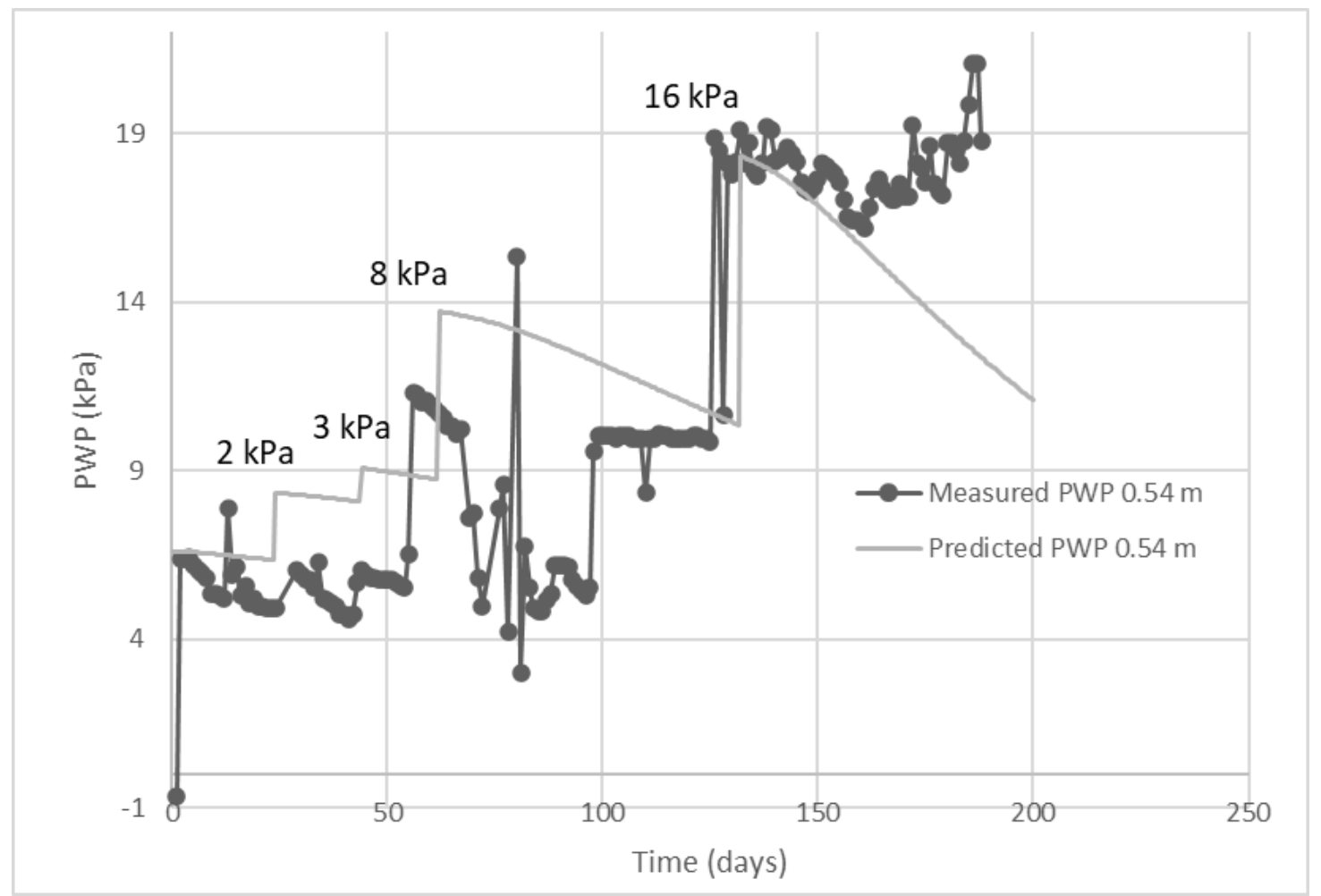

Figure 5.31. Measured and predicted PWP profile at $0.54 \mathrm{~m}$ depth using calibrated hydraulic conductivity.

\subsubsection{Tailings height over time}

The settlement prediction using oedometer calculated hydraulic conductivity showed series of steep settlement due to self-weight consolidation and applied loads (2, 3, 8 and $16 \mathrm{kPa}$ ) when compared to the measured data (Figure 5.32). 


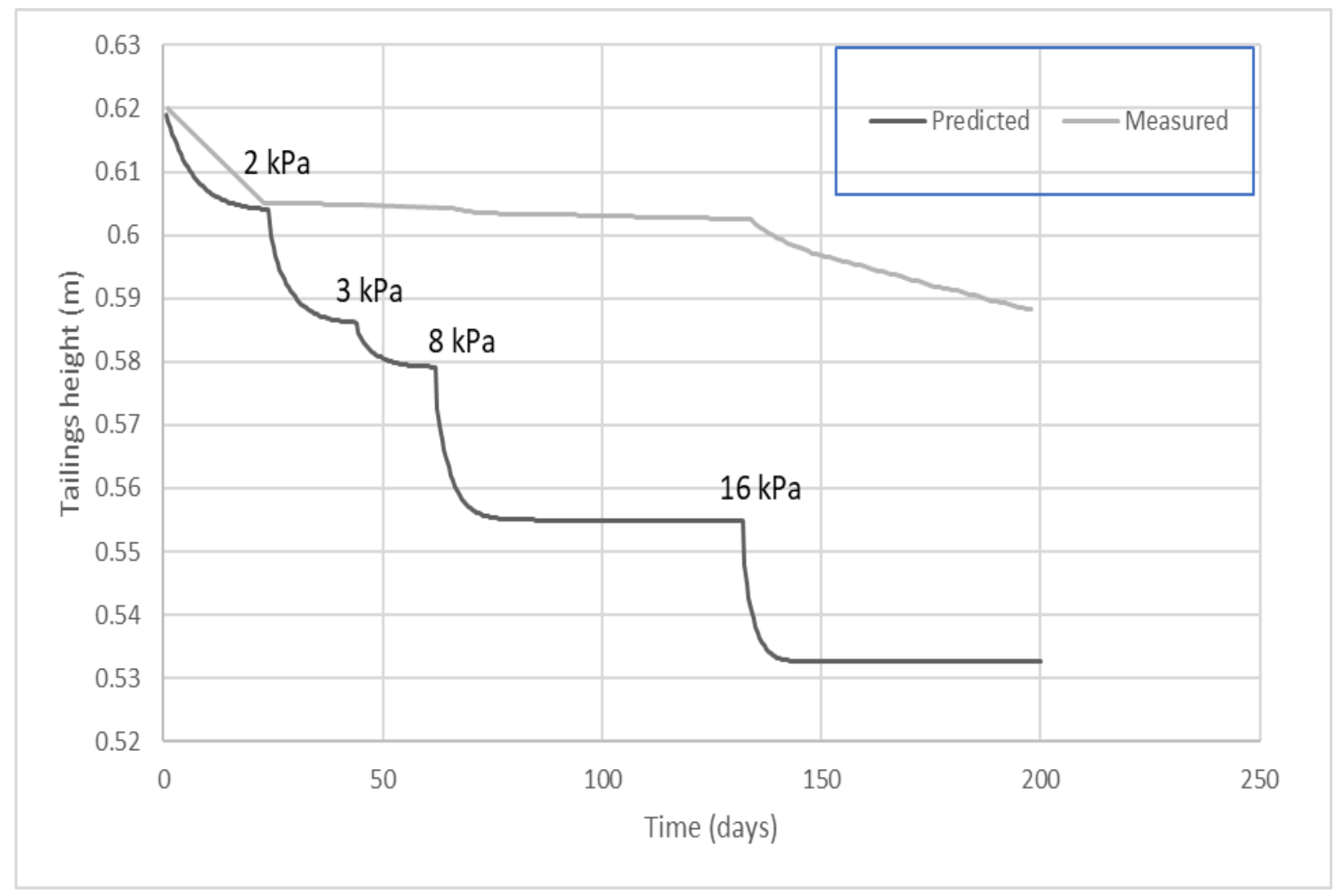

Figure 5.32. Measured and predicted tailings height over time using oedometer calculated hydraulic conductivity.

The calibrated model predicted a slower settlement rate when compared to the model predicted using the oedometer calculated hydraulic conductivity (Figure 5.33). This is expected since the hydraulic conductivity is lower for the calibrated model. After the initial settlement due to self-weight consolidation, the measured data showed little settlement for mostly 2 and 3 $\mathrm{kPa}$ and significant settlement between 8 and $16 \mathrm{kPa}$. This can be explained by the aging phenomenon of development of preconsolidation pressure leading to a structured sample and significant settlement only occurred after the preconsolidation pressure was exceeded. 


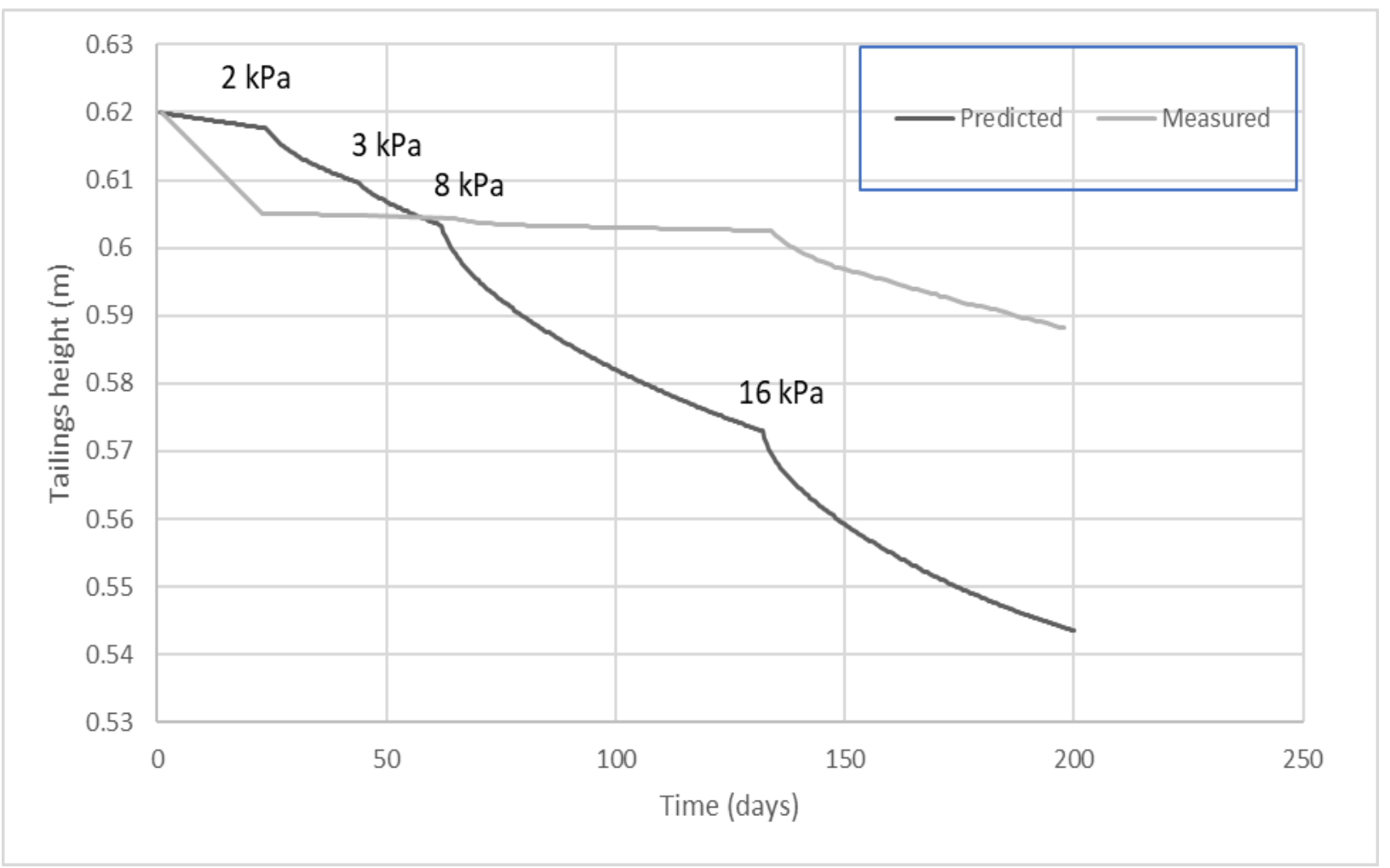

Figure 5.33. Measured and predicted tailings height over time using calibrated hydraulic conductivity.

\subsection{Comparison to field results}

Results from the phase I and II were compared to data from pilot study of centrifuge cake FFT deposited in a $3 \mathrm{~m}$ wide casing at an initial height of $10 \mathrm{~m}$ and an initial solids content of $44 \%$ (Canadian Natural, 2017; COSIA, 2018). The large-scale trials were conducted by collaboration between Canadian oil sands member companies at a CNRL site in Northern Alberta.

\subsubsection{Solids Content}

Most of the increase in solids content at the bottom of the casing occurred within the first year with little changes happening over the next year (Figure 5.34). Similar trend was observed in the $0.10 \mathrm{~m}$ column (Phase I) where water content versus depth profile showed a decrease in the water content at the bottom of the column within the first 42 days and little or no changes after that (Figure 5.35). Substantial deformation at the surface was also observed in both the pilot study and $0.10 \mathrm{~m}$ column test on centrifuge tailings. 


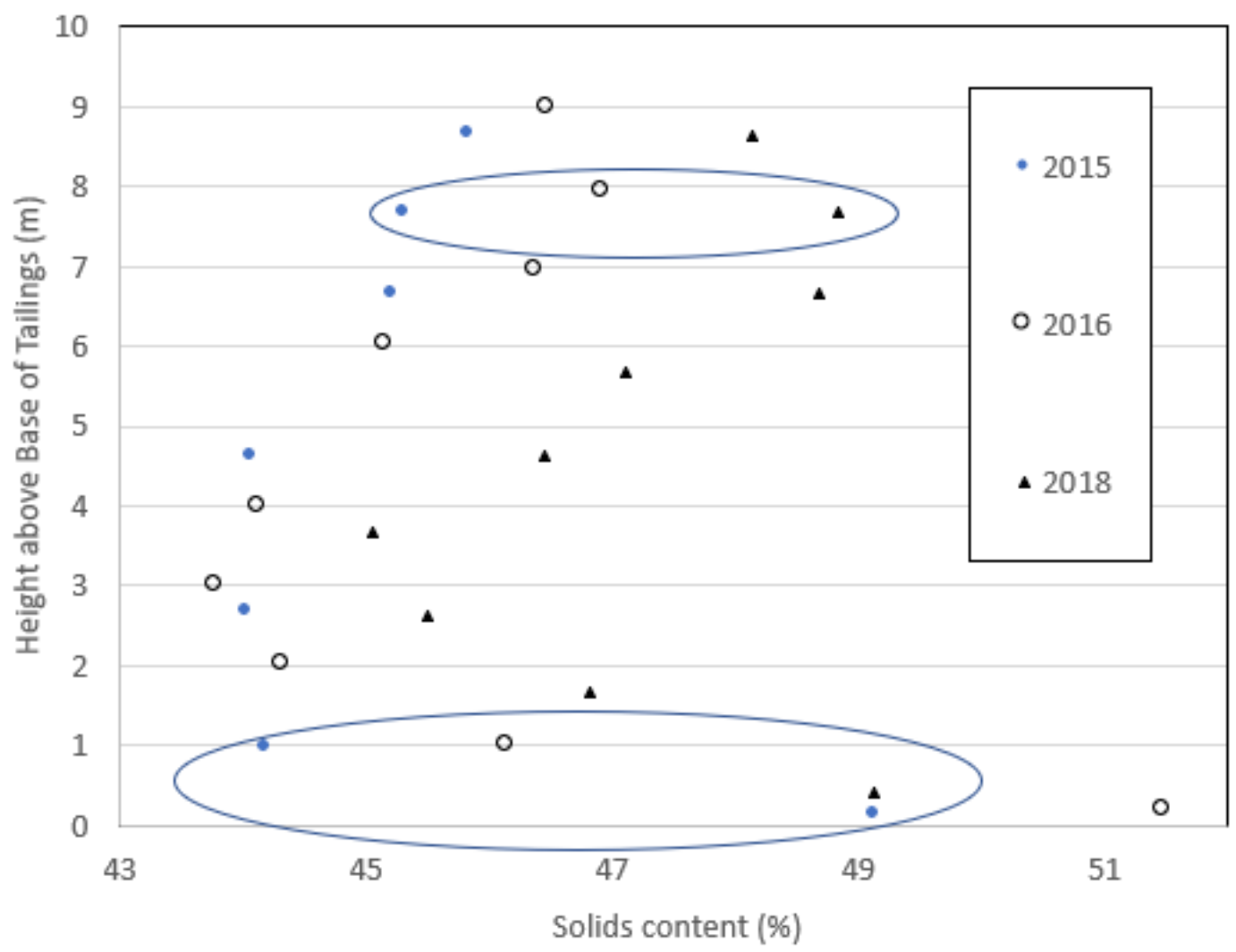

Figure 5.34. Solids content versus depth profile in a $10 \mathrm{~m}$ deep pilot study of consolidation of centrifuge cake FFT. 


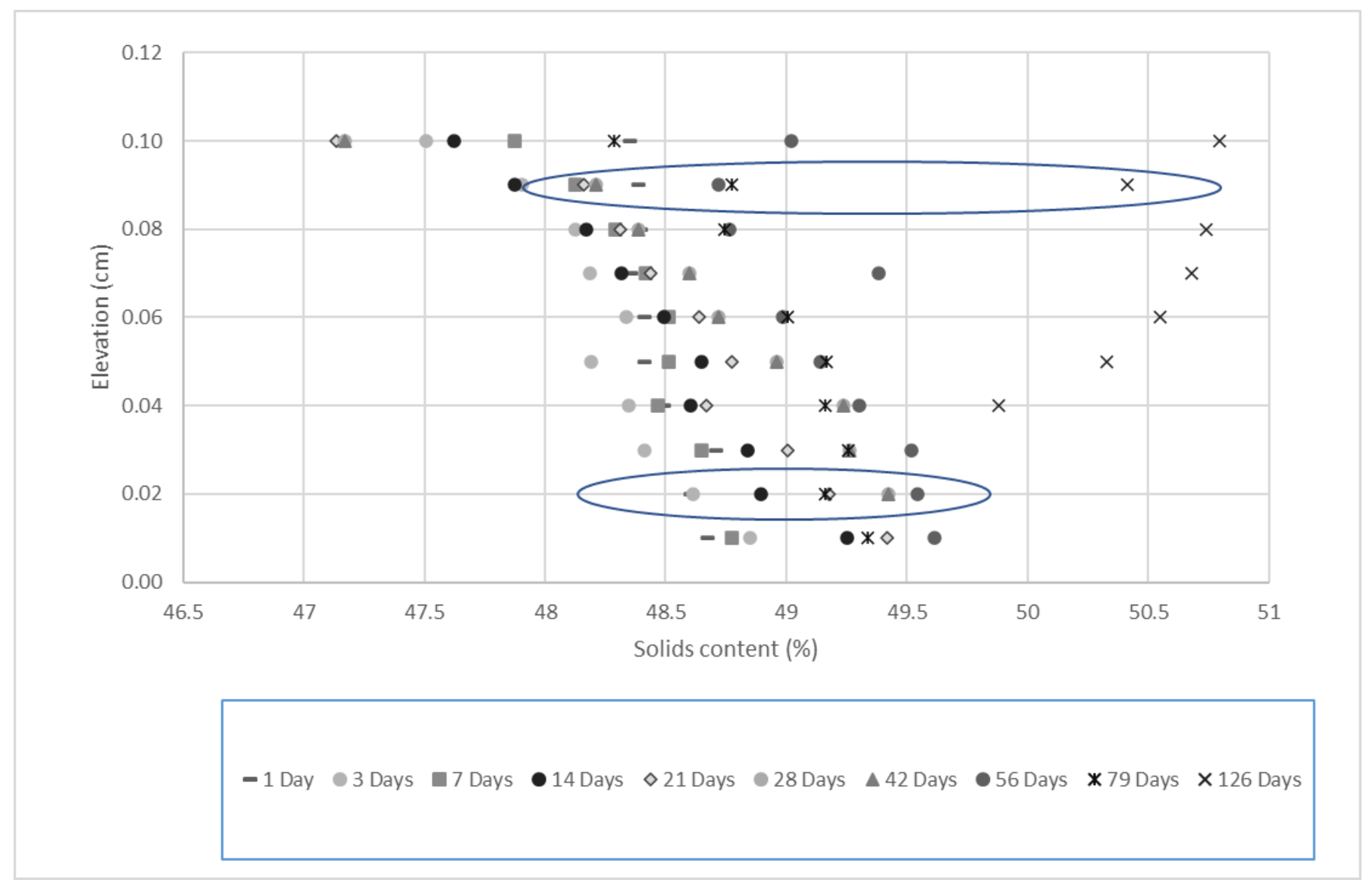

Figure 5.35. Solids content versus depth profile in $0.10 \mathrm{~m}$ columns experimental investigation (phase I).

\subsubsection{Pore-water pressure}

Immediately after the centrifuge cake were pored in the casing, PWP increased and reduced but complete dissipation of excess PWP was not achieved even after 2 years. This appears similar to the results from 8 and $16 \mathrm{kPa}$ in phase II of the laboratory investigation, where excess PWP did not completely dissipate even though settlement occurred (Figures 5.36 and 5.37). 


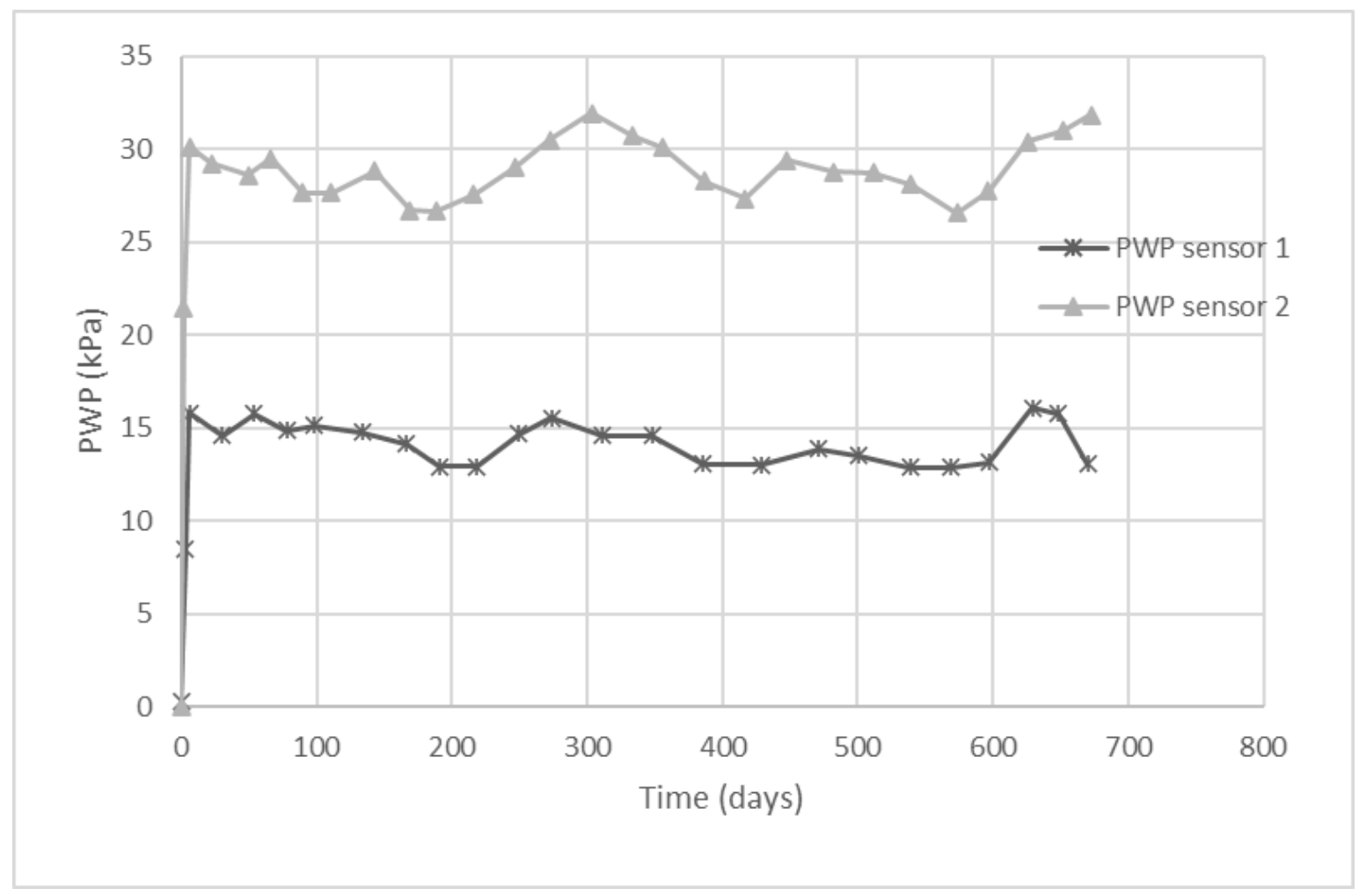

Figure 5.36. Pore-water pressure measurement in a $10 \mathrm{~m}$ deep pilot study of consolidation of centrifuge cake FFT. 


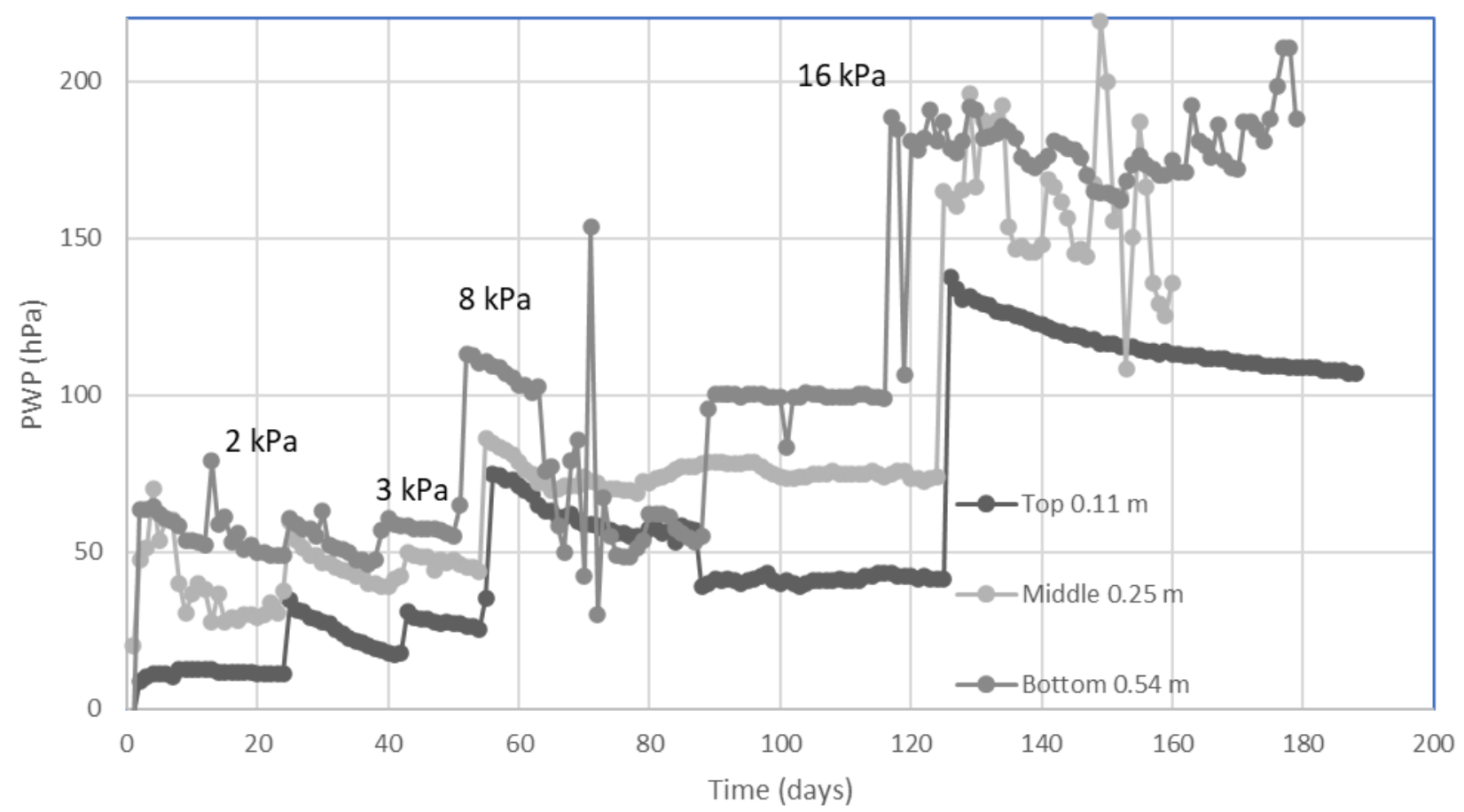

Figure 5.37. PWP pressure measurements for 8 and $16 \mathrm{kPa}$ loading steps at different elevations in the steel box (phase II).

\subsubsection{Sensitivity}

The sensitivity ratio from the pilot study ranges between 1 and 2 for after 1 year and 2 and 4 after 2 years (Figure 5.38). This compares reasonably to the sensitivity ratio (2.82) calculated for $0.10 \mathrm{~m}$ column test (Phase I) after 518 days. 


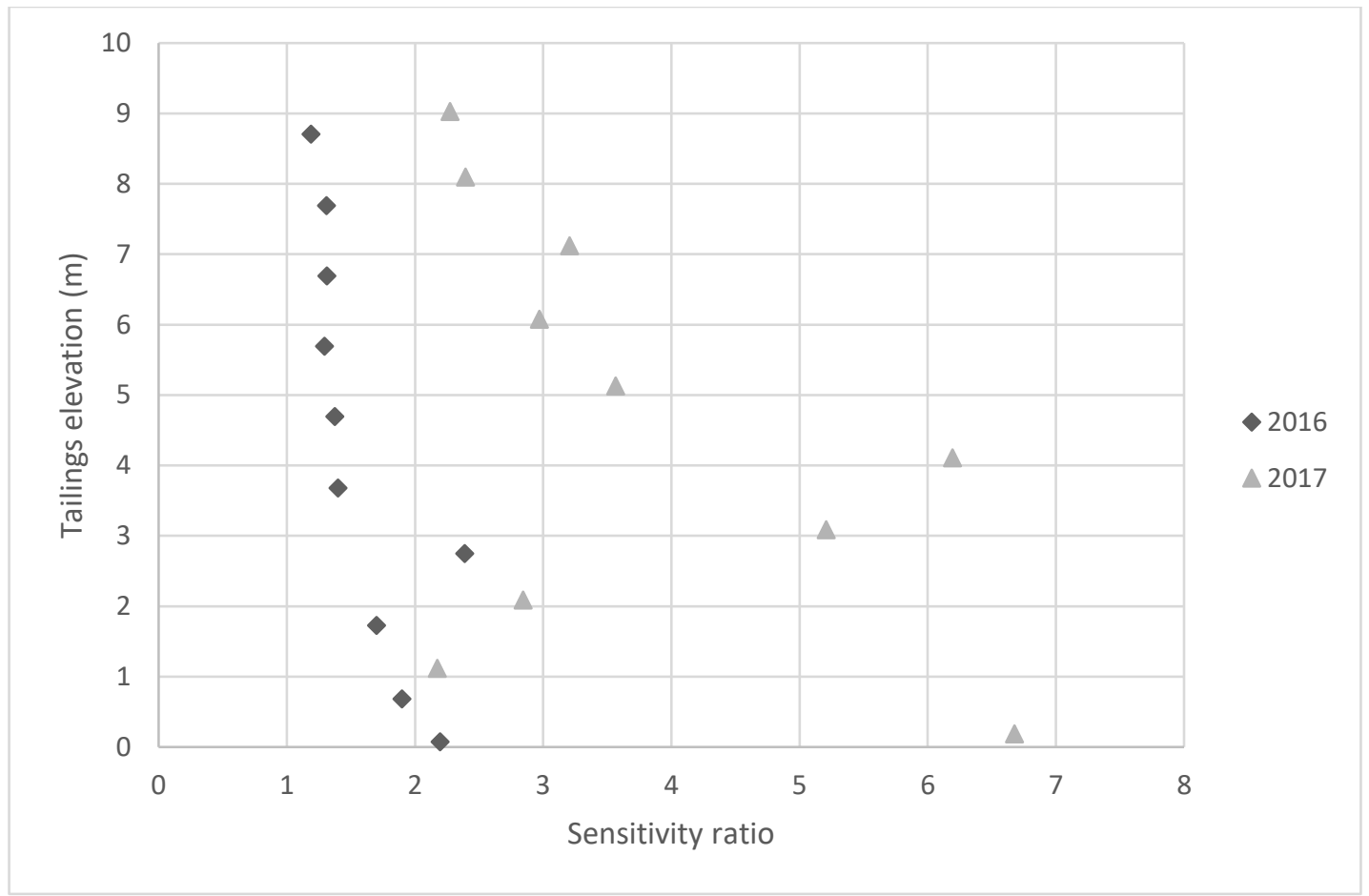

Figure 5.38. Sensitivity profile in a $10 \mathrm{~m}$ deep pilot study of consolidation of centrifuge cake FFT. 


\section{Chapter 6 : Summary and conclusion}

\subsection{Key findings and observations}

To study aging in centrifuge cake during consolidation, self-weight consolidation tests were conducted in $0.10 \mathrm{~m}$ columns (Phase I), which were subsequently loaded in oedometers; and a large consolidation test was conducted on a $\sim 0.6 \mathrm{~m}$ thick deposit of tailings in a large steel box. Pore-water pressure (PWP), volumetric water content, undrained shear strength measurements (fall cone) were also conducted.

Phase I showed that the centrifuge cake exhibited both substantial creep and aging, though somewhat less when compared to flocculated fluid fine tailings. Samples increased in strength and in preconsolidation pressure up to $~ 110$ days, but not substantially after that. Maximum strengths were $2.80 \mathrm{kPa}$, compared to a remoulded strength of $1 \mathrm{kPa}$. A preconsolidation pressure developed between the 8 and $16 \mathrm{kPa}$ loading steps, which is consistent with the ratio between shear strength and preconsolidation pressure observed in fFFT, and in other clays (0.22). Also consistent with clayey materials, the creep coefficient was much reduced below the preconsolidation pressure, but high at the preconsolidation pressure. $\mathrm{C}_{\alpha e} / \mathrm{C}_{\mathrm{c}}$ range is between 0.01 and 0.09 , compared to 0.01 and 0.09 in fFFT (Salam, 2020) and 0.03 and 0.09 in other soft clays (Graham et al., 1983).

The self-weight consolidation part of the Phase I experiments were modelled using a large strain consolidation model, using material properties from the oedometer tests. A better fit to the data was obtained when the absolute value of hydraulic function at a given void ratio (the "a parameter") was reduced by 20.

In Phase II, after the initial consolidation phase, very little settlement was observed until the last loading step of $16 \mathrm{kPa}$. Small amounts of creep could observed the lowest load steps, but for the $8 \mathrm{kPa}$ and $16 \mathrm{kPa}$ load steps, creep and associated stress-relaxation were substantial, and PWP values begin to hold near constant values or even slightly increase, while settlement continued. The in-situ compressibility curve appears to follow the aged sample from the Phase I tests.

Modelling of the Phase II data showed that the PWP dissipation at the lower loading steps could be simulated, and the initial trend in the 8 and $16 \mathrm{kPa}$ loading steps, could be simulated 
when the calibrated hydraulic conductivity function was used. However, the slow dissipation of PWP observed in the $8 \mathrm{KPa}$ and $16 \mathrm{kPa}$ loading steps at later times could not be simulated.

Therefore, it appears that both phenomena, aging and creep, appear to be important to the evaluation of tailings deposition plans employing centrifuge cake tailings. Ongoing modelling work incorporating creep and aging will use this data set for calibration.

\subsection{Recommendations for future work}

Considering the key findings of this study, the following recommendations are made for future research:

- Model incorporating creep and aging for better prediction should be calibrated using data from this experiment and if successful, field conditions should be modelled.

- Temperature influence on creep and aging effects in tailings should be investigated. Section 2.3 highlighted studies in clays that showed temperature affected creep and time dependent behaviours. Alberta experiences extreme weather conditions (summer and winter) and how this temperature influences the overall settlement of the tailings pond is an important research topic. 


\section{References}

Abdulrahman, A. (2019). Load transfer and creep behaviour of pile foundations in frozen soils (PhD thesis). Carleton University, Ottawa.

Aboshi, H. (1973). "An experimental investigation on the similitude in the consolidation of a soft clay including the secondary creep settlement," Proc. 8th Intnl. Conf. SMFE, Vol.4, pp. 88.

Abuel-Naga, H. M., Bergado, D. T., Soralump, S., Rujivipat, P., (2005). Thermal consolidation of soft Bangkok clay. Lowland Technology International 7, 13-21.

Ahmed, S., \& Siddiqua, S. (2013). A review on consolidation behavior of tailings. International Journal Of Geotechnical Engineering, 8(1), 102-111.

https://doi.org/10.1179/1939787913y.0000000012

Alberta Energy Regulator. (2015). Alberta's Energy Reserves 2014 and Supply/Demand Outlook 2015-2024. Retrieved June 2020 from the website:

https://wsm.ercb.cloud.opentext.com/documents/sts/ST98/ST98-2015.pdf

Alberta Energy Regulator. (2017). Directive 085. Retrieved April 2018 from the website: http://www.aer.ca/rules-andregulations/directives/directive-085.

Alberta Energy Regulator. (2018). State of Fluid Tailings Management for Mineable Oil Sands. Retrieved June 2020 from the website: https://www.aer.ca/providing-information/bytopic/tailings/tailings-management.html

ASTM (2017). ASTM D4318-17e1: Standard test methods for liquid limit, plastic limit, and plasticity index of soils. West Conshohocken, PA, USA: ASTM International.

Athanasopoulos, G. (1993). Effects of ageing and overconsolidation on the elastic stiffness of a remoulded clay. Geotechnical And Geological Engineering, 11(1), 51-65. doi:

10.1007/bf00452921.

Augustesen, A., Liingaard, M., \& Lade, P. (2004). Evaluation of Time-Dependent Behavior of Soils. International Journal Of Geomechanics, 4(3), 137-156. doi: 10.1061/(asce)15323641(2004)4:3(137).

Azam, S., Jeeravipoolvarn, S., \& Scott, J. (2015). Numerical Modeling of Tailings Thickening for Improved Mine Waste Management. JOURNAL OF ENVIRONMENTAL INFORMATICS, 13(2), 111118. Retrieved from http://www.jeionline.org/index.php?journal=mys\&page=article\&op=view\&pa

Babaoglu, Y., \& Simms, P. (2018). Estimating Saturated Hydraulic Conductivity from Compression Curves for Fluid Fine Tailings. In Canadian Geotechnical Conference. Edmonton. 
Baig, K. (1968). Strain Rate Effects in One-Dimensional Consolidation of Peat (MASc). University of British Columbia.

Banas, L. C. (1991). Thixotropic behaviour of oil sands tailings sludge (Master's thesis). The University of Alberta, Edmonton, Alberta.

Baniak, G., \& Kingsmith, K. (2018). Sedimentological and stratigraphic characterization of Cretaceous upper McMurray deposits in the southern Athabasca oil sands, Alberta, Canada. AAPG Bulletin, 102(02), 309-332. doi: 10.1306/0502171619317010.

Beier, N., \& Sego, D. (2008). The Oil Sands Tailings Research Facility. Geotechnical News, 26, no. 2 (2008): 72-7.

Beier, N., \& Sego, D. (2013). Tailings Management in Canada's Oil Sands. In Proceedings of the 5th International Young Geotechnical Engineers' Conference. Marne-la-Vallée.

Beier, N., Wilson, W., Dunmola, A. and Sego, D. (2013). Impact of flocculation-based dewatering on the shear strength of oil sands fine tailings. Can. Geotech. J. 50(9), 1001-1007.

BGC Engineering Inc. (2010). Oil sands tailings technology review. OSRIN Report No. TR-1. Edmonton, AB, Canada: Oil Sands Research and Information Network, University of Alberta, School of Energy and the Environment. Retrieved April 2020 from the website:

https://era.library.ualberta.ca/items/d54a3e22-cf15-4c3b-baeb-

2ee10578a259/view/ad8166dd-861d-4162-afac-949a5ac82582/Tailings-20Technology20Review-20--202010-2007-2019.pdf.

Bharat, T. V., \& Sharma, J. (2011). Prediction of compression and permeability characteristics of mine tailings using natural computation and large-strain consolidation framework. GeoFrontiers 2011, Geotechnical Special Publication No, 211, 3868-3877.

Bjerrum, L. (1967). Engineering geology of Norwegian normally-consolidated marine clays as related to settlements of buildings. Geotechnique, 17(2), 83-118.

Bonin, M., Nuth, M., Dagenais, A., \& Cabral, A. (2014). Experimental Study and Numerical Reproduction of Self-Weight Consolidation Behavior of Thickened Tailings. Journal Of Geotechnical And Geoenvironmental Engineering, 140(12), 04014068. doi:

10.1061/(asce)gt.1943-5606.0001179.

Boratynec, D.J. (2003). Fundamentals of rapid dewatering of composite tailings. M.Sc. thesis, Department of Civil and Environmental Engineering, University of Alberta, Edmonton, Alta.

Boratynec, D.J., Chalaturnyk, R.J. and Scott, J.D. (1998). Proceedings of 51th Canadian Geotechnical Conference. 1998, Edmonton, Alberta, Canada.

Bromwell, L. (1984). Consolidation of mining wastes. InSedimentation Consolidation ModelsPredictions and Validation. ASCE, 275-295. 
Burchfield, T. E. \& Hepler, L.G. (1979). "Some chemical and physical properties of tailings water from oil sands extraction plants." Fuel 58(10): 745-747.

Burland, J. B. (1990). On the compressibility and shear strength of natural clays. Géotechnique, 40(3), 329-378.

Canadian Association of Petroleum Producers. 2016. Canada's Oil Sands. Retrieved May 2020 from the website: http://www.oscaalberta.ca/wp-content/uploads/2017/06/CAPP-Oil-SandsFact-Booklet.pdf

Canadian Natural. (2017). Tailings Consolidation Casing Experimental Project Pilot [PDF document].

Carrigy, M.A. (1963): The K.A. Clark volume: a collection of papers on the Athabasca Oil Sands presented to K.A. Clark on the 75th anniversary of his birthday; Research Council of Alberta, RCA/AGS Information Series 45, 248 p.

Chalaturnyk, R. J., Don Scott, J., \& Özüm, B. (2002). Management of oil sands tailings. Petroleum Science and Technology, 20(9-10), 1025-1046.

Chandler, G. (2017). "Settling the tailings pond question". CIM, (7), 50-53.

Chastko, P. A. (2004). Developing Alberta's oil sands: from Karl Clark to Kyoto. University of Calgary Press.

Chaudhary, K., Fredlund, M., Lu, H., \& Xu, L. (2015). Benchmarking of large-strain consolidation, sedimentation, and creep process for oil-sands tailings. Retrieved 2 July 2020, from https://open.library.ubc.ca/clRcle/collections/59368/items/1.0320847

Cho, W. J., Lee, J. O., Chun, K. S., (1999). The temperature effects on hydraulic conductivity of compacted bentonite. Applied Clay Science 14, 47-58.

COSIA. (2014). Guidelines for Performance Management of Oil Sands Fluid Fine Tailings Deposits to Meet Closure Commitments.

COSIA. (2017). Improving environmental performance through open innovation. Retrieved June 2020 from the website: https://portfolio.cosia.ca/wp-content/themes/cosia/pdf/2017-COSIAProject-Portfolio.pdf

COSIA. (2018). Tailings research report. Retrieved September 2020 from the website:

https://www.cosia.ca/sites/default/files/attachments/2018\%20Tailings\%20Research\%20Report FINAL\%2003Jun2019.pdf

Cottrell, J. H. (1963). Development of an anhydrous process for oil-sand extraction; in K. A. Clark Volume, Res. Coun. Alberta, Edmonton, p. 193-206.

Crawford, C. B. (1968). Quick clays of eastern Canada. Engineering Geology, 2(4), 239- 265. 
Crawford, C. B., \& Bozozuk, M. (1990). Thirty years of secondary consolidation in sensitive marine clay. Canadian Geotechnical Journal, 27(3), 315-319.

Daliri, F., Simms, P., \& Sivathayalan, S. (2016). Shear and dewatering behaviour of densified gold tailings in a laboratory simulation of multi-layer deposition. Canadian Geotechnical Journal, 53(8), 1246-1257.

Decagon. (2016). 5TE Water Content, EC and Temperature Sensor. Retrieved August 2020, from:

http://manuals.decagon.com/Retired\%20and\%20Discontinued/Manuals/13509 5TE Web.pdf

Degago S.A., Grimstad G., Jostad H.P., Nordal S. (2009) The non-uniqueness of the end-ofprimary (EOP) void ratio effective stress relationship, [In:] Proc. 17th Inter. Conference on Soil Mechanics and Geotechnical Engineering, Alexandria, Egypt, 324-327.

Delage, P. (2010). A microstructure approach to the sensitivity and compressibility of some Eastern Ca Delage, P., \& Lefebvre, G. (1984). Study of the structure of a sensitive Champlain clay and of its evolution during consolidation. Canadian Geotechnical Journal, 21(1), 21- 35.nada sensitive clays. Géotechnique, 60(5), 353-368.

Devenny, D. (2010). A Screening study of Oil Sand Tailings Technologies and Practices. Alberta Energy Research Institute, 44.

Dimitrova, R. S., \& Yanful, E. K. (2011). Undrained strength of deposited mine tailings beds: effect of water content, effective stress and time of consolidation. Geotechnical and Geological Engineering, 29(5), 935-951.

Dunmola, A., Dhadli, N., Freeman, G., Kolstad, D., Fasking, T., Song, J., \& Langseth, J. (2013a). Geotechnical benefits of flocculation in dewatering oil sands mature fine tailings. In Proceedings of the 66th Canadian Geotechnical Conference and the 11th Joint CGS/IAH-CNC Groundwater Conference, Montreal.

Dunmola, A., Cote, C., Freeman, G., Kolstad, D., Song, J., \& Masala, S. (2013b). Dewatering and shear strength performance of in-line flocculated mature fine tailings under different depositional schemes. Proceeding of Tailings and Mine Waste.

Elnaggar, H.A., Krizek, R.J. and Karadi, G.M. (1973). Effect of non-Darcian flow on time rate of consolidation. Journal of the Franklin Institute 296:323-337.

Fatahi B., Le T. M., Le M. Q., Khabbaz H. (2013) Soil creep effects on ground lateral deformation and pore water pressure under embankments. Geomechanics and Geoengineering 8, 2, 107-124. DOI: 10.1080/17486025.2012.727037.

Feda, J. (1989). Interpretation of creep of soils by rate process theory. Géotechnique, 39(4), 667-677. doi: 10.1680/geot.1989.39.4.667. 
Feng, T. W. (2001). A linear log $d$ - log w model for the determination of consistency limits of soils. Can. Geotech. J., 38, 1335-1342.

Fox, P., \& Berles, J. (1997). CS2: A PIECEWISE-LINEAR MODEL FOR LARGE STRAIN CONSOLIDATION. International Journal For Numerical And Analytical Methods In Geomechanics, 21(7), 453-475. doi: 10.1002/(sici)1096-9853(199707)21:7<453::aidnag887>3.0.co;2-b.

Fox, P., Pu, H., \& Berles, J. (2014). CS3: Large Strain Consolidation Model for Layered Soils. Journal Of Geotechnical And Geoenvironmental Engineering, 140(8), 04014041. doi: 10.1061/(asce)gt.1943-5606.0001128.

Fredlund, D. G., and Xing, A. (1994). "Equations for the soil-water characteristic curve." Can. Geotech. J., 31(4), 521-532.

Giesy, J., Anderson, J., \& Wiseman, S. (2010). Alberta oil sands development. Proceedings of The National Academy Of Sciences, 107(3), 951-952. doi: 10.1073/pnas.0912880107.

Graham, J., Crooks, J., \& Bell, A. (1983). Time effects on the stress-strain behaviour of natural soft clays. Géotechnique, 33(3), 327-340. doi: 10.1680/geot.1983.33.3.327.

Gibson, R. E., England, G. L., \& Hussey, M. J. L. (1967). The Theory of one-dimensional consolidation of saturated clays: 1 . finite non-Linear consolidation of thin homogeneous layers. Geotechnique, 17(3), 261-273.

Gingras, M., Rokosh, D. (2004). A Brief Overview of the Geology of Heavy oil, Bitumen and Oil Sands Deposits. Canadian Society of Exploration Geologists National Convention, pp. 1-3.

Gupta, B., (1964). Creep of saturated soil at different temperatures. Master Thesis, The University of British Columbia, Canada.

Hansbo, S. (1957). A new approach to the determination of the shear strength of clay by the fall-cone test. Proc. Royal Swedish Geotechnical Institute, 14:7-47.

Hazell, E. (2008). Numerical and experimental studies of shallow cone penetration in clay. Retrieved 28 June 2020, from https://ora.ox.ac.uk/objects/uuid:6b5380f1-2d02-4da0-92e0ae83ad5c4698.

Hockley, D., \& Omotoso, O. (2018). Introduction to oil sands clays (22nd ed.). The Clay Minerals Society.

Hubbard, M., Smith, G., Nielsen, H., Leckie, A., Fustic, M., Spencer, J., and

Bloom, L., (2011), Seismic Geomorphology and Sedimentology of a Tidally Influenced

River Deposit, Lower Cretaceous Athabasca Oil Sands, Alberta, Canada, AAPG Bulletin, 
accepted - in press.

Hurtado, O. (2018). Desiccation and Consolidation in Centrifuge Cake Oil Sands Tailings (Master's thesis). Carleton University, Ottawa, 202.

Igbinedion, D., Salam, M., \& Simms, P. (2019). Creep and structuration in centrifuge cake oil sands tailings. In Canadian Geotechnical Conference. St. John's.

Imai, G. (1980). Settling Behavior of Clay Suspension. Soils And Foundations, 20(2), 61-77. doi: 10.3208/sandf1972.20.2_61.

Imai, G. (1981). Experimental Studies on Sedimentation Mechanism and Sediment Formation of Clay Materials. Soils And Foundations, 21(1), 7-20. doi: 10.3208/sandf1972.21.7.

Ito, M., \& Azam, S. (2013). Large-strain consolidation modeling of mine waste tailings. Environmental Systems Research, 2(1), 7. doi: 10.1186/2193-2697-2-7

Jamiolkowski M., Ladd, C.C., Germaine, J.T., Lancellolta, R. (1985) New developments in field and laboratory testing of soils. [In:] Proc. 11th Int. Conf. on Soil Mechanics and Foundation Engineering, San Francisco, 57-153.

Jarad, N. (2017). Temperature impact on the consolidation and creep behaviour of compacted clayey soils. Retrieved 7 October 2020, from https://tel.archives-ouvertes.fr/tel-01532182

Jeeravipoolvarn, S. (2005). Compression behaviour of thixotropic oil sands tailings. M.Sc. Thesis, University of Alberta, Edmonton, Alberta, Canada.

Jeeravipoolvarn, S., Chalaturnyk, R. J., and Scott, J. D. (2008). Consolidation modeling of oil sands fine tailings: History matching. Proceedings of GeoEdmonton'08, Edmonton, Alberta, Canada, 190-197.

Jeeravipoolvarn, S., Scott, J. D., and Chalaturnyk, R. J. (2009). 10 m standpipe tests on oil sands tailings: Long-term experimental results and prediction. Canadian Geotechnical Journal, 46(8), 875-888.

Jeeravipoolvarn, Silawat. (2010). Geotechnical behavior of in-line thickened oil sands tailings. 10.13140/2.1.4432.0329.

Kaczmarek, Ł., \& Dobak, P. (2017). Contemporary overview of soil creep phenomenon. Contemporary Trends In Geoscience, 6(1), 28-40. doi: 10.1515/ctg-2017-0003.

Kaminsky, H. (2014). Demystifying the methylene blue index. In 4th International Oil Sands Tailings Conference. Lake Louise, AB, The University of Alberta Geotechnical Centre and the Oil Sands Tailings Research Facility (OSTRF).

Kaminsky, H., Mian, H., Cavanagh, P., Graham, M., Mimura, M., Al-Mamun, M., Lord, E., Geremew, A., \& Salehi R. (2015). Measuring undrained shear strength of oil sands tailings 
deposits. Retrieved from https://www.cosia.ca/sites/default/files/attachments/COSIADepositCharacterization.pdf

Kasperski, K., \& Mikula, R. (2011). Waste Streams of Mined Oil Sands: Characteristics and Remediation. Elements, 7(6), 387-392. doi: 10.2113/gselements.7.6.387

Kessick, M. (1978). "Clay slimes from the extraction of Alberta Oil sands, Florida phosphate matrix and other mined deposits." CIM Bull 71: 80-88.

Kolstad, D., Dunmola, A., Dhadli, N., O'Kane, M., Song, J., \& Masala, S. (2012). Towards the improvement in geotechnical performance of atmospheric fines drying (AFD) deposits at Shell's Muskeg River Mine. In Proceedings of the 3rd International Oil Sands Tailings Conference, Edmonton, Alta (pp. 3-5).

Koumoto, T., \& Houlsby, G. (2001). Theory and practice of the fall cone test. Géotechnique, 51(8), 701-712. doi: 10.1680/geot.2001.51.8.701.

Krizek, J. R. (2004). Slurries in geotechnical engineering [PDF document]. Retrieved from https://ceprofs.civil.tamu.edu/briaud/Buchanan\%20Web/Slurries\%20in\%20Geotechnical\%20En gg.pdf

Kuhn M., Mitchell J. (1993). New Perspectives on Soil Creep. Journal of Geotechnical Engineering 119, 3, 507-524. DOI: 10.1061/(ASCE)0733-9410(1993), 119:3, 507.

Le T., Fatahi B., Khabbaz H. (2012). Viscous Behavior of Soft Clay and Inducing Factors. Geotechnical and Geological Engineering 30, 5, 1069-1083. DOI: 10.1007/s10706-012-9535-0.

Le T.M., Fatahi B., Disfani M., Khabbaz H. (2015). Analyzing consolidation data to obtain elastic viscoplastic parameters of clay. Geomechanics and Engineering 8, 4, 559-594. DOI: 10.12989/gae.2015.8.4.559.

Lee, K. (1979). An analytical and experimental study of large strain soil consolidation. Retrieved 25 July 2020, from https://ora.ox.ac.uk/objects/uuid:9521ec26-f27b-46fo-8704-de5145b4d519

Lekha, K., Krishnaswamy, N., \& Basak, P. (2003). Consolidation of Clays for Variable Permeability and Compressibility. Journal Of Geotechnical And Geoenvironmental Engineering, 129(11), 1001-1009. doi: 10.1061/(asce)1090-0241(2003)129:11(1001).

Leong, E. C. \& Rahardjo, H. (1997). Permeability functions for unsaturated soils. J. Geotech. Geoenviron. Engng 123, No. 12, 1118-1126.

Leoni, M., Karstunen, M., \& Vermeer, P. (2008). Anisotropic creep model for soft soils. Géotechnique, 58(3), 215-226.

Leroueil, S., \& Le Bihan, J. P. (1996). Liquid limits and fall cones. Canadian Geotechnical Journal, 33(5), 793-798. 
Leroueil, S., \& Vaughan, P. R. (1990). The general and congruent effects of structure in natural soils and weak rocks. Géotechnique, 40(3), 467-488.

Liu, M. (2017). "A Study on Hydraulic Conductivity of Fine Oil Sand Tailings" (Master's thesis). University of Western Ontario.

Locat, J. and Lefebvre, G. (1986). The origin of structuration of the Grande-Baleine marine sediments,Québec, Canada. Quarterly Journal of Engineering Geology and Hydrogeology, 19(4), 365-374.

Mamer, M. (2010). Oil sands tailings technology : understanding the impact to reclamation. Retrieved from https://pdfs.semanticscholar.org/c22f/52531843d156d308c26253933a65c00e5615.pdf

Masala, S., Nik, R.M., Freeman, G., and Mahood, R. (2014). Geotechnical insights into deposition, dewatering and strength performance of thickened and paste tailings deposits at Shell Canada's tailings test facility. Pp. 277-288 in: Fourth International Oil Sands Tailings Conference (IOSTC) (D.C. Sego, W. Wilson, and N.A. Beier, editors). University of Alberta, Edmonton, Alberta, Canada.

Markgraf, W., Horn, R., \& Peth, S. (2006). An approach to rheometry in soil mechanicsstructural changes in bentonite, clayey and silty soils. Soil and Tillage Research, 91(1-2), 1-14.

Masliyah, J., Zhou, Z., Xu, Z., Czarnecki, J., \& Hamza, H. (2008). Understanding Water-Based Bitumen Extraction from Athabasca Oil Sands. The Canadian Journal Of Chemical Engineering, 82(4), 628-654. doi: 10.1002/cjce.5450820403.

McKenna, G., ,amm, V., Fisseha, B., Beier, N. and Olmedo, N., (2016). The Geotechnical Vane Shear Strength of Soft Tailings. IOSTC, pp.329-339. Available at:

https://www.researchgate.net/profile/Bereket Fisseha3/publication/311537256 THE GEOTEC HNICAL VANE SHEAR STRENGTH OF SOFT TAILINGS COMPARED TO SOFT FOODS/links/58 4f0a4d08aed95c250995f7/THE-GEOTECHNICAL-VANE-SHEAR-STRENGTH-OF-SOFT-TAILINGSCOMPARED-TO-SOFT-FOODS.pdf

McNeill, J. and Lothian, N., (2017). Review Of Directive 085 Tailings Management Plans.

Pembina Institute, March 22 2017. Retrieved April 2020 from this website:

https://www.pembina.org/reports/tailings-whitepaper-d85.pdf

McRoberts E.C., and Nixon J.F. (1976). A theory of soil sedimenta- tion, Can. Geotech. J., 13, 294-310.

McVay, M., Townsend, F. and Bloomquist, D. (1986). Quiescent consolidation of phosphatic waste clays. J. Geotech. Eng., 112, (11), 1033-1049. 
McWhinney, R. (2014). Oil sands environmental impacts. Canadian energy research institute. Retrieved from https://ceri.ca/studies/oil-sands-environmental-impacts.

Mesri, G. (1973). Coefficient of Secondary Compression. Journal Of The Soil Mechanics And Foundations Division, 99(1), 123-137. Retrieved from

https://cedb.asce.org/CEDBsearch/record.jsp?dockey=0020169

Mesri, G. (1975). New design procedure for stability of soft clays. Journal of Geotechnical and Geoenvironmental Engineering, 101(Discussion).

Mesri, G. \& Godlewski. P. M. (1977). Time and stress compressibility interrelationships. ASCE J. Geotech. Eng Div, 103(5), 417-430.

Mesri, G., \& CHOI, Y. (1985). THE UNIQUENESS OF THE END-OF-PRIMARY (EOP) VOID RATIOEFFECTIVE STRESS RELATIONSHIP. PROCEEDINGS OF THE ELEVENTH INTERNATIONAL CONFERENCE ON SOIL MECHANICS AND FOUNDATION ENGINEERING, SAN FRANCISCO, 12-16 AUGUST 1985. Publication Of: Balkema (AA). Retrieved from https://trid.trb.org/view/284527. Mesri, G., Feng, T. W., and Benak, J. M. (1990), Postdensification Penetration Resistance of Clean Sands, Journal of Geotechnical Engineering, Vol. 116, No. 7, ASCE, pp. 1095-1115.

Mesri, G., \& Rokhsar, A. (1974). Theory of Consolidation for Clays. Journal Of The Geotechnical Engineering Division, 100(8), 889-904. Retrieved from

https://cedb.asce.org/CEDBsearch/record.jsp?dockey=0022212\#: :text=A\%20large\%20strain\% 20theory\%20of,is\%20controlled\%20by\%20indexes\%20of

Meter Environment. (2018). User manual T5/T5x pressure transducer tensiometer. Retrieved August 2020, from http://library.metergroup.com/Manuals/UMS/T5 Manual.pdf

Meyer, R. (1977). The future supply of nature-made petroleum and gas. Pergamon Press. ISBN 978-0-08-021735-2.

Mikasa, M., (1965). The consolidation of soft clay, A new consolidation theory and its application. Japanese Society of Civil Engineers (Reprint from Civil Engineering in Japan, 1965, p. 21-26).

Mikula, R., \& Omotoso, O. (2006). Role of Clays in Controlling Tailings Behaviour in Oil Sands Processing. Clay Science, 12(Supplement2), 177-182.

Miller, W. G. (2010). Comparison of geoenvironmental properties of caustic and non-caustic oil sand fine tailings.

Mitchell, J. (1960). Fundamental aspects of thixotropy in soils. Journal of the soil mechanics and foundations division, 86(3), 19-52.

Mitchell, J. K. (1962). Components of pore water pressure and their engineering significance. In Clays and clay minerals (pp. 162-184). Pergamon. 
Mitchell, J. K. (1976). Fundamentals of Soil Behaviour. Wiley. New York. NY.

Mohamadi, M., Wan, R., and Shen, Z. (2018). "An elastoplastic description of frictional destructuration in natural clays and shales". Acta Geotechnica, 13(4), 911-924.

Moritz, L., (1995). Geotechnical properties of clay at elevated temperatures. Swedish Geotechnical Institute (SGI), Linköping, Sweden.

Motta Cabrera, S. (2009). Characterization of oil sands tailings using low field Nuclear Magnetic Resonance (NMR) technique. Library and Archives Canada = Bibliothèque et Archives Canada, Ottawa, 42.

Moussavi Nik, R. (2013). Application of Dewatering Technologies in Production of Robust NonSegregating Tailings. Retrieved 20 May 2020, from https://era.library.ualberta.ca/items/acb8cce9-93b2-4a9a-9bfc-96af3ce81783

Murakami, Y. (1980). A Method for Estimating the Consolidation of a Normally Consolidated Clay of Some Age. Soils And Foundations, 20(4), 83-93. doi: 10.3208/sandf1972.20.4_83.

Nagaraj, T. S., Murthy, B. S., Vatsala, A., \& Joshi, R. C. (1990). Analysis of compressibility of sensitive soils. Journal of Geotechnical Engineering, 116(1), 105-118.

Nalezny, C., \& Li, M. (1967). EFFECT OF SOIL STRUCTURE AND THIXOTROPIC HARDENING ON SWELLING BEHAVIOR OF COMPACTED CLAY SOILS. Highway Research Record, (209). Retrieved from https://trid.trb.org/view/121037

Narges, G., Salam, M., Qi, S., \& Simms, P. (2019). Structuration in natural clays, dredged sediments, and oil sands tailings. Proceedings of the GeoSt.John's 2019, 72nd Canadian Geotechnical Conference. St. John's, Newfoundland and Labrador.

NRCan, N. R. (2013). Natural Resources Canada. Retrieved February 2018, from Oil Sands Processes: http://www.nrcan.gc.ca/energy/oil-sands/5853

NRCan. (2018). Inline Dewatering of Oil Sands Tailings. Retrieved May 2020, from https://bowvalleycollege.libguides.com/c.php?g=494959\&p=3386853

Oil Sands Discovery Centre. (2016). Facts about Alberta's oil sands and its industry. Retrieved from https://open.alberta.ca/dataset/d5a7fec7-6e37-431c-9f33eb98510c65e4/resource/eb20740d-d1bc-4e60-b441-99f6c84998d8/download/2016-oil-sandsdiscovery-centre-osdc-facts-about-albertas-oil-sands-and-its-industry.pdf

Orland, K. (2018). 340 Billion Gallons of Sludge Spur Environmental Fears in Canada. Retrieved April 2018 from the website: https://www.bloomberg.com/news/articles/2018-01-16/340billion-gallons-of-sludge-spurenvironmental-fears-in-canada

Osipov, V. I., Nikolaeva, S. K., \& Sokolov, V. N. (1984). Microstructural changes associated with thixotropic phenomena in clay soils. Geotechnique, 34(3), 293- 303. 
OSTC Companies. (2012). Technical Guide for Fluid Fine Tailings Management. Retrieved July 2020, from

\section{https://www.cs2.ca/uploads/documents/id7/TechGuideFluidTailingsMgmt Aug2012.pdf}

Owolagba, J. O. (2013). Dewatering Behavior of Centrifuged Oil Sand Fine Tailings

for Surface Deposition (Doctoral dissertation, Faculty of Graduate Studies and

Research, University of Regina).

Pollock, G. (1988). Large strain consolidation of oil sand tailings sludge (Master's thesis). University of Alberta.

Priestley, D. (2011). Modeling multidimensional large strain consolidation of tailings (Doctoral dissertation, University of British Columbia).

Proskin, S., Sego, D., \& Alostaz, M. (2010). Freeze-thaw and consolidation tests on Suncor mature fine tailings (MFT). Cold Regions Science And Technology, 63(3), 110-120. doi: 10.1016/j.coldregions.2010.05.007.

Qi, S., Salam, M., \& Simms, P. (2018). Creep and structuration in tailings and in natural clays. Proceedings of the 6th International Oil Sands Tailings Conference. Edmonton, Alberta.

Qi, S., Simms, P., Daliri, F., \& Vanapalli, S. (2019). Coupling elasto-plastic behaviour of unsaturated soils with piecewise linear large-strain consolidation. Géotechnique, 70(6), 518537. https://doi.org/10.1680/igeot.18.p.261

Qi, S., Simms, P., \& Vanapalli, S. (2017). Piecewise-linear formulation of coupled large strain consolidation and unsaturated flow. I: Model development and implementation. Journal of Geotechnical and Geoenvironmental Engineering, 143(7), 04017018.

Qiu, Y., \& Sego, D. C. (2001). Laboratory properties of mine tailings. Canadian Geotechnical Journal, 38(1), 183-190.

Roberts, S. (2018). Separating the Sands: Karl Clark and Early Oil Sands Research in Alberta. Master thesis. Western University, London. Retrieved 3 July 2020, from https://ir.lib.uwo.ca/etd/5568/

Rowe, R. K., \& Hinchberger, S. D. (1998). The significance of rate effects in modelling the Sackville test embankment. Canadian Geotechnical Journal, 35(3), 500-516.

Salam, M. (2020). Effect of polymers on short- and long-term dewatering of oil sands tailings (PhD thesis). Carleton University, Ottawa.

Salam, A. M., Simms, P. H., \& Örmeci, B. (2018). Structuration in polymer amended oil sands fine tailings. Proceedings of GeoEdmonton 2018, 71st Canadian Geotechnical Conference. Edmonton, Alberta. 
Schmertmann, J.H. (1991), "The Mechanical Aging of Soils", Journal of geotechnical Engineering, vol. 117, No. 9, pp.1288-1330.

Scott, J., Dusseault, M., \& David Carrier, W. (1985). Behaviour of the clay/bitumen/water sludge system from oil sands extraction plants. Applied Clay Science, 1(1-2), 207-218. doi:

10.1016/0169-1317(85)90574-5.

Scott, J. D., Jeeravipoolvarn, S., Kabwe, L., Wilson, G. W., \& Sorta, A. (2013). Properties which affect the consolidation behaviour of mature fine tailings. In Proceedings of the 17th international conference on tailings and mine waste, Banff, Alberta.

Scully, R.W., Schiffman, R.L., Olsen, H.W. and Ko, H.Y. 1984. Validation of consolidation properties of phosphatic clay at very high void ratios. Sedimentation consolidation models: predictions and validation: In proceedings of a symposium, R.N. Yong and F.C. Townsend Eds, ASCE, Newyork: 158-181.

Seed, H., \& Chan, C. (1957). Thixotropic Characteristics of Compacted Clays. Journal Of The Soil Mechanics And Foundations Division, 83(4), 1-35. Retrieved from

https://cedb.asce.org/CEDBsearch/record.jsp?dockey=0011086

Seneviratne, N. H., Fahey, M., Newson, T. A. \& Fujiyasu, Y. (1996). Numerical modelling of consolidation and evaporation of slurried mine tailings. Int. J. Numer. Analyt. Methods Geomech. 20, No. 9, 647-671.

Sethi, A. (1995). Methylene Blue Test for Clay Activity Determination in Fine Tails. MRRT Procedures.

Shahriar, A., Abedin, M., \& Jadid, R. (2018). Thixotropic aging and its effect on 1-D compression behavior of soft reconstituted clays. Applied Clay Science, 153, 217-227. doi:

10.1016/j.clay.2017.12.029.

Skempton, A. W. \& Northey, R. D. (1952). The sensitivity of clays. Geotechnique 3, No. 1, 30-53.

Sobkowicz, J. (2012). OIL SANDS TAILINGS TECHNOLOGY DEPLOYMENT ROADMAPS (pp. 1-273). Retrieved from http://www.assembly.ab.ca/lao/library/egovdocs/2012/alai/220928.pdf

Soga, K. (1994). Mechanical behavior and constitutive modelling of natural structured soil. Ph. D. thesis. Univ. of California at Berkeley.

Soga, K. (2005). Time Effects Observed in Granular Materials. In the COE Workshop on Evaluation of Mechanical Behavior of Granular Materials, Lecture (Vol. 3).

Soleimani, S., Simms, P., Dunmola, A., Freeman, G., \& Wilson, G. W. (2014). Desiccation and consolidation in thin-lift deposition of polymer-amended mature fine tailings. In Proc., 17th Int. Seminar on Paste and Thickened Tailings (pp. 307-322). Australian Centre for Geomechanics, Crawley, Australia. 
Somogyi, F. (1980). Large Strain Consolidation of Fine Grained Slurries. Canadian Society for Civil Engineering. Winnipeg.

Somogyi, F., and Gray, D. (1977), Engineering properties affecting disposal of red mud, Proc., Conf. on Geotech., Practice for Disposal of Solid Waste Materials, ACSE, 1-22.

Sorensen, K. K. (2006). Influence of viscosity and ageing on the behaviour of clays (Doctoral dissertation, University College London).

Speight, J. (2013). Oil sand production processes. Elsevier/Gulf Professional Pub.

Sridharan, A., \& Rao, A. (1982). Mechanisms controlling the secondary compression of clays. Géotechnique, 32(3), 249-260. doi: 10.1680/geot.1982.32.3.249.

Starr, J.L., and Paltineanu I.C. (2002). Methods for Measurement of Soil Water Content: Capacitance Devices. p. 463-474. In J.H.Dane, and G.C.Topp (ed.) Methods of Soil Analysis: Part 4 Physical Methods. Soil Science Society of America, Inc., Soil Science Society of America, Inc.

Suthaker, N. (1995). Geotechnics of oil sand fine tailings (PhD thesis). University of Alberta.

Suthaker, N. N., \& Scott, J. D. (1994). Large strain consolidation testing of oil sand fine tails in a wet landscape. In Proceedings, 47th Canadian Geotechnical Conference (pp. 514-523).

Suthaker, N. N., \& Scott, J. D. (1997). Thixotropic strength measurement of oil sand fine tailings. Canadian Geotechnical Journal, 34(6), 974-984.

Tanaka, H., Hirabayashi, H., Matsuoka, T., \& Kaneko, H. (2012). Use of fall cone test as measurement of shear strength for soft clay materials. Soils And Foundations, 52(4), 590-599. doi: 10.1016/j.sandf.2012.07.002.

Taylor, D. W. (1942). Research on consolidation of clays (Vol. 82). Massachusetts Institute of Technology.

Terzaghi, K., Peck, R. B., \& Mesri, G. (1996). Soil mechanics in engineering practice. John Wiley \& Sons.

Vajihinejad, V., Gumfekar, S. P., Bazoubandi, B., Rostami Najafabadi, Z., \& Soares, J. B. (2019). Water Soluble Polymer Flocculants: Synthesis, Characterization, and Performance Assessment. Macromolecular Materials and Engineering, 304(2), 1800526.

Vajihinejad, V., \& Soares, J. B. (2018). Monitoring polymer flocculation in oil sands tailings: A population balance model approach. Chemical Engineering Journal, 346, 447-457.

Van Olphen, H. (1977). Introduction to clay colloid chemistry, Wiley.

Varatharajan, S. (2011). 1D compression creep behaviour of kaolinite and bentonite clay. 
Wahls, H. (1983). UNDRAINED SHEAR STRENGTH OF SATURATED CLAY. Transportation Research Record, (919). Retrieved from https://trid.trb.org/view/202814

Wang, C. (2017). Flocculation-assisted dewatering of fluid fine tailings using a volute screw press. Retrieved 5 July 2020, from https://era.library.ualberta.ca/items/0aa2a0f9-4379-4a19$\underline{\text { bae3-cbf40b8d5f46 }}$

Watabe Y., Udaka K., Nakatani Y., Leroueil S. (2012) Long-term consolidation behavior interpreted with isotache concept for worldwide clays. Soils Found 52, 449-464.

Webster, S., Brown, W., Derakhshandeh, B., Dubash, N., Gomez, C., Veenstra, C., \& Junaid, A. (2016). A COMPREHENSIVE CONTROL SCHEME FOR DYNAMIC INLINE FLOCCULATION OF OIL SANDS TAILINGS. In International Oil Sands Tailings Conference. Lake Louis. Retrieved 21 May 2020, from https://coanda.ca/wp-content/uploads/2017/02/IOSTC Paper ManuscriptControl Scheme-Final.pdf.

Wells, P. S., Revington, A., \& Omotoso, O. (2011). Mature fine tailings drying-technology update. Paste, (pp. 155-166).

Wilson, G., Kabwe, L., Beier, N., \& Scott, J. (2018). Effect of various treatments on consolidation of oil sands fluid fine tailings. Canadian Geotechnical Journal, 55(8), 1059-1066.

https://doi.org/10.1139/cgj-2017-0268.

Yin, J. H., \& Feng, W. Q. (2016). A new simplified method and its verification for calculation of consolidation settlement of a clayey soil with creep. Canadian Geotechnical Journal, 54(3), 333347.

Yin, J. H., \& Graham, J. (1994). Equivalent times and one-dimensional elastic viscoplastic modelling of time-dependent stress-strain behaviour of clays. Canadian Geotechnical Journal, $31(1), 42-52$.

Yuan, S., Lorentz, J., Siman, R., \& Joe Gu, Y. (2016). OIL SANDS FLUID FINE TAILINGS DEWATERING USING ADDITIVES. United states of America. Retrieved 20 May 2020, from https://patents.justia.com/patent/20160311709\#history.

Zhang, X., Kong, L., Yang, A., and Sayem, H. (2017). "Thixotropic mechanism of clay: A microstructural investigation". Soils and Foundations, 57(1), 23-35.

Zhu, Q. (2013). Understanding the role of caustic addition in oil sands processing (Master's thesis). University of Alberta. 


\section{Appendices}

Appendix A. AGAT laboratory tailings characterization test results:

\begin{tabular}{|c|c|c|c|c|c|}
\hline \multirow{2}{*}{ SAMPLE \# } & \multirow{2}{*}{ Sample ID \# } & \multicolumn{2}{|c|}{ Weight (Grams) } & Methylene Blue & \multirow{2}{*}{ meq/100g } \\
\cline { 3 - 5 } & & Recommended & Actual & Volume (mL) & \\
\cline { 3 - 5 } & RAWFFT & 2.00 & 2.02 & 7.50 & 3.72 \\
\hline 8 & Centrfuge FFT & 2.00 & 2.03 & 15.00 & 7.39 \\
\hline 9 & $600-$ PPM \& FFT & 2.00 & 2.05 & 9.50 & 4.64 \\
\hline 10 & 1000 - PPM \& FFT & 2.00 & 2.05 & 9.00 & 4.40 \\
\hline
\end{tabular}

Figure A-1. Methylene blue index analysis for centrifuge cake FFT.

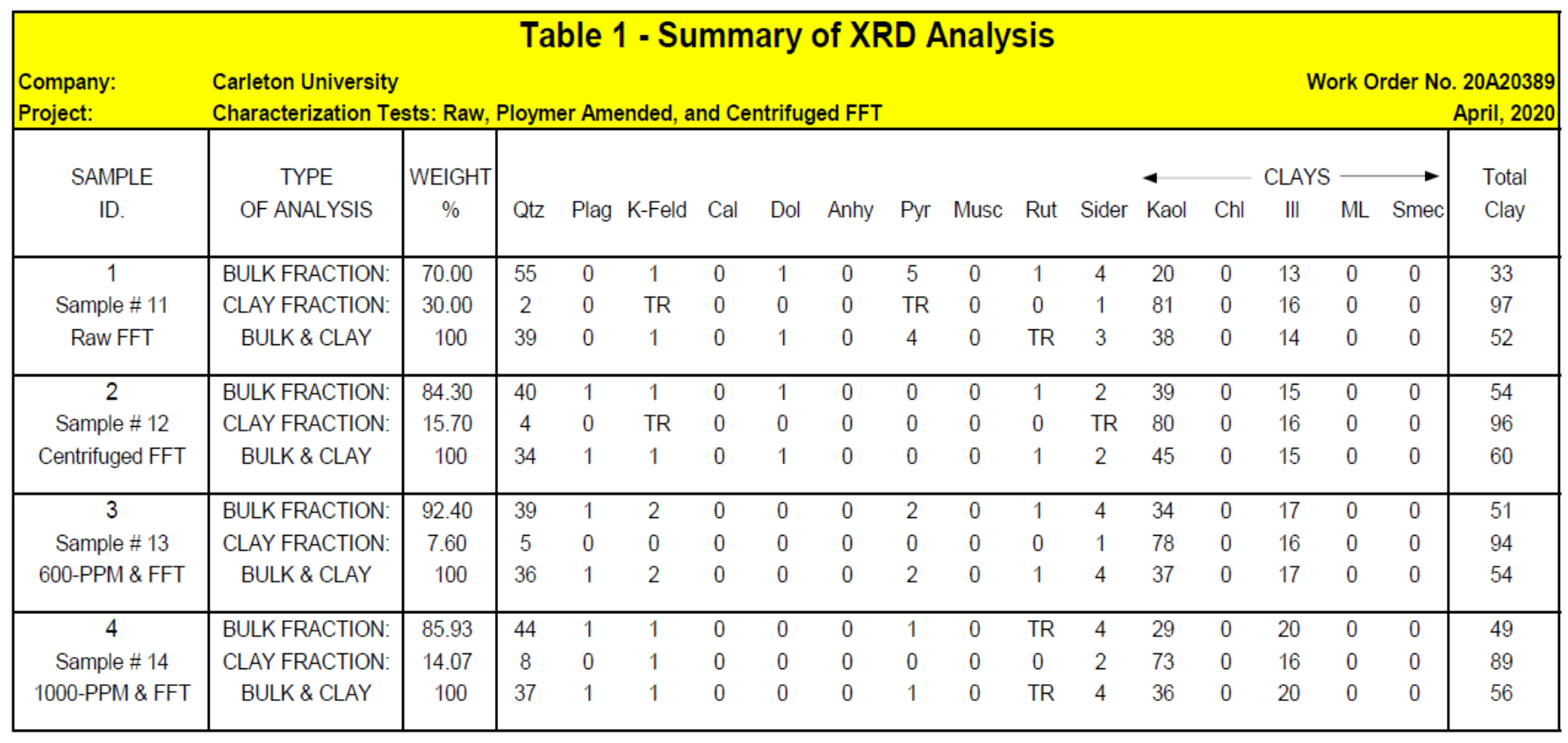

Figure A-2. XRD analysis for centrifuge cake FFT. 


\begin{tabular}{|c|c|c|c|c|c|c|}
\hline & & & & \multicolumn{3}{|c|}{ Inorganic Chemistry (Water) } \\
\hline \multicolumn{7}{|c|}{ DATE RECEIVED: $2020-03-20$} \\
\hline \multirow[b]{5}{*}{ Parameter } & \multirow[b]{5}{*}{ Unit } & \multicolumn{4}{|c|}{ Syncrude Raw } & \multirow{5}{*}{$\begin{array}{c}\text { Centrifuge } \\
\text { Water } \\
2020-03-18 \\
1040024\end{array}$} \\
\hline & & \multirow{3}{*}{\multicolumn{2}{|c|}{$\begin{array}{r}\text { SAMPLE DESCRIPTION: } \\
\text { SAMPLE TYPE: } \\
\text { DATE SAMPLED: }\end{array}$}} & \multirow{4}{*}{$\begin{array}{c}\text { FT } \\
\text { Water } \\
2020-03-18 \\
1040020\end{array}$} & & \\
\hline & & & & & & \\
\hline & & & & & & \\
\hline & & G/S & RDL & & RDL & \\
\hline Electrical Conductivity & $\mu \mathrm{S} / \mathrm{cm}$ & & 2 & 1760 & 2 & 967 \\
\hline $\mathrm{pH}$ & $\mathrm{pH}$ Units & & NA & 7.97 & NA & 7.84 \\
\hline Total Dissolved Solids & $\mathrm{mg} / \mathrm{L}$ & & 20 & 884 & 20 & 744 \\
\hline Total Suspended Solids & $\mathrm{mg} / \mathrm{L}$ & & 10 & $<10$ & 10 & 2630 \\
\hline Alkalinity (as $\mathrm{CaCO} 3$ ) & $\mathrm{mg} / \mathrm{L}$ & & 5 & 531 & 5 & 136 \\
\hline Fluoride & $\mathrm{mg} / \mathrm{L}$ & & 0.07 & $<0.07$ & 0.05 & 1.87 \\
\hline Chloride & $\mathrm{mg} / \mathrm{L}$ & & 1.0 & 191 & 0.50 & 26.5 \\
\hline Nitrate as $\mathrm{N}$ & $\mathrm{mg} / \mathrm{L}$ & & 0.5 & $<0.5$ & 0.25 & $<0.25$ \\
\hline Sulphate & $\mathrm{mg} / \mathrm{L}$ & & 1.0 & 15.0 & 0.50 & 254 \\
\hline Total Calcium & $\mathrm{mg} / \mathrm{L}$ & & 0.25 & 17.45 & 0.25 & 56.05 \\
\hline Total Magnesium & $\mathrm{mg} / \mathrm{L}$ & & 0.25 & 9.65 & 0.25 & 18.70 \\
\hline Total Potassium & $\mathrm{mg} / \mathrm{L}$ & & 0.25 & 6.77 & 0.25 & 14.62 \\
\hline Total Sodium & $\mathrm{mg} / \mathrm{L}$ & & 0.25 & 289.70 & 0.25 & 92.93 \\
\hline Iron $(\mathrm{Fe}++)$ & $\mathrm{mg} / \mathrm{L}$ & & 0.05 & 0.05 & 0.05 & 0.12 \\
\hline Iron (Fe+++) & $\mathrm{mg} / \mathrm{L}$ & & 0.05 & $<0.05$ & 0.05 & $<0.05$ \\
\hline Total Iron & $\mathrm{mg} / \mathrm{L}$ & & 0.010 & 0.050 & 0.010 & 0.141 \\
\hline Total Manganese & $\mathrm{mg} / \mathrm{L}$ & & 0.002 & 0.073 & 0.002 & 0.263 \\
\hline $\begin{array}{l}\text { \% Difference/ Ion Balance } \\
\text { (Calculated) }\end{array}$ & $\%$ & & NA & 5.07 & NA & 0.545 \\
\hline
\end{tabular}

Figure A-3. Inorganic chemistry water for centrifuge cake FFT.

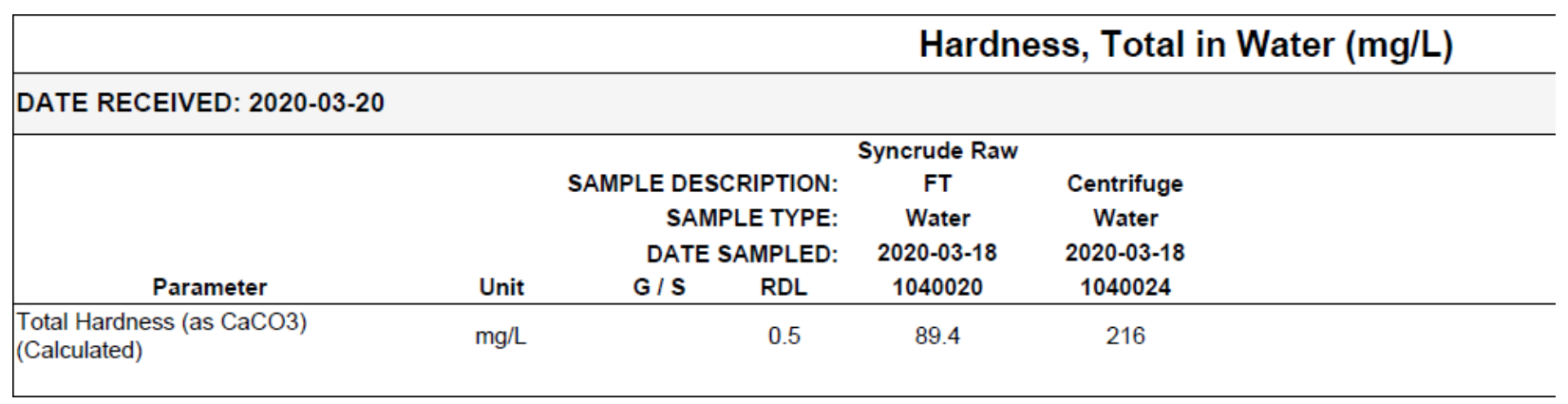

Figure A-4. Total water hardness for centrifuge cake FFT. 


\begin{tabular}{|c|c|c|c|c|c|c|c|c|c|c|c|c|c|}
\hline & & & & Sample & & & & & Solids & & & & \\
\hline $\begin{array}{l}\text { Work } \\
\text { Order }\end{array}$ & $\begin{array}{c}\text { Sample } \\
\text { Description }\end{array}$ & $\begin{array}{c}\text { Date } \\
\text { Sampled }\end{array}$ & $\begin{array}{c}\text { Time } \\
\text { Sampled }\end{array}$ & $\begin{array}{l}\text { Wet } \\
\text { IIt } \\
(\mathrm{g})\end{array}$ & $\begin{array}{c}\text { Hydrocarbons } \\
\pi t \\
(g)\end{array}$ & $\begin{array}{c}\% \\
\text { Hydrocarbous }\end{array}$ & $\begin{array}{c}\text { Water } \\
\pi t \\
(\mathrm{~g})\end{array}$ & $\begin{array}{c}\% \\
\text { Water }\end{array}$ & $\begin{array}{l}D r y \\
\pi t \\
\text { (g) }\end{array}$ & $\begin{array}{l}\% \\
\text { Solids }\end{array}$ & $\begin{array}{c}\text { Discrep } \\
\Pi_{t} \\
(\mathrm{~g})\end{array}$ & $\begin{array}{c}\% \\
\text { Discrep }\end{array}$ & $\begin{array}{c}\% \\
\text { Cumm }\end{array}$ \\
\hline 20220389 & Syncrude FFT Raw & 18-Mar-2020 & 10:00 AM & 122,16 & 3.82 & 3.127 & 87,69 & 71,783 & 30.44 & 24.918 & 0.21 & 0.172 & 99,828 \\
\hline $20 A 20389$ & Centrifuged FFT & 18-Mar-2020 & 10:00 AM & 125.86 & 0.91 & 0.723 & 58.94 & 46,830 & 65.76 & 52.249 & 0.25 & 0.199 & 99.802 \\
\hline $20 A 20389$ & Polymer-Amended Tailing (600-PPM FFFT) & 18-Mar-2020 & 10:00 AM & 127,38 & 4.20 & 3.297 & 76.19 & 59.813 & 46,91 & 36.827 & 0.08 & 0.063 & 99.937 \\
\hline $20 A 20389$ & Polymer-Amended Taling (1000-PPM fFFT) & 18-Mar-2020 & 10:00 AM & 124,19 & 2.17 & 1.747 & 80,36 & 64.707 & 41.61 & 33.505 & 0.05 & 0.040 & 99,959 \\
\hline
\end{tabular}

Figure A-5. Dean stark analysis for centrifuge cake FFT. 
Appendix B. Phase I.

Table B-1: Pre-mixing and after mixing solids content for phase I.

\begin{tabular}{|l|l|l|l|l|l|l|l|}
\hline Date & Sample & Dish (g) & Wet (g) & Dry (g) & GWC & MC & SC \\
\hline 11-Mar-19 & Top & 1.15 & 28.40 & 13.99 & 1.12 & 0.53 & 0.47 \\
\hline 11-Mar-19 & Middle & 1.15 & 21.00 & 10.86 & 1.04 & 0.51 & 0.49 \\
\hline 11-Mar-19 & Bottom & 1.13 & 18.60 & 9.36 & 1.12 & 0.53 & 0.47 \\
\hline 12-Mar-19 & Top & 1.16 & 35.82 & 17.01 & 1.19 & 0.54 & 0.46 \\
\hline 12-Mar-19 & Middle & 1.14 & 28.92 & 14.15 & 1.14 & 0.53 & 0.47 \\
\hline 12-Mar-19 & Bottom & 1.16 & 22.84 & 11.47 & 1.10 & 0.52 & 0.48 \\
\hline Date & Sample & Dish (g) & Wet (g) & Dry (g) & GWC & MC & SC \\
\hline 13-Mar-19 & Top & 1.14 & 27.07 & 13.08 & 1.17 & 0.54 & 0.46 \\
\hline 13-Mar-19 & Middle & 1.14 & 19.29 & 10.05 & 1.04 & 0.51 & 0.49 \\
\hline 13-Mar-19 & Bottom & 1.14 & 16.54 & 8.92 & 0.98 & 0.49 & 0.51 \\
\hline 25-Mar-19 & Top & 1.14 & 33.57 & 16.73 & 1.08 & 0.52 & 0.48 \\
\hline 25-Mar-19 & Middle & 1.15 & 24.30 & 12.57 & 1.03 & 0.51 & 0.49 \\
\hline 25-Mar-19 & Bottom & 1.15 & 24.07 & 12.42 & 1.03 & 0.51 & 0.49 \\
\hline Bucket & & & & & & & \\
\hline Date & Sample & Dish (g) & Wet (g) & Dry (g) & GWC & MC & SC \\
\hline 26-Mar-19 & Top & 1.14 & 31.76 & 15.90 & 1.07 & 0.52 & 0.48 \\
\hline
\end{tabular}


Table B-2: Fall cone 1 solids content by depth broken after 518 days.

\begin{tabular}{|c|c|c|c|c|c|c|c|c|}
\hline $\begin{array}{c}\text { Depth } \\
\text { (m) }\end{array}$ & Date & Sample & Dish (g) & Wet (g) & Dry (g) & GWC & MC & SC \\
\hline \multirow[t]{2}{*}{0.1} & $\begin{array}{l}\text { 5-Mar- } \\
19\end{array}$ & Top & 1.55 & 35.85 & 19.29 & 0.93 & 0.48 & 0.52 \\
\hline & $\begin{array}{l}\text { 5-Mar- } \\
19\end{array}$ & Middle & 1.17 & 35.06 & 18.83 & 0.92 & 0.48 & 0.52 \\
\hline \multirow[t]{2}{*}{0.2} & $\begin{array}{l}\text { 5-Mar- } \\
19\end{array}$ & Bottom & 1.15 & 27.13 & 14.63 & 0.93 & 0.48 & 0.52 \\
\hline & $\begin{array}{l}\text { 6-Mar- } \\
19\end{array}$ & Top & 1.16 & 30.49 & 16.38 & 0.93 & 0.48 & 0.52 \\
\hline \multirow[t]{2}{*}{0.3} & $\begin{array}{l}\text { 6-Mar- } \\
19\end{array}$ & Middle & 1.14 & 31.33 & 16.74 & 0.94 & 0.48 & 0.52 \\
\hline & $\begin{array}{l}\text { 6-Mar- } \\
19\end{array}$ & Bottom & 1.15 & 30.85 & 16.39 & 0.95 & 0.49 & 0.51 \\
\hline \multirow[t]{2}{*}{0.4} & $\begin{array}{l}\text { 7-Mar- } \\
19\end{array}$ & Top & 1.14 & 26.81 & 14.35 & 0.94 & 0.49 & 0.51 \\
\hline & $\begin{array}{l}\text { 7-Mar- } \\
19\end{array}$ & Middle & 1.14 & 25.71 & 13.79 & 0.94 & 0.49 & 0.51 \\
\hline \multirow[t]{2}{*}{0.5} & $\begin{array}{l}\text { 7-Mar- } \\
19\end{array}$ & Bottom & 1.14 & 32.94 & 17.36 & 0.96 & 0.49 & 0.51 \\
\hline & $\begin{array}{l}\text { 8-Mar- } \\
19\end{array}$ & Top & 1.13 & 30.30 & 15.92 & 0.97 & 0.49 & 0.51 \\
\hline \multirow[t]{2}{*}{0.6} & $\begin{array}{l}\text { 8-Mar- } \\
19\end{array}$ & Middle & 1.16 & 30.20 & 15.90 & 0.97 & 0.49 & 0.51 \\
\hline & $\begin{array}{l}\text { 8-Mar- } \\
19\end{array}$ & Bottom & 1.14 & 27.20 & 14.33 & 0.98 & 0.49 & 0.51 \\
\hline \multirow[t]{2}{*}{0.7} & $\begin{array}{l}\text { 9-Mar- } \\
19\end{array}$ & Top & 1.14 & 29.72 & 15.58 & 0.98 & 0.49 & 0.51 \\
\hline & $\begin{array}{l}\text { 9-Mar- } \\
19\end{array}$ & Middle & 1.14 & 31.34 & 16.40 & 0.98 & 0.49 & 0.51 \\
\hline \multirow[t]{2}{*}{0.8} & $\begin{array}{l}\text { 9-Mar- } \\
19\end{array}$ & Bottom & 1.15 & 26.45 & 13.95 & 0.98 & 0.49 & 0.51 \\
\hline & $\begin{array}{l}\text { 11- } \\
\text { Mar-19 }\end{array}$ & Top & 1.16 & 30.51 & 15.98 & 0.98 & 0.50 & 0.50 \\
\hline \multirow[t]{2}{*}{0.9} & $\begin{array}{l}\text { 11- } \\
\text { Mar-19 }\end{array}$ & Middle & 1.15 & 28.47 & 14.96 & 0.98 & 0.49 & 0.51 \\
\hline & $\begin{array}{l}\text { 11- } \\
\text { Mar-19 }\end{array}$ & Bottom & 1.15 & 29.48 & 15.49 & 0.98 & 0.49 & 0.51 \\
\hline
\end{tabular}


Appendix Table B-3: Fall cone 2 solids content by depth broken after 518 days.

\begin{tabular}{|c|c|c|c|c|c|c|c|c|}
\hline $\begin{array}{l}\text { Depth } \\
\text { (m) }\end{array}$ & Date & Sample & Dish (g) & Wet (g) & Dry (g) & GWC & $\mathrm{MC}$ & SC \\
\hline \multirow[t]{2}{*}{0.1} & $\begin{array}{l}\text { 5-Mar- } \\
19\end{array}$ & Top & 1.15 & 24.02 & 12.24 & 1.06 & 0.52 & 0.48 \\
\hline & $\begin{array}{l}\text { 5-Mar- } \\
19\end{array}$ & Middle & 1.15 & 32.48 & 16.42 & 1.05 & 0.51 & 0.49 \\
\hline \multirow[t]{2}{*}{0.2} & $\begin{array}{l}\text { 5-Mar- } \\
19\end{array}$ & Bottom & 1.15 & 26.43 & 13.64 & 1.02 & 0.51 & 0.49 \\
\hline & $\begin{array}{l}\text { 6-Mar- } \\
19\end{array}$ & Top & 1.16 & 27.69 & 14.34 & 1.01 & 0.50 & 0.50 \\
\hline \multirow[t]{2}{*}{0.3} & $\begin{array}{l}\text { 6-Mar- } \\
19\end{array}$ & Middle & 1.15 & 26.05 & 13.61 & 1.00 & 0.50 & 0.50 \\
\hline & $\begin{array}{l}\text { 6-Mar- } \\
19\end{array}$ & Bottom & 1.16 & 22.90 & 12.03 & 1.00 & 0.50 & 0.50 \\
\hline \multirow[t]{2}{*}{0.4} & $\begin{array}{l}\text { 7-Mar- } \\
19\end{array}$ & Top & 1.14 & 25.06 & 13.17 & 0.99 & 0.50 & 0.50 \\
\hline & $\begin{array}{l}\text { 7-Mar- } \\
19\end{array}$ & Middle & 1.16 & 24.01 & 12.66 & 0.99 & 0.50 & 0.50 \\
\hline \multirow[t]{2}{*}{0.5} & $\begin{array}{l}\text { 7-Mar- } \\
19\end{array}$ & Bottom & 1.14 & 22.10 & 11.71 & 0.98 & 0.50 & 0.50 \\
\hline & $\begin{array}{l}\text { 8-Mar- } \\
19\end{array}$ & Top & 1.14 & 31.16 & 16.26 & 0.99 & 0.50 & 0.50 \\
\hline \multirow[t]{2}{*}{0.6} & $\begin{array}{l}\text { 8-Mar- } \\
19\end{array}$ & Middle & 1.13 & 29.92 & 15.65 & 0.98 & 0.50 & 0.50 \\
\hline & $\begin{array}{l}\text { 8-Mar- } \\
19\end{array}$ & Bottom & 1.13 & 26.57 & 13.92 & 0.99 & 0.50 & 0.50 \\
\hline \multirow[t]{2}{*}{0.7} & $\begin{array}{l}\text { 9-Mar- } \\
19\end{array}$ & Top & 1.15 & 27.86 & 14.63 & 0.98 & 0.50 & 0.50 \\
\hline & $\begin{array}{l}\text { 9-Mar- } \\
19\end{array}$ & Middle & 1.15 & 31.39 & 16.38 & 0.99 & 0.50 & 0.50 \\
\hline \multirow[t]{2}{*}{0.8} & $\begin{array}{l}\text { 9-Mar- } \\
19\end{array}$ & Bottom & 1.15 & 28.73 & 15.11 & 0.98 & 0.49 & 0.51 \\
\hline & $\begin{array}{l}11- \\
\text { Mar-19 }\end{array}$ & Top & 1.15 & 26.48 & 13.99 & 0.97 & 0.49 & 0.51 \\
\hline \multirow[t]{2}{*}{0.9} & $\begin{array}{l}\text { 11- } \\
\text { Mar-19 }\end{array}$ & Middle & 1.13 & 28.22 & 14.87 & 0.97 & 0.49 & 0.51 \\
\hline & $\begin{array}{l}\text { 11- } \\
\text { Mar-19 }\end{array}$ & Bottom & 1.14 & 32.38 & 17.02 & 0.97 & 0.49 & 0.51 \\
\hline
\end{tabular}


Appendix C. Phase II.

Table C-1: Initial solids content of tailings by depth in the box at the beginning of the test.

\begin{tabular}{|c|c|c|c|}
\hline Depth (m) & GWC & $M C$ & SC \\
\hline 0 & 0.84 & 0.45 & 0.54 \\
\hline 0 & 0.84 & 0.45 & 0.54 \\
\hline 5 & 0.84 & 0.45 & 0.54 \\
\hline 5 & 0.85 & 0.45 & 0.54 \\
\hline 10 & 0.84 & 0.45 & 0.54 \\
\hline 10 & 0.84 & 0.45 & 0.54 \\
\hline 15 & 0.85 & 0.46 & 0.53 \\
\hline 15 & 0.85 & 0.45 & 0.54 \\
\hline 20 & 0.85 & 0.46 & 0.53 \\
\hline 20 & 0.85 & 0.45 & 0.54 \\
\hline 25 & 0.85 & 0.45 & 0.54 \\
\hline 25 & 0.85 & 0.46 & 0.53 \\
\hline 30 & 0.84 & 0.45 & 0.54 \\
\hline 30 & 0.85 & 0.45 & 0.54 \\
\hline 35 & 0.84 & 0.45 & 0.54 \\
\hline 35 & 0.85 & 0.45 & 0.54 \\
\hline 40 & 0.84 & 0.45 & 0.54 \\
\hline 40 & 0.84 & 0.45 & 0.54 \\
\hline 45 & 0.83 & 0.45 & 0.54 \\
\hline 45 & 0.86 & 0.46 & 0.53 \\
\hline 50 & 0.83 & 0.45 & 0.54 \\
\hline 50 & 0.84 & 0.45 & 0.54 \\
\hline 55 & 0.85 & 0.46 & 0.53 \\
\hline 55 & 0.83 & 0.45 & 0.54 \\
\hline 60 & 0.83 & 0.45 & 0.54 \\
\hline 60 & 0.83 & 0.45 & 0.54 \\
\hline
\end{tabular}


Table C-2: Initial solids content of tailings by depth in the box at the end of self-weight consolidation.

\begin{tabular}{|l|l|l|l|}
\hline Depth $(\mathrm{m})$ & GWC & MC & SC \\
\hline 5 & 0.87 & 0.46 & 0.53 \\
\hline 5 & 0.84 & 0.45 & 0.54 \\
\hline 10 & 0.86 & 0.46 & 0.53 \\
\hline 10 & 0.87 & 0.46 & 0.53 \\
\hline 15 & 0.84 & 0.45 & 0.54 \\
\hline 15 & 0.84 & 0.45 & 0.54 \\
\hline 20 & 0.85 & 0.46 & 0.53 \\
\hline 20 & 0.86 & 0.46 & 0.53 \\
\hline 25 & 0.82 & 0.45 & 0.54 \\
\hline 25 & 0.83 & 0.45 & 0.54 \\
\hline 30 & 0.81 & 0.44 & 0.55 \\
\hline 30 & 0.83 & 0.45 & 0.54 \\
\hline 35 & 0.82 & 0.45 & 0.54 \\
\hline 35 & 0.81 & 0.44 & 0.55 \\
\hline 40 & 0.83 & 0.45 & 0.54 \\
\hline 40 & 0.82 & 0.45 & 0.54 \\
\hline 45 & 0.83 & 0.45 & 0.54 \\
\hline 45 & 0.82 & 0.45 & 0.54 \\
\hline 50 & 0.82 & 0.45 & 0.54 \\
\hline 50 & 0.82 & 0.45 & 0.45 \\
\hline 55 & 0.83 & 0.45 & 0.54 \\
\hline 55 & 0.83 & 0.45 & \\
\hline 60 & 0.83 & & \\
\hline 60 & 0.45 & & \\
\hline
\end{tabular}


Table C-3. Estimated saturation of the core sample taken at the beginning and end of selfweight consolidation.

\begin{tabular}{|l|l|l|l|}
\hline Day 0 & Saturation & Day 23 & Saturation \\
\hline Depth $(\mathrm{m})$ & & & \\
\hline & & Depth $(\mathrm{m})$ & 0.99 \\
\hline 0.05 & 0.94 & 0.05 & 0.98 \\
\hline 0.1 & 0.96 & 0.1 & 0.98 \\
\hline 0.15 & 0.94 & 0.15 & 0.98 \\
\hline 0.2 & 0.95 & 0.2 & 0.98 \\
\hline 0.25 & 0.92 & 0.25 & 0.98 \\
\hline 0.3 & 0.91 & 0.3 & 0.99 \\
\hline 0.35 & 0.91 & 0.35 & 0.98 \\
\hline 0.4 & 0.92 & 0.4 & 0.97 \\
\hline 0.45 & 0.92 & 0.45 & 0.97 \\
\hline 0.5 & 0.92 & 0.5 & 0.97 \\
\hline 0.55 & 0.91 & 0.55 & 0.97 \\
\hline 0.6 & 0.92 & 0.6 & \\
\hline
\end{tabular}




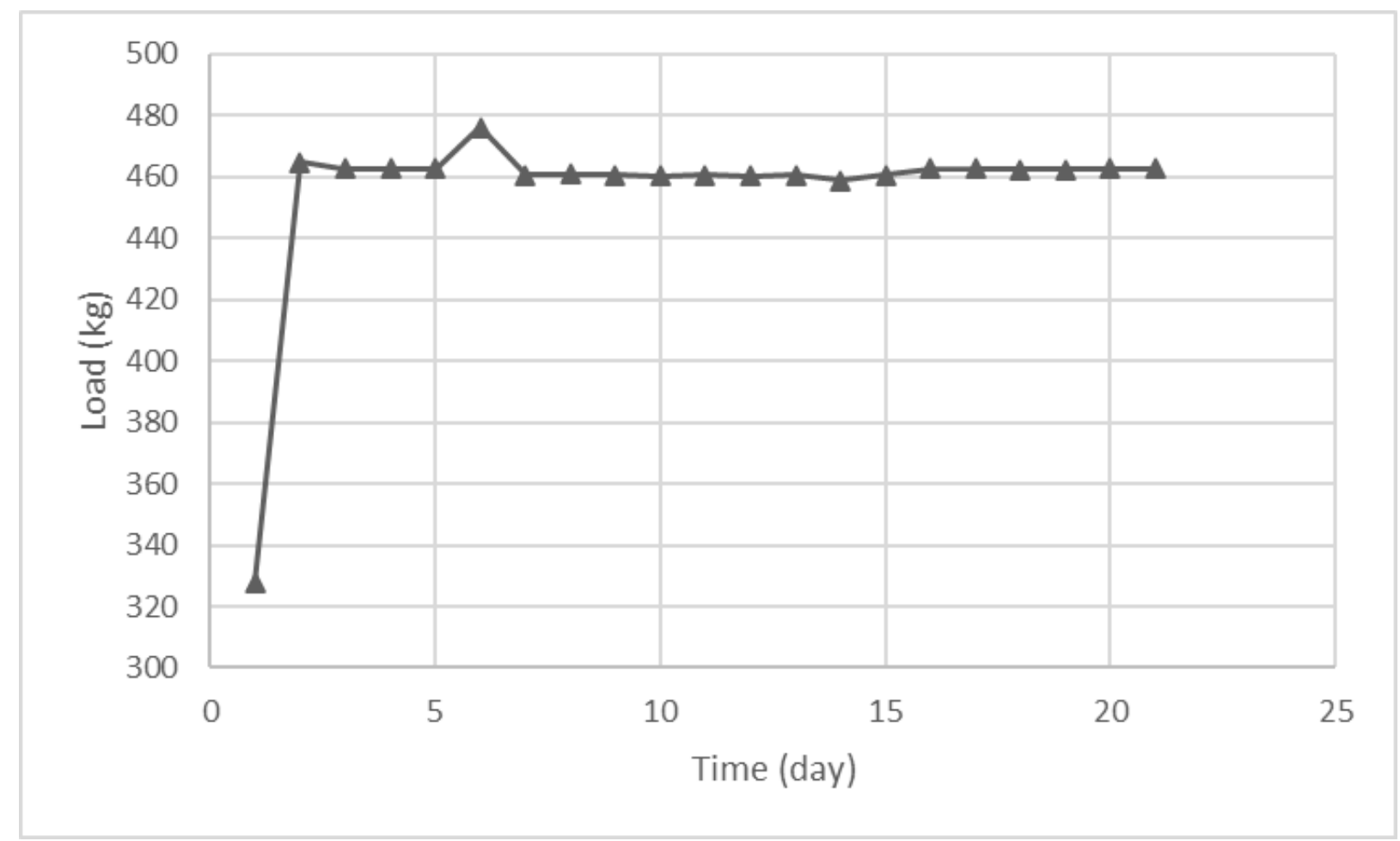

Figure C-1. Load cell underneath steel box tracking mass changes in the box during self-weight consolidation. 


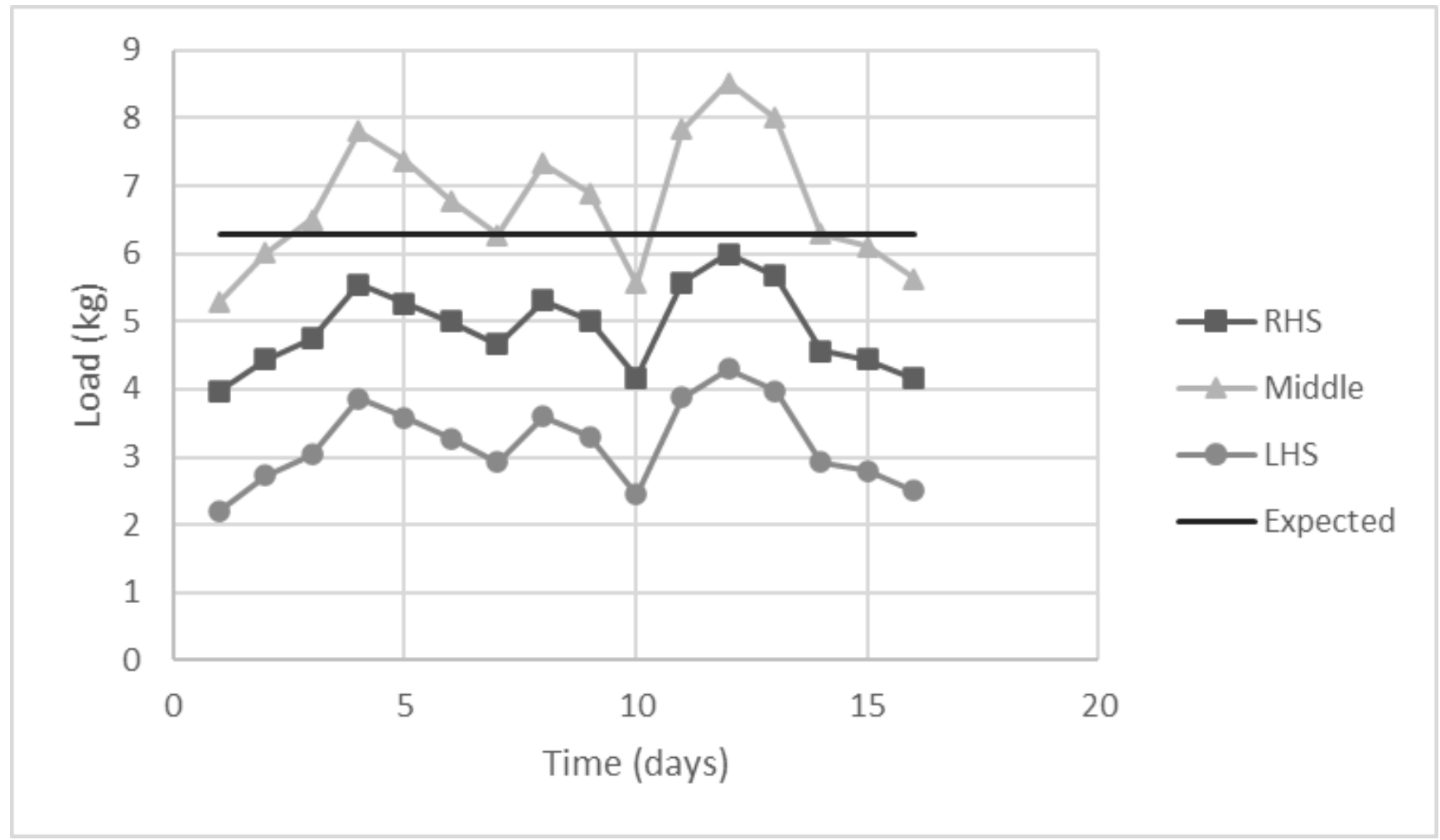

Figure C-2. Three pressure gauges positioned at the bottom of the box in different orientations track stress at the bottom of the box during self-weight consolidation. 


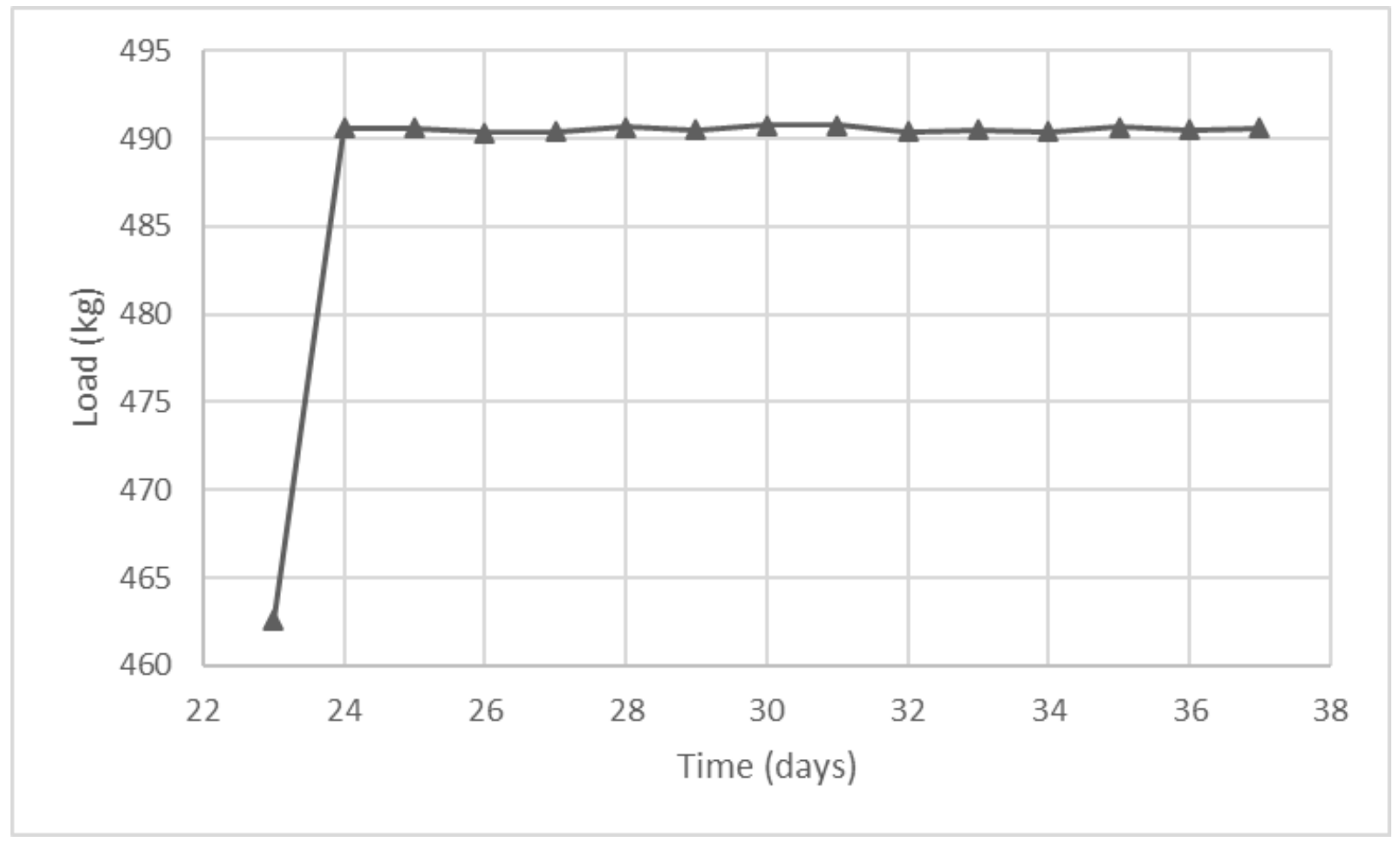

Figure C-3. Load cell underneath steel box tracking mass changes in the box during $2 \mathrm{kPa}$ loading step. 


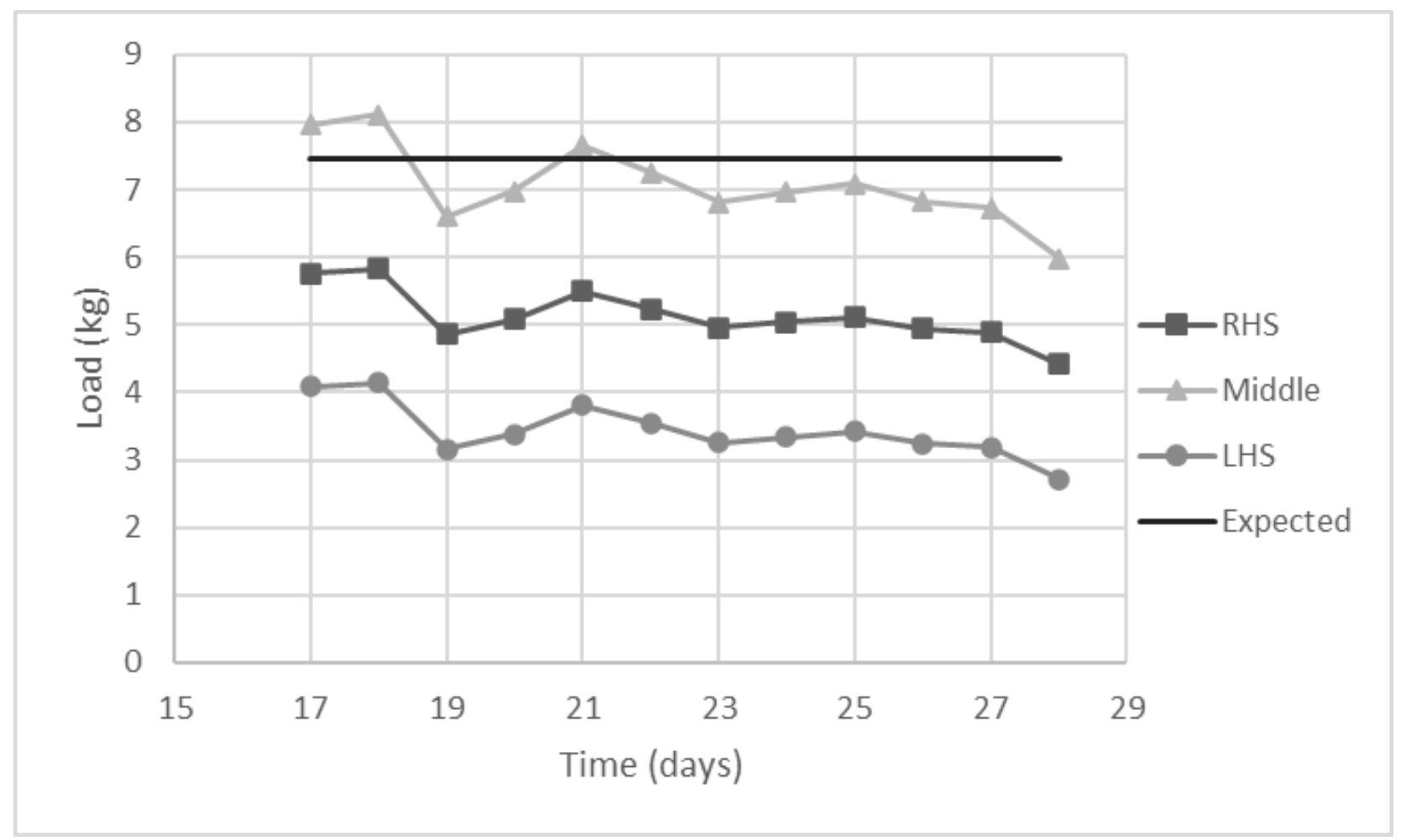

Figure C-4. Three pressure gauges positioned at the bottom of the box in different orientations track stress at the bottom of the box for $2 \mathrm{kPa}$ loading step. 


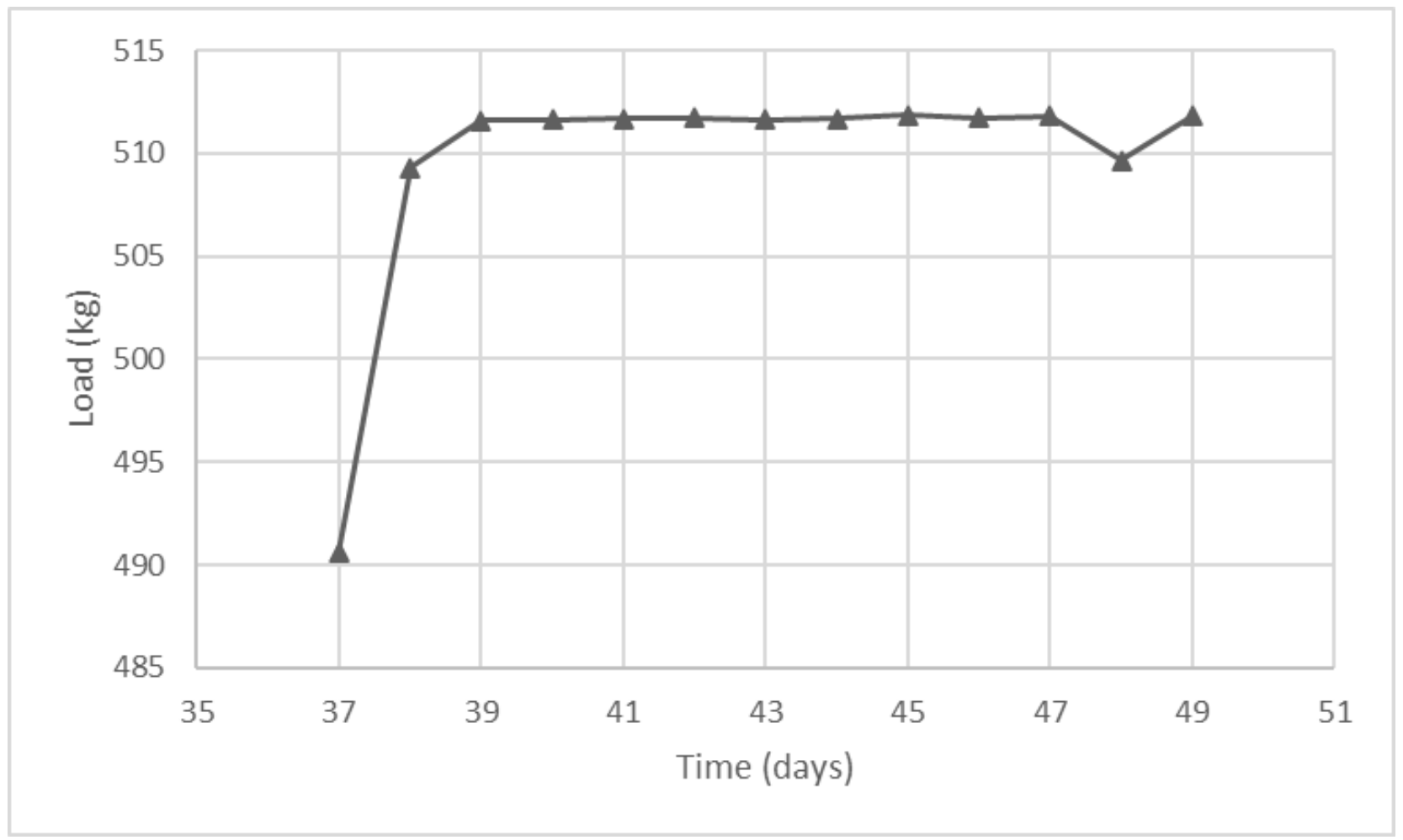

Figure C-5. Load cell underneath steel box tracking mass changes in the box during $3 \mathrm{kPa}$ loading step. 


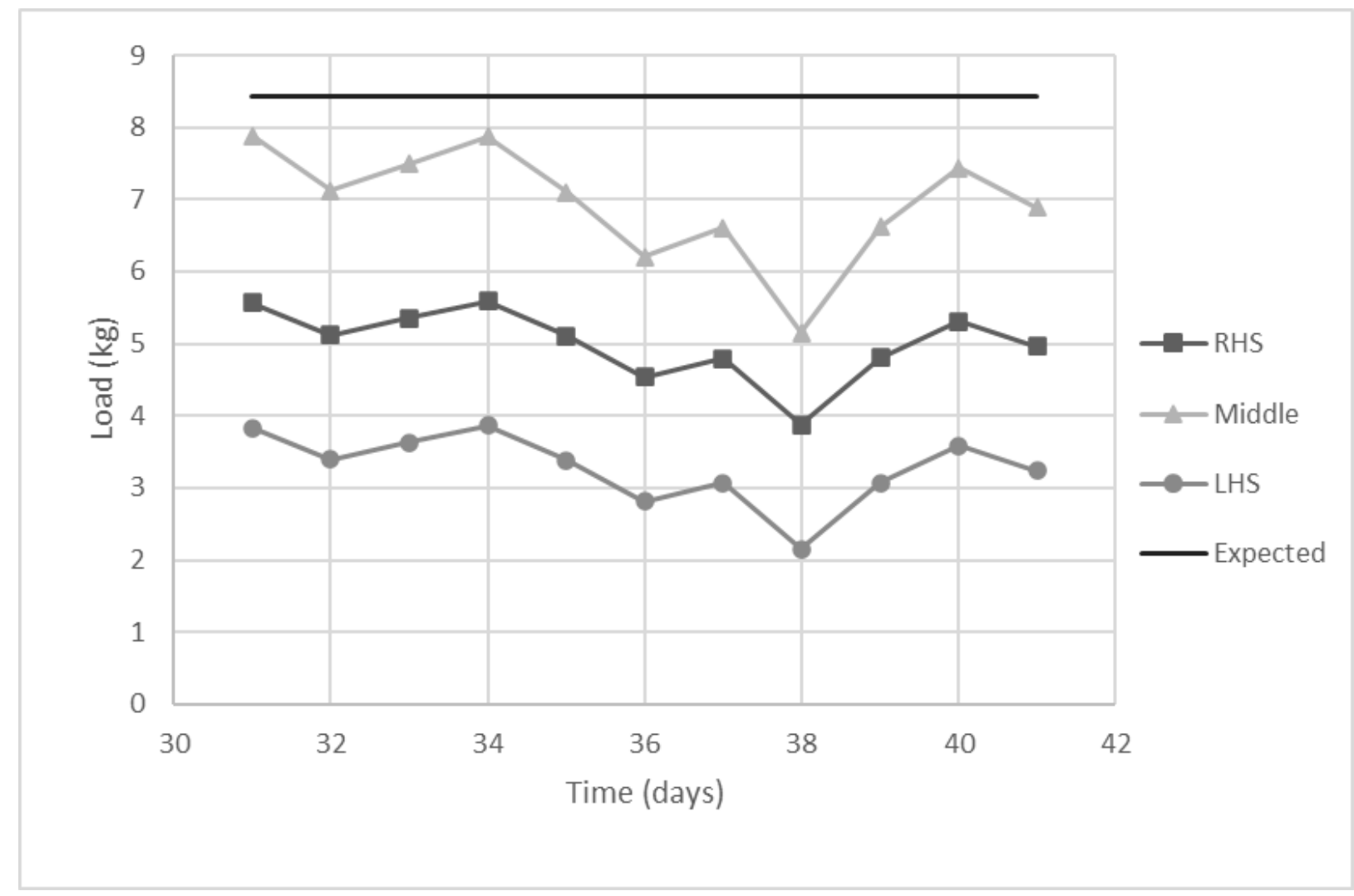

Figure C-6. Three pressure gauge positioned at the bottom of the box in different orientations track stress at the bottom of the box for $3 \mathrm{kPa}$ loading step. 


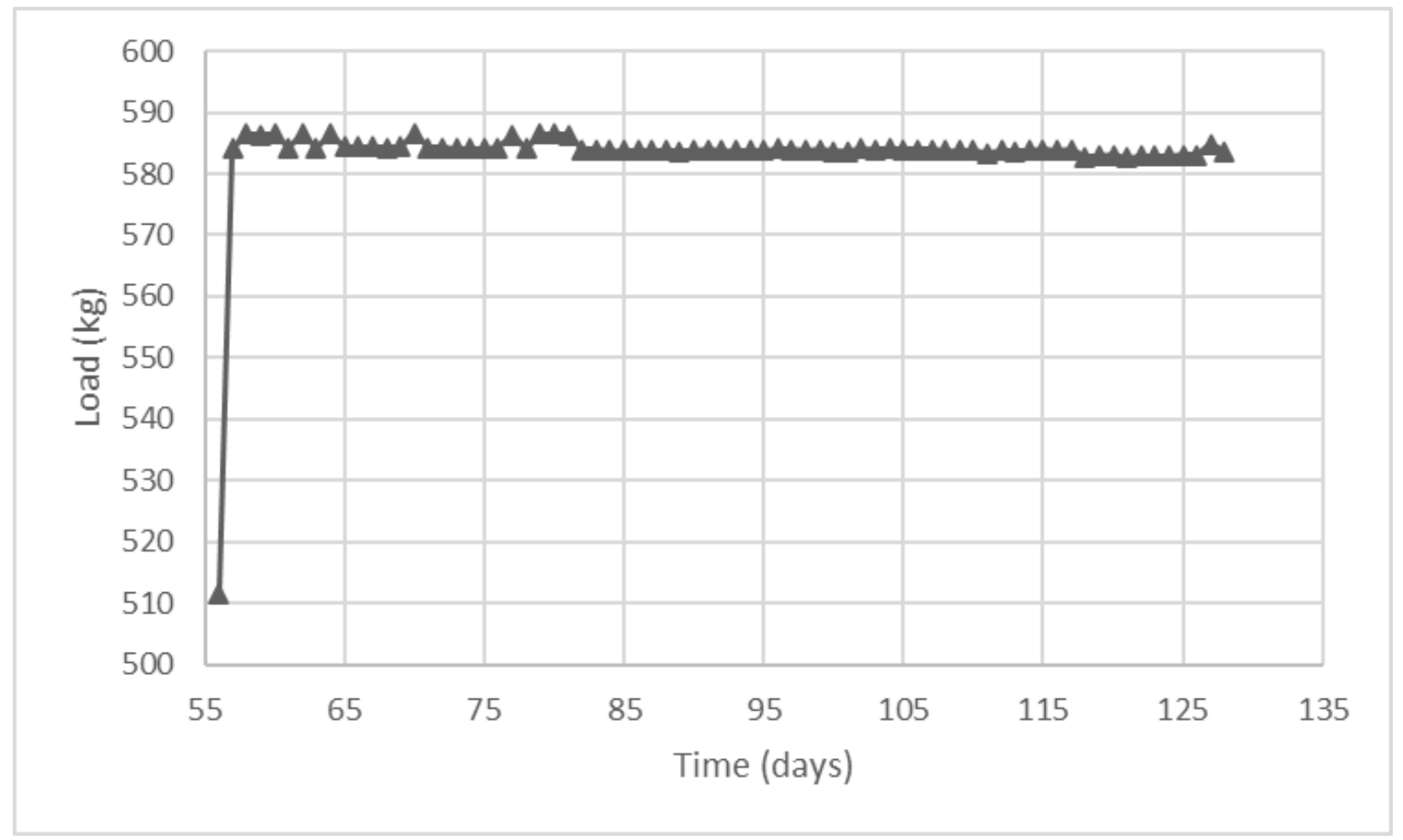

Figure C-7. Load cell underneath steel box tracking mass changes in the box during $8 \mathrm{kPa}$ loading step. 


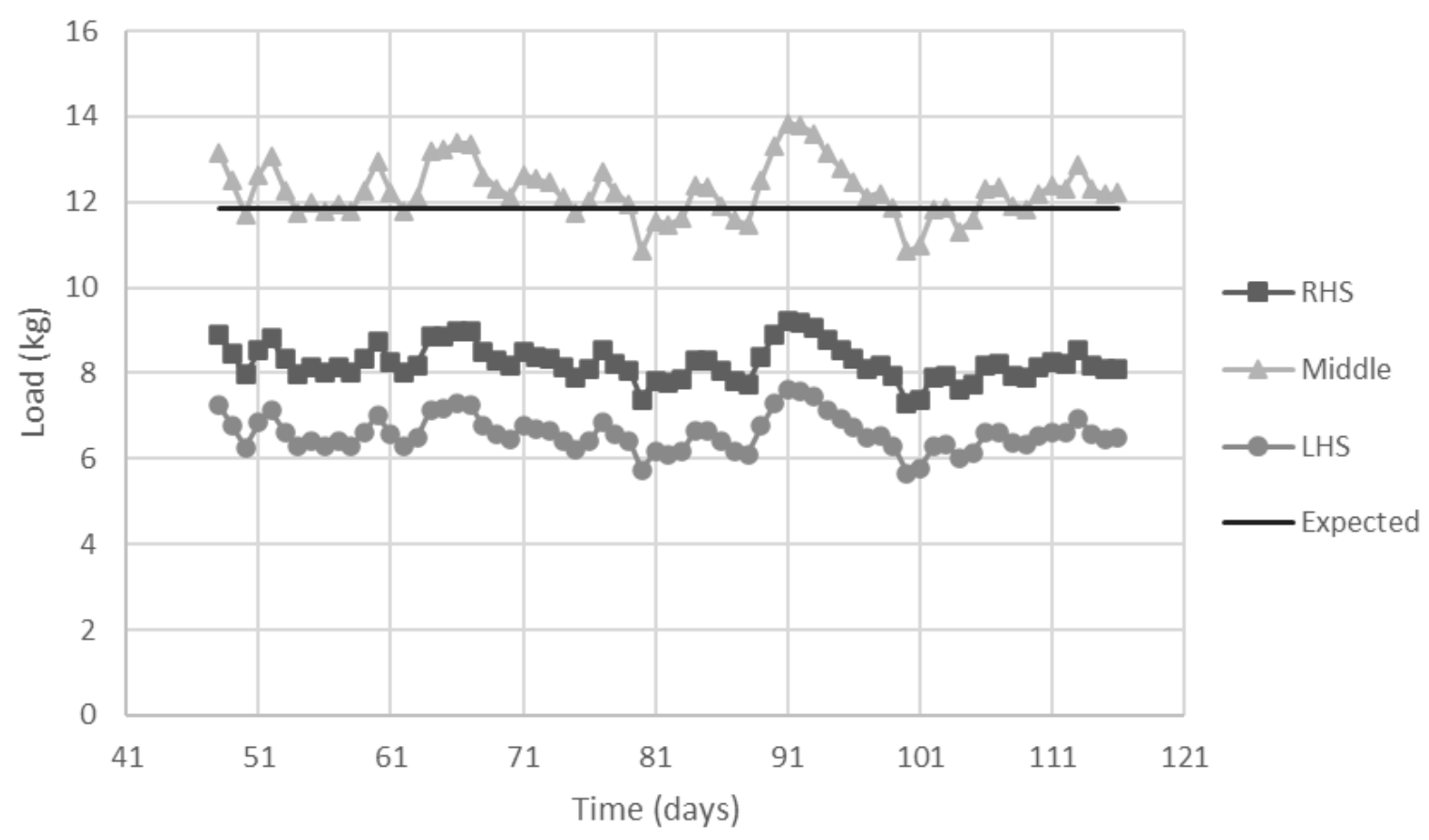

Figure C-8. Three pressure gauge positioned at the bottom of the box in different orientations track stress at the bottom of the box for $8 \mathrm{kPa}$ loading step. 


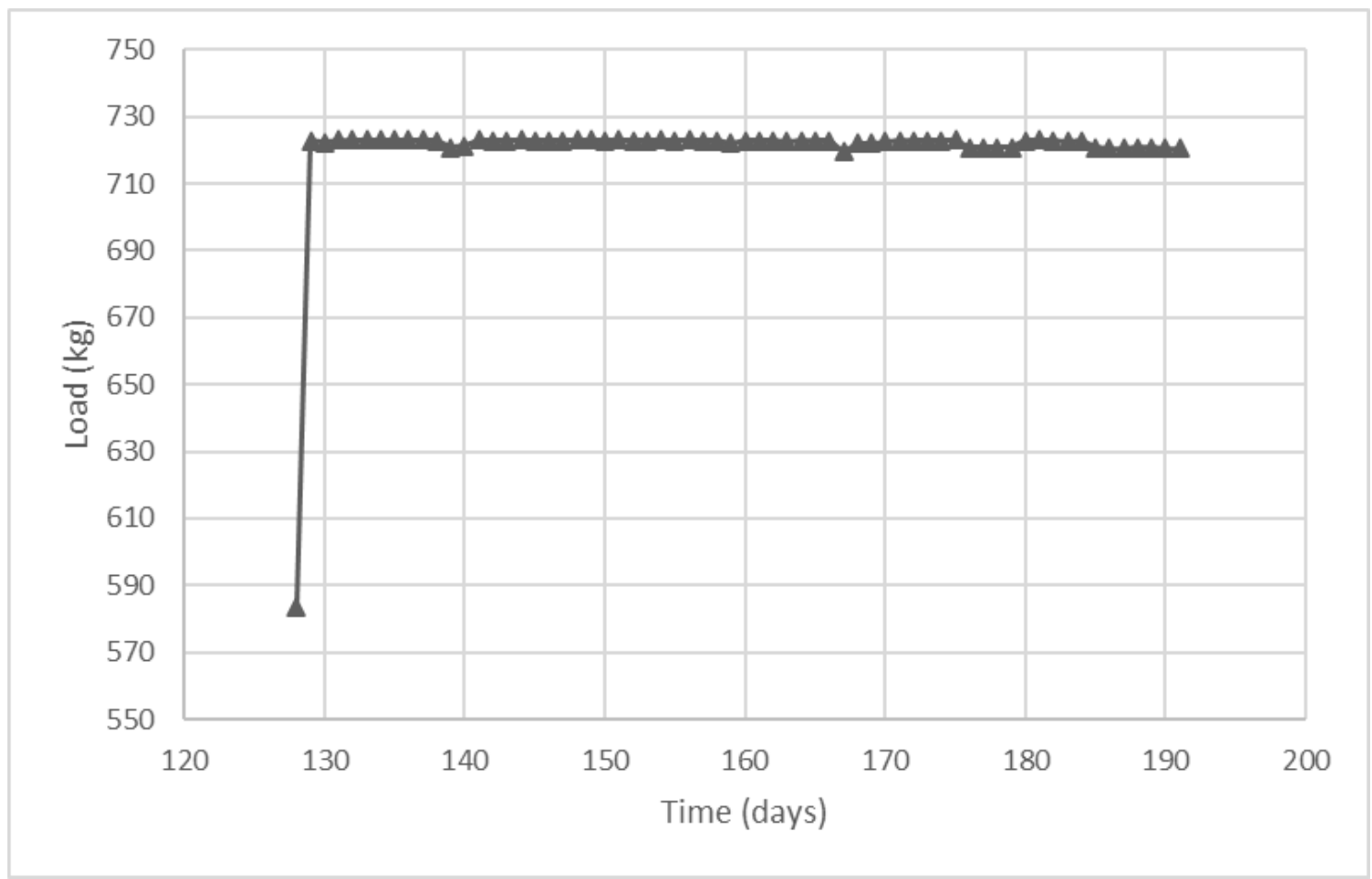

Figure C-9. Load cell underneath steel box tracking mass changes in the box during $16 \mathrm{kPa}$ loading step. 


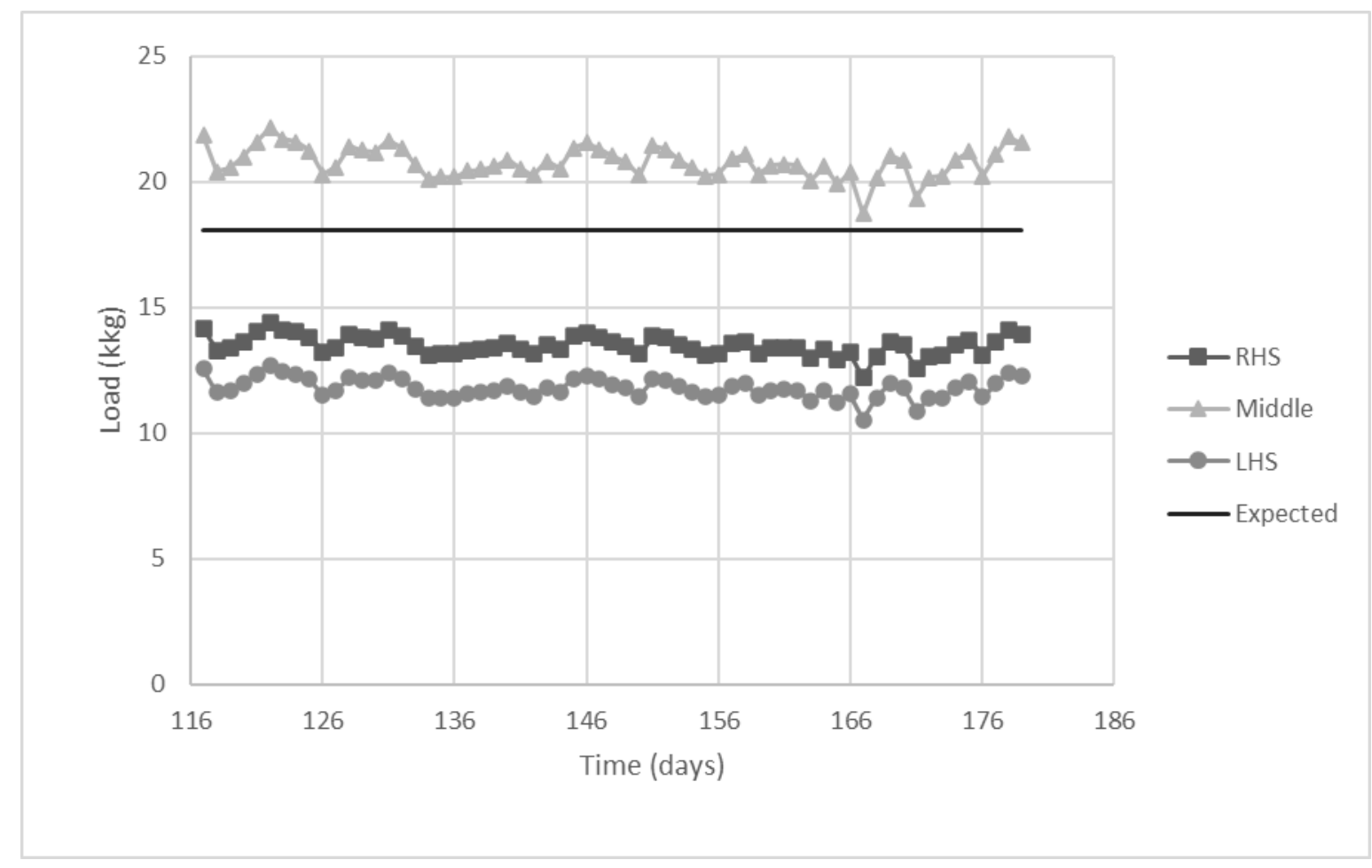

Figure C-10. Three pressure gauge positioned at the bottom of the box in different orientations track stress at the bottom of the box for $16 \mathrm{kPa}$ loading step. 


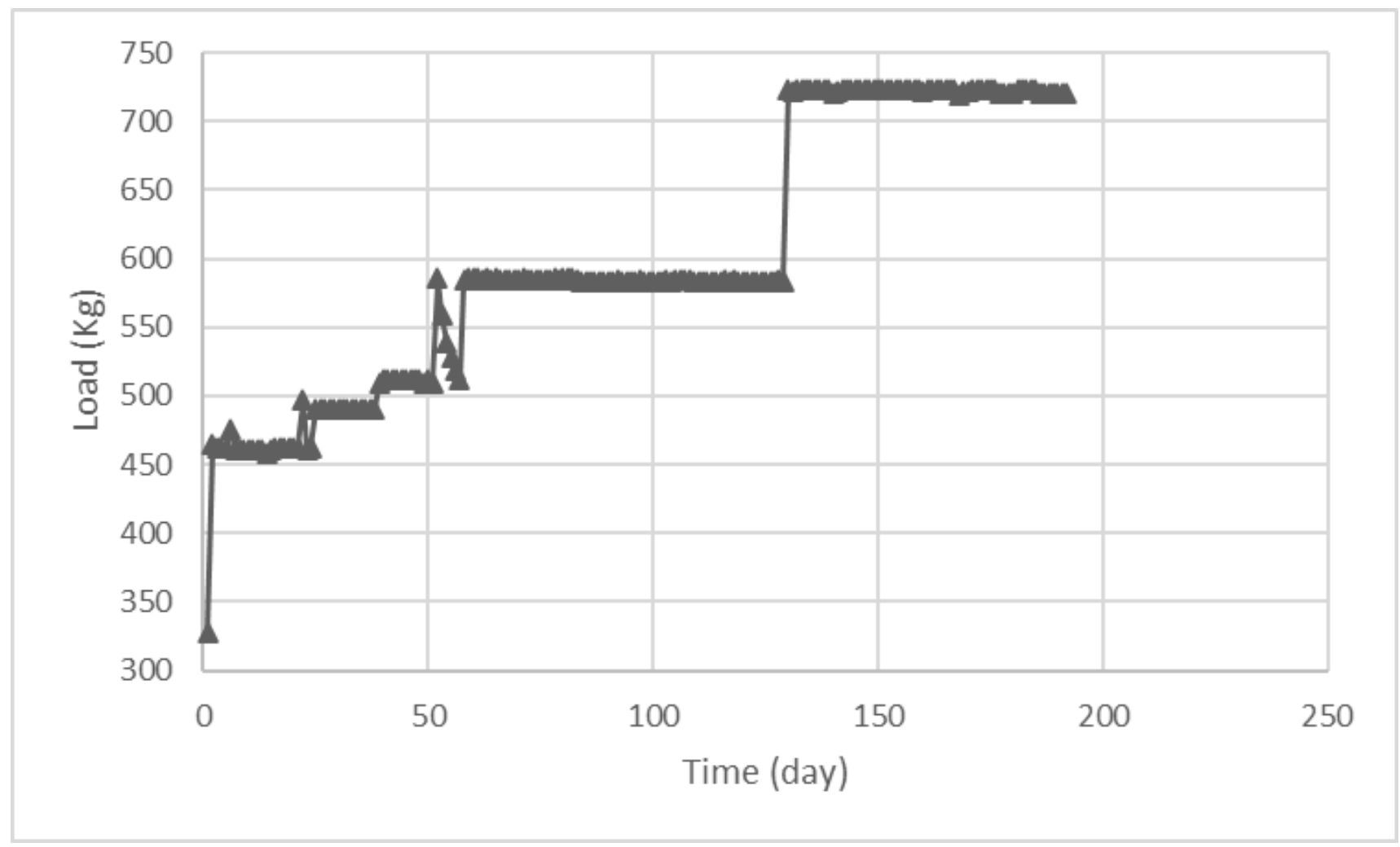

Figure C-11. Load cell measurement over the duration of the experiment. 


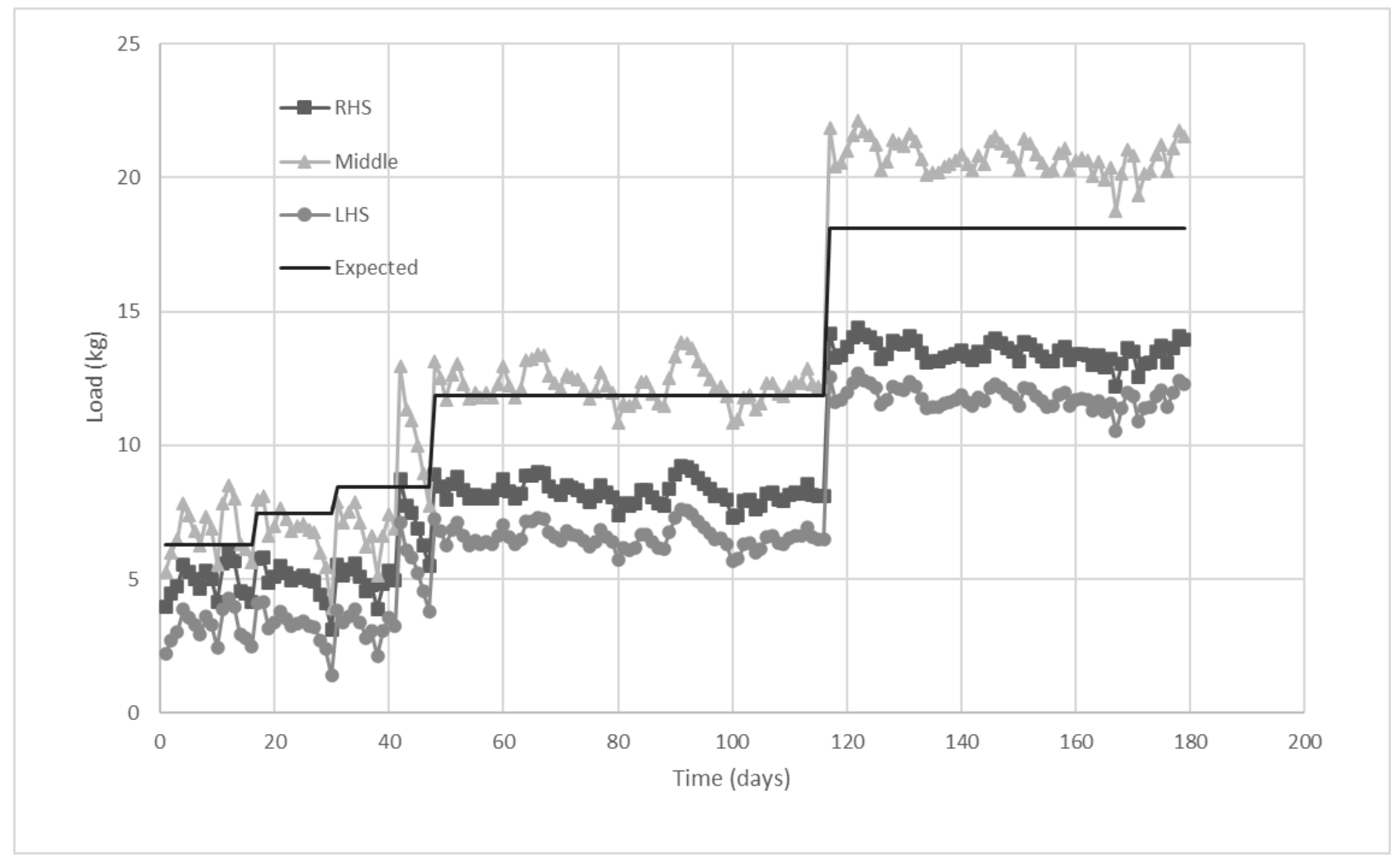

Figure C-12. Pressure gauge readings over the duration of the experiment. 


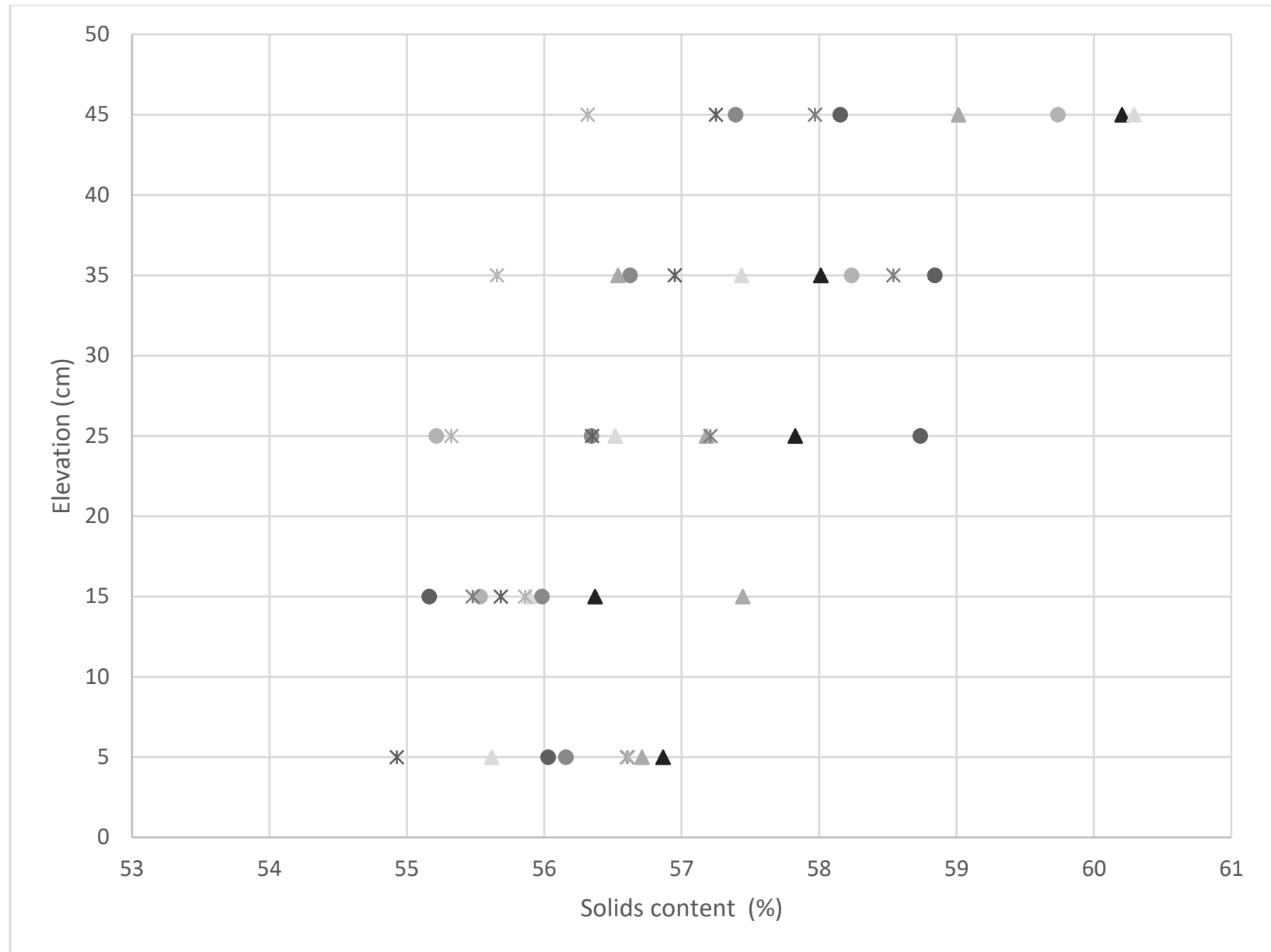

Figure C-13. Core samples at different horizonal locations solids content depth profile taken at the end of the test. 
Appendix D. Phase II box and apparatus design
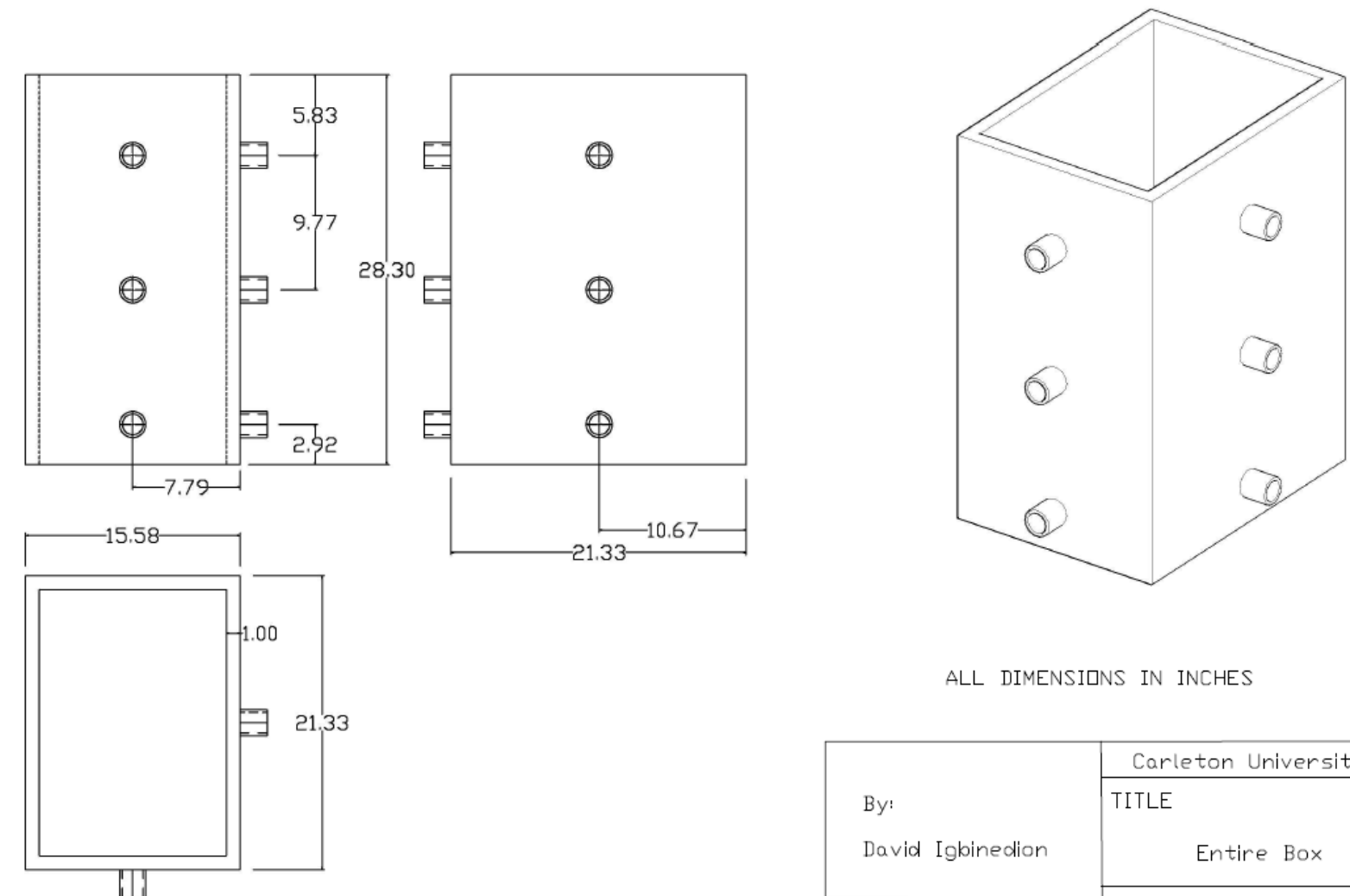

ALL DIMENSIONS IN INCHES

\begin{tabular}{|l|l|l|}
\hline \multirow{2}{*}{ By: } & \multicolumn{1}{|c|}{ Carleton University } \\
\cline { 2 - 3 } David Igbinedion & \multicolumn{2}{|c|}{ TITLE } \\
\cline { 2 - 3 } \\
\cline { 2 - 2 } \\
\cline { 2 - 2 }
\end{tabular}

Figure D-1. Schematic diagram of entire steel box. 


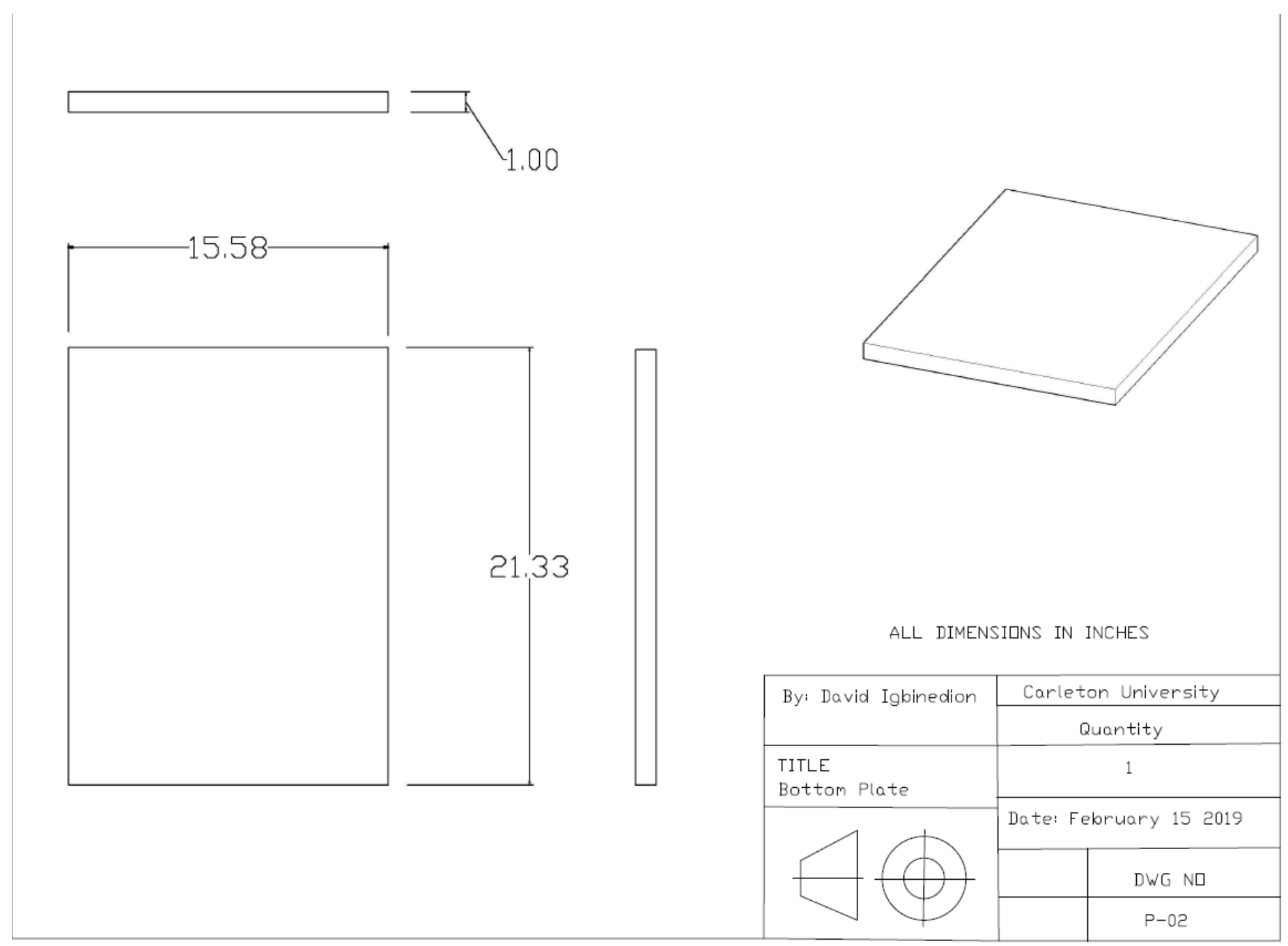

Figure D-2. Schematic diagram of box bottom plate. 


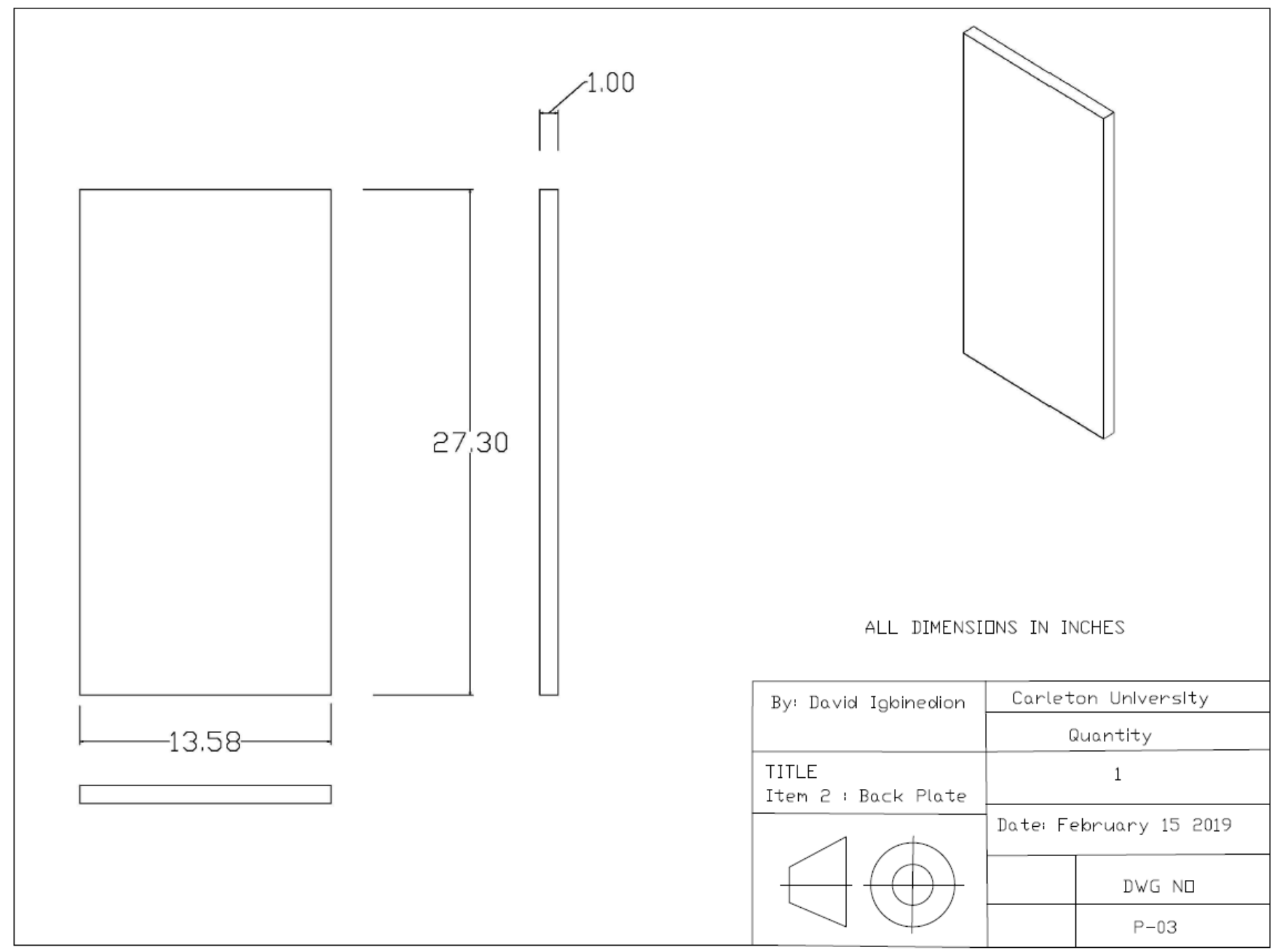

Figure D-3. Schematic diagram of first side plate without opening. 

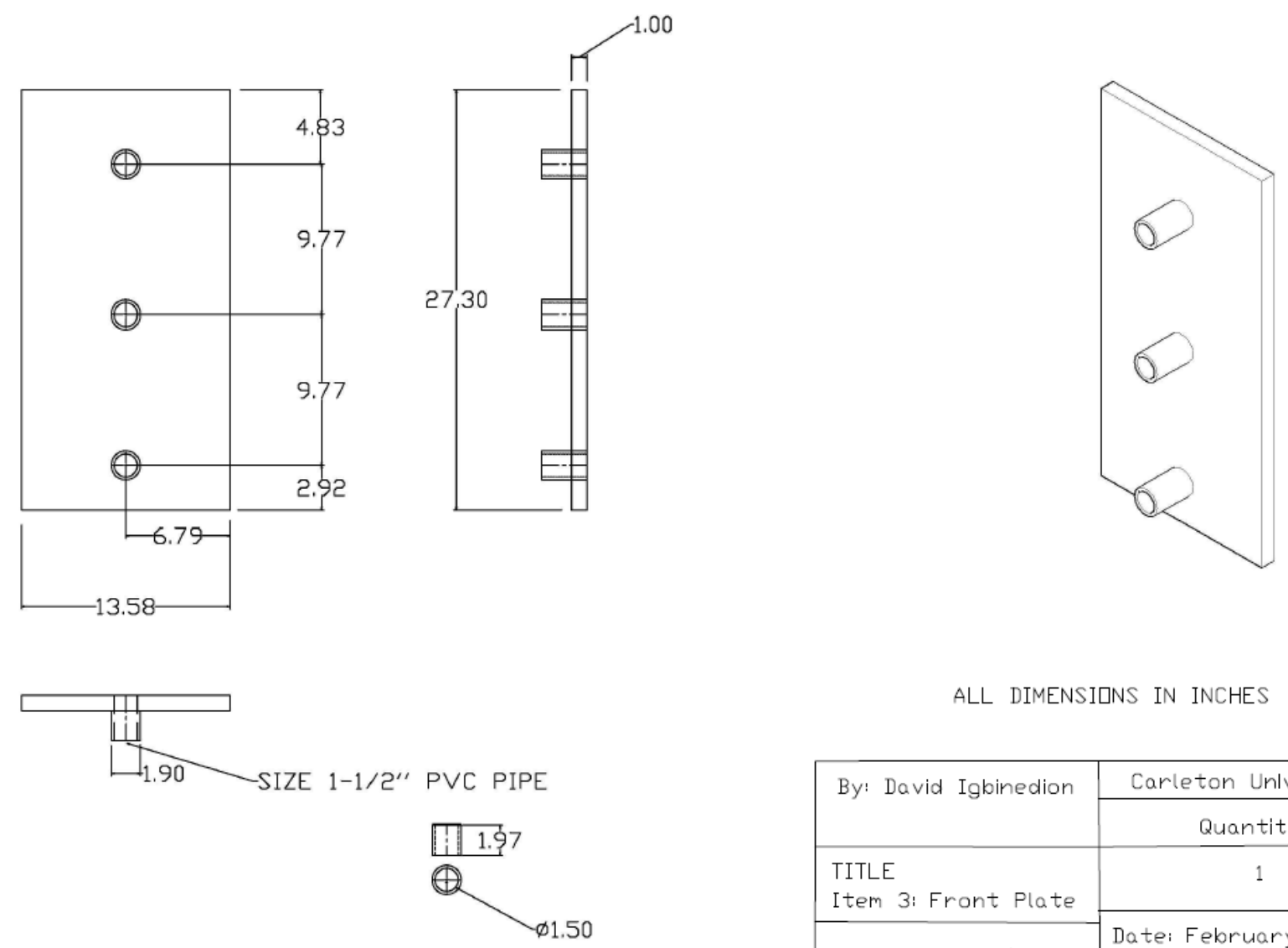

ALL DIMENSIONS IN INCHES

\begin{tabular}{|l|c|}
\hline \multirow{2}{*}{ By: David Igbinedion } & \multicolumn{1}{|c|}{ Carleton Unlverslty } \\
\cline { 2 - 2 } $\begin{array}{l}\text { TITLE } \\
\text { Item 3i Front Plate }\end{array}$ & \multicolumn{2}{|c|}{ Quantity } \\
\hline \multirow{2}{*}{} \\
\cline { 2 - 2 }
\end{tabular}

Figure D-4. Schematic diagram of first side plate with holes. 

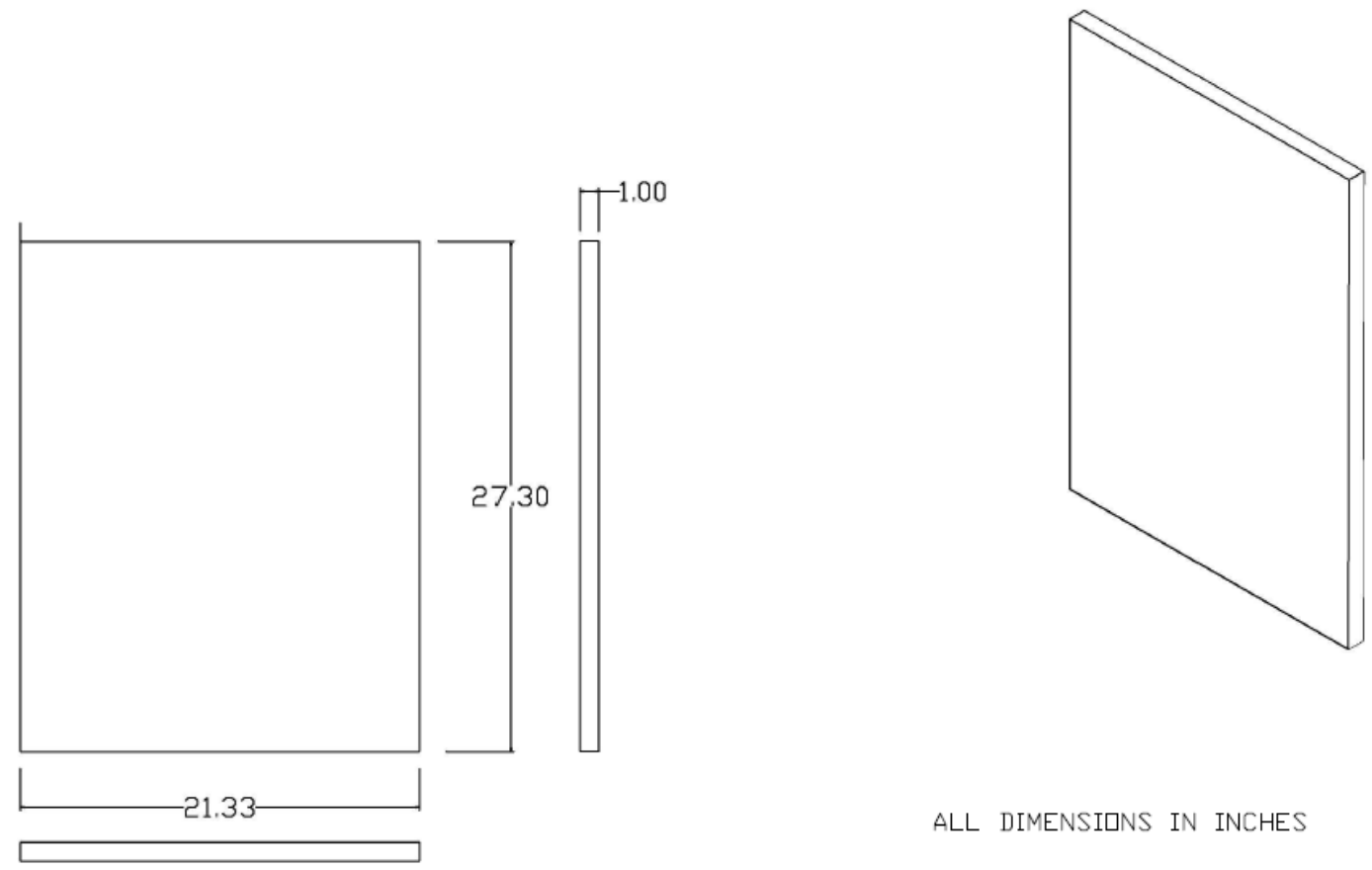

ALL DIMENSIONS IN INCHES

\begin{tabular}{|l|c|}
\hline \multirow{2}{*}{ By: David Igbinedion } & \multicolumn{1}{|c|}{ Carleton University } \\
\cline { 2 - 2 } & \multicolumn{1}{|c|}{ Quantlty } \\
\hline $\begin{array}{l}\text { TITLE } \\
\text { Item 41 Left Plate }\end{array}$ \\
\hline \multirow{2}{*}{} \\
\cline { 2 - 2 } \\
\hline
\end{tabular}

Figure D-5. Schematic diagram of second side plate without holes. 


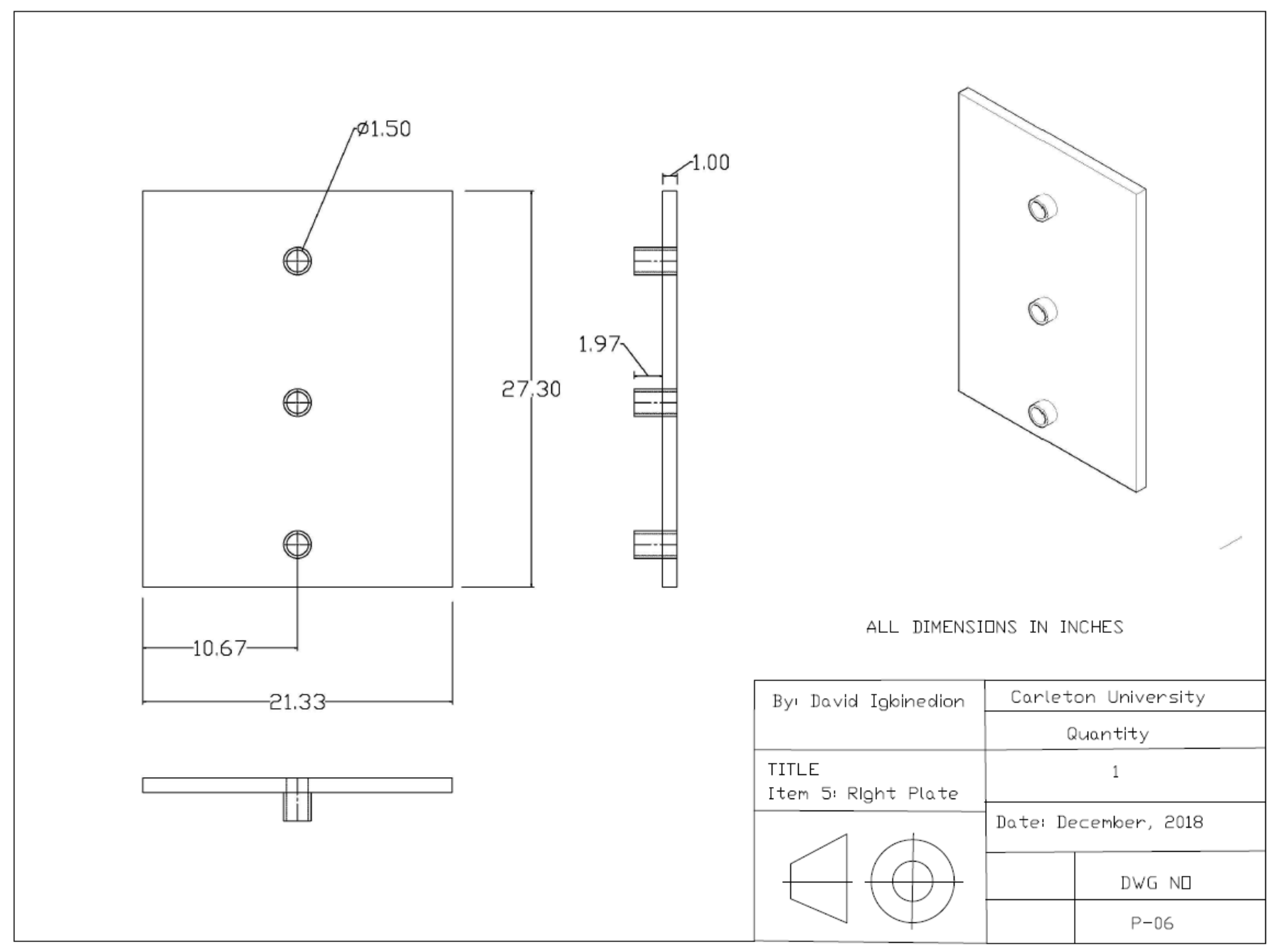

Figure D-6. Schematic diagram of second side plate with holes. 

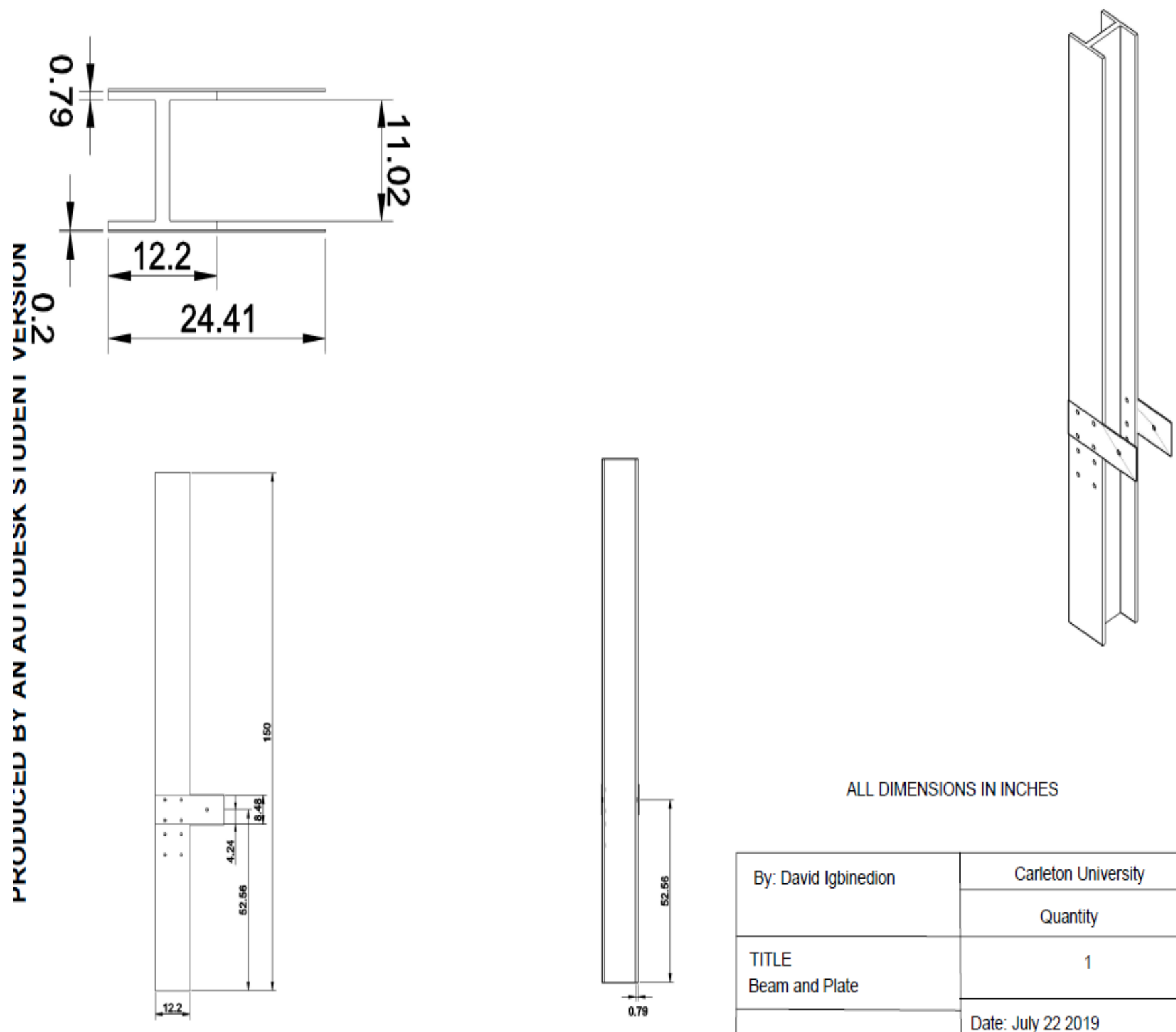

ALL DIMENSIONS IN INCHES

\begin{tabular}{|l|c|}
\hline \multirow{2}{*}{ By: David Igbinedion } & \multicolumn{2}{|c|}{ Carleton University } \\
\cline { 2 - 2 } & \multicolumn{2}{|c|}{ Quantity } \\
\hline $\begin{array}{l}\text { TITLE } \\
\text { Beam and Plate }\end{array}$ & 1 \\
\hline \multicolumn{1}{|c|}{} \\
\hline
\end{tabular}

Figure D-7. Schematic diagram showing beam component with two connecting side plates. 


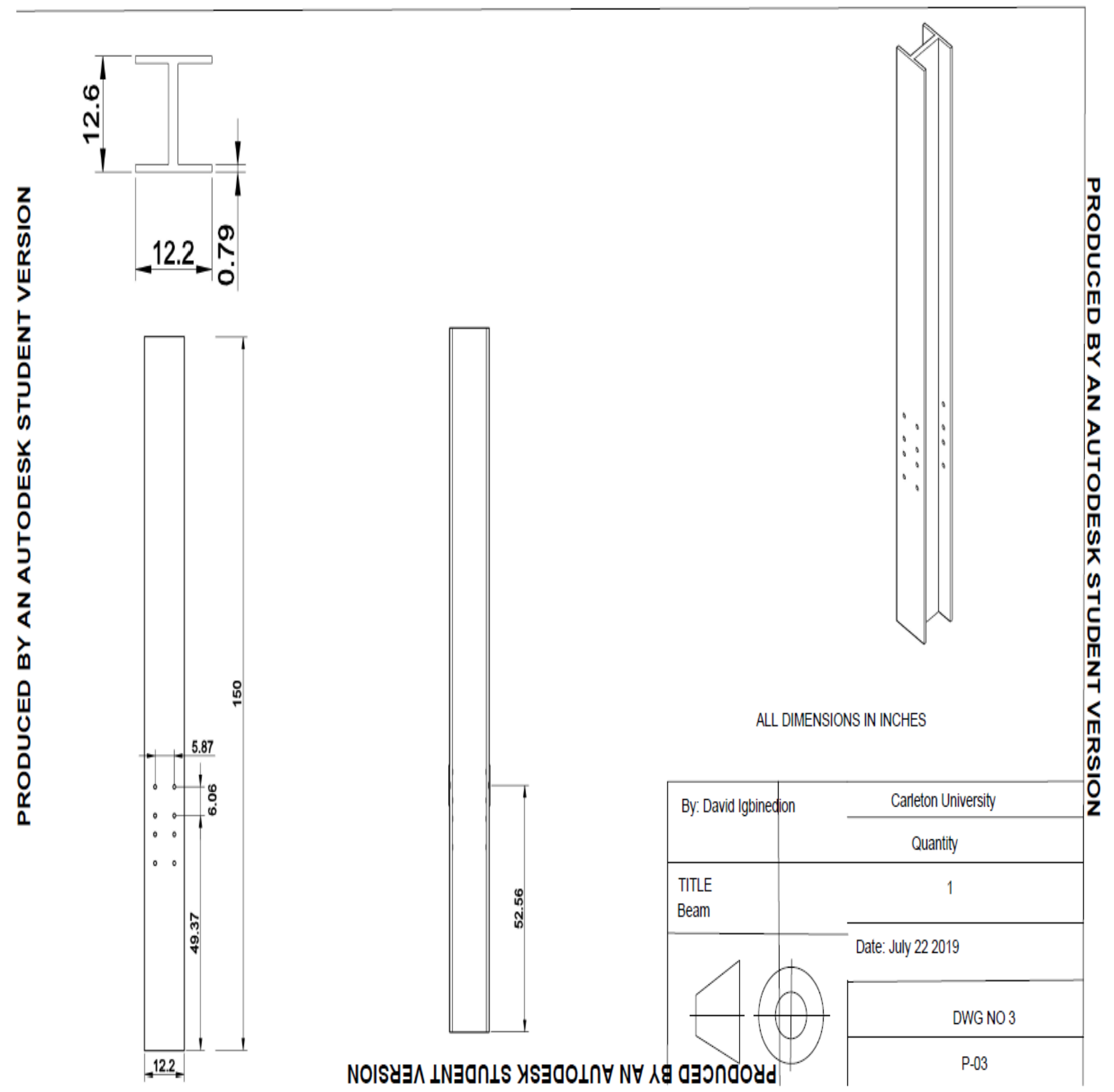

Figure D-8. Schematic diagram showing the beam component of the lever arm loading system. 


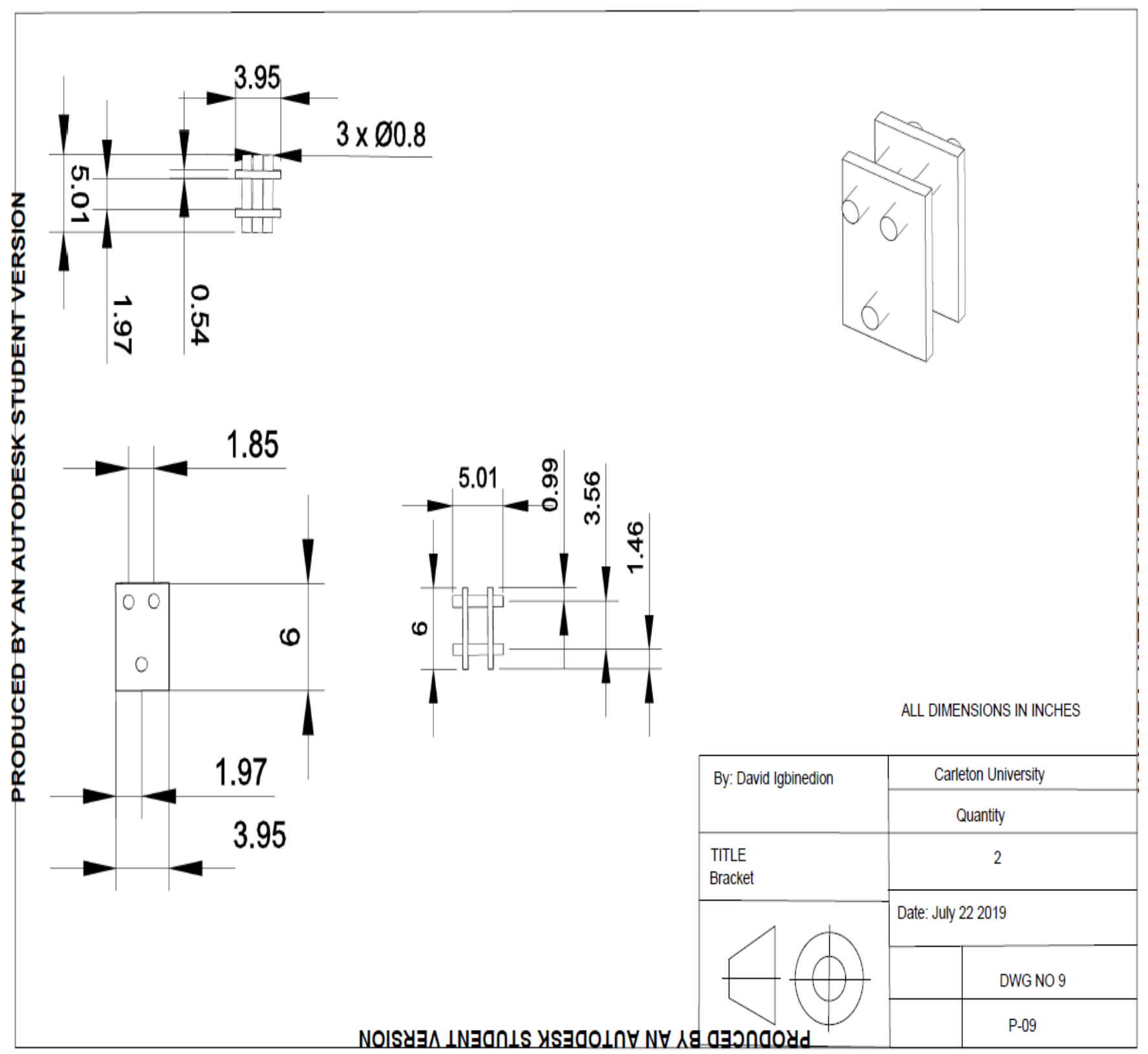

Figure D-9. Schematic diagram showing the connecting bracket for the loading arm apparatus. 

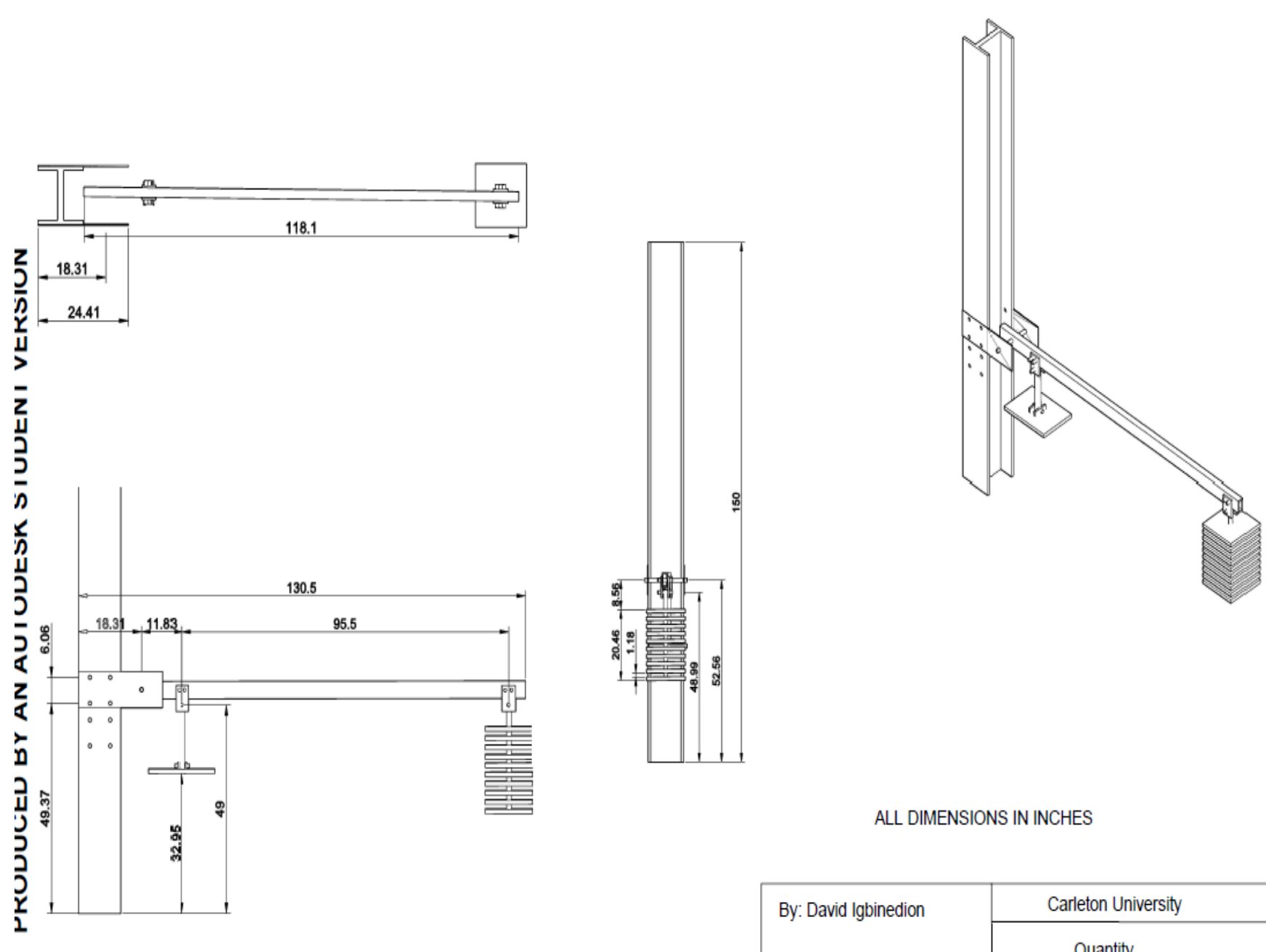

ALL DIMENSIONS IN INCHES

\begin{tabular}{|l|c|}
\hline \multirow{2}{*}{ By: David Igbinedion } & \multicolumn{2}{|c|}{ Carleton University } \\
\cline { 2 - 2 } & \multicolumn{2}{|c|}{ Quantity } \\
\hline \multirow{2}{*}{$\begin{array}{l}\text { TITLE } \\
\text { Consolidation Apparatus }\end{array}$} \\
\hline \multicolumn{1}{|c|}{} \\
\cline { 2 - 2 } \\
\cline { 2 - 2 }
\end{tabular}

Figure D-10. Schematic diagram showing the entire apparatus - loading arm, beam, load platform and load application. 


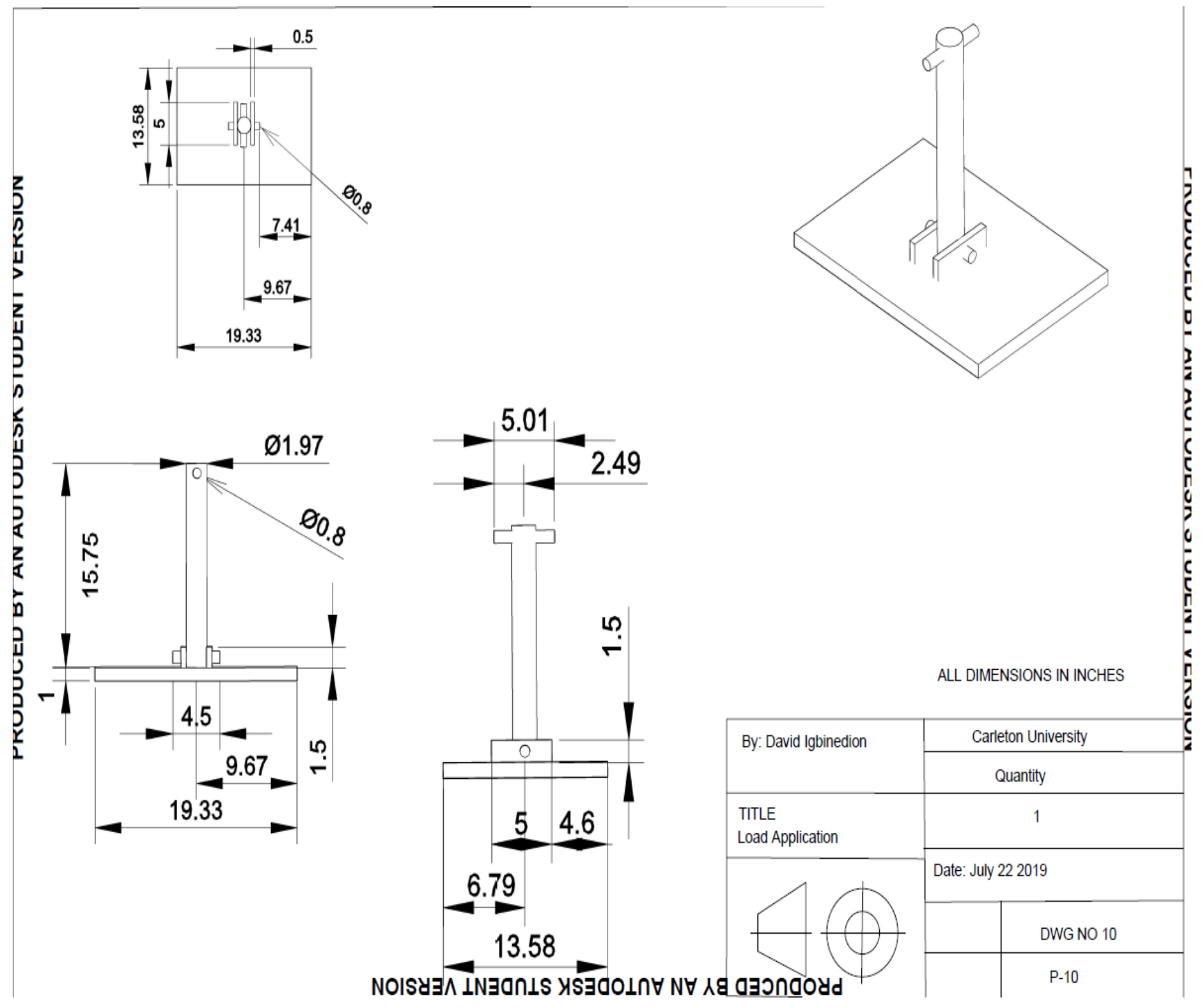

Figure D-11. Schematic diagram showing load transfer component of the lever arm loading system. 


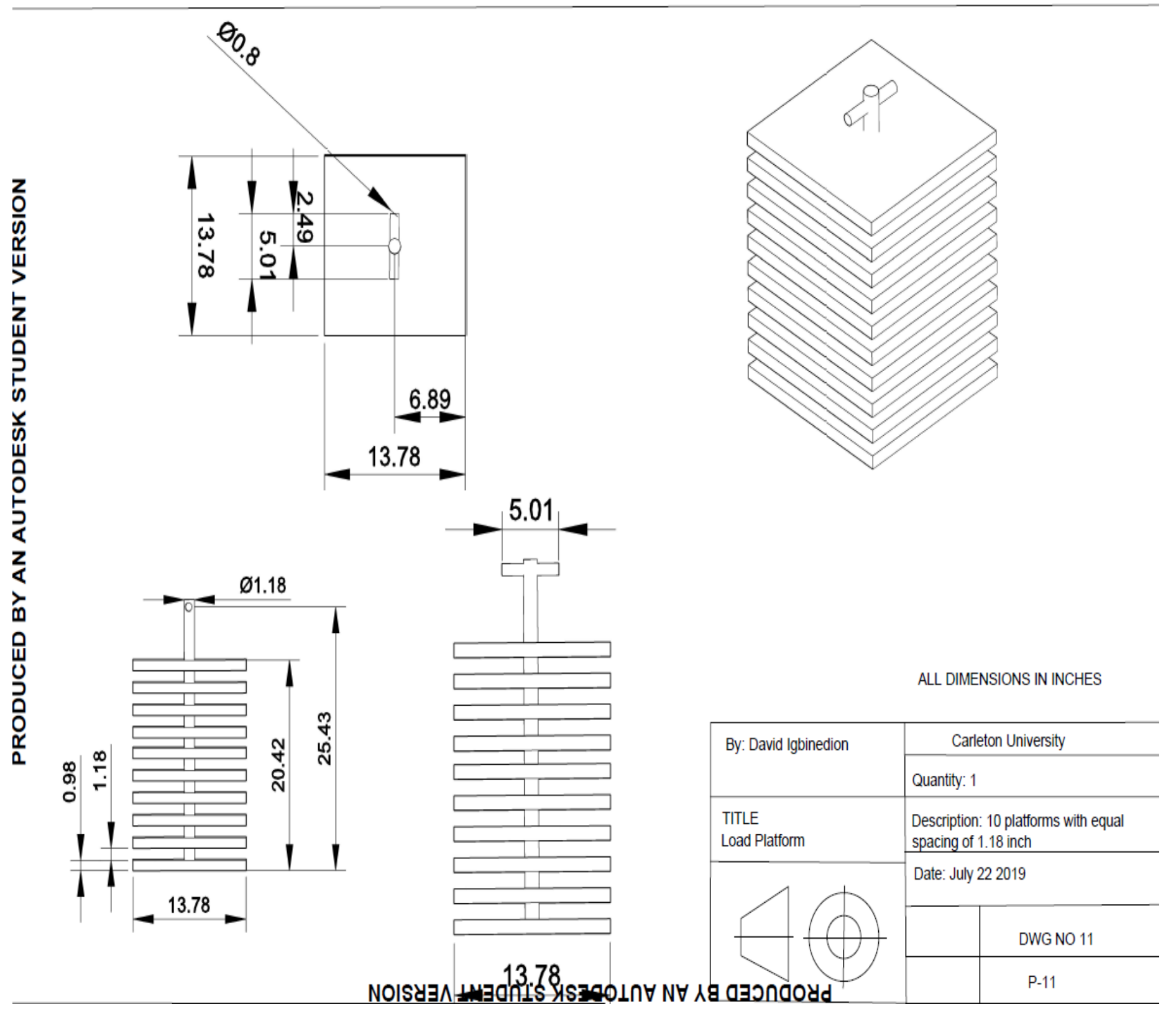

Figure D-12. Schematic diagram showing load application component of the lever arm loading system. 

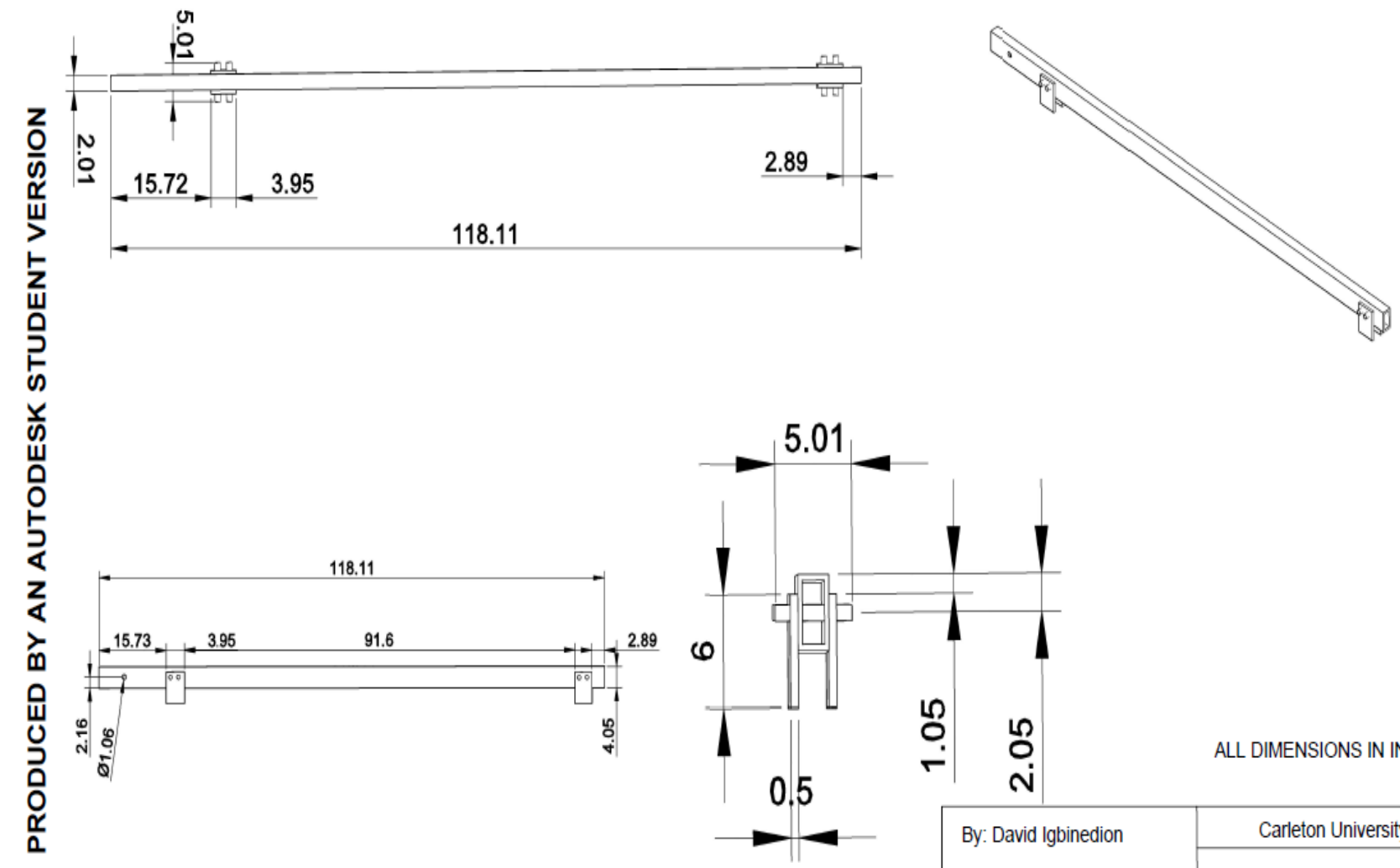

NOISY $\Lambda \perp N \exists O \cap \perp S$ YS

\begin{tabular}{|l|c|}
\hline \multirow{2}{*}{ By: David Igbinedion } & \multicolumn{2}{|c|}{ Carleton University } \\
\cline { 2 - 2 } & \multicolumn{2}{|c|}{ Quantity } \\
\hline $\begin{array}{l}\text { TITLE } \\
\text { Loading arm }\end{array}$ & \multicolumn{2}{|c|}{1} \\
\hline \multicolumn{1}{|c|}{} \\
\cline { 2 - 2 } \\
\cline { 2 - 2 }
\end{tabular}

Figure D-13. Schematic diagram showing loading arm component of the lever arm loading system. 


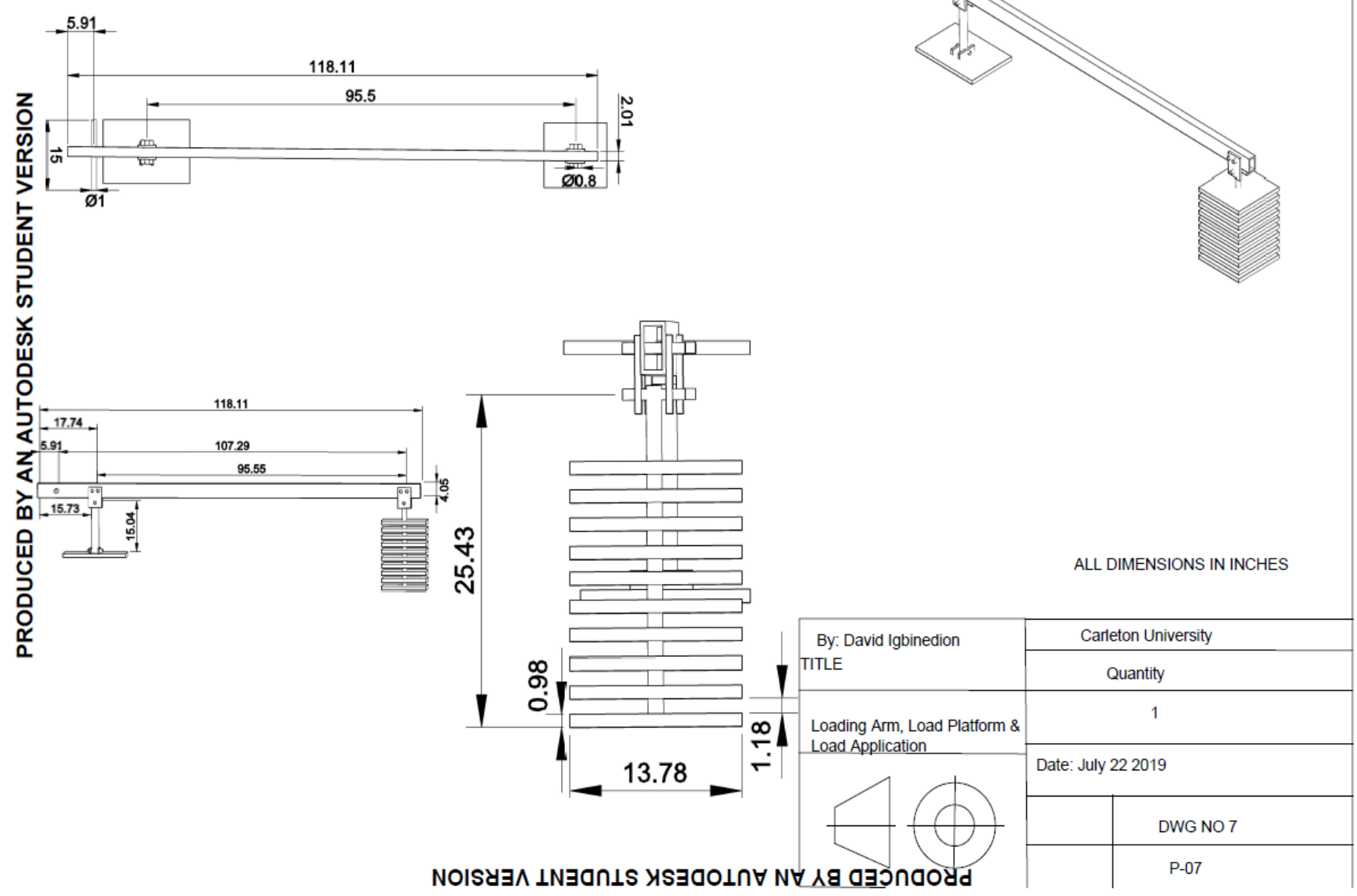

Figure D-14. Schematic diagram showing the loading arm, load transfer and load application components. 


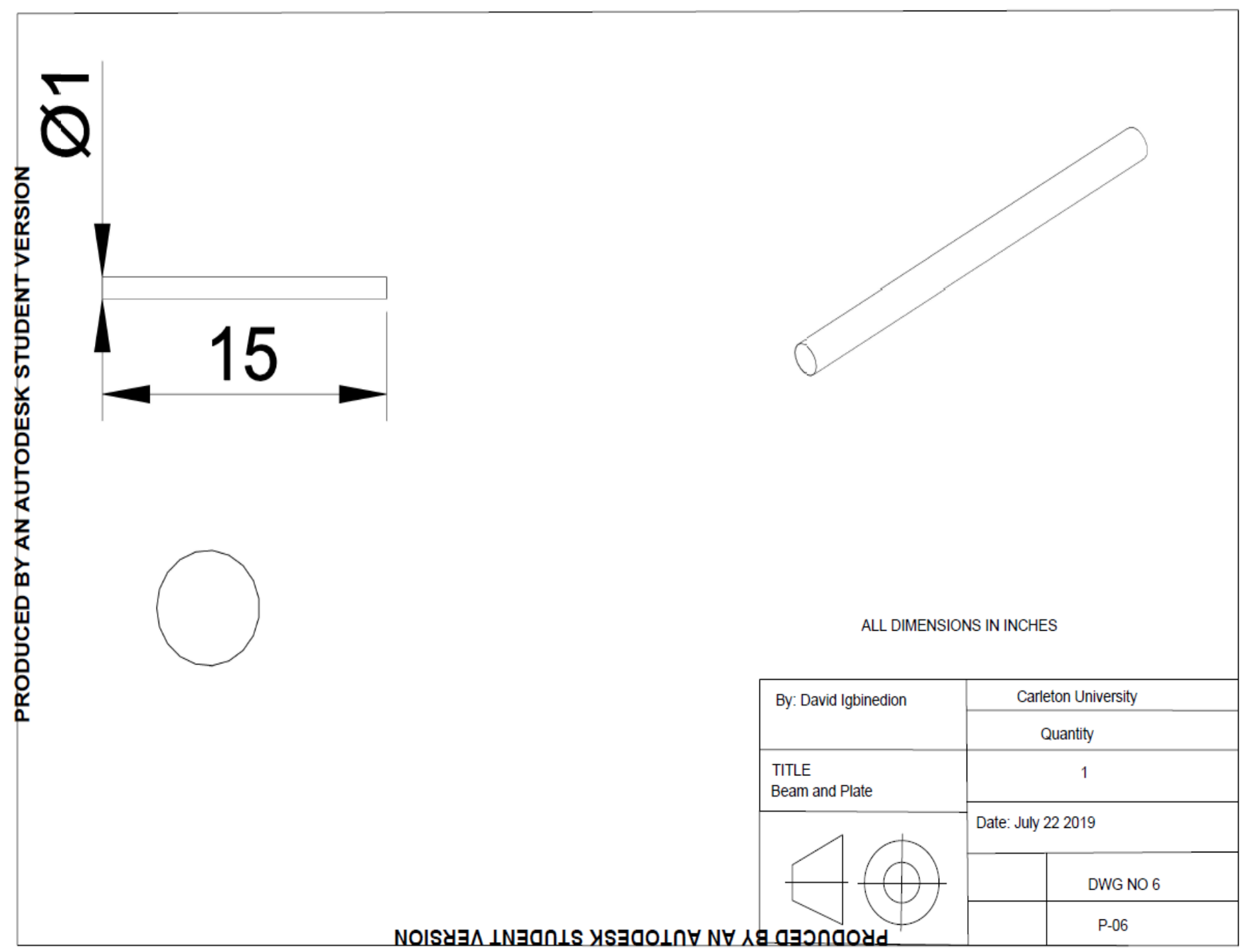

Figure D-15. Schematic diagram showing the pivot bolt apparatus for the loading arm. 


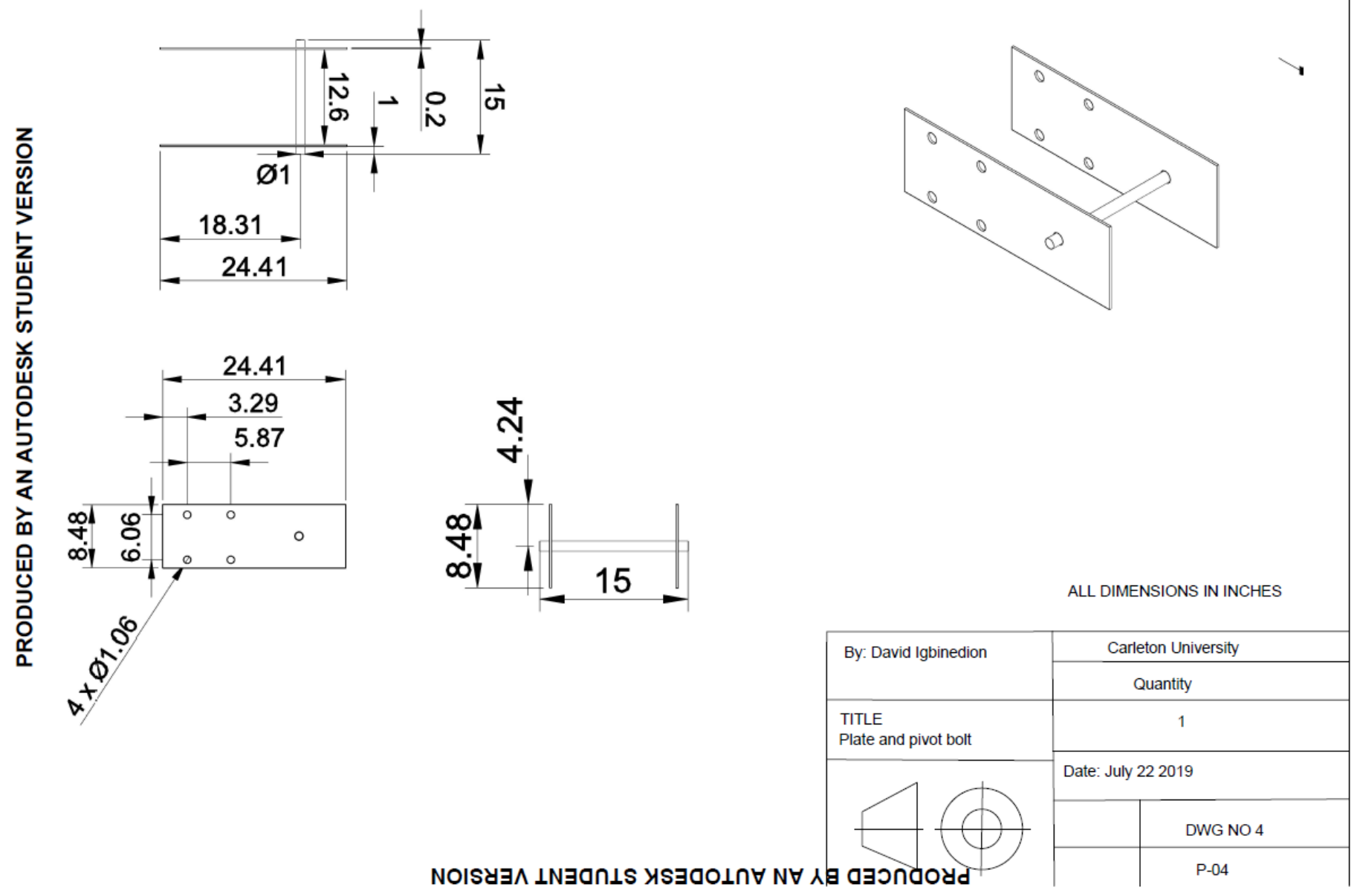

Figure D-16. Schematic diagram showing the connecting pivot bolt and side steel plates connected to the beam. 


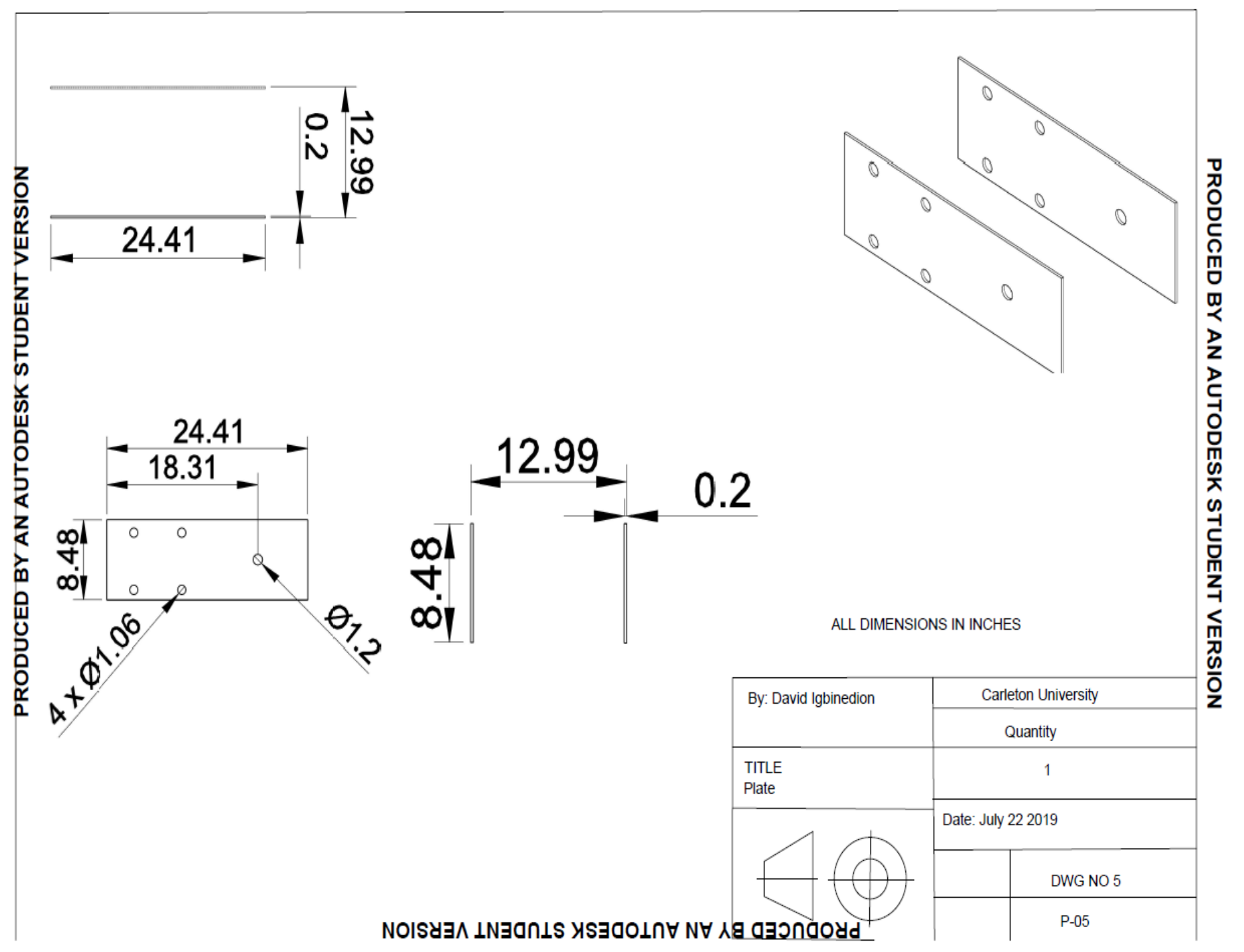

Figure D-17. Schematic diagram showing the steel plates attached to beam. 
Appendix E. UNSATCON.
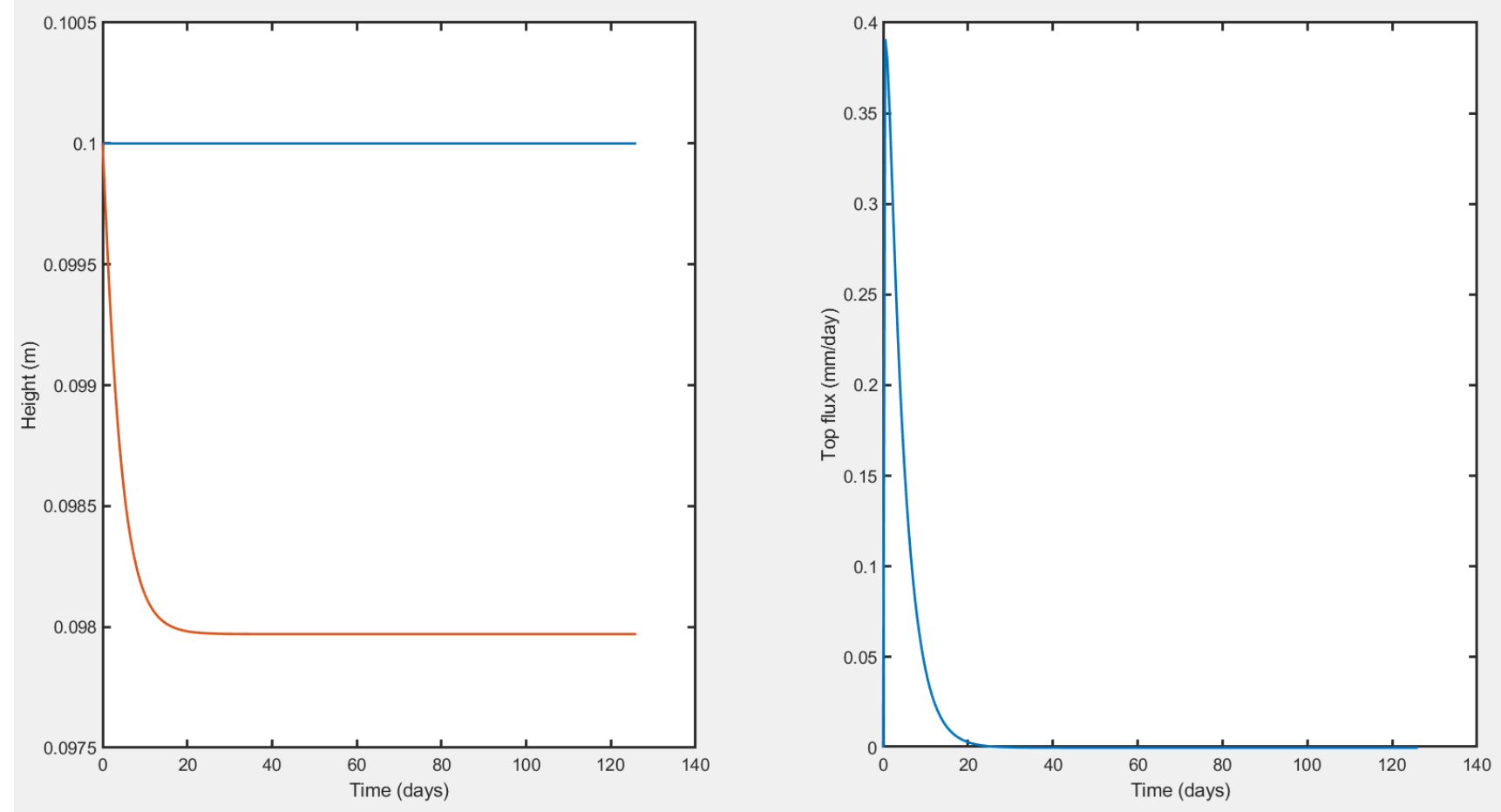

Figure E-1. Overall settlement plot generated by UNSATCON for $0.10 \mathrm{~m}$ column using oedometer calculated hydraulic conductivity. 

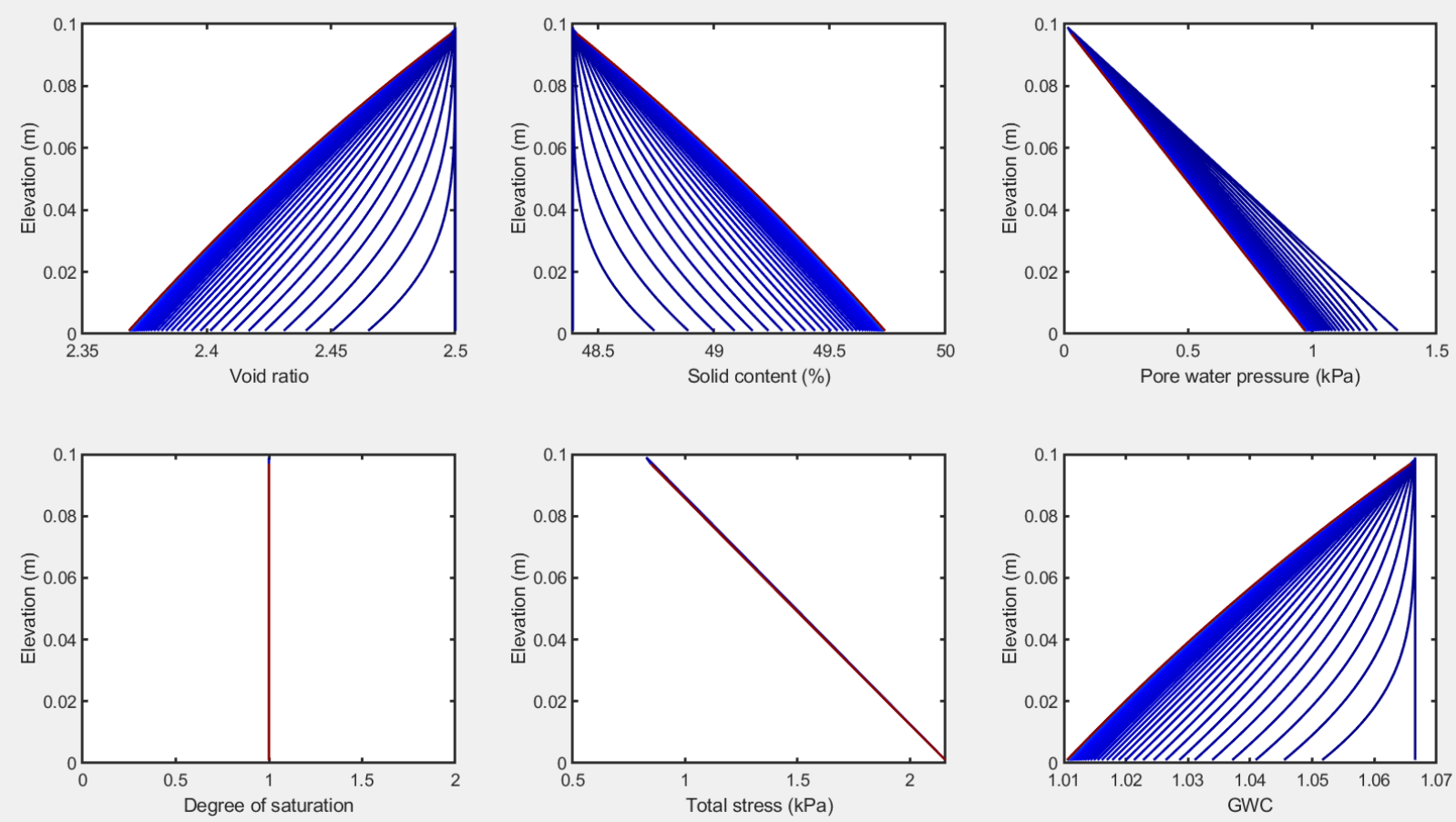

Figure E-2. Overall result from UNSATCON with plotted geotechnical properties for $0.10 \mathrm{~m}$ column using oedometer calculated hydraulic conductivity. 

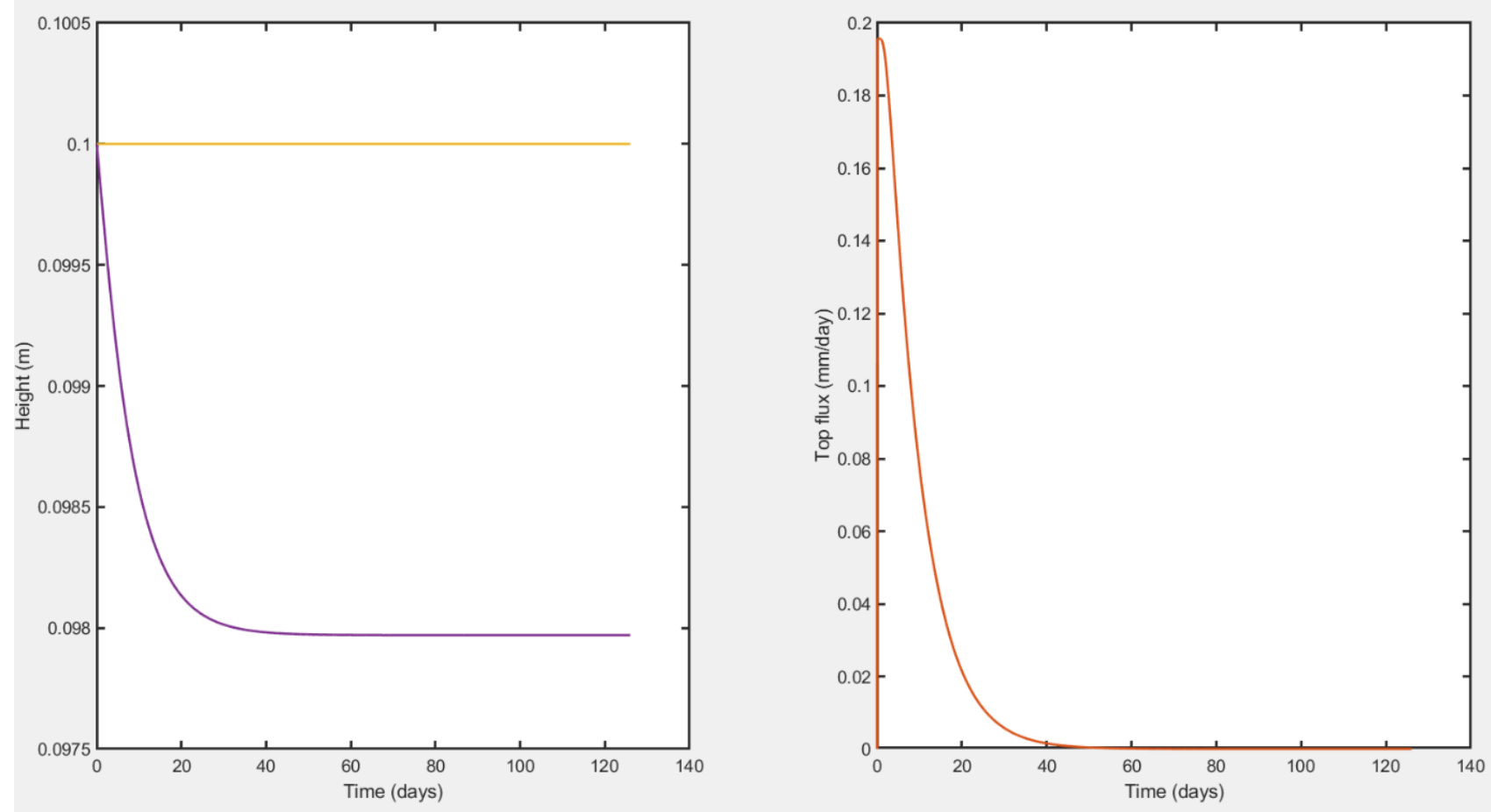

Figure E-3. Overall settlement plot generated by UNSATCON for $0.10 \mathrm{~m}$ column using calibrated hydraulic conductivity. 

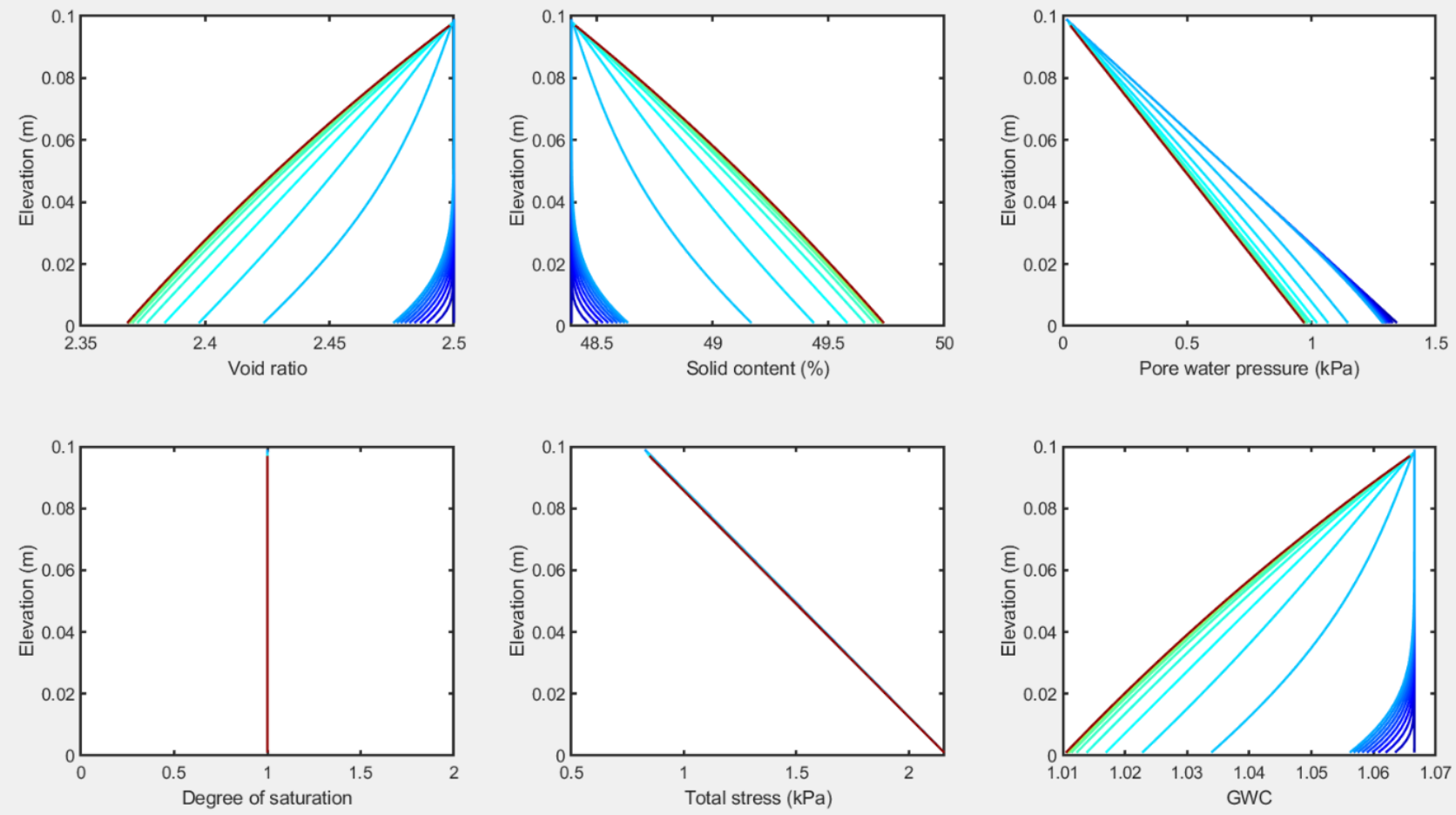

Figure E-4. Overall result from UNSATCON with plotted geotechnical properties for $0.10 \mathrm{~m}$ column using calibrated hydraulic conductivity. 


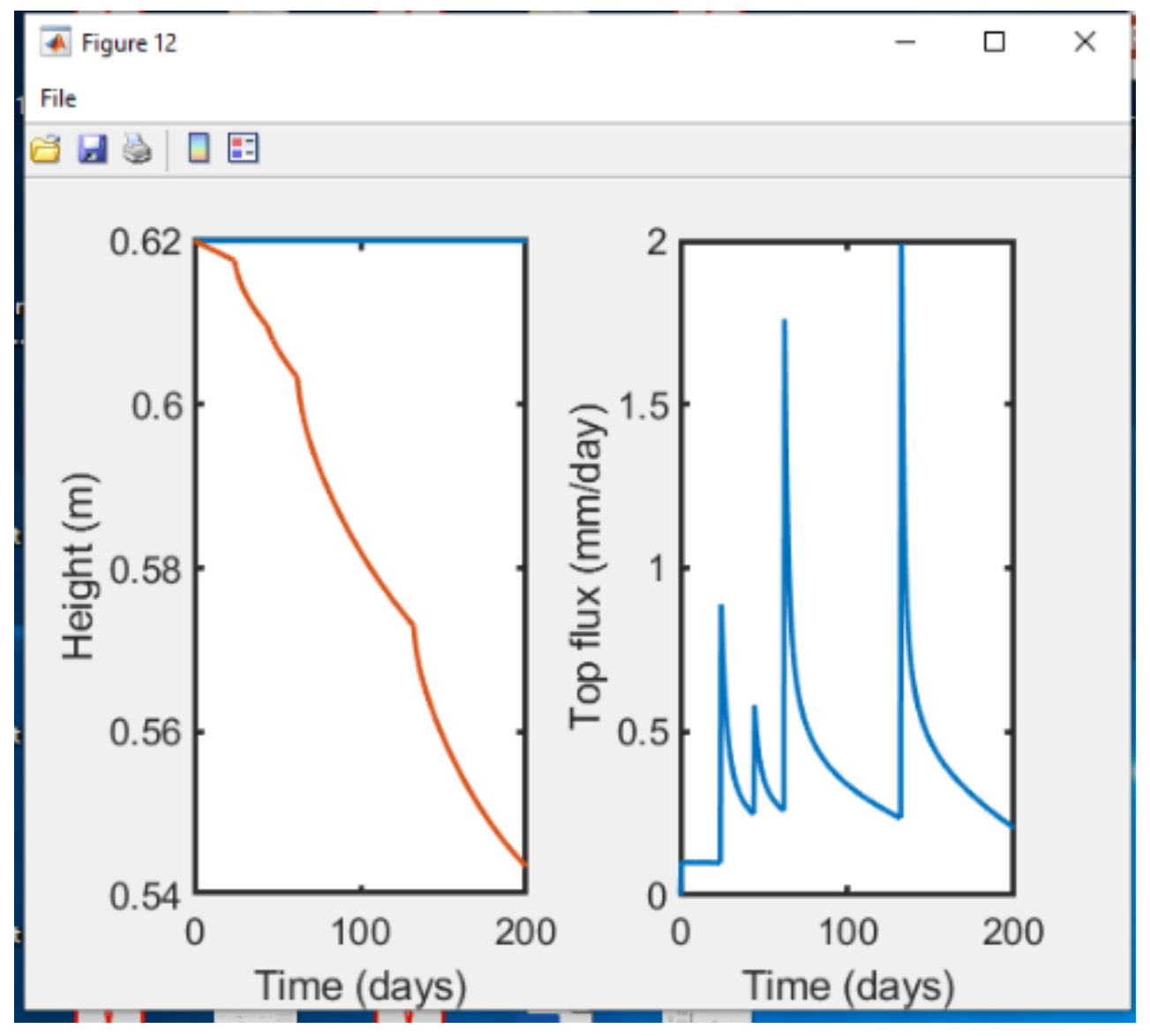

Figure E-5. Overall settlement versus time plot generated by UNSATCON for steel box using calibrated hydraulic conductivity. 

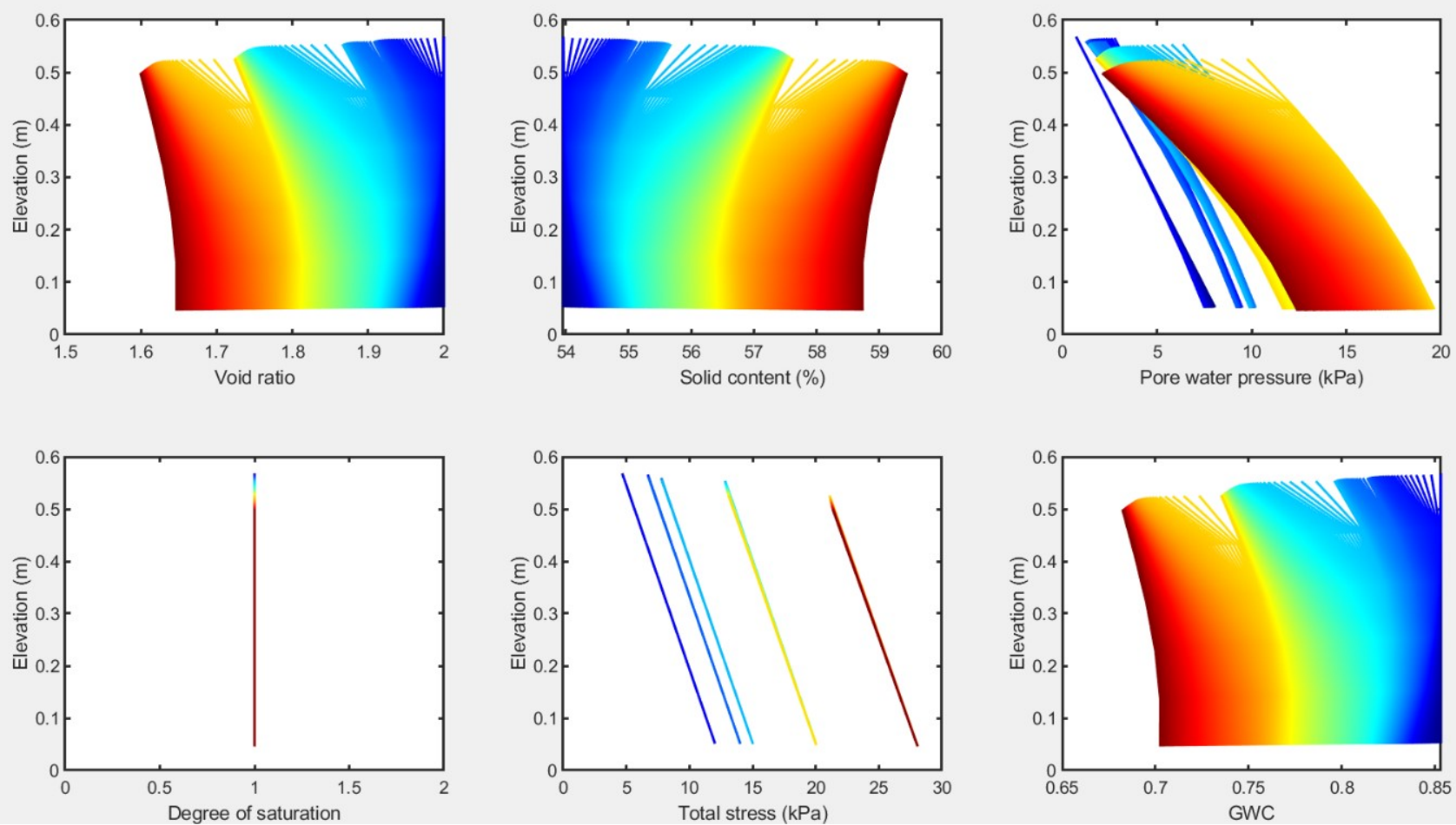

Figure E-6. Overall results from UNSATCON with plotted geotechnical properties for steel box using calibrated hydraulic conductivity. 

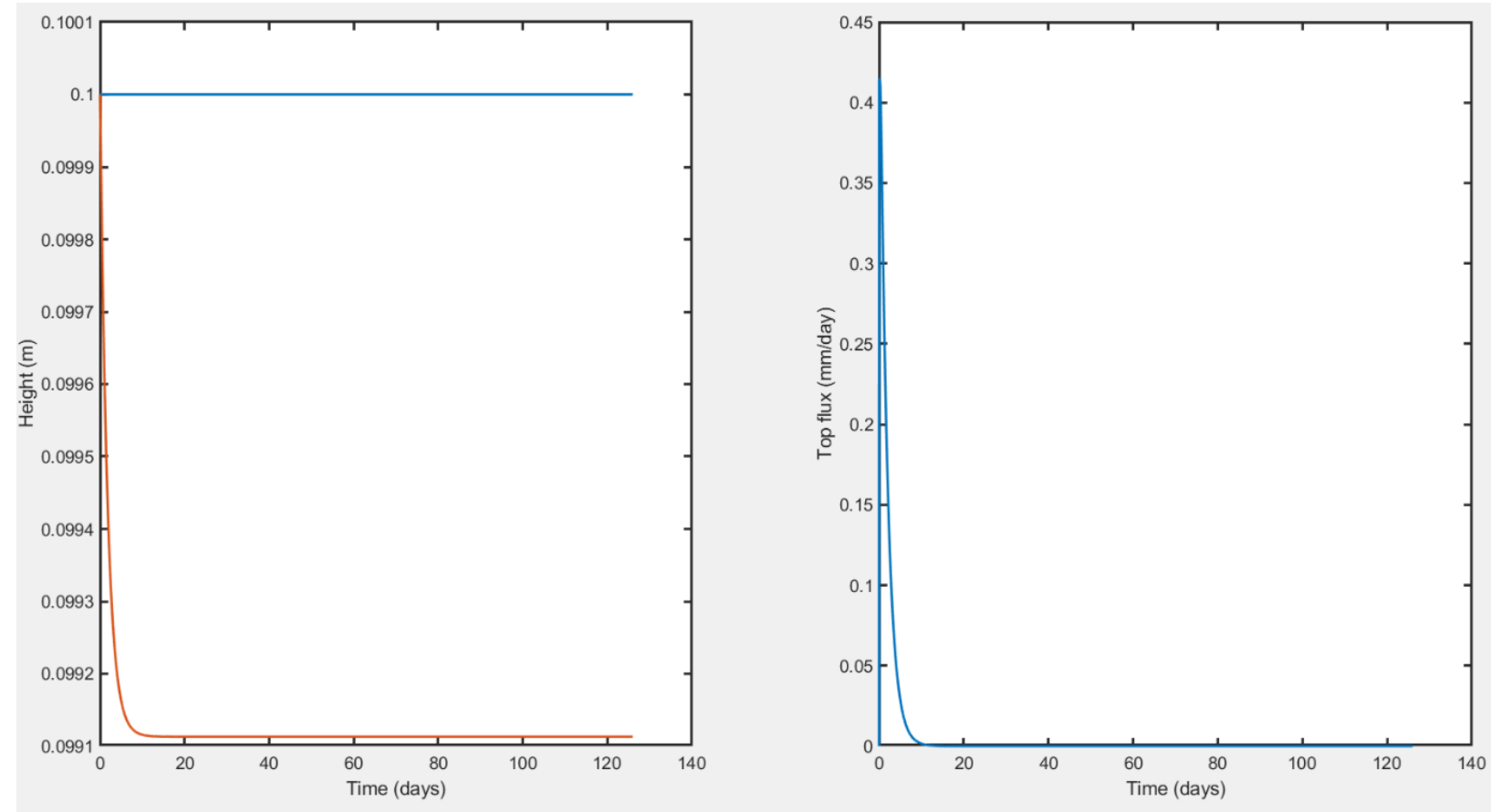

Figure E-7. Overall settlement versus time plot for $0.10 \mathrm{~m}$ columns using a spatial node of 20 and time increment of 50 s. 


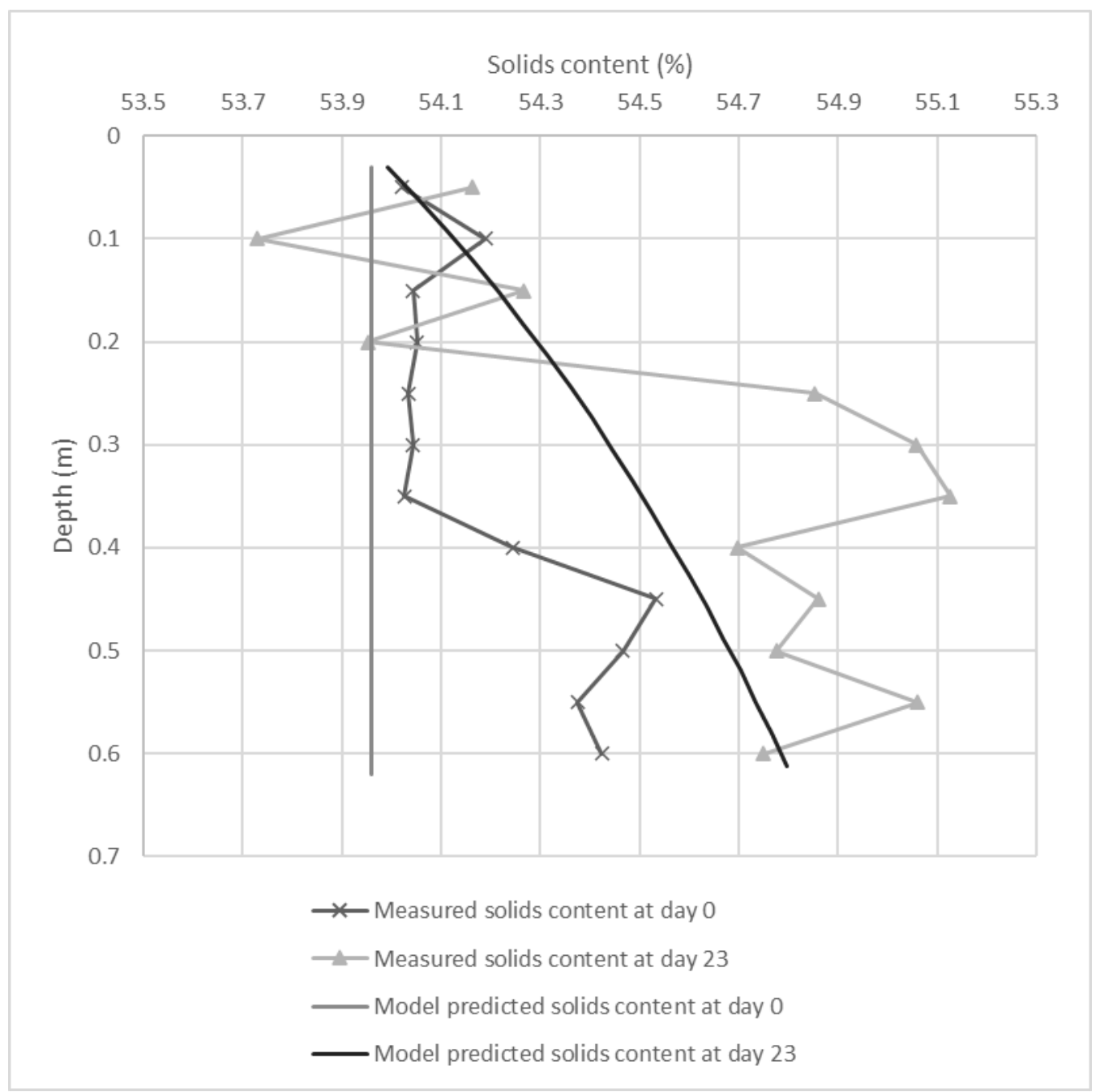

Figure E-8. Solids content by depth profile for steel box (phase II) using a spatial node of 20 and time increment of 10 s. 